\title{
Explaining audiovisual media piracy in China. Media control, enforcement and globalisation
}

Citation for published version (APA):

Creemers, R. J. E. H. (2012). Explaining audiovisual media piracy in China. Media control, enforcement and globalisation. [Doctoral Thesis, Maastricht University]. Rogier Creemers. https://doi.org/10.26481/dis.20120202rc

Document status and date:

Published: 01/01/2012

DOI:

$10.26481 /$ dis.20120202rc

Document Version:

Publisher's PDF, also known as Version of record

\section{Please check the document version of this publication:}

- A submitted manuscript is the version of the article upon submission and before peer-review. There can be important differences between the submitted version and the official published version of record.

People interested in the research are advised to contact the author for the final version of the publication, or visit the DOI to the publisher's website.

- The final author version and the galley proof are versions of the publication after peer review.

- The final published version features the final layout of the paper including the volume, issue and page numbers.

Link to publication

\footnotetext{
General rights rights.

- You may freely distribute the URL identifying the publication in the public portal. please follow below link for the End User Agreement:

www.umlib.nl/taverne-license

Take down policy

If you believe that this document breaches copyright please contact us at:

repository@maastrichtuniversity.nl

providing details and we will investigate your claim.
}

Copyright and moral rights for the publications made accessible in the public portal are retained by the authors and/or other copyright owners and it is a condition of accessing publications that users recognise and abide by the legal requirements associated with these

- Users may download and print one copy of any publication from the public portal for the purpose of private study or research.

- You may not further distribute the material or use it for any profit-making activity or commercial gain

If the publication is distributed under the terms of Article $25 \mathrm{fa}$ of the Dutch Copyright Act, indicated by the "Taverne" license above, 
Explaining Audiovisual Media Piracy in China Media Control, Enforcement and Globalization

NUR-code: 828

(C) 2012 Rogier Creemers, Maastricht

Cover illustrations: (C) Viktorus | Dreamstime.com 
Explaining Audiovisual Media Piracy in China

Media Control, Enforcement and Globalization

\section{DISSERTATION}

To obtain the degree of Doctor

At Maastricht University

On the authority of the Rector Magnificus,

Prof. dr. G.P.M.F. Mols

In accordance with the decision of the Board of Deans,

To be defended in public

On 2 February, 2012, at 14:00 hours

By

Rogier Jaak Eugeen Helena Creemers

Born in Bree on 9 December 1982 


\section{Supervisor}

Prof. dr. mr. Anselm Kamperman Sanders

\section{Assessment Committee}

I) Prof. dr. Michael Faure (Chair)

2) Prof. dr. Bruno de Witte

3) Prof. dr. mr. Madeleine de Cock Buning (Utrecht University) 


\section{Table of Contents}

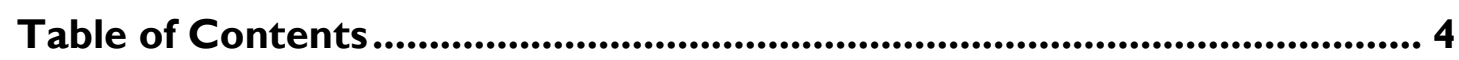

Acknowledgements ................................................................................. 7

Table of Abbreviations........................................................................................ 9

Introduction ................................................................................................................. I I

Chapter I: An Angle into China's Media Piracy ........................................... I5

Defining audiovisual media piracy ......................................................................... 15

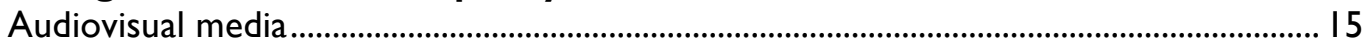

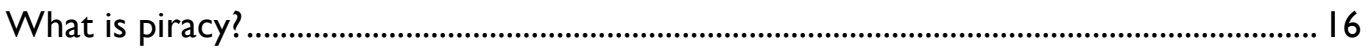

Why audiovisual media? …………………………………………………………………………... 18

The piracy value chain …………………………………………………………………………. 19

The economic damage of media piracy ...................................................................................... 31

Fiscal and social damage of media piracy ................................................................................... 32

The consumer ............................................................................................................ 32

Research question .................................................................................................... 33

Existing explanations of piracy ..................................................................................... 34

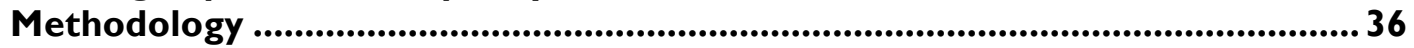

Motivations for piracy: demand and supply side ................................................................. 37

Structure of the study .................................................................................................. 39

Objectives of the study .................................................................................................. 4 I

About copyright, market and piracy ……………………………………………………………. 4

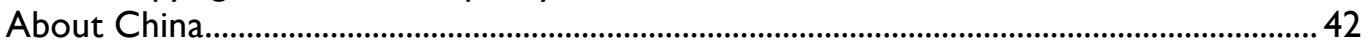

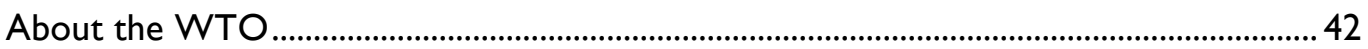

A note on ethics.............................................................................................................. 43

Chapter II: A bird's eye view of copyright law and its relationship with freedom of expression in China ........................................................................... 44

The international system of authors rights ...........................................................44

The current conception of copyright ………………………………………………………........ 45

International copyright treaties ……………………………………………………………………... 5 I

Copyright and other concerns ................................................................................................... 54

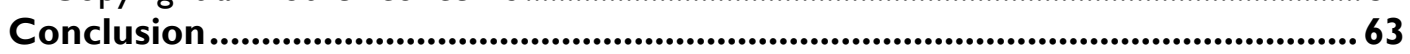

Chapter III: China's Copyright Legislation ......................................................65

Evolution and internationalization of the Chinese copyright system .................66

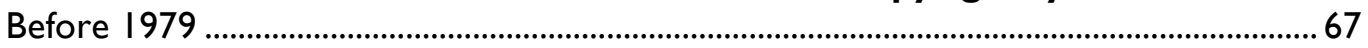

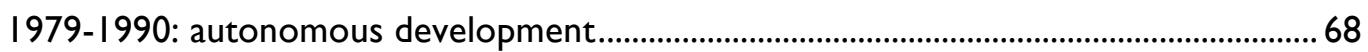

1992-1996: foreign pressure and cycles of futility ………………………………………….... 73

1996-current: international integration and the Internet.........................................................75

Related developments ......................................................................................... 82

Conclusion: Limits of copyright law analysis and linkages to the corresponding

chapters .................................................................................................................... 83

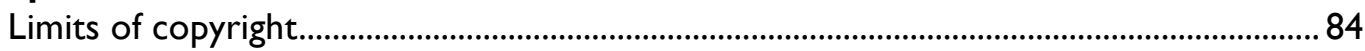

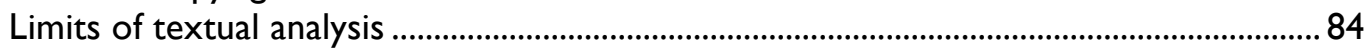

Chapter IV: The mechanics of China's media control ................................. 85

The institutional structure - the propaganda system ..........................................8 86 


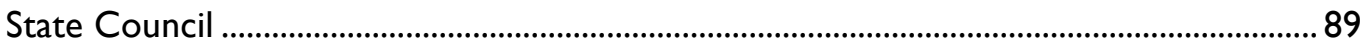

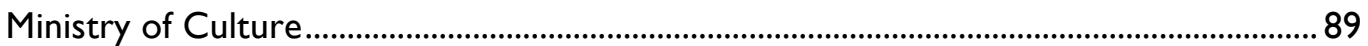

State Administration of Radio, Film and Television.........................................................90

General Administration of Press and Publications............................................................. 90

The rules of media control ............................................................................9 9 I

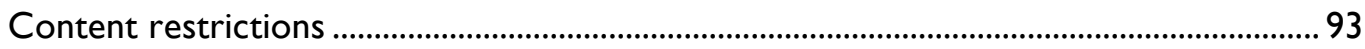

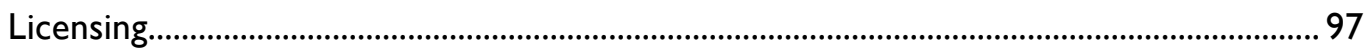

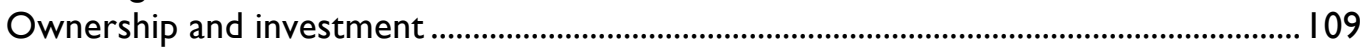

Screening restrictions .................................................................................................. I I

Personnel matters ...................................................................................................... I |

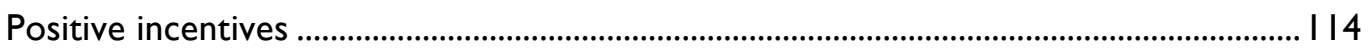

Mobilizing the Industry: a tale of two campaigns...................................... I I 5

Cultural development plans ..................................................................................... I I 7

Conclusion ............................................................................................................ I I 9

Chapter V: Understanding the political underpinnings of Chinese media

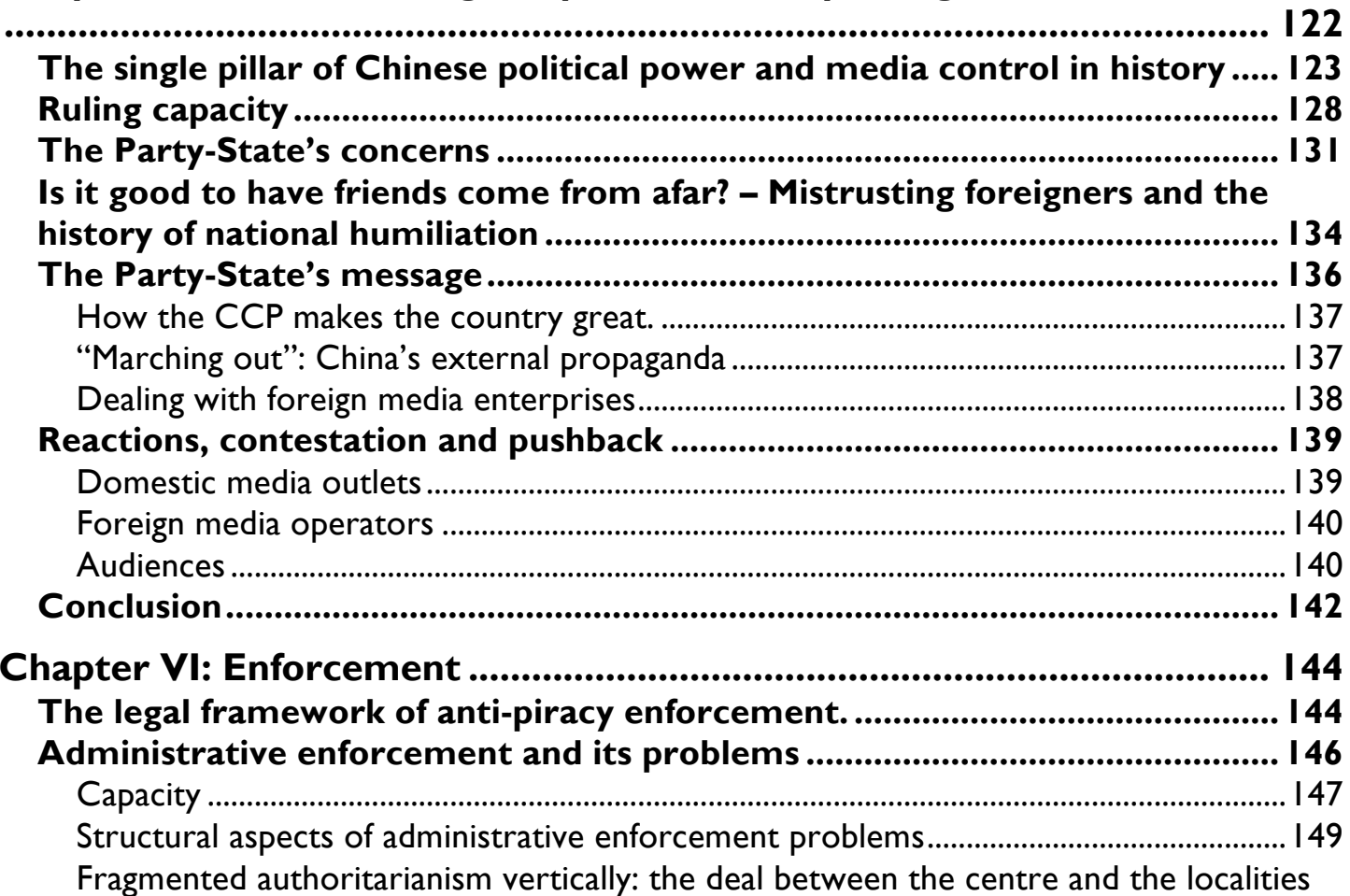

Fragmented authoritarianism horizontally: why administrative departments do not like

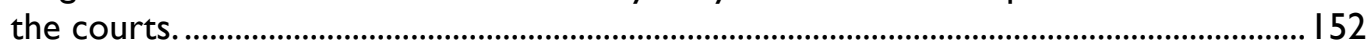

The problem of supervision: quis custodiet?.................................................................... 153

Enforcement styles, deckchairs and the Titanic ............................................................ 156

Prioritization: politics before copyright infringement ...................................................... 158

Internal conflicts: Administration as judge and party .................................................... 160

Personnel: the weakest link........................................................................................... 160

Copyright enforcement through the courts................................................. I 62

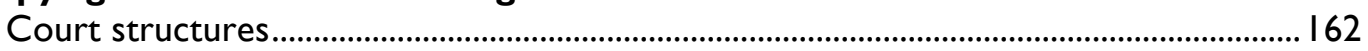

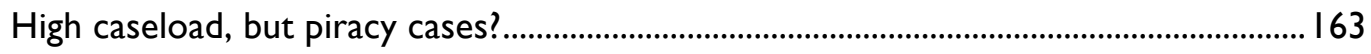

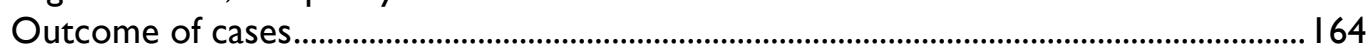

The problem of enforcement of verdicts - the return of the first paradox................... 165

The cases that never happened ....................................................................................... 165

The success story of the Internet ............................................................ 166

Conclusion .................................................................................................................. I 67 
Chapter VII: the WTO, China and piracy....................................................... 169

Why China joined the WTO ............................................................................... 170

China's commitments concerning audiovisual media .......................................... 172

The cases against China .......................................................................................... 173

DS362/China - Intellectual Property ……………………………………………………........ 174

DS 363/China - Audiovisuals............................................................................................. 178

Evaluation of the literal decisions of the cases................................................... 182

Implementation and the bargaining framework............................................... 183

Implementation of DS363 .................................................................................. 185

Results of the WTO process on the audiovisual media market........................ 187

Conclusion: evaluation of WTO influence on audiovisual media piracy ......... 188

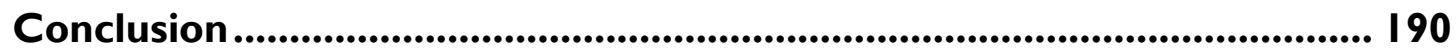

Results of this study.............................................................................................. 190

Piracy in context: substantive, theoretical and empirical implications........... 192

One last thought: where do we go from here?.................................................... 193

ANNEX: Chinese legal texts .......................................................................... 194

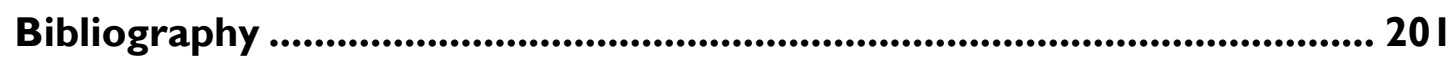

Academic sources..................................................................................................... 201

Reports and parliamentary hearings ................................................................... $2 \mathrm{II}$

Internet sources............................................................................................. $2 / 2$

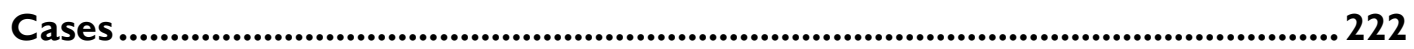

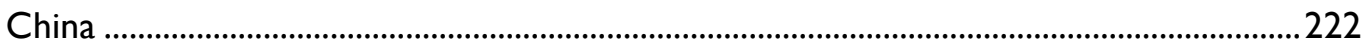

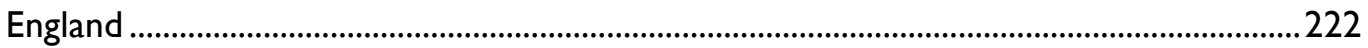

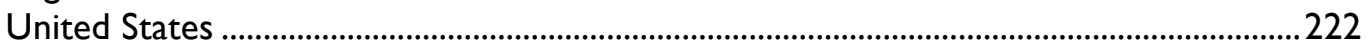

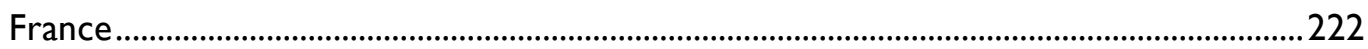

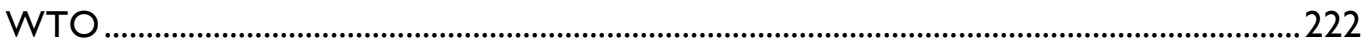

Legal documents ................................................................................ 223

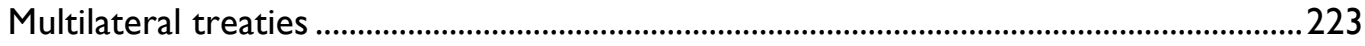

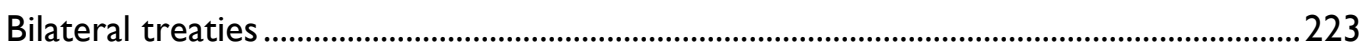

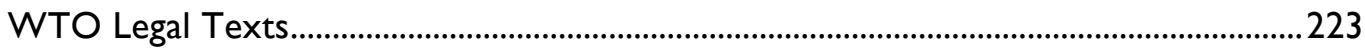

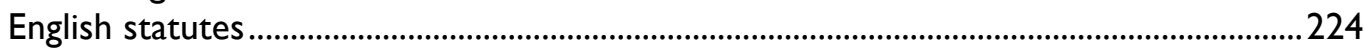

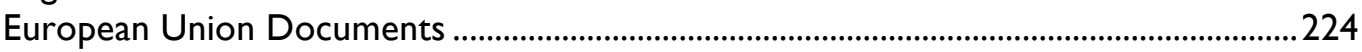

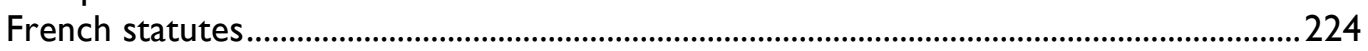

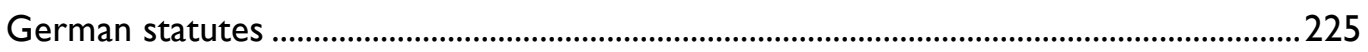

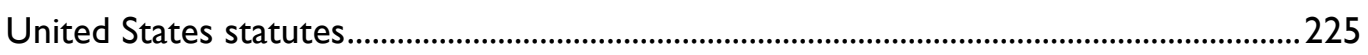

Chinese legal and regulatory documents ..............................................................................225

Nederlandstalige samenvatting: Een verklaring voor audiovisuele

mediapiraterij in China: mediacontrole, afdwinging en globalisering .... 239

Inleiding ............................................................................................................... 239

De ontwikkeling van het auteursrecht en de markt voor mediaproducten ..240

Mediacontrole: methodes en redenen ..............................................................24 I

Afdwinging ................................................................................................................ 24 I

De WTO .............................................................................................................. 242

Conclusie ............................................................................................................... 243

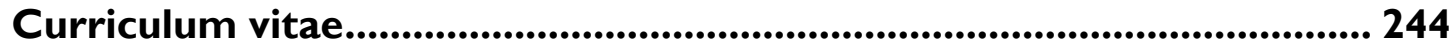




\section{Acknowledgements}

A dissertation is much more a collective effort than is often assumed. Certainly, this study would not have been possible without the input, help and support from a host of people, both within and outside of Maastricht University.

My supervisor, Anselm Kamperman Sanders, has been a great supporter from before the start of this project until its present conclusion. Our discussions on China, IP, technology, development, economy and politics have done much to shape the line of this study, and I am very grateful for them.

Aalt Willem Heringa, the then Dean of the Faculty has been very supportive of this study and my work on Chinese law, which has been invaluable in bringing this to a successful conclusion.

I have been very lucky with my two roommates in room 0.229. Jos Vaessen was a great inspiration in better understanding the intricacies of interdisciplinary research, and Dalindyebo Shabalala was a great help in getting the manuscript right, and in so many other things.

My colleagues at the Instutute of Globalization and International Regulation have been a great support, and I learnt a lot through our discussions and meetings. Peter, Denise, Nishara, Leilla, Arkadiy, Anke, Jennifer, Valentina, Cees and all the others, I had a lovely time. It has also been an enriching experience to meet with people working in so many different areas in the Faculty. Tanja, Mariken, Gary, Maartje, Mieke, Nicole, Bram, Stefan, Licette, Marlies, Hilde, Jaap, Rudolf, Jasper, Josine, Sascha, Bastiaan, Phyllis, Maaike, Hester, and everybody else, it was wonderful to work with you. In UCM, Teun Dekker has been an inspiration, in an unconventional (and therefore highly useful) manner, and I challenge him to find a little tip of his in this work. Through the different Asia projects, I also had the pleasure of working with Tom van Veen and Thomas Christiansen.

In China, I had the good luck to meet many people with whom I was able to discuss Chinese law, politics and economics, which helped me to provide a broader basis for this study, and, I hope, a greater relevance of the conclusions. In no particular order, I'd like to thank Peter Yu, Bryan Mercurio, Eva Pils, Peter Chan, Victor Bekink, Mattie Johnstone, Nancy Kremers, Wu Handong, Mark Cohen, Eric Smith, Liu Chuntian, Zheng Ning, Chen Xiahong, Li Xin, Riccardo Benussi, Benoit Misonne, Jacques van Vliet, Zhao Jiayi, Jiang Zhipei, Kristof van den Troost and Stephanie Balme.

Part of this research was made possible by a research visit grant from the China-EU School of Law, for which l'd like to extend my gratitude.

My family, and in particular, my parents, have been a pillar of support throughout this project, through the good times and sometimes the hard ones. My brother Frederik, who joined me in Maastricht, was an indispensible source of mirth. I couldn't have done without them. Neither could I have done without the support of my friends, Thomas, Karen, Pieter-Jan, Kristof, Leen and Ellen. 
This book is dedicated to the memory of Elisa Aerts, who always valued learning, and of Jef Fox and Gie Dandois, who nudged me in its direction.

Last, but not least, I can never in words do justice to everything she does for and means to me. Eveline, thank you, so much.

Research for this study was concluded at the end of June $201 \mathrm{I}$, with small additions afterwards. 


\begin{tabular}{|c|c|}
\hline$A B$ & Appellate Body \\
\hline$A B C$ & American Broadcasting Corporation \\
\hline ACTA & Anti-Counterfeiting Trade Agreement \\
\hline BBC & British Broadcasting Corporation \\
\hline BBFC & British Board of Film Censorship/Classification (after 1984) \\
\hline CAVCA & China Audiovisual Copyright Association \\
\hline CCP & Chinese Communist Party \\
\hline CD & Compact Disc \\
\hline CCTV & China Central Television \\
\hline CFC & China Film Corporation \\
\hline CFCA & China Film Copyright Association \\
\hline CNC & Centre National du Cinéma et de l'Image Animée (France) \\
\hline CNY & Chinese Yuan \\
\hline CPD & Central Propaganda Department \\
\hline CPPCC & China People's Political Consultative Committee \\
\hline CSA & Conseil Supérieur de l' Audiovisuel \\
\hline DRM & Digital Rights Management \\
\hline DSB & Dispute Settlement Body \\
\hline DSU & Dispute Settlement Understanding \\
\hline DVD & Digital Versatile Disc \\
\hline EU & European Union \\
\hline FCC & Federal Communications Relevision \\
\hline GAPP & General Administration of Press and Publications \\
\hline GATT & General Agreement on Trade and Tariffs \\
\hline GATS & General Agreement on Trade in Services \\
\hline GDP & Gross Domestic Product \\
\hline GMD & Guomindang \\
\hline HD-DVD & High-Definition DVD \\
\hline IBA & Independent Broadcasting Authority \\
\hline IIPA & International Intellectual Property Alliance \\
\hline $\mathrm{IP}(\mathrm{R})$ & Intellectual Property (Rights) \\
\hline ISP & Internet Service Prvider \\
\hline ITA & Independent Television Authority \\
\hline ITV & Independent Television \\
\hline LD & LaserDisc \\
\hline MII & Ministry of Information Industry \\
\hline MFN & Most Favoured Nation \\
\hline MoC & Ministry of Culture \\
\hline MOFCOM & Ministry of Commerce \\
\hline MOFTEC & Ministry of Trade and Economic Cooperation \\
\hline MOU & Memorandum of Understanding \\
\hline MPAA & Motion Pictures Association of America \\
\hline MRFT & Ministry of Radio, Film and Television \\
\hline MRT & Ministry of Radio and Television \\
\hline MTV & Music Television \\
\hline NCA & National Copyright Administration \\
\hline NDRC & National Development and Reform Commission \\
\hline
\end{tabular}


NICAM Netherlands Institute for the Classification of Audiovisual Media

NPC National People's Congress

OECD Organization for Economic Cooperation and Development

P2P Peer-to-peer

PRC People's Republic of China

RIAA Recording Industry Association of America

SARFT State Administration of Radio, Film and Television

SID

Source Identification

SPA State Publications Administration

TRIPS Trade-Related Aspects of Intellectual Property Rights

UNESCO United Nations Educational, Scientific and Cultural Organization

UCC United Copyright Convention

US United States

USD US Dollar

USSR Union of Socialist Soviet Republics

USTR United States Trade Representative

VCD Video Compact Disc

VOD Video On Demand

VHS Video Home System

WCT WIPO Copyright Treaty

WIPO World Intellectual Property Organization

WPPT WIPO Performances and Phonograms Treaty

WTO World Trade Organization 


\section{Introduction}

The post-1978 transformation of the Chinese economy and society is without a doubt one of the most significant events of the last century. At home, it has amongst many other things - created jobs, brought material welfare to millions and stimulated the construction of enormous amounts of infrastructure. At the international level, the profile of China has raised enormously. It is now the second largest economy and the largest exporter in the world. The Beijing Olympics, Shanghai World Expo and Guangzhou Asian Games would have been unthinkable in the Seventies. At the same, this process has not been without costs. Environmental pollution, and growing inequality are two enormous challenges that China will need to confront in the coming years. Also, economic development has mainly been built on export-led manufacturing and domestic construction and infrastructure, while other sectors - notably the services sector - remain underdeveloped. Economic development also strongly outpaces regulatory development. While China has succeeded in building a comprehensive business law framework, it has not been able to prevent pollution, corruption, and other problematic phenomena.

It has also not been able to prevent audiovisual media piracy. In the early Eighties already, Hong Kong films were smuggled in and shown in Chinese cinemas. As Chinese consumers became more affluent and home entertainment products came in reach of more households, piracy shifted to video, VCD and DVD. Following the further expansion of digital technology, the Internet became another important channel on which first music and later films and television programmes were available in pirated versions. Coupled with large-scale copying of software, the emergence of increasing amounts of counterfeit goods and of technological imitation, the large incidence of piracy has contributed in the West to creating an image of China as a country that copies and imitates everything, without having innovative power on its own. At the same time, the increasing competition from the Chinese economic machine has led many observers to complain about this copying and imitation, saying it damages foreign economic interests, destroys jobs and reduces innovation.

Very rapidly, foreign observers and governments started addressing these matters under the heading of intellectual property protection, which became one of the core issues in China's trade relations with the United States, and - to a lesser extent with Europe. In other words, piracy, together with counterfeiting and technological imitation, was seen as the result of an inadequate framework to protect intellectual property. As a result of this diagnosis, significant efforts have been made from all sides to strengthen IP protection of intellectual property in China. Following strong lobbying by IP organizations such as the IIPA, the United States pressured China to improve its legislative and institutional IP framework, in a bilateral fashion during the Nineties, and through the World Trade Organization (WTO) dispute settlement mechanism in 2009. Both Europe and the US continue to finance and support programmes that aim to build capacity and awareness of IP protection. Most importantly, as China's development progressed, the Chinese leadership increasingly came to see IP as an important factor to support further development in higher valueadded industrial sectors, rather than a tax on foreign knowledge. 
In academia, media piracy in China is usually connected to China's IP framework as well. Many publications point to inadequate laws or implementation problems to explain piracy's prevalence. However, the explanatory power of an argument based on IP to understand the causes of piracy in China may be limited. First, IP is a broad term that covers many rights, which in turn govern a substantial part of a modern economy. Hence, factors that may cause certain phenomena in one sector may not explain similar phenomena in another field. Second, IP is considered to be private law, regulating relations between private parties, with criminal sanctions only present for certain egregious infringements. Consequently, diagnosing piracy through the IP lens presupposes a certain economic structure and legal expectations of different actors. Moreover, it assumes a certain concept of the State, which may not necessarily be appropriate to understand the Chinese context. But most importantly, an IPbased analysis does not help us in explaining why piracy seems to remain rampant after more than a quarter century of IP reform, legislation and institution building.

Furthermore, a significant part of the literature is dedicated to the relationship between piracy and trade, and more specifically, the World Trade Organization. When China joined the WTO in 200I, observers suggested that an effective deterrent against piracy and counterfeiting would be made possible through the WTO's IP discipline. As only states are bound by WTO discipline, this implicitly assumes state responsibility for protecting IP. In the media field, this responsibility would be directed at protecting the economic rights and interests of media enterprises. This presupposes that the state has the capacity to do so, not only in legislating, but also in creating institutions that are able to influence behaviour.

There are other methodological problems in the current English-language literature. Problematically, there are significant gaps in our understanding of media piracy. While a substantial number of articles and books have been dedicated to the phenomenon, only a few writings go anywhere beyond scratching the surface of what causes audiovisual media piracy in China. There is preciously little empirical data analyzing piracy. Many primary sources are only available in the Chinese language, making them hard to access for foreign observers. Some studies are based on statistics and assumptions that are controversial, incomplete or partisan'. As a result, the diagnosis of media piracy in the literature is incomplete and one-sided, focusing on copyright law and related enforcement, on the piracy of American works, and on the relation of piracy with international trade.

Copyright, however, is a legal construction that is embedded in political, economic and social structures. Its prime economic function is to balance the incentive to create works against the necessity for access to those works ${ }^{2}$. The immediate assumption here is that both creation of more works as well as public access to these works are desirable, and that a market-based solution based on artificial scarcity created by a legal entitlement will advance both. In other words, the function of copyright as an economic mechanism depends on the design and functioning of the underlying structure governing the production, distribution and consumption of works.

\footnotetext{
I See also Chapter I.

${ }^{2}$ Landes and Posner, 1989, p. 326.
} 
The European conception of copyright and media markets has been constructed around the idea of private ordering, market-based solutions and an increasing withdrawal of the State and related actors from active control over content. International copyright law had since the end of the $19^{\text {th }}$ century prohibited any form of content requirement for copyright grant, although it allowed for censorship procedures. In China, however, any discussion of media must involve the State and the Party, for whom media control is a high priority. It is not unreasonable to assume that media control will have consequences for the media market, changing the context in which the economic mechanism of copyright is supposed to operate. In other words, it might be possible that an issue that may manifest itself as copyright infringement is partly caused or enhanced by change in the underlying conditions required for the market mechanism to work. Also, given the attention that intellectual property protection receives in international trade discussions, and that the WTO governs states, not private actors, it is worth exploring whether and how these underlying conditions are subject to WTO influence.

Thus, the objective of this study is to explain and understand two things: the causal factors of audiovisual media piracy that are based in the Chinese Party-State, as well as the influence that can be brought to bear on those factors through the WTO. Such an understanding of media piracy is at the same time broader and deeper than the present literature. On the one hand, this study hopes to avoid the problems of an IP angle by concentrating on one specific sector rather than a legal right or family. Starting from the explanandum makes it possible to inventorize the legal and regulatory frameworks that govern the sector, avoiding the problem of the assumptions inherent in law-based approaches that might obscure the influence of certain actors and other legal framework. It also ensures that the analysis can be more specific and nuanced, as it narrows the scope of the problem to be explained from all IP-related industries to a smaller range of products and services. On the other hand, the study sheds light on the domestic processes related to the implementation of international trade law by providing a case study of whether and how international trade obligations influence domestic mechanisms of lawmaking and law enforcement.

The first question, on the State-based contributing factors to piracy, is analyzed on the basis of a functional explanatory analysis. The study argues that piracy occurs whenever suppliers and consumers believe it is in their interest, and it is possible, for them to do so. By outlining the comparative differences in the political, economic and legal context of copyright legislation in China and a number of Western jurisdictions, the study identifies media control as a significant inhibiting factor for media market development in China. This results in a lack of choice of legitimate products, stimulating demand for illegitimate ones. Furthermore, the study identifies institutional factors in China's enforcement structures that create opportunities for commercial pirates to evade or mitigate the effects of enforcement, lowering the potential cost for them as well. Concerning the influence of the WTO, the study argues that, while Chinese media control measures partly fall under the aegis of WTO discipline, its influence is relatively limited. This is first, because of the specific nature of Chinese commitments and obligations and second, due to mechanisms within the WTO that permit members to persist with non-compliance if the issue is of sufficient domestic importance. 
This study does not portend to offer a complete explanation of piracy in China. It focuses on the role that the State plays in causing piracy, through limiting the legitimate market and being unable to realize strong and rationalized anti-piracy enforcement. However, there are many other contributing factors to piracy, including market failures, for example where legal transactions do not take place as the cost difference between legitimate and pirated products make piracy attractive. However, this study argues that the lawful existence of a market is logically prior to it functioning well, at least in the case of piracy. The study's focus on the State therefore means that this study does not address broader issues of media market failure. Second, this study is limited in its ability to calculate the extent of the impact of the contributing factors indicated above. To a large extent, this is due to methodological issues. It is very difficult to measure non-events, and hence we cannot say how many films or television programmes are not made or adapted due to the chilling effects of media control or the economic deterrent of high piracy rates, and to what extent these factors are mutually reinforcing. This study merely attempts to explain that media control and lack of enforcement are important contributing factors to piracy.

The study comprises six chapters. The first chapter contains a description of piracy in China, as well as the methodology used to understand the linkages between the Party state and piracy. The second chapter analyzes the historical evolution and interrelation between copyright law, the evolution of the media economy and freedom of expression. The third chapter will contrast the Western experience of copyright and media with the origins of Chinese copyright law, in order to foreground the philosophical differences between these two historical trajectories, even in circumstances where the black letter law is similar. The fourth chapter will then outline the broader regulatory and institutional framework governing audiovisual media production and distribution, illustrating the limits to market entry, ownership and content production that restrict the freedom to operate in the Chinese media market. The fifth chapter provides an explanation for these frameworks from the political imperatives that are central to China's body politic. Having identified the Party-State based causal factors for piracy, the sixth chapter then moves to analyze how these factors are influenced through the WTO. More specifically, this chapter uses two cases against China on audiovisual media to point to the exact mechanisms at play between the international and domestic level, and how they interact. 


\section{Chapter I: An Angle into China's Media Piracy}

Audiovisual media piracy is a complex issue. It exists at the nexus of law, economy, politics and society. It touches upon issue areas as different as human rights, state capacity and trade relations. However, in contrast to the amount of attention given to media piracy in China-related trade discussions, academic literature offers relatively little theoretical understanding of the phenomenon. This study takes the empirics of audiovisual media piracy as a basis for the diagnosis of the phenomenon, with a special focus on the role of the State. Therefore, it is necessary to understand the actors and processes that are at work, as well as the incentive structure and the economic value chain.

This chapter consists of three parts. First, it provides the working definitions for two concepts that are basic to the study: audiovisual media piracy and the Party-State. Second, a factual overview of the specific characteristics of piracy in China is offered. The third part proposes a methodological framework for understanding piracy, which underpins the rest of the study.

\section{Defining audiovisual media piracy}

\section{Audiovisual media}

Audiovisual media comes in a multitude of forms and shapes. They comprise the traditional - often linear - forms of media, including film, radio and television, as well as new means of delivery made possible by digitalization, the Internet and mobile technology, in which the consumer has increasing power to decide the time and means of media consumption. The term covers news media, entertainment programming, documentaries and other forms of content, but often also includes commercials. Media can be only visual (such as silent films), only auditive (in the case of music), and both. They may include professionally produced cinema films costing millions of dollars and amateur cartoons posted on video web sites. In the light of piracy, this scope is overly broad, as piracy tends to be mostly an issue with commercial audiovisual media products. Hence, for the purposes of this study, a narrower definition is proposed: the audiovisual media to be covered in this study are film-like or television like works, primarily aimed at entertainment, not dealing with current affairs or news, and made for commercial distribution. This definition has two main advantages, which are especially important in the Chinese context. First, the commercial aspect points to the political relevance of piracy, which figures highly on the issue agenda because a number of influential lobby groups, particularly in the United States, have put it there. In other words, piracy is mainly framed as damaging economic interests. Second, concentrating on entertainment work avoids the politically sensitive nature of news media. In China, news and current affairs reporting is subject to a highly specific regulatory framework, involving specific actors and interests, and a strong emphasis on immediate political control and constant guidance. Regulation of entertainment works is also quite strict and politically influenced, but is implemented 
through different channels. Entertainment works and news media also have a different economic role and impact. Moreover, news media are rarely subject to piracy ${ }^{3}$.

\section{What is piracy?}

Piracy is a strong term, which is used to cover many activities in a large number of industrial sectors, including media, but also biotech and other technology sectors. In the field of media, the term often refers to unlicensed broadcasting, such as the pirate radio stations broadcasting from ships anchored in international waters to a number of European countries in the Sixties. More often, piracy is used in a property context. The Motion Pictures Association of America (MPAA), for example, lists several forms of "content theft", including camcording, P2P, on-line streaming, several forms of hard-goods piracy, signal theft, broadcasting theft and illegal public performance ${ }^{4}$. Furthermore, piracy cases have been filed in cases where audiovisual works or parts thereof were used in a transformed manner, for example by using a song as a background to a YouTube movie ${ }^{5}$. In yet other cases, the questions become even more difficult: is theft the appropriate framework where books are published using well-known characters and setting created by other authors ${ }^{6}$ or where one television enterprise broadcasts programmes using a format of another enterprise without authorization or reimbursement ${ }^{7}$ ? In other words, as the word piracy can cover a multitude of different processes and actors, the concept remains very broad and unclear, reminding of an old EC definition that piracy is "whatever the knowledge industries say they need protection from ${ }^{8}$ ". Hence, for the purposes of this study, a clearer definition is necessary, for example through legal norms relating to piracy. We can derive some indication of the legal aspects of piracy from the above examples: licensing and ownership, reflected in the legal fields of media regulation and copyright law.

Generally speaking, media regulation refers to rules on access, ownership and competition in the media sector, but also contains rules on moral content of media works. It is also strongly influenced by the right to freedom of expression as well as cultural rights, such as access to information and cultural life, the protection of tangible and intangible cultural heritage, and by personal rights such as the rights to reputation and privacy. Economically speaking, media regulation has been increasingly liberalized, opening up access to the sector and expanding the market in media products. With the advent of the Internet and digital media production technologies, the scope of potential producers, as well as the channels of distribution, have widened greatly. At the same time, morality rules have generally become less strict, and more nuanced, to the extent that it is very rare for media products to be banned off the market'.

\footnotetext{
${ }^{3}$ Although there are some concerns about signal theft in case of sports broadcasting. Envisional and Net Result, 2008 and Congress Hearing III-94, 2009.

${ }^{4}$ MPAA, $201 \mathrm{l}$.

${ }^{5}$ Lessig, 2008, p. 2.

${ }^{6}$ At least a dozen Harry Potter books that were not written by J.K. Rowling are available on the Chinese market. French, 2007.

${ }^{7}$ For an in-depth analysis of Chinese interpretations of Western television formats, see Keane, 2002, pp. 80-90.

${ }^{8}$ Quoted in Johns, 2010 , p. 6.

${ }^{9}$ For example, less than fifteen films were banned in the United Kingdom after the Second World War, with most of them eventually being passed after a period of time. See also Chapter II.
} 
As a result, in Western markets, copyright has become the dominant legal framework that governs the production and distribution of audiovisual media products, leading to the entire sector that it protects to be called "copyright industry". It is also the legal field that is most closely associated with piracy, and some legal definitions of piracy explicitly consider it to be an infringement of intellectual property law. In the Anti-Counterfeiting Trade Agreement (ACTA), which was under negotiation at the time of writing, the term "pirated copyright goods" is used. These are defined as "[...] any goods that are copies made without the consent of the right holder or person duly authorized by the right holder in the country of production and that are made directly or indirectly from an article where the making of that copy would have constituted an infringement of a copyright or a related right under the law of the country in which the procedures set out in Sections 2, 3, 4 and 5 of Chapter 2 are invoked ${ }^{10}$."

However, equating piracy with copyright infringement has two significant problems in the light of this study, one in copyright theory and one in connection with the Chinese legal system. First, as digitalization and the Internet have made it increasingly easy to cut, paste, share and distribute works, the debate on the role that copyright is supposed to play in balancing the interests of rights holders and the interests of society has become increasingly complex. New technologies make it possible to use works in ways that could not have been envisaged at the time these laws were drafted, and many questions about the realignment of interests and obligations between different stakeholders remain to be resolved. Hence, the media industry's arguments about piracy may be political as well as legal, and certain uses of works that are branded as piracy by the media industry may be within the scope of limitations and exceptions in copyright law. There are debates around copyright term extensions as well as extensions for performer's rights", and questions on the protection of the public domain. At the same time, arguments are raised on the fact that the media industry itself was built on IP infringement ${ }^{12}$, or that the United States did not recognize foreign copyrights during the $19^{\text {th }}$ century, to the detriment of European authors ${ }^{13}$.

These debates are complex, and it is not the objective of this study to go into them deeply. Rather, the study concentrates on commercial piracy as defined by Lawrence Lessig, which refers to businesses that "do nothing but take others people's copyrighted content, copy it, and sell it - all without the permission of a copyright owner ${ }^{14}$," and which "doesn't transform the content it steals; it doesn't transform the market it competes in. It merely gives someone access to something that the law says he should not have ${ }^{15}$." The caveat needs to be made, however, that "selling" can have different meanings depending on the business model, as is analyzed further in this Chapter. It also means that the individual user side of file sharing is not addressed per se, as it is very often

\footnotetext{
${ }^{10}$ ACTA, Chapter I, Section B, Article I.X.

" See for example Eldred v. Ashcroft, 537 U.S. 186 (2003), a Supreme Court ruling in which the constitutionality of the Sonny Bono Copyright Term Extension Act was questioned.

${ }^{12}$ One of the reasons the fledgling US film industry took to Hollywood was to evade patents on film technology held by Thomas Edison. Emerging forms of media, such as cable television and radio broadcasted works without paying remuneration in their beginning period. See Lessig, 2005, p. 60.

${ }^{13}$ Johns, 2010, pp. 307 et seq.

${ }^{14}$ Lessig, 2005, p. 63.

${ }^{15}$ Id. p. 66.
} 
non-commercial ${ }^{16}$, but will concentrate on commercial actors gaining from facilitating on-line piracy.

Second, there is a problem concerning the nexus of copyright law and piracy in the Chinese context. Copyright is a relatively new concept in Chinese law, and its role in the production and distribution of media products is rather more limited than generally understood in the West. The first formal copyright law was passed in 1990, by which time piracy had already become entrenched. It also contained an article withholding copyright protection from all works that were not permitted on the Chinese market. However, that does not mean that there were no rules on production and distribution of audiovisual media before, or that piracy of prohibited works was legal. For this, it is necessary to look at the broader characteristics of Chinese media regulation. Throughout the early Communist era, the Chinese media sector had been run as a planned economy, and regulations emphasized not so much the individual intellectual property rights of creators, but the administrative power of certain Stateowned entities to produce, distribute and show certain audiovisual media. Creators were paid salaries, with small bonuses if their works were successful, but there were few individualized incentives for creation ${ }^{17}$. Copyright was brought into this sector partly to create such an incentive, but its role remains limited to creating a payment mechanism for creators, rather than liberalizing the sector. In other words, although it is necessary to have authorization from the rights holder to bring a work onto the market, it is not sufficient. It is simply one of the many boxes that must be ticked, including licensing of all enterprises in all links of the value chain as well as licensing of the work itself. All of these licenses are based on criteria that are amongst others aimed to ensure political control over the media market, as shall be analyzed in Chapter IV. Hence, equating piracy to copyright infringement in the Chinese context presents us with difficulties. How do we deal with a situation where a legitimate rights holder has authorized a Chinese enterprise to bring a work to the market, but where this enterprise receives no government approval to do so?

Therefore, for the purposes of this study, piracy is defined on the basis of three characteristics. It refers first to the production and distribution of complete works, in order to not tackle the question of transformation of works or use of parts of works. Second, this production and distribution takes place with the aim of profit in the marketplace. Third, it takes place outside of the legitimate economic channels, as defined by media regulations, of which copyright is a part.

\section{Why audiovisual media?}

The choice of audiovisual media piracy as the subject of this study is based on a number of factors.

First, from a methodological point of view, it is submitted that it is more informative to start from an empirical problem, rather than from a theoretical or doctrinal concept. Theories often come with hidden assumptions and preconceptions, which may well obscure or deny the complexity of a certain phenomenon. Also, they may prejudice the role of significant factors internal to the phenomenon, but not to the

\footnotetext{
${ }^{16}$ By non-commercial, it is meant that the objective of those sharing media files often is not to secure direct monetary gain. This does not imply that there can be no economic objective in file sharing, as it allows someone to obtain for free what otherwise should be paid for. However, excluding file sharing allows us to concentrate on the commercial form of piracy, which is more characteristic of China.

${ }^{17} \mathrm{Qu}, 2002$, pp. 27 et seq.
} 
theory. Specifically, piracy and counterfeiting are some of the most debated issues China's international commercial relations, and therefore frequently in the spotlight of academic writing as well. The problem is that covering the whole gamut of intellectual property in China, unless in a sizeable monograph, runs the risk of being overly generalizing, or running into the complexities of Chinese governance. Intellectual property issues belong to the responsibilities of a significant number of different administrative entities, meaning that what may be true for copyright matters, may not work in the case in patents, or that even within one issue area or industry sector, a number of administrative bodies will fight turf wars over powers and jurisdictions. In order to capture these complexities well, and give an insight into the workings of China's governance structure, a narrower, issue-based approach is more appropriate.

Second, audiovisual entertainment media carry a special significance in the Chinese context, in it that they are seen by the Party-State as a crucial transmission belt between the rulers and the ruled ${ }^{18}$. This makes them different from a number of other products protected by copyright, such as scientific works and non-content computer software, such as productivity software and operating systems ${ }^{19}$, which do not carry politically sensitive content. They are also different from other products susceptible to counterfeiting. Where machine parts, food or medicine are concerned, the political salience of counterfeiting relates to potential danger to public health or product safety, which requires a different response than pirated media, which do not cause direct physical harm to consumers ${ }^{20}$.

Consequently, while piracy and counterfeiting of different products often seem alike to the observer, the factors causing them may be slightly different, which in turn influences the formulation of political preferences and policy ${ }^{21}$. Moreover, the political economy surrounding audiovisual media piracy will be dissimilar from that of other products, which will be of importance when analyzing the role of enforcement in these questions.

\section{The piracy value chain}

In order to understand piracy, we need to understand how it takes place, and which stakeholders are involved. The following sections outline a broad view of how the piracy value chain is structured, who is involved, and how the process of piracy takes place.

\section{The data problem}

Media piracy is an unlawful activity, which means that hard and accurate data, describing and quantifying the problem, is not available. There are primary sources en-

\footnotetext{
${ }^{18}$ See, for example, Shirk, 20II, and Zhao, 2008.

${ }^{19}$ Computer games are seen as content works, and hence regulated in ways that are comparable to films and television programmes.

${ }^{20}$ Of course, pirated products may cause economic harm by destroying a legitimate market and depriving individual rights holders of income, cf. infra.

${ }^{21}$ For example, Lu and Poddar propose a one-size fits all strategy for rights holders in combating piracy and infringement, without differentiating between different products. Consequently, any influence from product-specific issues, such as trade barriers or regulatory measures, is taken out of the equation, while they might be quite significant for the way in which right holders can lawfully operate. Of course, counterfeiters are not burdened by these concerns. Lu and Poddar, 2008. Similar problems are present in Yang, 2008.
} 
deavouring to describe the problem, but these suffer methodological issues, such as a lack of reliability, neutrality and completeness. Most of these sources can be classified into three categories.

First, there are reports prepared by governmental and non-governmental organisations and institutions ${ }^{22}$. As these documents are intended for policy-influencing purposes, the data they offer is often biased ${ }^{23}$. Also, as the private and secretive nature of piracy makes comprehensive data gathering very hard, estimates depend on extrapolation of very little original data, again potentially inflating damage figues. Lastly, damage to the sector is often calculated in terms of gross revenue or consumer spending loss, instead of net loss to the industry ${ }^{24}$.

Some studies are also not publicly available, such as a report used as evidence in the China-Intellectual Property WTO case, an American association comprising different copyright-related trade groups ${ }^{25}$. Data may be out of date. The most recent MPAA Chinese piracy statistics date from $2005^{26}$, leaving us without any numbers for the subsequent periods, in which the Internet made its inroad into entertainment media. Second, Chinese government statistics about piracy mainly concern enforcement efforts, but do not give an overview of the state of the complete market ${ }^{27}$. They also do not offer complete detailed breakdowns of the nature of the goods confiscated, such as the content or the nationality of confiscated items. Instead, they mainly consist of lists of numbers concerning the types of confiscated items, broken down by province. Moreover, very little data is available concerning further enforcement of piracy cases. It is not clear how many people are sentenced for piracy and what the extent of those sentences is ${ }^{28}$, and it is also not made clear how confiscated products are disposed of.

Third, there is anecdotal evidence. This consists of traveller's tales, blogs, press articles and such. This is relatively plentiful, but unfortunately does not offer a systemic picture of the phenomenon ${ }^{29}$. Most stories by non-Chinese authors do not offer a Chinese outlook on the matter. It may well be that expat consumption of pirated material exacerbates the situation or skews the balance of content in the favour of foreign productions. Also, most anecdotal evidence focuses on large cities such as Beijing, Shanghai and Shenzhen, but offers little or no detail on the countryside.

The few quantitative studies that exist concerning piracy in China focus mainly on consumer behaviour and preferences in connection with audiovisual products, rather than production and distribution networks. These studies often suffer from small

\footnotetext{
${ }^{22}$ These include the annual Special 30 I submissions by related industry associations such as the IIPA, as well as one-off reports such as MPAA, 2005 and CEAS, 2006.

${ }^{23}$ For example, a calculation method often used in these reports assumes that every instance of piracy displaces a legitimate sale. This is not necessarily true, but results in inflated damage figures, intended to put the problem higher on the political agenda. Bai and Waldfogel, on the other hand, identified that this displacement rate was extremely small. Bai and Waldfogel, 2009.

${ }^{24}$ Wang, 2003, p. 26. This is amongst others true for the IIPA reports. For more information on IIPA's methodology, see IIPA, 2009A, Appendix B: Methodology.

${ }^{25}$ This report, listed under evidence number US-4I was widely cited in the U.S. submissions concerning this case, but not made public as a whole.

${ }^{26}$ IIPA, 2009B, p. 85. Data for business software and music piracy in China are available until 2008.

Later IIPA reports only contain unsubstantiated percentages about optical disc piracy.

${ }^{27}$ See, for example, NCA, 2008.

${ }^{28}$ This is aggravated by the fact that piracy in China is punishable under two sets of regulations: copyright law and publications regulations.

${ }^{29}$ See, for example Buckley, 2003; Butterton, 1996; Rabinovitch, 2008; Mertha, 2005A, p. 6.
} 
sample size. Also, many studies concerning Greater China originate from Hong Kong or Taiwan, rather than from the mainland, or compare Hong Kong with the mainland, without accounting for certain intervening variables that may influence consumer behaviour ${ }^{30}$, such as product availability and the efficacy of retail outlets. Again, Mainland studies are predominantly conducted in larger cities ${ }^{31}$, and therefore provide little to no information about the rural piracy situation.

Consequently, there is little factual information on a number of important topics. The identity of pirates, structure of their networks and the functioning of distribution often remains a matter of conjecture, although it is often assumed that they function as highly sophisticated organized crime networks. We know very little about enforcement ${ }^{32}$, which would be of significant assistance to learn more about piracy structures. The sheer size of the problem also would presuppose connivance with State organs at some level. The impact of expatriate consumption on piracy is unknown, and may be important, as expatriates may form a disproportionally large section of the pirated media clientele.

This lack of primary sources is regrettable but must be accepted. Even the United States was found unable to bring enough factual evidence to support its allegations in the China - Intellectual Property case before the WTO ${ }^{33}$. It does however not invalidate the study. Although detailed information is lacking, the quantity of the information and the political salience of piracy in trade relations illustrate that the problem exists, and has been determined to be important by crucial actors, including governments. It also allows for combination of data, making it possible to paint at least a broad picture of the phenomenon. Therefore, this section builds on the available data, combined with personal observation of the author, but will also indicate where these data are inconclusive or contradictory.

How did audiovisual media piracy evolve?

The initial instances of piracy in China quickly followed in the footsteps of the reform and opening up (gaige kaifang 改革开放) campaign, initiated at the end of the Seventies. At that time, mainly books, scientific magazines and software programmes were copied ${ }^{34}$. These books would be sold in special sections of state-owned stores, marked "internal” (neibu 内部), which meant that foreigners could not legally enter ${ }^{35}$. In order to stimulate economic development, state-owned publishing houses or state organs would take out one subscription to foreign scientific magazines, copy that magazine and send it to all "sub-subscribers" within China ${ }^{36}$. Piracy of audiovisual media was limited mostly to public showing. Cinemas, broadcasters and "mobile pro-

\footnotetext{
${ }^{30}$ Cheung and Prendergrast, 2006. This study compares consumer preferences on VCDs in Hong Kong and Shanghai, but does not take into account market access differences in both markets.

${ }^{31}$ See, for example, Cheung and Prendergrast, 2006; Kwong et al., 2003; Wang, 2005.

${ }^{32}$ The United States provided a report drafted by the China Copyright Alliance (CCA), an alliance of IP industry groups in the DS362 case. This report provided more information about, amongst others, quantities of goods confiscated in administrative enforcement actions. China strongly contested this report, which was never made public. DS362, US Second Submission.

${ }_{33}$ DS362, Report of the Panel, p. 124.

${ }^{34}$ Zhang, 2007, p. 27.

${ }^{35}$ Butterton, 1996, p. 1082.

${ }^{36}$ In this study, piracy of scientific publications and computer software will not be further addressed. While there are a number of joint causal factors, the policies and regulatory frameworks concerning these are quite different. Similarly, they occupy a different position in the law and reality of international trade.
} 
jection units" would show legal copies of films without remuneration, or simply pirated copies.

Audiovisual media piracy for home use started popping up in the middle of the Eighties in some areas. In 1986, an interministerial notice reported sale of pirated audiovisual products in certain areas. Some of these products were smuggled in and others were produced in $\mathrm{China}^{37}$. In 1988, widespread commercial distribution of unauthorized foreign videotapes had reportedly not yet emerged, but was already anticipated in the light of statistics on quickly increasing sales of video tape recorders ${ }^{38}$. By the middle of the Nineties, audiovisual media piracy had become a major phenomenon. Estimated damage due to piracy doubled from 1995 to $1996^{39}$. All available media carriers at that time, such as magnetic tape, CD, VCD and Laserdisc (LD) were subject to piracy, which swiftly took up about ninety per cent of the market. Crackdowns and political campaigns were of no avail in combating this high level of piracy, which swiftly followed technological evolution.

Currently, hard-goods audiovisual piracy mainly involves CDs and DVDs, but the new Blu-Ray format has also arrived on the market ${ }^{40}$. At the same time, online piracy has also become a widespread phenomenon. Many efforts by public and private parties notwithstanding, piracy is still estimated to occupy about ninety per cent of the total audiovisual market. Moreover, unauthorized screening and broadcast of audiovisual media remain present.

\section{Hard goods piracy}

The business model of hard goods piracy networks closely resembles legitimate production and distribution networks: source material is adapted to a physical carrier, which is then duplicated and distributed to the consumer market. However, these networks are fundamentally illicit in nature. This section provides an overview of the data presently available on the range of products and the different facets of the production process.

\section{Product range}

Anecdotal evidence suggests that the number of available audiovisual titles in China, at least in large cities, is extensive. Roadside peddlers may have several hundreds of different titles for sale. In large shops, thousands of titles of different media types may be available.

A first type of pirated media is the motion picture. The supply of these is very large and exhaustive. The titles on offer range from ' 50 s Humphrey Bogart movies to the very latest Hollywood blockbusters and from French art-house films to Japanese Manga. Mainstream movie titles are the most popular, specific bestsellers being imported blockbuster films, new foreign films not shown in China, and big-budget Chinese films. The extent to which a film is pirated seems to depend on their level of commercialization, the scale of associated marketing campaigns, and market appeal ${ }^{4 !}$. This creates a "free ride" for pirates, who profit from marketing campaigns being financed by the rights holder. However, movie buffs are well catered for as well. In one DVD shop in Ji'nan, the capital of Shandong Province, the author found art house and classic movies by Leni Riefenstahl, Krysztof Kieslowski, Peter Greenaway

\footnotetext{
${ }^{37} 1986$ Audiovisual Rectification Notice.

${ }^{38}$ Simone, 1988, p. 35.

${ }^{39}$ Butterton, 1996, p. 1095.

${ }^{40}$ Although these discs are not yet of good quality, Robson, 2008.

${ }^{41}$ CEAS, 2006, p. 9.
} 
and other less well-known foreign directors. Even the Dutch criminal film De Dominee (The Preacher) and the Belgian film De Zaak Alzheimer (Memory of a Killer) are on sale in China.

Second, there are television series and documentaries. The range of foreign television series on offer is very exhaustive and complete as well. One trundle to the shops in Shanghai in May 2008 sufficed for a bundle of series as diverse as Coupling, Blackadder, House MD, Family Guy, as well as a host of Korean and Japanese series. There is a definite Anglo-American bias in the range of products on sale. It is much harder to find French, German or Spanish-language television series than it is to find feature films in these languages.

Last, Western music seems less popular in China than movies, with a more limited and often dated selection generally offered for sale, although some shops are specialized in more obscure items. Asian music, on the other hand, is much more popular, witnessed by the availability of K-pop and J-pop bands such as H.O.T. Chinese music is represented by Mainland or Taiwanese performers such as F4, S.H.E., Jay Chou and Yang Chenguang. Music is available on CD and concert DVDs.

\section{Formats}

Audiovisual media is mainly available on DVD, VCD. It is very hard to determine which of these formats is most prevalent, but the general tendency seems to be that DVDs are more present in larger cities, where the population is generally more affluent and can afford the higher-priced players and discs. Many city shops and sellers are not carrying VCD anymore (and ironically, leading to an increased proportion of legal copies in the range of VCDs still available) due to lower profits. Still, they remain popular and widely available in the countryside. Older formats, such as LD and VHS have all but disappeared from the market.

During the '90s and early 2000s, VCD was the preferred format for audiovisual products in Asia. It technology never gained a large market share in the West, since it was quickly rendered obsolete by the advent of DVD. However, it became popular in South-East Asia, due to the low price of patent licences ${ }^{42}$. This popularity engendered a vicious circle in which on one hand VCD piracy grew because of the ubiquity of players, and on the other, players remained popular because of the range of films available. Most Chinese DVD players still are VCD-capable.

Pirates are very quick to adapt to new technology. On a visit to China in November 2008, the author found pirated movies on Blu-Ray Disc in Beijing. This only became a mainstream technology in the beginning of that year, when efforts to promote its competitor format, HD-DVD, ceased in February.

\section{Product quality and pricing}

The pirated audiovisual media market exhibits a high degree of differentiation. Many popular films and television series are available in different editions, with varying quality and price.

Content quality is variable and depends on price. Lower-capacity DVD-5 discs, contain only the main feature film. Higher-capacity DVD-9 discs are more expensive, but often contain extra features, dropped scenes and other add-ons. Chinese subtitles are usually provided, as are - depending on origin of the original copy -English, Thai, Japanese, Korean, French, Spanish, or even Dutch subtitles ${ }^{43}$. Also, pirates may com-

\footnotetext{
${ }^{42}$ Wang, 2003, p. 49.

${ }^{43}$ If English subtitles are not present on the source material, they are often added by pirate producers. The quality of this varies strongly, however. For on-line films, a scene has sprung into being
} 
bine portions of different editions of a certain film to create a “complete edition” (完 美版 wanmeiban) ${ }^{44}$. Another phenomenon is the “compressed disc” (压缩碟 yasuodie), which contains a number of films, with lowered image quality, at a lower price $^{45}$.

Image and sound quality generally are good. Some very recent films may have been "camcorded" - recorded in a cinema, resulting in a lower quality film. Older films, in contrast, rarely present bad image quality. In a minority of cases, there is a more fundamental problem. Hoaxes sometimes happen. The author holds a copy of what is purported to be the movie Battle of Britain, that name being even printed on the CD label, but that the disc contained a German war movie. Also, Spider Man 2 was sold as Spider Man 3, before the latter was released" ${ }^{46}$. The success of French film "Le Fabuleux Destin d'Amélie Poulain" led to a previous film starring lead actress Audrey Tautou being issued in China as "Amelie 2". Also, some music CDs are in fact cover versions of the originals ${ }^{47}$. In rare cases, a disc will not play ${ }^{48}$. However, many shops are flexible in taking back or exchanging these discs.

Not all pirated hard goods compete in the low price market. Although most films are sold in simple plastic wrapping without a box, some pirates produce very high quality special editions of certain films and television series. These include better and nicer wrapping, but also certain other extras. A version of the World War Tworelated television series "Band of Brothers" was marketed, which included copies of period, photographs, a book about the invasion of Normandy, a replica army bag, a replica army knife and other such gadgets ${ }^{49}$.

Pricing depends largely on these quality factors. In Beijing and Shanghai, lower quality DVD-5 discs cost about 5 to 8 CNY, higher quality DVD-9 discs cost between 10 and 15 CNY apiece. Deluxe editions sometimes are more expensive than standard legitimate products. Some foreign film companies, such as Warner Bros. have tried to combat pirates by drastically lowering prices and offering "simple packaging" DVDs, without a box. However, prices of pirated products in general are still much lower than the prices of legitimate DVDs.

\section{Piracy of Chinese products}

In terms of nationality, the most pirated films are American-made, followed by Korean films. Films from Hong Kong, Taiwan and Japan are also important targets for pirates ${ }^{50}$. European films are less popular, but still relatively plentiful.

Foreign observers frequently overlook the degree in which Chinese products are pirated and the consequent damage to the Chinese film industry. Chinese films and television series are present in large numbers in DVD shops. Problematically, it is much harder to determine the legality of Chinese media products on first sight. Usually, with a bit of background knowledge and a sharp eye, differentiating between

where amateurs and hobbyists provide fan-sourced subtitles ("fansubs") to non-Chinese films and television programmes. Barboza, 2010A.

${ }^{44}$ Xin, 2006.

${ }^{45}$ Zhao, 2008.

${ }^{46}$ Reuters, 2007A.

${ }^{47}$ The author possesses a "Beatles" album, which consists of Beatles songs performed by - admittedly good - cover bands.

${ }^{48}$ Bad quality of pirated discs has had the remarkable effect of providing an incentive for the development of more tolerant DVD readers. One well-known DVD player brand, Bubugao, provides an "error correction function”, enhancing “low-quality” discs. Goldkorn, 2003.

${ }^{49}$ Xin, 2006, p. 34.

${ }^{50}$ CEAS, 2006, p. 10. 
counterfeit and legal Western products is relatively easy. This is not so with Chinese products.

Some works and events get special governmental protection against piracy, but even that does not seem to deter pirates. For example, in the autumn of 2008, pirated copies of the Beijing 2008 Olympic Games DVDs - which were supposed to be protected more strictly - could be found easily in Beijing DVD shops. Concurrently, the 2009 all-star cast film Founding of a Republic” (Jianguo Daye 建国大业), produced to celebrate the sixtieth anniversary of the People's Republic's founding, appeared on the streets of Zhengzhou only four days after the first screening, despite being a focal point for copyright enforcement agencies ${ }^{51}$.

A comparison of piracy of Chinese and foreign media products may be useful in determining the degree to which the piracy problem harms domestic film sector growth, as well as providing a background for deeper study into the relation of foreign and domestic interests in the copyright system. Currently, inadequate empirical data makes this impossible. Most studies dealing with media piracy are commissioned by Western institutions or industry groups, which tend to approach matters from self-interest. Consequently, there are even less reliable data on piracy of Chinese media than of Western media.

Pirated hard-goods production

The production of a pirated DVD is a relatively complicated process. The producer not only needs the capacity to produce a large number of copies, but he also has to obtain the original material, adapt it to the Chinese market, and bring the products to the market afterwards.

The first step in the production process is obtaining original material. Where older material is concerned, it is very easy to obtain a legal copy of a film, which is then duplicated. In principle, that could mean that one copy of a film could potentially satisfy the entire Chinese market.

Moreover, pirates are able to bring new films to the market quickly. Large and popular blockbusters often appear on pirated DVDs before or only days after cinematographic release ${ }^{52}$. These are sourced through, pre-release screener discs sent to journalists or award committee members ${ }^{53}$, or by camcording - recording a film in a cinema with a hand-held camera. A consequence of both sources is that they lower the quality of the finished product. These DVDs are mainly produced for a public that values novelty higher than picture quality. When inquiring about a very new movie, the author often was given the advice to wait a few days, when better quality examples would be available ${ }^{54}$. Sometimes, Chinese film producers sell "distribution rights" to pirates, in order to recoup at least some of their investment or income lost to piracy ${ }^{55}$, especially in cases where the film was not approved for public distribution.

When the parent material has been obtained, it must be adapted to the target market. This entails - for foreign language films - that Chinese-language subtitling or

\footnotetext{
${ }^{51}$ Liu, 2005.

${ }^{52}$ Wang, 2003, p. 8.

${ }^{53}$ Neigel, 2000 , p. 196.

${ }^{54}$ Id.

55 MPAA, 2005, p, 18. Filmmaker Wang Zhebin was offered I million RMB for the right to distribute the film "Balzac and the Little Chinese Seamstress" by a pirate distribution group, after SARFT refused to approve it. She turned the offer down, but the film was available on pirated DVD soon after, anyway. Montgomery, 2004.
} 
dubbing must be present. Sometimes, especially for older materials, these are already present on the original copy. Otherwise, students, earning a bit of extra income, make translations ${ }^{56}$. In large cities, expatriate workers and foreign students are also an important client group, so pirates often include English subtitles as well. When original subtitles are not available on the source material, Chinese subtitles are sometimes run through a translation computer, resulting in erroneous English subtitles. It also happens that subtitles of another movie are copied ${ }^{57}$.

The next step is reproduction. Sources are divided as to where this takes place. Some sources contend that a significant part of illegal film production shifted to other localities in South-East Asia, such as Hong Kong and Thailand, after the antipiracy campaigns in 1996 and 1997. On the other hand, news reports on seizures of illegal production lines in China appear regularly in the press. One such report dating from 2007 boasts that since 1996, 23I fake production lines have been closed, indicating that significant levels of production in mainland China still take place. Most production takes place in Guangdong province, in the south of China, where cities such as Dongguan, Han'an, Shenzhen and Shantou are centres of illegal DVD reproduction $^{58}$. The DVD production lines used are usually high tech, with a significant number of them coming from abroad ${ }^{59}$.

Two different kinds of piracy operations exist. First, legitimate audiovisual companies produce unlicensed runs of DVDs. In 2003, total legitimate optical disc replication capacity in China was estimated to be 2,7 billion on 774 registered DVD/VCD production line. However, only 353,3 million licensed audiovisual media discs were sold in China, representing only $17,7 \%$ of production capacity ${ }^{60}$. The resulting overcapacity suggests these production lines are also used for illegitimate purposes. For example, enterprises produce pirated versions of films for which they are licensed, thus guaranteeing high quality but evading royalty payments. These products are paid for in cash, thus helping the producer evade taxation. Some distributors also illegally license copyright content to multiple licensees, who are acting in good faith ${ }^{61}$.

Second, underground operations can be hidden by legitimate non-audiovisual companies or in remote locations such as little villages in the countryside, or caves ${ }^{62}$. Examples of the former include the Guangming Paper Mill in Shenzhen, which was discovered in January $2008^{63}$, a factory, operating under the cover of a duckling hatchery, closed in early $1997^{64}$ and a factory operating under the cover of a bird flu research centre in Jiangxi, shut down in 2007. This factory had been moved there from Guangdong in 2004, as enforcement officials there were stepping up investigation into piracy ${ }^{65}$.

An upcoming phenomenon is the burner lab, in which films are burned to order from computer disks. This phenomenon is especially present in Guangdong, where the market size is estimated at least 300 million illegally burned discs ${ }^{66}$.

\footnotetext{
${ }^{56}$ Buckley, 2003.

${ }^{57}$ The author holds a number of discs on which this is the case.

${ }^{58}$ Buckley, 2003; Xinhua, 2008.

${ }^{59}$ Reuters, 2007B.

${ }^{60} 48,5$ million of these were DVDs, 305 million were VCDs, CEAS, 2006, p. II .

${ }^{61}$ Id., p. 13.

${ }^{62}$ Reuters, 2007B.

${ }^{63}$ Xinhua, 2008.

${ }^{64}$ Faison, 1997.

${ }^{65}$ Xinhua, 2007.

${ }^{66}$ CEAS, 2006, p. 13.
} 


\section{Distribution and sale}

Production can occur in a central location, but the geographical spread of distribution channels makes protection there much harder, causing those involved to show great creativity. Pirates tend to hide their wares in different packages, drivers and transporters are not being aware of the nature of the goods they are transporting ${ }^{67}$. Sale occurs in many locations. Sellers are either mobile vendors or fixed stores. In Beijing, these vendors were ubiquitous before the 2008 Olympic Games, peddling their wares out of sports bags in the Beijing Metro or the trendy Sanlitun bar district, as well as delivering directly to homes. Recently, there seems to be a marked evolution towards the disappearance of street peddlers. Especially in Beijing, the government was bent on keeping the streets clean because of the Olympics. Different expatriates report that the majority of peddlers did not return after the games.

Fixed shops take up the largest part of the market. These shops have the largest collection of titles and are often reported as very customer-friendly, for example allowing for return of bad-quality discs. Many stores, especially in larger cities, sell both legitimate and pirate media, sometimes clearly distinguishing $\mathrm{so}^{68}$. Some shops are part of state-owned or state-operated stores, such as the Friendship Store in Beijing's Sanlitun embassy district or located in government buildings, such as a police building in Yiwu ${ }^{69}$. There are also disc stalls in open-plan markets.

Depending on the political climate, many of these stores operate in a very public fashion. During crackdowns, they may only publicly show legitimate goods, but are still able to deliver pirated goods when asked. During the "Hundred Days" crackdown of 2006, the author was shown a back room, hidden in the building of one of Beijing's most popular tourist markets, which had a full complement of wares on display, most customers being foreigners. Other stores are hidden away at the back of another store, in basements or apartment blocks, and can only be reached if one knows where to look ${ }^{70}$.

Are hard goods exported?

In comparison with the vast numbers of pirated products sold on the Chinese domestic market, export numbers remain relatively low and predominantly centred on Asia. Export to the West is relatively limited.

Both in the United Kingdom and the United States, ethnic Chinese criminal networks control significant parts of the counterfeit disc market, which are then peddled on the street, in car boot sales or market stalls. Profit margins can reach II50 per cent ${ }^{71}$. Some illegal Chinese migrants are forced to sell pirated discs abroad in order to pay their "transportation fees" to the snakehead organizations that brought them. However, the origin of counterfeit discs has largely shifted from Asia to domestic production ${ }^{72}$. Links between crime networks overseas and inside China may be present, but are not substantiated.

\footnotetext{
${ }^{67}$ Id., p. 35.

${ }^{68}$ Mertha, $2005 \mathrm{~A}$, p. 4 . This in itself is a tangible change, as around 2000 , there were nearly no legitimate CDs in stores, while now there are some. This also contrasts with the near $100 \%$ piracy rate in smaller cities and the countryside, Priest, 2006, p. 838.

${ }^{69}$ Mertha, 2005A, p. 4.

${ }^{70}$ Buckley, 2003.

${ }^{71}$ Figure for DVDs transported from Malaysia to the United Kingdom, UK National Criminal Intelligence Service SU/Drug Project, 2004, quoted in Treverton, 2009, p. 28.

${ }^{72}$ Communication with Eddy Leviten, FACT UK, on file with the author.
} 
There have also been instances of smaller and larger efforts to sell pirated Chinese media via the Internet ${ }^{73}$. Also, many foreign tourists and expatriates bring their film collection with them when leaving China, although this might lead to problems with Customs. Nevertheless, this problem remains relatively small compared with the total size of the worldwide DVD market, estimated at 1.2 billion units in $2005^{74}$.

Who are the pirates?

Very little is known about those in charge of the hard goods networks. Some links to vague terms such as "terrorism" or "organized crime" are suggested, but are rarely expounded upon. Sometimes, a piracy network is connected to official instances, such as the People's Liberation Army ${ }^{75}$ or the Public Security Bureau ${ }^{76}$. One unsubstantiated account suggests that there are six to eight large piracy networks in China, which allegedly determine amongst themselves who will distribute which films $^{77}$. These networks are structured in a way that most operatives only know the person one step removed from them. Network bosses often do not reside in China, in order to evade prosecution.

The market power of some producers is such that they have "brand names" for their pirated products, which each have their own specialty and reputation. In an ironic development, these brand names themselves are becoming the victim of counterfeiting, as newer players on the media market try to take advantage of already established reputations ${ }^{78}$.

The secrecy of piracy networks notwithstanding, it is possible to outline their basic mode of operation. Wang Shujen has argued that piracy networks evolved following technological evolution that reduced costs of production and distribution, and international integration of trade and commerce flows. They involve "complex, interrelated and dynamic relations among different networks and actors, as well as multiple structures of power ${ }^{79}$, , which thrive on challenging the predominant business strategy of the film industry. This profit-maximization strategy consists of temporal and geographical division of the market, and control over reproduction and distribution of the different marketization stages of audiovisual media. Consequently, a niche opens up in which speed and product range are rewarded. Not burdened by the necessity of meeting overhead and production costs, pleasing shareholders or complying with regulatory regimes, piracy networks can pursue profit maximization strategies of their own, essentially competing against the legitimate media players. This study will show that in China, the important role the State plays in media distribution

\footnotetext{
${ }^{73}$ Illustrative is the case of Randoph Guthrie III, an American who was arrested in Shanghai in 2004. At the time of his arrest, he had a stockpile of about 120,000 pirated discs, and made about US $\$ 25,000$ a month exporting them to the United States. Altogether, he had sold about 180,000 discs via his own website and online auctioning website eBay. Eventually, he was fined 500,000RMB and sentenced to two-and-a-half years imprisonment. The network supplying Guthrie was never investigated. Liu, 2005; Davis, 2005.

${ }^{74}$ Snider, 2005. In recent years, DVD sales have dropped. This is partly due to piracy, but also partly due to consumers transferring to other forms of legitimate consumption, such as paid-for digital services or high-definition discs. Sherwin, 2010.

${ }^{75}$ Mertha, 2005A, p. 156. Also, where piracy activities take place on PLA land, it is very hard for other administrative authorities to carry out enforcement activities. These premises are virtually immune from external law enforcement, as the PLA has its own system of courts and investigatory bodies.

Dimitrov, p. 156.

${ }^{76}$ Mertha, p. 4.

77 Swike, 2008, p. 496.

${ }^{78}$ Xin, 2006.

${ }^{79}$ Wang, 2003, p. 190.
} 
slows the speed and reduces the range of products that are available, further opening up this niche.

\section{Internet media piracy in China}

The MPAA defines Internet piracy as: "[...] the downloading or distribution of unauthorized copies of works such as movies, television and music via the Internet." This form of media piracy has quickly become very popular in the West, amongst others due to the evolution of larger capacity hard drives and faster Internet connections, and the possibility of acquiring large quantities of works for the price of the Internet connection. In China, where the number of Internet users has grown from 103 million people in 2004 to 485 million in July $2011^{80}$, Internet piracy has grown ever more rampant.

Because of technological requirements, Internet piracy occurs mainly in larger cities. Relatively well-educated young males are the largest group of online pirates ${ }^{81}$. Universities are especially seen as Internet piracy black spots ${ }^{82}$. Due to the high speed and low cost of their internal networks, impecunious students can easily exchange audiovisual files and software programmes.

There are different ways of pirating media on-line. First, P2P transfer implies that users link up to an exchange network, downloading content off others' computers, often while simultaneously uploading content stored on theirs. Different protocols and client programmes are available, such as LimeWire, Kazaa and BitTorrent. The former two allow for programmes to index the contents of a user's hard drive, and make this content available to other users of the same protocol. BitTorrent requires the user to download a small meta-level file from a web site. This file contains information on the larger file the user would like to download from peers who are again - connected to a network with a specialized programme. The BitTorrent websites were quite popular. One of the largest Chinese sites, BTChina, boasted 50 million members, and the major international BitTorrent sites such as the Pirate Bay are popular in China as well ${ }^{83}$. In 2004, MP3 and BT (short for BitTorrent), were the first and fifth most popular search terms on Baidu, China's largest Internet search website $^{84}$, and CNNIC statistics indicated that 222.4 million web users used videosharing websites in the first half of 2009.

Second, dedicated websites may directly provide or offer deep links to infringing content. This phenomenon has been subject to a continuing battle in the West ${ }^{85}$, and is also very much a part of China's online landscape. Baidu itself owes a significant part of its current success to its MP3 search service, which accounted for 20 per cent of its total traffic at some point. In July 2009, 47 million individuals used this service, which offers links to - often infringing - MP3 music files, Tudou and Youku,

\footnotetext{
${ }^{80}$ CNNIC 20II, p.4.

${ }^{81}$ CEAS, 2006, p, 13.

${ }^{82}$ Priest, 2006, p. 800.

${ }^{83}$ The Pirate Bay itself made a survey about the geographical origin of signals connecting to its trackers. About a third came from China, amounting to 7 million individual users. Considering the Pirate Bay is blocked in China, this is an impressive number.

${ }^{84}$ Priest, 2006, p. 800.

${ }^{85}$ The example of YouTube is instrumental. YouTube allows individual users to post videos online, but was sued repeatedly for failing to oversee the posting of infringing material. It is still possible to find infringing material, such as episodes of television series, on YouTube, but a safe harbour provision has been created whereby the website will delete infringing content on request of the rights holder, and thereby avoids liability for copyright infringement.
} 
China's most popular audiovisual websites, and other comparable web sites contain many infringing films ${ }^{86}$.

Online piracy differs strongly from hard-goods piracy. Most importantly, while hardgoods piracy essentially is a commercial, for-profit operation, online piracy consumption usually is free. P2P users tend to share on a quid-pro-quo basis, with many of the $\mathrm{P} 2 \mathrm{P}$ protocols encouraging such sharing. Websites offering entertainment content gain income from other sources, such as advertising. Internet distribution also does not depend on a large, structured production and distribution network such as the sort needed for hard-goods piracy, as no logistical operations, factories and stores are required.

Moreover, apart from the financial side, online piracy is more flexible in terms of the range of offered content, offering a wider range of titles at a larger amount of convenience than hard good shops. Consequently, a number of reports, and anecdotal evidence, suggests that the hard-goods piracy in China is increasingly being displaced by the Internet. This echoes developments in the West, where on-line piracy has hit CD and DVD sales hard. In other words, Chinese hard-goods pirates also cannot compete with free.

This is not to say that commerce is completely absent in Internet piracy. As indicated before, Baidu became China's Internet search market leader on the back of offering access to MP3 files. Tudou and Youku are big commercial operators in their own right. And last but not least, China's enormous Internet café sector also survives to a large extent on offering access to films or music. A Data Consultancy survey indicated that two thirds of Chinese Internet café users are used to watching movies or listening to music on-line, and that at least 80 per cent of this content is infringing $^{87}$. In 2009, there were about 138.000 Internet cafés in China, with about 135 million customers ${ }^{88}$, which gives some indication about the extent of the issue.

\section{Illegal projection and broadcasting}

One form of media piracy that is less conspicuous but still present is illegal projection or broadcasting. In the middle of the Nineties, pirated films and television programme were reportedly shown in "mini cinemas' and luxury hotels, as well as being broadcast by state-owned television stations ${ }^{89}$. In larger cities, illegal video showings in public halls have been less frequent in recent years. Cinemas and television stations outside the largest cities still project or broadcast audiovisual material without paying remuneration ${ }^{90}$ or even without censor's authorization. The State Administration of Radio, Film and Television (SARFT) reported in 2002 that a number of television channels were offering television programmes without SARFT agreement in violation of regulations concerning the permitted scheduling of foreign television programmes. In 2007, it was reported that the television series Prison Break was shown on some Chinese television stations, although - as is the case with many crimerelated series - it did not pass censorship ${ }^{91}$. In another report, it was alleged that in north Anhui, there were more than 600 illegal television stations, broadcasting un-

\footnotetext{
${ }^{86}$ Although they have recently come under scrutiny, see also People's Daily, 2010.

${ }^{87}$ Quoted in Shen, 2010.

${ }^{88}$ Shen, 2010.

${ }^{89}$ Butterton, 1996, p. 1095.

${ }^{90}$ CEAS, 2006, p. 13.

${ }^{91}$ The source material for this sort of broadcast may be illegal DVDs. Reuters, 2007C.
} 
authorized programmes ${ }^{92}$. Hotels often offer films without royalty payment and Karaoke bars also often infringe copyright.

\section{The economic damage of media piracy}

Copyright infringement levels in China are reportedly very high. The market share of pirated audiovisual content was estimated at $90 \%$ in $2006^{93}$. Piracy creates economic damage on many different levels and in many areas. A first major group of victims are filmmakers and studios. The total consumer spending loss to the global film industry due to piracy was reported to be 18.2 billion USD in the $2005^{94}$. Of this total, 2,689 billion USD was racked up in China, 565 million USD of which was suffered by MPAA members ${ }^{95}$. In 2010, it was calculated that the pirated DVD market was worth 40 billion CNY, nearly seven times the cinema box office income of that year, which was about 6 billion $C N Y^{96}$.

For foreign companies, these losses are painful and damaging, but since China is not their main market, their viability is not directly affected. Chinese film industry companies, on the other hand, are directly threatened by film piracy. This is not only because of the direct loss of income due to piracy, but also because the still-developing Chinese film industry has a hard time competing with the plethora of foreign entertainment products available cheaply or freely through piracy. This, in turn, strongly affects both quality and quantity of films being made in China, as the link between the content market and content industry is severed. Privately owned enterprises are especially at risk, since they are not funded a priori by state capital. Also, many stateowned film studios have long since stopped making films, instead turning to renting out equipment and facilities, and administrative services as main sources of income, decreasing their sensitivity to piracy. Consequently, many famous Chinese filmmakers have chosen to market their films abroad first, thus guaranteeing some form of income there, before promoting their films in China. In the end, this contributes to the small number of albums and films released by domestic Chinese artists ${ }^{97}$. On the other hand, as copyright protection remains largely incidental to prevailing business models $^{98}$, some entertainment companies view piracy as free promotion; whilst monetizing their content through other means, such as advertising licensing, merchandising, or in the case of music, mobile telephone ring tones and live performances $^{99}$.

Other industry branches are also affected by piracy. Cinema chains see box office returns drop as a result of piracy. The movie Baober In Love, for example, raked in 6 million CNY in box-office revenue during its first day of screening. By the second day, pirated copies were already available, and revenues dropped by two-thirds ${ }^{100}$. A similar fate befell "The Touch", when pirate copies became available four days after release $^{101}$. Copies of an album by folk group Yi Ren Zhi Zao were available before

\footnotetext{
${ }^{92}$ Pan, 2011.

93 CEAS, 2006, p. 9.

94 MPAA, 2005,

${ }^{95}$ Id. The MPAA groups the six major American film companies: Disney, Paramount, Sony, 20th Century Fox, Universal and Warner Bros.

${ }^{96}$ Xinhua, 2010A.

${ }^{97}$ Priest, 2006, 842.

${ }^{98}$ Montgomery and Keane, 2004, p. 3.

${ }^{99}$ Priest, 2006, p. 841.

${ }^{100}$ CEAS, 2006, p. 27.

${ }^{101}$ Kahn, 2002.
} 
the official release date, and in the end $4 \mathrm{I}$ different versions of this album were available, the legitimate one's market share being estimated at 1.4 per cent ${ }^{102}$. One cinema chain completely ceased its operations in Hong Kong, citing piracy as the main reason for its falling revenue ${ }^{103}$. Legitimate producers of legal audiovisual materials find that piracy exerts negative pressure on royalty payment incomes, which makes it difficult for them to lower prices of legitimate products ${ }^{104}$.

\section{Fiscal and social damage of media piracy}

More indirectly, piracy damages government and societal interest. Although piracy employs thousands of people in China, it has little effect on the overall level of employment in China's film industry ${ }^{105}$. In other words, these jobs would probably mostly be maintained if the sector would operate legally. Moreover, working conditions in underground facilities are often unsafe and unhealthy. As it is considered to be less harmful to the public than narcotics or other forms of illicit income, piracy has also become an important source of income for organized crime.

Piracy also reduces tax revenues directly and indirectly. First, as an illegal industry, it does not pay tax itself. This fiscal damage to China was estimated at 228 million USD in $2005^{106}$. Second, by lowering incomes for legal companies, it exerts an indirect downward pressure on taxes. On some local levels, however, piracy has increased unofficial government incomes, often via kickbacks to officials in return for acquiescence ${ }^{107}$, "case-handling fees" asked of rights holders for administrative enforcement and fines.

On a higher level, high levels of IPR infringement damage China's image abroad. It is

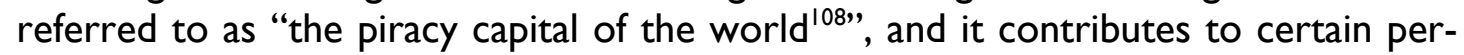
ceptions of Chinese as being untrustworthy.

\section{The consumer}

Anecdotal evidence suggests that the range of people purchasing pirated hard goods or downloading pirated content off the Internet is relatively broad, including individuals from all regions and nationalities, both sexes and different age groups ${ }^{109}$. However, as with piracy in general, detailed data is preciously scarce.

A 2006 Internet study into pirated goods buying habits found that 84 per cent of respondents had bought pirated goods in the preceding year. On average, this group bought 7.82 pirated film DVDs per year, as well as 4.10 music CDs, 3.96 TV series and 2.9I cartoon DVDs. In Hong Kong, an OECD study found that 63 per cent of respondents purchased pirated films or music ${ }^{110}$. Another study of consumers in Hong Kong, Wuhan and Shanghai "' provides some important insights into the main demographic aspects of purchasers and their perceptions of the products they buy. Heavy purchasers of pirated DVD discs tend to be males, with tertiary education in white-collar occupations. In general, they did not consider their purchases ethical or legal. This tendency is strongest in Hong Kong, followed by Shanghai and Wuhan.

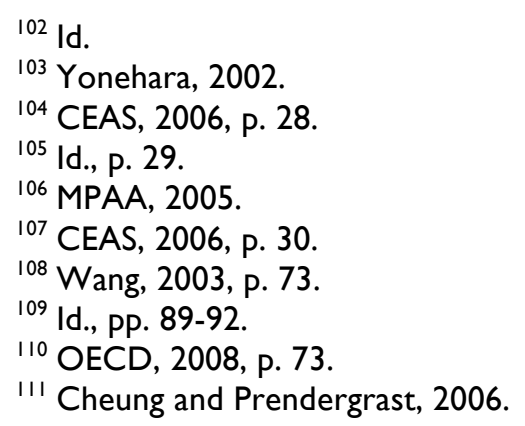


Also, quality of the product is seen as a problem, as well as after-sales service and support by readers. The respondents were more positive about the supply and variety of pirated DVDs, the speed of publication and the popularity with friends and family.

Another study comparing buyers' attitudes concerning non-deceptive counterfeit products in the UK and China found that demographic divisions have a relatively small influence in counterfeit purchases. It also confirmed buyers are well aware that the product they purchase is illegal ${ }^{1 / 2}$.

\section{Research question}

For a large part, media piracy in China has a commercial basis. In other words, products are bought and sold, and for-payment services rendered, ranging from optical discs to the hourly fees in Internet cafés. Moreover, these activities are exercised at significant scale. This differs from the Western experience of media piracy, the largest part of which takes place through not-for-profit file sharing through the internet, or minor incidences of very small-scale copying, within the private social circle ${ }^{1 / 3}$. Consequently, does not require complex legal analysis or new theory building on copyright. As we shall see in Chapter III, the Chinese government has created a comprehensive system of copyright law, which complies with international standards and commitments. While China faces questions on how to proceed with further copyright regulation in the Internet era, these questions are of themselves not fundamentally different from the questions faced in the West. Rather, piracy in China is generally a straightforward violation of the most basic principles of copyright law: the right of right holders to exclude others from reproducing, distributing and communicating their works.

An explanation of piracy in China must therefore clarify how is it possible that such a large-scale black market comes into being and can persist? It also means that it is necessary to expand the methodological frameworks that apply, as traditional, consumer-driven piracy models are less relevant. For example, the concept of the "copyright divide" as elaborated by Peter Yu can be a useful conceptual tool for analyzing how copyright law in the West has not succeeded in reconciling the interests of rights holders and consumers, but applying it to the Chinese situation would mean that a number of factors are not taken into account. By reducing media piracy to the tension between haves and have-nots, the significant role of the state, at least in China, and the influence of commercial piracy networks is excluded. Yet, both the State and the pirates have significant interests of their own, and piracy networks and service providers may have significant political and economic clout. An explanation of Chinese piracy therefore cannot be limited to outlining the broken bridge between rights holders and consumers, must include the influence of State interests, but also those of the piracy industry. Given that the Chinese state takes a strong interest in its media market, it is not unreasonable to assume that it has a stake in combating media piracy. However, this is hard to reconcile with the prevalence of piracy Therefore, in order to further understand media piracy in China, the relation between the state, the media and the piracy industry needs to be better understood.

\footnotetext{
112 Bian and Veloutsou, 2007.

113 The preponderance of music downloading, for example, can be illustrated by a number of industry reports calculating the impact of music piracy on the US economy, in which the sole empirical basis for piracy method is the IFPI estimate of number of songs downloaded, and no mention is made of other forms of piracy. MPAA, 2005.
} 
In other words, a central question in explaining audiovisual media piracy in China, and the first main question in this study, is how the Chinese State creates perverse incentives which has allowed the piracy industry to come into being and to persist.

Audiovisual media piracy also has a strong trade dimension, as the majority of foreign - and mainly American - works on the Chinese market are pirated, resulting in a flurry of articles analyzing media piracy in China from a US trade angle. These articles in general follow similar patterns ${ }^{1 / 4}$, indicating that piracy in China is rampant, that Chinese legislation protects US copyright products insufficiently, enforcement is lacking and that there is no interest in protecting US interests. In these articles, there is usually a link to China's WTO membership, and an implied claim that the WTO should "do something about it".

Often, the mechanism in the middle is insufficiently analyzed. When claiming that the WTO could influence the piracy phenomenon in China, a series of implied assumptions are made. First, it is assumed that there is a relationship between state action and piracy, as WTO discipline is only binding upon Member States. This study argues that such a link exists. Second, it is assumed that the State measures relating to piracy are subject to WTO discipline. Third, it is assumed that these measures violate WTO law, that - if found so after a WTO case - these measures will be changed, and that such changes include the factors within the state measures that drive piracy. This leads to the second research question guiding the study, which is to seek an answer to whether and how WTO membership can influence the state-related causes of media piracy in China.

\section{Existing explanations of piracy}

Previous studies have attempted to diagnose piracy from a number of angles. The first monograph dedicated to understanding Chinese intellectual property law, To Steal a Book is an Elegant Offense ${ }^{1 / 5}$, advanced an explanation based on culture. The gist of this argument is that the Confucianism precluded the advent of intellectual property law in China, because of its veneration of the past and the need to emulate old masters and sages. However, this explanation is too simple and insufficiently explanatory.

First, Wei Shi ${ }^{16}$ forcefully argues that, while Confucianism may not immediately call for a system resembling intellectual property protection, it is not inherently antithetical to it either. Moreover, historical practice shows that copyright-like claims were printed in books during the Song dynasty ${ }^{117}$. Second, if Confucianism were a crucial determinant, it is to be expected that other Confucian societies would have intellectual property troubles as well. Neighbouring Japan and Korea were able to construct a well-functioning intellectual property law system, and closer to home, Taiwan and Hong Kong, while having seen significant levels of media piracy in the past, are now praised as success stories. Third, this explanation implies that Chinese are somehow fundamentally different from Westerners in their attitudes towards intellectual creations. Two arguments speak against this. On one hand, the popularity of counterfeit and pirated goods with foreign tourists in China seems to indicate that the willingness to at least buy pirated goods is not exclusively Chinese terrain. Indeed, after the decline of hard goods shops in Beijing, most large remaining DVD

\footnotetext{
${ }^{114}$ See, for example, Butterton, 1996; Haber, 2006.

115 Alford, 1997.

${ }^{116}$ Shi, 2008, pp. I07-I 55.

117 Zheng and Pendleton, 199I, p. II.
} 
stores are located in the Sanlitun area of Beijing, where many embassies, as well as most expat-related venues are. On the other hand, this would entail that other societies would not have the same piracy issues China does. One glance at comparative piracy statistics shows that Russia, and some South American countries have similarly high piracy rates ${ }^{118}$.

Fourth, it is intellectually incorrect to attribute piracy, a modern-day phenomenon, to a belief system developed twenty-five centuries ago. International intellectual property law is quite a recent thing, with the major copyright treaty, the Berne Convention, dating from 1886, a time when the United States were considered by British authors as the prime pirating nation. The current commoditized business model of media distribution has been predominantly developed in the United States, after the Second World War. During that period China experienced significant internal turmoil, resulting in the end of the Empire, and a subsequent tumultuous $20^{\text {th }}$ century, including the internal division and tumultuous strife characterizing the Chinese Republican Era, the Japanese invasion, the Second World War, and the disastrous first three decades of Communist rule. During the early Republic, some abortive attempts towards instituting an intellectual property system were made, but the Communists opposed IP on an ideological basis, and it did not become part of PRC law. While it is impossible to know how IP would have developed had historical circumstances been different, it would not be unreasonable to assume that, had China been a part of the Western trading system after 1945, the situation would have been completely different. The main advantage of the cultural approach lies in its simplicity and its emotional appeal, but unless "culture" is broken down into more concrete components that are better susceptible to detailed analysis, it must be rejected as a factor explaining media piracy.

A second factor often invoked as causing piracy in China is economic. Chinese individuals and companies are deemed to lack the purchasing power to purchase legitimate products. This argument has its merit. Legitimate products, and especially foreign legitimate products where available, were offered at a price that would not be affordable to many Chinese citizens. One report suggests that in other emerging markets, piracy is often a consequence of the lack of purchasing power to purchase legitimate goods ${ }^{119}$. It also resonates with the argument made about piracy being especially prevalent amongst college students in the United States, partly because students are seen to not dispose of the financial means to purchase legitimate products. The cost differential between piracy and legitimate consumption is also one of the IP lobby's central supporting points for stricter punishments, as they argue that "you can't compete with free" 120 . On the other hand, it is also identified as one of the root causes for piracy in lower-middle income countries ${ }^{121}$.

However, the explanatory power of this argument for China is limited, for two reasons. China's middle class, especially in the larger cities, has grown larger and richer.

\footnotetext{
118 MPAA, 2005; Karagianis, 2011.

119 Karagianis, 2011.

${ }^{120}$ Although this argument also merits some contextualization. Intervening variables might be that American college students tend to be me more tech-savvy than average, which makes it easier for them to pirate, and have better and faster Internet connections than average. As this generation grows older and broadband connections spread, further research will be needed to chart the further evolution of piracy.

${ }^{121}$ Karagianis, 2011.
} 
China's per capita increased more than tenfold between 1990 and $2004^{122}$, but in the same period of time, audiovisual media piracy showed no signs of abating. Also, hard goods media piracy is not free. This can mean two things: either legitimate products are still too expensive, or price is not the chief deciding factor. But more importantly, it is nearly impossible to evaluate the economic argument on its merits, due to the restrictions on the Chinese market. As a large range of products and services is not legally available, consumers often cannot make an economic choice between legitimate and pirated media.

A third argument is based on the perceived inadequacy of China's law enforcement organs in preventing piracy from happening, due to resource shortages, corruption and the high thresholds for criminal prosecution of copyright violations. China's law enforcement problems are well known, and reflected in the phrase "implementation is difficult" (zhixing nan 执行难) $)^{123}$. Nonetheless, bad enforcement and lax enforcement standards can only be a part of the problem. While bad enforcement may facilitate the development of large audiovisual media piracy networks, it does not influence the incentives creating demand for pirated products.

In this context, some observers put forward the rather extreme position that China not enforcing against piracy is a political choice, and that China could eradicate piracy at the drop of a hat, if it wanted to, by making a comparison with the anti-Falun Gong campaigns of $1999^{124}$. First, this argument is ethically reprehensible. It seems to suggest that gross human rights violations such as wanton arrests and imprisonments - while to be frowned upon when dealing with religious sects - would be quite permissible if it would serve the special interests of the audiovisual media industry. Second, it seems to assume that Chinese state power, which can be formidable, is fungible between different interests. As Chapter VI will demonstrate, however, this power is highly contingent upon the topics at issue and the actors that are involved, and a subtler analysis is necessary.

A fourth argument that pops up in the sidelines of Western observations relates to market access, with the most touted figure that of the twenty foreign films allowed on Chinese screens on a revenue-sharing basis per year. For reasons outlined in the following parts on methodology, the author holds this argument deserves more attention than it gets, and that it must be extended to domestic products as well. It is well known China has a strict media control regime, which inevitably has a strong impact on the production, import and distribution of media works.

\section{Methodology}

In order to answer both research questions adequately, as well as include the concerns identified in the previous paragraphs, the study needs to fulfil the following criteria: first, it needs to identify supply-side incentives for media piracy and how these can be shaped through State action. Second, it needs to outline how this State action can be explained in the light of internal political factors Third, the study will need shed light on the incentives influencing anti-piracy enforcement. Subsequently, examining how WTO membership can influence this relationship requires identification the nexus of China's media regulation and WTO discipline, as well as an outline of

\footnotetext{
122 UN, 2009.

${ }^{123}$ Chen, 2008, 66l et seq.

${ }^{124}$ See, for example, Chow, 2006, p. 222, and Ting, 2007, p. 436 et seq.
} 
the intervening variables that are present between the letter of WTO discipline and a reduction of piracy levels on the ground.

In the next paragraphs, I will sketch a theoretical framework for audiovisual media piracy, which includes the State and its interests, as a basis for the rest of the study.

\section{Motivations for piracy: demand and supply side}

Explaining the State-based contributory factors to piracy requires us to explain piracy itself. In other words, we need an answer to the question why piracy occurs in the first place, before it is possible to bring contexts and circumstances into the equation. Using the functional explanatory model developed by Gerald Cohen ${ }^{125}$, this study assumes that piracy will tend to occur whenever both producers and consumers believe it is in their interest, and when it is possible for them to do so ${ }^{126}$. This does not mean that piracy is reduced to a mere transaction between suppliers and consumers, rather that the different parties connected to audiovisual media and piracy, each through exercising their own interests, may bring about a situation where piracy is a rational option for consumers and suppliers. This requires us to identify the stakeholders in the media market, their interests and incentives.

In order to do so, a four-party model of incentives is proposed. It not only includes consumers and rights holders, but also the state and the piracy industry. In this sense, this model goes further than Yu's "copyright divide", which defines media piracy as " $a$ battle between the stakeholders and non-stakeholders over the change and retention of the status quo ${ }^{127}$. While this basic, nearly contractual model might be enlightening in understanding the tug-of-war presently taking place between on-line piracy advocates and large media conglomerates, it runs the risk of oversimplification. For starters, the State does not play an explicit role in the system. If we are to assume that the State is to be considered as a disinterested balancer between the stakeholders and non-stakeholders, potentially important matters of political economy in policy formation, the asymmetry between the political clout of different interest groups, and perhaps most importantly, the role of the State in safeguarding interests of the whole society, are ignored. Moreover, the definition of stakeholder in this model is relatively vague, and so it is hard to define exactly which players will be included in the model, and on the basis of which interests. Perhaps there are complex questions that transcend the tug-of-war between two parties, such as the role of technology, access to information or freedom of speech.

At the same time, most, if not all, studies concerning piracy, in China and elsewhere, explain piracy through the lens of copyright. As indicated earlier, ignoring fields other than copyright law that regulate the production and distribution of media, is not appropriate in the Chinese context. Where Western audiovisual media markets are predominantly based on private ordering and private law enforcement through independent courts, the Chinese state regulates its media system more strictly. In other words, a model built to understand audiovisual media piracy in China must take more than just copyright law into consideration, and include the entire governance structure of the media market.

\footnotetext{
${ }^{125}$ Cohen, 1978, Chapter IX.

126 The emphasis on the personal belief and intention of the actor resolves some of Elster's concerns about the potential reverse temporality of a functional explanation, i.e., explaining a phenomenon by another occurrence taking place later in time. See also Elster, 2008, p. 30.

${ }^{127} \mathrm{Yu}, 2003$, p. 55.
} 
Lastly, this study aims to explain media piracy in an internal perspective. Often, Western observers have analyzed media piracy in comparison to an idealized legal order, which somehow manages to perfectly prevent media piracy. In this view, China's piracy situation is exceptional. A number of figures suggest this is not true. Countries such as Russia or Paraguay have similarly high figures of pirated products' market share ${ }^{128}$. A century ago, the United States itself was considered a prime producer of pirated books ${ }^{129}$. Therefore, rather than comparing China to an imaginary yardstick, to which it can only fail to measure up, the objective of this study is to answer the question how China internally is unable to prevent an issue it deems important.

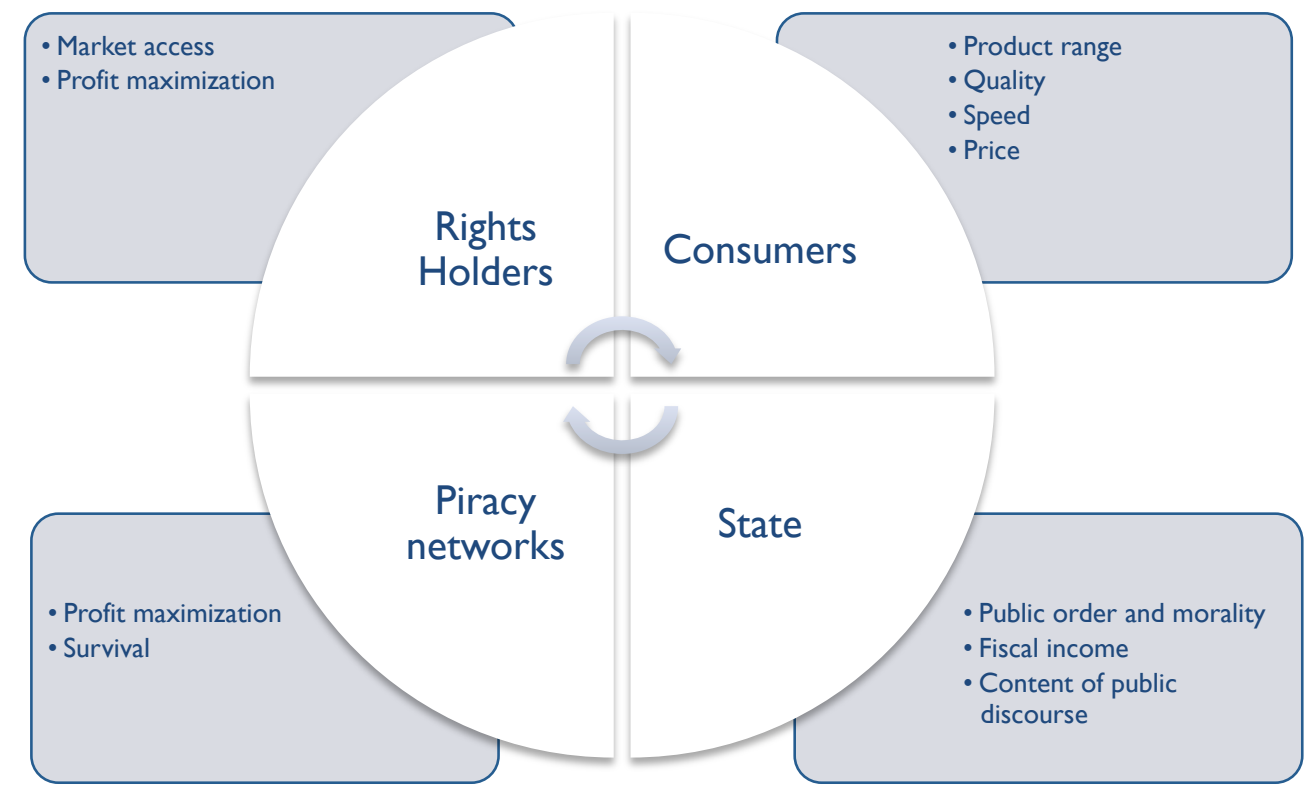

Figure I: stakeholders of the media market and their interests

The "four corners model" addresses some of these concerns, although it is set up primarily to deal with the Chinese situation. First, by incorporating the State as an important player in audiovisual media piracy, it is possible include State interests and capacity limitations into the explanation of piracy. Second, including the piracy industry recognizes that - at least in China - piracy carries significant economic consequences, which in turn may influence piracy enforcement.

The basic assumption in this model is that these groups react to interests and incentives. Consumers want a large range of high-quality products to be made available cheaply and conveniently. Rights holders want to maintain control over dissemination of copyright works, both in terms of price and terms of availability, in order to maximize profits. These interests often conflict, and there are two ways in which this can materialize, and where the space for piracy opens up. Media piracy takes place when consumers are either unwilling or unable to procure audiovisual media at the price and in the method they are offered.

\footnotetext{
${ }^{128}$ Karagianis, 2011.

129 Johns, pp. 295-307.
} 
Unwillingness can be triggered by aspects such as price, similar quality of pirated and legitimate products, ease of use or access, but in general implies that the consumer has a choice between a legitimate product and a pirated one, and actively chooses for the pirated one. It is the main basis for media piracy in the West, as media products tend to be available for consumption in some way ${ }^{130}$.

Inability to consume the legitimate product is more insidious, since it means that consumers cannot access a certain product, even if they are willing to pay for it. This inability can be temporary, for example when film release schedules are staggered, or American television shows are shown in Europe months after first screening in the United States. It may also be permanent, in cases where a product is never brought onto the legal market, screened or broadcast in a given locality. Also, sometimes works are not made available to certain sections of the population, such as age restrictions for films. Obviously, modern Internet technology is capable to overcome these barriers, vastly increasing its attractiveness for consumers who are otherwise not able to access the works they'd like to consume.

This is where a third player, the State, comes into the model. States have a range of interests in the audiovisual industries. Every government has a media policy, reflecting the relationship between government, press, and other forms of media, which also outline the country's media structure. The State has moral interests, dealing for example with issues of sex, violence, profanity and horror scenes, and sometimes cultural interests, protecting the national language and identity. There are concerns relating to freedom of speech, and balancing access to information with the interests of rights holders. In order to do so, governments have the power to block certain works from circulation or restrict their audiences.

The last player, the piracy industry, is self-evident. As the above section on the piracy value chain demonstrates, a substantial number of Chinese citizens earn their livelihood directly or indirectly through offering products and services related to audiovisual media piracy. The production and sale of pirated CDs and DVDs is the prime example of this, but the ecosystem extends to owners of Internet cafés where infringing films are being watched online, operators of buses where films are shown to passengers, etc. Of course, this industry also has political clout, especially at the lower administrative levels, which impacts the efficacy of anti-piracy enforcement. Assuming that interests of consumers and rights holders in China are not significantly different from those in the rest of the world, the study concentrates on exactly how State and piracy industry interests contribute to piracy as we see it in China.

\section{Structure of the study}

This study contains four main parts. The first part gives an overview of how the legal structures governing the production and distribution of media works evolved in the United States, the United Kingdom, France and Germany. This provides a basic understanding of the relationship between intellectual property, regulation of expression and the functioning of the media market. The second part aims to analyze the evolution of Chinese copyright law as well as the broader structure of media regulation into which it fits. This part will build on a thorough overview of original

\footnotetext{
${ }^{130}$ For example, as indicated in Chapter II, there are French and German regulations that require a minimum proportion of broadcast music to be in French or German, respectively. However, this does not preclude other music to be freely available through retail outlets.
} 
Chinese legislative and regulatory documents. More than 200 Chinese legislation and regulation documents dealing with copyright and media regulation, from 1978 until present, were translated for this purpose ${ }^{|3|}$. This set of documents offers a fascinating insight in how the leadership tries to balance different media-related objectives, while continuously maintaining the space for discretionary intervention. The most crucial objective, for which discretion is most needed, identified in these documents, is control over the media market. In other words, the Chinese leadership is most concerned with keeping public discourse within the parameters that it sets. It does so not only through content-related measures, but also by limiting participation of private and foreign actors in the media market.

This study argues that this is space for piracy is created in China. Chinese media policy, directly and indirectly, limit the scope, and in some cases, the numbers, of entertainment products that can be brought onto the market, how they can be distributed, and who is allowed to do so, thereby limiting legitimate consumer choice and creating a space for consumer demand for illegitimate products. Piracy, commercial or otherwise, responds to this demand, and often at a lower price compared with similar products. As it conquers the market, products that are available on the market legally are pirated as well. In turn, producers retreat from the legitimate market altogether, eventually looking to monetize content in different ways. Also, new entrants and products, even if they would be legal, are deterred from entering.

However, outlining this space in which piracy can occur is not sufficient. It must also be explained why piracy can persist, or in other words, why copyright enforcement is not successful in reducing piracy rates by intervening in this vicious circle.

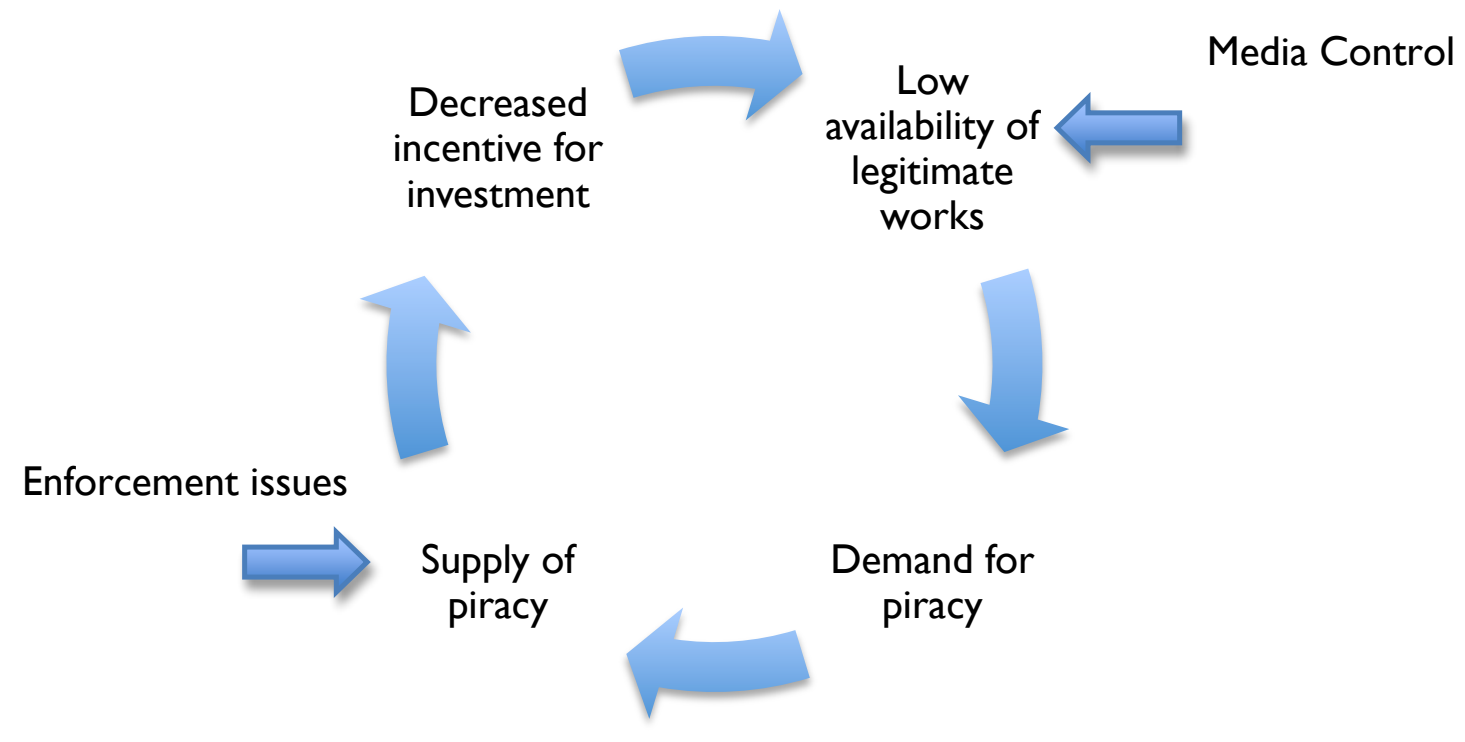

Figure 2: The vicious cycle of piracy and the impact of media control and lack of enforcement

The third part - Chapters V and VI - explains the political economy of both media regulation and enforcement. On one hand, China's media control regime is explained

\footnotetext{
${ }^{131}$ A full collection of these documents is available on the author's Internet page: http://chinacopyrightandmedia.wordpress.com.
} 
in the light of the political imperatives the Party-State faces. On the other hand, I will analyze the alignment of political incentives in different State institutions designated to fight piracy in the view of the conclusions reached earlier. Here, I will argue that China's failure to provide effective enforcement ${ }^{132}$ results out of two factors: lack of enforcement resources and political economy ${ }^{133}$ issues. Given China's emphasis on State-based (and therefore State-funded) law enforcement, allocation of resources, administrative incentives and overall capacity are important systemic indicators of prioritization of enforcement, strategic behaviour by stakeholders and enforcement outcomes. In other words, this section will analyze how actors inside and outside of the State try to use politics and law to either effect change or maintain the status quo, and realize their objectives.

The fourth part connects the regulatory factors creating piracy to China's WTO commitments. First, the areas of Chinese law and regulation that are subject to WTO discipline are identified. Subsequently, the cases DS362 and DS363 will be used as a basis to analyze to what extent Chinese policy violates WTO commitments. Lastly, possible scenarios for the consequence of these cases on China's media policy will be outlined.

\section{Objectives of the study}

This study aims to shed light on a number of aspects related to media piracy as a phenomenon, legal reform and rule of law issues inside China, China's integration with the rules-based international trade law system, and the scope and effectiveness of the WTO in resolving trade problems as perceived by its members.

\section{About copyright, market and piracy}

This study hopes to make a contribution to the presently raging debate about audiovisual media piracy, copyright reform and the future of the audiovisual media industry. More specifically, the analysis of the linkages between State action, audiovisual media market liberalization and incentives for piracy, sheds more light on the consequences of audiovisual media distribution strategies that result in reduced market access for rights holders, or reduced supply to consumers.

Moreover, this study will demonstrate that China's media piracy situation is highly contingent on its audiovisual media policy. This calls into question the applicability of the media business model based on copyright as enshrined in the present international copyright-related treaties, such as the Berne Convention and TRIPS. The economic aspects of copyright were designed to function in an environment where the market for ideas is mostly free, and market dynamics attribute commercial values to works on the basis of popularity. Consequently, the question can be raised whether or not copyright is useful for safeguarding the rights and interests of creators in a highly regulated marketplace, in which a whole range of products and services is kept off the market for political reasons.

\footnotetext{
132 By effective enforcement, the author understands enforcement resulting in a sizable diminution of pirated products market share.

${ }^{133}$ By political economy, the author understands the way in institutional actors engage in exchange to realize both programmatic and institutional objectives, and the way in which different transaction costs influence the opportunities for exchange. See also Horn, 1995.
} 


\section{About China}

At the time of writing, China stands at a crucial point in its trajectory of reform and opening up. Both Chinese and Western observers are concerned with the middle income trap, arguing that having graduated to middle-income country status, China now faces the difficult test of moving away from an industrial model based on investment and export-led growth and low value-added production ${ }^{134}$. Different commentators consider China's perceived lack of the rule of law, as well as its difficulty in policy implementation as some of the factors more likely in endangering China's future growth and political stability ${ }^{135}$. China's transition has been referred to as "trapped ${ }^{136 ",}$ China itself as "fragile" 137 . Other observers have a more positive outlook, arguing that China has shown in the past to be able to overcome a number of hurdles, and probably will be able to do so in the future ${ }^{138}$. Given the overall importance of intellectual property protection for the continued ascendance of China on the technology ladder, and that the audiovisual industries have been identified by the Government as key sectors in the next development stages, this study hopes to add to the academic debate about the evolution of China's transition. Also, by analyzing why China fails to realize a flourishing and lawful media market, this study hopes to identify, concretize and illustrate a number of factors contributing to policy implementation problems. This may inform Chinese actors working on further systemic reform, and non-Chinese policy-makers in determining objectives, methods and policies.

\section{About the WTO}

As economic diplomacy moves to the centre stage of international politics, the WTO has come to the forefront as the prime location for the resolution of international trade disputes between states, but also as a new diplomatic channel in which countries may interact, negotiate, and confront tensions. The power and prestige of the WTO's Dispute Settlement Body have reshaped possibilities and strategies for diplomacy, and it increasingly acts as a battleground for conflicting economic policies.

The power of the DSB is closely based on its reputation for political neutrality and lack of activism. In order to avoid evisceration of its mandate, the DSB has taken a line of narrow, textualist approach ${ }^{139}$, and increasingly moves to raise standards of empirical evidence. The United States discovered this at their detriment when the Panel in the China - Intellectual Property case found that it did not meet the burden of proof requirements for challenging certain enforcement thresholds in the Chinese criminal law ${ }^{140}$. In other words, at least where the substantive resolution of disputes are concerned, the DSB endeavours to be a body of law, not of politics. But both in the pre- and post-dispute stages, political activity is intense. WTO cases are only filed after a complex internal decision-making process, and aren't undertaken lightly. Ex post, as the DSB limits itself to findings of consistency and inconsistency with

\footnotetext{
${ }^{134}$ See, for example, Xinhua, 20I IA; Economist, 20I I; Magnus, $201 \mathrm{I}$.

135 Huang, 2008.

${ }^{136}$ Pei, 2006.

137 Shirk, 2007.

138 Peerenboom, 2002.

139 This textualist approach has been challenged from a number of angles, where commentators have argued that given the DSB's increased stature and prestige in the adjudication of international trade law, it should take a number of "soft" issues into account in its decision-making process. See, for example Magnuson, 20I0, as well as Qin, 20II and Wu, 20I0, both discussing the DS363 case.

140 DS362, Report of the Panel.
} 
WTO law. It cannot order an unruly Member to comply but only authorize the complainant to impose countervailing measures. Hence, the implementation of DSB findings and actual change in Member behaviour are subject to political dynamics both between the dispute parties, and within the losing Member ${ }^{141}$.

By concretely analyzing the effect of two WTO cases related to audiovisual media piracy, this study hopes to add to the literature on international trade dispute resolution, by evaluating the effectiveness of the WTO in reducing piracy.

\section{A note on ethics}

There are a number of ethical and philosophical concerns underlying any analysis of media piracy, and more specifically analyses of media-related law in China. Semantically, the copyright lobby has been quite successful in determining the words with which we refer to unauthorized media distribution, framing the debate with emotionally charged terms such as "piracy" or "theft", and associating it with taking the bread out of the mouth of hard-working workers in the audiovisual media sector. Some copyright-sceptic groups, such as the Swedish Pirate Party, have taken up this sobriquet with glee ${ }^{142}$. In any case, technological innovation and the separation of the bond between medium and content have destabilized the existing copyright-based system of content distribution, with resolution still seeming far away. A debate is presently ranging on the complex relationship between copyright law, technology, rights of consumers versus producers, prevailing business models, creativity and cultural diversity ${ }^{143}$.

Moreover, as this study will conclude, in China, piracy is often the only way in which it is possible to obtain foreign media products. Furthermore, the Chinese government has shown its readiness to disregard procedural and substantive rights in enforcement. Therefore, the debate on piracy carries significant human rights concerns with it, both relating to the freedom of expression and the right of information. There are concerns that pushing for stronger copyright protection will arm the Chinese government with one more weapon to go after dissidents ${ }^{144}$, and will remove an important source of information operating outside of the censorship system.

While the author acknowledges these concerns, this study will not attempt to go deeper into them. Rather, it will analyze the causes of piracy in order to explain the phenomenon, rather than its consequences in order to excuse it. Similarly, my aim is not to propose a normative view of the Chinese political structure, nor to provide normative recommendations for Chinese political reform. This study does not claim to support or oppose the current Chinese setup. Rather, the objective in this study is to analyze and understand the internal functioning of this structure, and identifying the dysfunctional points where mutually conflicting goals are pursued. The author hopes that this approach results in a constructive, but critical appraisal of China's governance over audiovisual entertainment media, which may then serve as a basis for normative debate.

\footnotetext{
${ }^{141}$ Bown and Pauwelyn, 2010, see also Chapter VI.

142 Pirate Party Website.

143 Lessig, 2004; Hugenholtz, 2001.

${ }^{144} \mathrm{Yu}, 2009$.
} 


\section{Chapter II: A bird's eye view of copyright law and its relationship with freedom of expression in China}

In the past, the perceived lack or inadequacy of Chinese copyright protection was considered to be a prime cause for copyright piracy. However, a closer look at Chinese regulations shows that copyright regulation came into being quite rapidly after the beginning of the reform era. By now, China has created a comprehensive system of copyright legislation that complies with its international commitments. However, copyright is only one aspect of the legal framework governing production and distribution of audiovisual media. The following chapters will analyze how the Chinese system of media regulation creates consumer demand for illegitimate products, even in a situation where the copyright law is of high quality.

The approach taken here does not intend to imply that the international copyright system, as mainly exemplified in the Berne Convention, TRIPS and a number of WIPO treaties, is completely successful in preventing or eradicating audiovisual media piracy. In emerging economies, the majority of the media market remains illegitimate. In developed counties, Internet piracy has dramatically changed the face of the audiovisual media business worldwide, and the sector is struggling to find an answer to this challenge. However, the international copyright system is taken as a benchmark here, as its wide membership and application has made it authoritative, and it is generally seen as normative in its field.

At the same time, these chapters recognize that an approach focusing only on copyright is overly limited, and does not take into account significant factors underpinning copyright legislation, such as policy objectives, external pressure, and its relationship to enforcement and domestic legal culture. It also does not take into account the relationship between the rights of the author and the broader interests of society, reflected amongst others in the right of freedom of expression. This chapter endeavours to contextualize the function of copyright, by foregrounding the tenuous relationship that has always existed in different European countries, and later in the United States, between copyright law and the freedom of the press, which was a prime driver of the early copyright legislation process. More specifically, it aims to demonstrate in this chapter that copyright law and freedom of expression are closely interwoven, and that we must therefore look at the broader legal framework that was created in symbiosis with a rapidly developing entertainment industry.

\section{The international system of authors rights ${ }^{145}$}

As a legal doctrine, author's rights have evolved from distinct national tendencies into a relatively coherent system. Technological innovation and the widening of the range of goods protected by it have brought about a large part of this evolution, but there are other drivers in the process, such as the continuing debate on how the balance between creators and the public interest should be balanced.

\footnotetext{
${ }^{145}$ In order to be able to distinguish between different conceptions of the rights of authors, for the rest of this chapter, the terms copyright and droit d'auteur will be used to refer to specifically AngloAmerican and French aspects, and the term author's rights will be used to describe the overall concept.
} 


\section{The current conception of copyright}

The Oxford English Dictionary defines copyright as: "The exclusive right given by law for a certain term of years to an author, composer, designer, etc. (or his assignee), to print, publish, and sell copies of his original work". Le Grand Robert de la langue française defines droit d'auteur as "droit exclusif d'exploitation d'une œuvre par son auteur, d'une invention par son inventeur". These definitions both point to the economic function of copyright, i.e. the right to exploit a creative work in the marketplace. Creative works are non-competitive, or "public goods". The initial cost of producing them is very high, but the subsequent reproduction costs are often very low, especially in the digital era. According a monopoly right to the creator of a work creates scarcity which otherwise would not exist ${ }^{146}$. This creates a market into in which creative works, but also the rights protecting them, can be traded. Hence, the right to economically exploit a work in the marketplace is an incentive to potential creators.

A second function of author's rights, which mainly stems from the French tradition, is to protect the moral interest of authors. Since creative works are seen to be a personal expression of the author, a moral connection between the work and the author is assumed. Hence, a number of countries took measures to protect the moral rights of creators, among which are the right to be named as author, or paternity right, and the right of integrity of the work. This is slightly less accepted in some jurisdictions. Notably the United States do not protect a large range of moral rights, asserting that protection through other legal means is strong enough ${ }^{147}$.

In its economic aspect, author's rights need to balance the rights of authors with public interest. By creating an incentive for creation, author's rights have the potential to enrich cultural life and maximize creative output. However, if it is protected too strongly, public interest may be harmed. For example, strong anti-copying measures sometimes make it impossible to play certain compact discs on certain CD players, or digital rights management (DRM) software may act as spyware, possibly causing harm to consumers. Some copy protection measures also make it impossible to make lawful copies, as in many countries making a back-up copy of copyright material is allowed.

Author's rights cover literary and artistic works, which includes "every production in the literary, scientific and artistic domain, whatever may be the mode or form of its expression ${ }^{148,}$. This typically covers written works, such as books, plays, but also computer software; audiovisual works, such as films, music, graphic works, such as drawings, photos, works of architecture and databases. Also, the Berne Convention - the treaty providing minimum standards for the international protection of copyrights - prohibits any formality for grant of copyright, so it arises automatically upon creation of a work ${ }^{149}$.

In order to balance the interests of creators and society, author's rights are also subject to limitations and exceptions. The most basic limitation is the fact that author's rights only protect the expression of an idea, not the idea itself ${ }^{150}$. Furthermore, there are doctrines in different jurisdictions ${ }^{|5|}$ that limit the exclusive nature of

\footnotetext{
${ }^{146}$ Landes and Posner, 1989.

147 See Yu, 20II.

148 Art. 2(I) Berne Convention.

${ }^{149}$ Art. 5(2) Berne Convention.

150 This idea is expressed amongst others in Article 2 WIPO Copyright Treaty. See also Samuels, 2009.

151 These are called "fair use" in the United States, "fair dealing" in a number of other common law jurisdictions, and also exist in civil law jurisdictions.
} 
author's rights. These often include matters such as research and private study, criticism, review and satire. At the international level, the Berne Convention allows countries to permit reproduction of works in "certain special cases, provided that such reproduction does not conflict with a normal exploitation of the work and does not unreasonably prejudice the legitimate interests of the author ${ }^{152 " .}$

Two major legal traditions concerning author's rights exist. The Anglo-Saxon tradition puts the emphasis on the economic function of copyright, and more specifically, on the aspect of reproduction. In this tradition, copyright is a response to market failure. If there were no copyright, creative professionals would not receive due compensation for their efforts, due to freeloading.

The Continental European tradition sees copyright as the emanation of the natural rights of the individual creator, reflected in the French term droits de l'auteur. This conception of copyright clearly bears the stamp of the Enlightenment, and the French Revolution. In contrast to English copyright law, French copyright law was designed from the start as a corollary to the Republican idea of freedom of expression, which was in turn derived from strong natural law principles ${ }^{153}$. Hence, it included rights such as the right of paternity and the right of integrity that protected authors and their works against censorship and political influences. These differences are reflected in national legislation. For example, in the United Kingdom, moral rights - like economic rights - are limited in duration, whereas in continental systems, they are unlimited in time. The consequences of this difference should not be overstated, however. The Berne Convention, World Copyright Treaty, WIPO Phonograms and Performance Treaties and TRIPS show influences from both traditions, and due to their near universal membership, tend to promote convergence of international norms.

\section{History of the international copyright system}

The first vestiges of what we know now as copyright originated in $16^{\text {th }}$-century Europe after the invention of the printing press. Wary of this new technology, the Church and the ruling aristocracies of Europe aimed to regulate and control output. This control was deemed necessary in order to protect the public from the potentially destabilizing effect of the press, which could rapidly create perfect copies of books, allowing faster circulation and wider readership ${ }^{154}$. At the same time, the printing press also offered possibilities: Bibles and government documents or pamphlets could be produced and distributed much more efficiently than was possible before.

Consequently, efforts were made both to control and harness the power of the press. In I50I, a papal bull prohibited printing of books without the written approval of the local archbishop, or the Pope himself. Slightly later the church started to compile local indexes of prohibited books, culminating in the Index Librorum Prohibitorum, first published in 1557. This Index listed all books and authors censored by the Church. The last version of the Index was published as late as 1948.

\footnotetext{
${ }^{152}$ Article 9(2) Berne Convention.

${ }^{153}$ As an illustration of this strong natural law tradition, French droit d'auteur law did not require reciprocity of protection in order to protect foreigners' rights. In the Shostakovich case, the Paris Court of Appeal ruled that any creator's rights would be protected in France, as there was no legislation depriving foreigners from these rights. See Bertrand, $201 \mathrm{I}$.

${ }^{154}$ Johns, Chapter 2.
} 
Furthermore, all over Europe, indexes were compiled and publishing licence schemes implemented. These licenses, or privileges, usually granted by the local royalty, conferred to a printer the exclusive right to print a certain work for a given period of time, and usually included import prohibition of that work, as its printing in other territories could not be prevented.

In order to make control over the printing sector more effective, the printing monopolies were often centralized. In 1557, the English Crown issued a Royal Charter ${ }^{155}$ to the Stationer's Company, an association of 2 English universities and 21 printers in London, which jointly owned 53 printing presses. This gave the Company the power to licence all printing and publishing in England. All lawfully published books were entered into its Register, and only Company members could make entries. This access control essentially created a monopoly over the English printing sector. Progressive Star Chamber decrees in 1566 and 1586 further formalised the overlapping interests of stationers and the Crown ${ }^{156}$. This was a marriage of convenience, where the Crown brought legitimacy to act, and the stationers brought local knowledge and the ability to swiftly counter illegal printing activities.

In 1637, the Star Chamber issued a decree that, amongst others, maintained the prohibition of all books unpalatable to Crown and Church, maintained licensing obligations, and took control of type founding, requiring all printers to be licensed ${ }^{157}$. A short time later, in 164I, Parliament abolished the Star Chamber, which had become a vehicle of royal power abuse. This de facto abolished significant parts of the censorship regime. However, it wasn't Parliament's intention to permit free speech, but rather to assert more control over the press itself, curb royalist propaganda and protect parliamentary activities from their opponents. Hence, in 1643, Parliament passed the Licensing Order ${ }^{158}$, reintroducing most of the censorship procedures of 1637, such as pre-publication licensing, registration at Stationers' Hall, seizure and destruction of all books offensive to the government, arrest and imprisonment of dissenting writers and publishers, and the confirmation of the monopoly of the Stationers' Company.

In France, all books had to obtain a royal privilege before publishing, which meant approval by royal censors. As in England, this privilege concerned the act of reproduction, and authors were seen of less importance ${ }^{159}$. These were exclusive and lasted for six years, but could be renewed indefinitely. Furthermore, printing activities were repressed regularly as well. One printer, Etienne Dolet, was burned at the stake in $1546^{160}$, and many authors, printers and book dealers ended up in the Bastille until it was stormed in 1789. Nonetheless, the evolution of printing technology brought along the notion that dissent - voiced through the printing press, amongst others - was something that needed to be permitted rather than censured or repressed. Illustratively, Milton's Aeropagitica ${ }^{161}$ forcefully reacted against the assertion

\footnotetext{
155 I 557 Stationers' Charter.

${ }^{156} 1566$ and 1586 Star Chamber Decrees.

1571637 Star Chamber Decree.

1581643 Ordinance for the Regulating of Printing.

159 This does not mean authors were overlooked altogether. During the $17^{\text {th }}$ century, it became commonplace to remunerate authors of stage plays with a percentage of the income.

${ }^{160}$ Lalouette, 1989.

161 Milton, 1644.
} 
over control against printers, and articulated a number of basic strands of the discussion about freedom of expression.

By the end of the $17^{\text {th }}$ century, things had started to change. Economic life in England had been changing after the Queen's Bench declared that economic monopolies were damaging to both tradesmen and consumers in Darcy v. Allin ${ }^{162}$. Subsequently, the Statute of Monopolies in $1624^{163}$ repealed all monopolies except those granted over completely novel inventions. The Enlightenment was taking shape, embodied in Lockean ideas about the labour theory of property and liberalization, and based on a fundamental belief in the role of science and knowledge.

These evolutions were reflected in governance over printing. In 1694, following the Declaration of Rights of 1688, The English parliament allowed the Stationers' Company monopoly to lapse. In 1710, the new Parliament of Great Britain passed the first modern copyright law of Europe, "An Act for the Encouragement of Learning, by vesting the Copies of Printed Books in the Authors or purchasers of such Copies, during the Times therein mentioned", more popularly known as the Statute of Anne ${ }^{164}$. This first copyright law created a public copyright system, vested in the author of a work, and with copyright protection limited in time. This was the first time that authors were legally recognized as the economic stakeholders in their works. The Act also introduced the possibility that authors transfer their rights to "assigns", creating a marketplace for works. But more importantly, the Act fundamentally changed the relationship between authors, publishers, the State and the public. The declared objective of the act was to produce useful literature, and advance the spread of education, by encouragement of "learned men to compose and write useful books ${ }^{165}$ ". In order to do so, it limited the term of copyright protection to 14 years for new books and 21 years for books already in print, creating the notion of the public domain. Before the Statute of Anne, booksellers had perpetual rights to the books they sold, and all books had to meet their censorship standards.

The Statute of Anne was fought over for thirty years, during the "Battle of the Booksellers ${ }^{166 ",}$ as booksellers pulled all stops in order to regain the ground lost because of the new legislation. Parliament was lobbied for a term extension, and a number of court cases were filed on the basis of the argument that the Statute only supported a pre-existing common law copyright. In the end, it was established that copyright was a "creature of statute ${ }^{167}$,", and a vote in the House of Lords against perpetual copyright finally confirmed the existence of the public domain. This radically reformed the market for books in England. Classic authors, such as Shakespeare and Chaucer, became widely available on cheap reprints, and the book trade boomed. In the thirty years between 1772 and 1802, the number of booksellers in London nearly tripled, from III to $308^{168}$. Similarly, a magazine trade was beginning to establish itself, with titles such as Tatler and the Spectator.

\footnotetext{
${ }^{162}$ Darcy v. Allin. See also Fisher, 2011.

1631624 Statute of Monopolies.

${ }^{164}$ Statute of Anne, 1710.

165 Id., preamble.

${ }^{166}$ Stewart and Sandison, pp. 21-23.

${ }^{167}$ Donaldson v. Beckett, 1774.

${ }^{168}$ Van Horn Melton, 200I, pp. I40-I4I.
} 
The Statute of Anne embodied two large trends in the evolution of the print industry. First, it brought authors to the foreground, by recognizing their economic stake in their works, and assigning the fundamental copyright to them, rather than printers or booksellers. Second, by shifting the stated purpose of copyright law to the advancement of learning and the encouragement of creation, it emphasised the role of copyright as an economic incentive to create, rather than a mechanism for censorship. Moreover, by making the grant of copyright unconditional, this incentive expanded the scope for freedom of expression. Hence, the Statute of Anne significantly decreased the influence of government over printing.

In France, there was a similar shift from censorship to ownership. In the middle of the $16^{\text {th }}$ Century, a series of legislative acts created a system of pre-publication censorship and licensing ${ }^{169}$. However, creators came to the forefront through the protests of playwrights, who resented the fact that they were not entitled to compensation over public performance of plays. In 176I, the La Fontaine ${ }^{170}$ case granted a royal privilege to the heir of an author, rather than to the publisher. This brought about a debate about who should primarily enjoy the rights over works, similar to the Battle of the Booksellers in England. In $1777^{171}$, the system of royal privileges was reformed, with privileges being appointed for the longer of either 10 years or the author's life. The privilege could be passed on to the heirs, who would make it last into perpetuity, or to a publisher, in which case it could not be renewed. In the latter case, the work would end up in the public domain. In 1786, a similar system was established for musical works ${ }^{172}$.

After the French Revolution, in which all royal privileges were abolished, the Comédie Française was given an exclusive right to the public performance of all dramatic works. This privilege aroused strong opposition, and was abolished in I79I. As a consequence, all limits on the right to open theatres were removed ${ }^{173}$, and authors were given the lifelong exclusive right to authorise public performance of their works. After their death, the right was extended to heirs for another five years. In 1793, the first French statute ${ }^{174}$ on copyright was passed by the National Convention. This statute granted an exclusive right to sell, distribute and authorise sale and distribution of books, music composition, paintings and drawings, valid during the life of the author plus ten years. Following the inclusion of free speech and press in the 1789 Declaration of the Rights of Man, this law was called the Declaration of the Rights of Genius ${ }^{175}$, and the duration of protection was extended to fifty years after the death of the author.

In the agrarian United States, copyright was not a high priority during the first half of the $18^{\text {th }}$ century. In 1783 , a petition ${ }^{176}$ was sent to the Continental Congress to call for a property-like right over books. However, the Continental Congress had no

\footnotetext{
169 I547 French Censorship Act.

${ }^{170}$ La Fontaine case (I76I).

171 I 777 Decree on the Duration of Privileges.

1721786 Decree on Music.

${ }^{173}$ The freedom of theatre was of great political importance to the new revolutionary government. Stewart and Sandison, p. 19.

1741793 French Literary and Artistic Property Decree.

175 Ochoa, p. 142.

${ }^{176}$ I 783 Letter from Joel Barlow.
} 
power to legislate in the area of copyright. The individual states did, however, and by 1786, all states save Delaware had brought copyright legislation on the books. The new federal government passed a first Copyright Act in $1790^{177}$, with the stated objective of "encouragement of learning", which nearly literally repeated the Statute of Anne, including the fourteen-year period of protection.

Issues of freedom of expression, however, had a different impact during the colonial period. The common law doctrine of seditious libel was applied in the United States, making dissent against the government a criminal offence. Apart from that, most speech limitations revolved around religious expressions, as communities were much smaller, and self-reliant in terms of orthodoxy and, hence, speech. Nonetheless, as political dissent versus Great Britain grew, calls for freedom of expression in the political area expanded significantly in the $17^{\text {th }}$ and $18^{\text {th }}$ centuries. In 1791 , the Bill of Rights - aimed at limiting the power of the newly established Federal Government, listed freedom of expression first.

The differing experiences of Great Britain, France and the United States show an evolution in the relationship between author's rights and freedom of expression. In Great Britain, this evolution was very closely interlinked, and the combination of the continued assertiveness of Parliament with the entrepreneurialism of the British print trade after 1710 created a dynamism in which free speech de facto became increasingly established. In France, free speech came about rather more abruptly, after the French Revolution. The connection between the protection of works and the freedom of expression was openly made in the declaration of the rights of man. Especially the role of the theatre trade deserves close scrutiny: the protection of moral rights, such as the right of integrity, began as a protection for playwrights against intervention of censors, and to guarantee the freedom of theatre, which was an important political issue at that time. In the United States, freedom of expression was at first directed against a government perceived as increasingly foreign, and secondly against a government which faced strong opposition and mistrust. In the United States, the development of freedom of expression was less interlinked with the development of copyright however: by that time, the economic mechanism created by the Statute of Anne had started to lead its own life.

During the $19^{\text {th }}$ and $20^{\text {th }}$ centuries, free expression law and copyright law each went their own separate directions. Free expression law became one of the pillars of the developing field of human rights law, while copyright law joined patent law and trademark law in the also new field of intellectual property law. At present, copyright law and freedom of expression are often considered to be at odds ${ }^{178}$. Nonetheless, it must be remembered that the protection of anyone's individual works, without judgment as to content or quality of the work, against unauthorized reproduction, vested in a right resembling a property right, was one of the first real and effective guarantees for the open press.

The economic mechanism author's rights created - an artificial monopoly over a work that could be otherwise copied at very low cost without reimbursement to the original creator - became the basis of a business model built on the rights it pro-

\footnotetext{
1771790 Copyright Act.

${ }^{178}$ See, for example Hugenholtz, 200I.
} 
vided, and created ever more income for ever larger numbers of authors. However, as copyright law was still limited to individual countries, authors experienced excruciating difficulties at deriving income from abroad ${ }^{179}$. The next section will sketch how author's rights became a significant part of international economic law, and how it became interlinked with international trade.

\section{International copyright treaties}

During the $19^{\text {th }}$ century, growing internationalization of trade meant that an internationalization of copyright was called for. At first, this occurred on the basis of bilateral agreements, in which countries pledged to enforce each other's copyrights. However, it proved very difficult for authors to have their rights recognized and receive income in different jurisdictions. Charles Dickens, for instance, was one of the best-selling writers in the United States, but did not receive remuneration for his works published there. To respond to this need, the Berne Convention for the Protection of Literary and Artistic Works of 1886 was conceived ${ }^{180}$.

\section{The Berne Convention}

The Berne Convention has laid the groundwork for the international copyright regime as it exists today. It is based on three basic principles: national treatment, automatic protection and independence of protection. National treatment ${ }^{181}$ implies that a Member state must treat domestic and foreign works as equal; automatic protection $^{182}$ ensures that copyright arises upon the creation of the work, rather than through formalities; independence of protection ${ }^{183}$ means that protection of a work in one country cannot be dependent on protection in the country of origin of the work. The Convention also lays down minimum standards for copyright protection, in terms of works to be protected, rights assigned to rights holders and duration of protection.

Article 2(I) defines the scope of the treaty, which protects "every production in the literary, scientific or artistic domain, whatever be the mode or form of its expression". Barring some exceptions, limitations or reservations, the rights that must be protected are the rights of translation, adaptation and arrangement, performance, recitation, communication to the public, broadcast, reproduction, and use of a work as a basis for an audiovisual work.

Moreover, the Berne Convention establishes the possibility for legislators to provide limitations and exceptions to copyrights, such as for the purpose of teaching. However, it does limit the possible exceptions to the exclusive right of reproduction to certain special cases which do not conflict with the normal exploitation of the work, and which do not unreasonably prejudice the author's interests, the so-called Berne three-step test ${ }^{184}$. Moral rights were incorporated in the 1928 revision ${ }^{185}$. These consist of the right of paternity, i.e. the right to be identified as author of work; and the right of integrity, being that a work may not be altered in a way prejudicial to the author's honour or reputation.

\footnotetext{
${ }^{179}$ Stewart and Sandison, p. 25.

${ }^{180}$ For an in-depth historical overview of the Berne Convention's genesis, see Ricketson and Ginsburg, pp. 42-83.

${ }^{181}$ Article 5(I) Berne Convention.

${ }^{182}$ Article 5(2) Berne Convention.

183 lbid.

${ }^{184}$ Article 9(2) Berne Convention.

${ }^{185}$ Ricketson and Ginsburg, p. 108.
} 
The duration of copyright is fixed at the natural life of the author plus fifty years ${ }^{186}$. Some exceptions to this general rule exist: pseudonymous and anonymous works are protected for fifty years after being made available to the public lawfully; cinematographic works are protected for fifty years after release of the work; works of applied art and photography are protected for 25 years after creation ${ }^{187}$. These terms are all minimum standards; member countries are free to lengthen the duration of copyright protection. In the US and the EU, for example, the general duration of copyright is fixed at the natural life of the author plus seventy years ${ }^{188}$.

\section{The Universal Copyright Convention}

Some countries, such as the Soviet Union and some developing countries, considered the successive revisions of the Berne Convention too protective of rights holders, while not paying enough attention to the public interest. Others, such as the United States, had a copyright protection system requiring registration, and where duration of copyright was a fixed, renewable term. For these countries, another copyright convention was drafted under the aegis of UNESCO, being the Universal Copyright Convention. Many countries party to the Berne Convention also acceded to the UCC ${ }^{189}$. However, as most UCC member states have since joined the WTO and hence are bound by TRIPS, the UCC has lost much of its significance.

\section{The Geneva Phonograms Convention}

As the Berne Convention only protected the rights of authors, producers of "phonograms", i.e. products fixating sounds, were not protected, as they did not necessarily hold the copyright in the fixated work. The Geneva Phonograms Convention protects producers of these works from duplication without consent, for minimum twenty years ${ }^{190}$.

\section{The WIPO Copyright Treaty}

Technological advancements in the ' 90 s created the need for a copyright treaty that incorporated regulations on new technologies. WIPO, a specialized body of the United Nations, stepped up to the challenge, and in 1996 the World Intellectual Property Organization Copyright Treaty ${ }^{191}$ (WCT) came into being, although it only entered into force in March 2002. This treaty supplements the Berne Convention, as it provides additional copyright protection for copyright-dependent industries with regards to information technology. Its main points are that computer software is to be protected as a literary work and that database contents are protected. More importantly for this study, it prohibits circumvention of technological measures controlling access to a work protected by the treaty. In other words, this treaty implicitly supports the use of DRM technology used by copyright holders to digitally prevent users from accessing content.

\section{The WIPO Performances and Phonograms Treaty}

The WPPT broadened the scope of the Geneva Phonograms Convention by including also the rights of performers. It also extended the term of protection to fifty

\footnotetext{
${ }^{186}$ Article 7(I) Berne Convention.

${ }^{187}$ Article 7(4) Berne Convention.

${ }^{188}$ Article I, 2006 Copyright Term Directive.

1891952 Universal Copyright Convention, revised in 1971.

190 197I Geneva Phonograms Convention.

1911996 WIPO Copyright Treaty.
} 
years after publication, and obliged contracting parties to prohibit the circumvention of DRM, similar to the WCT ${ }^{192}$.

\section{TRIPS}

The abovementioned treaties deal mainly with the protection of substantive aspects of copyright; the problem was however that apart from outlining substantive aspects of copyright protection, these conventions did not contain provisions on enforcement, and therefore were considered relatively weak. This was tackled by creating a new intellectual property agreement, the Agreement on Trade-Related Intellectual Property Rights, which brought intellectual property into the trade arena, making it subject to the negotiation logic present in this environment. It originated in the Uruguay Round of the World Trade Organization in 1994 ${ }^{193}$. The innovations of TRIPS are not to be found in the field of substantive copyright protection, where any changes to the existing international regime are incremental at most. It incorporates Articles I to 21 of the Berne Convention, except Article 6bis, and shares some key points concerning software and database protection with the WCT. It also widens the scope of the Berne three-step test to exceptions on all exclusive rights, where this was limited to the right of reproduction in the Berne Convention.

The main importance of TRIPS is twofold: first, it lays down minimum standards for copyright enforcement, Where the Berne Convention and the WCT contain basic provisions on civil liability, part III of TRIPS lays down detailed substantive requirements and procedural rules for civil, administrative and criminal enforcement of copyright. Second, as a WTO treaty, failure to implement TRIPS can lead to a case before the WTO Dispute Settlement Body. The previous copyright treaties had no such binding dispute settlement procedure ${ }^{194}$.

In this study, TRIPS is of particular importance as it lays down the IPR-related obligations that China needed to fulfil when joining the WTO ${ }^{195}$. These included the substantive standards of the Berne Convention, including the automatic grant of copyright, and the enforcement standards that had by that time become a concern of the United States.

The abovementioned conventions and agreements have created a comprehensive system of international law, providing for minimum standards in both substantive and procedural aspects of copyright. The role of China in its development and design has been very limited. China was not a member of any of these conventions before the reform and opening up period, and was not present in their negotiation. Consequently, when China decided to join this international treaty, and realign its copyright system with international standards, it had its own expectations and assumptions, both in the general view of the legal system, as in the specific role of copyright in that system. These of course influenced the transposition of the international

\footnotetext{
1921996 WIPO Performances and Phonograms Treaty.

${ }^{193}$ Ricketson and Ginsburg, 155 et seq.

194 The Berne Convention did provide for optional dispute settlement via the ICJ. This option has not been used to date. Evans, 1998.

195 TRIPS must be read together with the other WTO agreements, and is therefore also subject to the general obligations of national treatment and most-favoured nation status, see also Chapter VII. Furthermore, although China made great concessions to join the WTO, these were relatively limited in the field of IPR. See also Accession Protocol and Working Party Report.
} 
standards into Chinese domestic law, creating a Chinese lens through which these standards are viewed.

\section{Copyright and other concerns}

Although copyright is considered the prime legal mechanism that regulates the market for creative works, other concerns also play a significant role in the governance of audiovisual media. At the international level, these mainly concern the protection of domestic markets against the perceived onslaught of American audiovisual entertainment. At the domestic level, these mainly concern issues of competition, access and ownership, and media content.

Throughout the world, audiovisual media have become progressively liberalized and commercialized ${ }^{196}$. The prime beneficiaries of this have been the large American media conglomerates, exporting films, television programmes and formats across the globe. In many countries, measures have been taken to protect domestic cultural creators. Countries such as France and the Québec region of Canada have been very active in protecting their national culture. However, these are not the only ones. In Europe, the EU, the Council of Europe and many Member States have been very active in extending subsidies to the audiovisual sector through audiovisual media funds, as well as organizing training programmes for film professionals and extending interest-free loans ${ }^{197}$. The EU, Australia, Canada and France have quotas for television broadcasting that limit the number of foreign television programmes. France imposes a tax on cinema box office income, broadcaster income and videotape revenue to support domestic film production. Brazil extends tax exemption to investment in audiovisual products. Switzerland limits the grant of operating licenses to foreign broadcasters unless a reciprocal right in the country of those broadcasters is granted. The EU Television without Frontiers Directive ${ }^{198}$ requires that the majority of transmission time is used to broadcast European fiction programmes.

For the purpose of this study, it is important to remember that these subsidies and support programmes serve to expand the scope of works by providing remuneration and incentives to create outside of market dynamics. They do not constitute import or distribution bans. As such, they do not impede the availability of individual other films and television programmes. Rather, these measures have the softer aim of limiting the impact of Anglo-American cultural impact, and maintaining domestic cultural jobs and capacities.

Legislators also tend to be concerned with media content. Although copyright in principle does not make any judgment over the aesthetic or moral quality of a work, enjoying copyright protection does not entail that a work can be exploited in whatever way the rights holder deems fit. In many markets, there are limitations about the content of media works. These can be divided in two categories.

\footnotetext{
${ }^{196}$ For a broader discussion of these phenomena, see Keller, $201 \mathrm{I}$.

197 Van den Bossche, 2008, Para. 2.2.

${ }^{198}$ Articles 4 and 51997 Television Without Frontiers Directive. These and other support policies aimed in this chapter are aimed at preserving cultural diversity and protecting domestic audiovisual industries. They do not have an explicit function in disseminating political communication. This is important to remember when discussing the Chinese support policies outlined in Chapters IV and V.
} 
On the one hand, there are the works that are not prohibited per se, but of which the exploitation is limited for reasons of public morality. Such measures are taken where films or television programmes contain sexual or violent scenes, which are not deemed suitable for certain sections of the public, for example minors. In most Western countries, rating systems are in place for films, limiting certain films to certain ages. Some are more complex, providing for more detailed indicators of the film's content. Similarly, the "watershed", the time of day after which adult content is permitted on television, is commonplace across different jurisdictions.

On the other hand, a number of works is prohibited outright, regardless of whether or not copyright is enjoyed. In Western states, the scope of prohibited works tends to be small, and limited to matters concerning hate speech, incitement to violence, and - in Europe - to expressions in support of Nazism and denial of the Holocaust. Interestingly, copyright is sometimes used to curb such expressions, as demonstrated most famously in the case of Adolf Hitler's treatise Mein Kampf. The German Bundesland Bayern inherited Hitler's estate and is therefore holder of the copyrights over his works. It has successfully used the power granted by copyright to prevent publishing of Mein Kampf in Germany ${ }^{199}$.

Content control regimes vary across different countries. Some of them are administered by public bodies, others are examples of self-regulation. The following section outlines the media control regimes of the United States, as it is the larges media producer in the world, the United Kingdom and France as the progenitors of modern copyright, and Germany, as its historical circumstances have given it a special sensitivity to issues of censorship and freedom of expression.

In the United States, rating control over entertainment media is mainly vested in private bodies. However, it was the State that initiated censorship over films. In 1915, the Supreme Court decided in Mutual Film Corporation v. Industrial Commission of $\mathrm{Ohio}^{200}$ that motion pictures were a form of commerce, not an art worthy of First Amendment protection. This gave local governments the power censor films, and very rapidly, censorship statutes proliferated. In order to forestall censorship at the national level, the Hollywood studios decided to establish an industry body, the Motion Pictures Producers and Distributors' Association ${ }^{201}$, headed by Will H. Hays. By 1927, Hays had compiled an informal list of subjects to be avoided, but lacked effective enforcement means. By that time, the advent of talking movies had further brought concerns about film morality to the foreground. With the help of lay Catholic Martin Quigley and Jesuit Daniel Lord, a code of standards was created, which was divided into two parts. The first part concerned general standards of morality, and the second part listed particular expressions that could not be depicted, including matters relating to crime, sex, profanity, religion and national feelings ${ }^{202}$.

Throughout the early Thirties, enforcement of the Code remained a problem. In the Great Depression, studios and theatres were more concerned with maintaining income than with maintaining moral standards. Hence, racy films were still being made and distributed. Increasing religious support for stronger government censorship led

\footnotetext{
199 This copyright will expire on I January 2016.

${ }^{200}$ Mutual Film Corporation v. Industrial Commission of Ohio, 236 U.S. 230 (19/5).

${ }^{201}$ This would later become the MPAA.

202 Motion Pictures Production Code, 1930, reprinted in Williamson, 2007.
} 
Hays to revise the censorship regime. A stronger enforcement body, the Production Code Administration (PCA), was formed, led by Joseph Breen. The PCA was very successful in its objectives, by strictly controlling media output, federal government intervention had been avoided and local censorship boards were for a large part dismantled ${ }^{203}$.

By the end of the Fifties, cracks started to appear in the Code. The advent of television - subject to even stricter self-censorship meant increasing competition for films. The Supreme Court overturned their 1921 decision in 1952, in Joseph Burstyn, Inc. v. Wilson ${ }^{204}$, by holding that motion pictures were entitled to First Amendment protection. The film industry had been vertically integrated, but anti-trust litigation meant that studios had to withdraw from owning theatres, paving the way for the advent of independent producers and more foreign films. Both of these were not bound by the Code ${ }^{205}$, and in 1954, the notoriously strict Breen retired. By the late ' 50 s, increasing numbers of films were released without approval, and some - such as Some Like It Hot - became outright hits. By the mid-Sixties, the Supreme Court had ruled that it was unconstitutional to criminalize screening of a film that had not been passed by a censorship board ${ }^{206}$. It was clear that the Code had had its day. Under the impetus of the new MPAA chairman, Jack Valenti, a voluntary film rating system was established in 1968, replacing the code ${ }^{207}$. This divided films into four (later five) categories, with corresponding age guidelines. This system is essentially still in use today. Being voluntary, it has no legal effect whatsoever. However, it does have a significant role in forestalling potential government regulation, and avoiding unfavourable publicity.

Contrary to the film sector, open-to-air broadcasters are subject to government regulation. More specifically, the Federal Communications Commission (FCC) fines broadcasters for certain expressions of profanity ${ }^{208}$. The FCC discipline does not cover cable television, paid television and the Internet. Nonetheless, on the initiative of Congress, the entertainment industry introduced a voluntary TV rating system, containing age suggestions and symbols indicating programme content. These are broadcast during the beginning titles of television programmes. A comparative - albeit simpler - scheme, is in place for music. The Recording Industry Association of America (RIAA) began to label albums with stickers warning against "explicit lyrics" ${ }^{209}$, after pressure from the Parents' Music Resource Centre.

In the United Kingdom, there was no constitutional protection of freedom of expression $^{210}$, which left the young film industry open to regulatory intervention. In 1912, the film industry set up the British Board of Film Censors in reaction to the advent of censorship after the 1909 Cinematograph Act took effect. This Act was passed in response to a number of fires that had been caused by the highly volatile cellulose film of the period, and required that all cinemas were licensed by their local

\footnotetext{
${ }^{203}$ For a discussion of the Production Code Administration, see Black, 1989.

${ }^{204}$ Joseph Burstyn, Inc. v. Wilson, 343 U.S. 495 ( ( 952 ).

${ }^{205}$ Foerstel, 1997, p. 150.

${ }^{206}$ Freedman v. Maryland, 380 U.S. 5 I (1965).

${ }^{207}$ Foerstel, 1997, p. 152.

${ }^{208}$ Foerstel, p. 30.

${ }^{209}$ RIAA Parental Advisory.

210 The United Kingdom only officially recognized this right after acceding to the European Convention of Human Rights, implemented in the United Kingdom by the 1998 Human Rights Act.
} 
councils $^{21 !}$. However, very soon, councils started to impose other licensing criteria, related to film content, for grant of a licence. This was confirmed in a court case, London County Council v. Bermondsey Bioscope Co. ${ }^{212}$, which revolved around a cinema licence being refused when the cinema opened on a Sunday. The London County Council won, as it was held that reasons for granting or refusing cinema licences were not limited to matters of public health and safety. As in the United States, the film industry was wary of dispersed power to censor. Hence, the BBFC was set up to establish a system of self-regulation for the film industry. The Board would pass advice over a film and issued film certificates in accordance with standards set nationwide. The local authorities - which maintain the powers granted to them in the 1909 Act to this day - generally followed this advice.

Close relationships between the BBFC and the Government developed in the interbellum $^{213}$. The Government feared the use of cinema for propaganda purposes, and hence discouraged the presence of controversial political content. This led to the establishment of a pre-production vetting system, where film studios were invited to submit screenplays to the BBFC for review before shooting started. However, imported films - mainly American films -were not subject to the same strict conditions. Hence, while a number of popular genres, such as the gangster film, remained off limits for British film producers, these were widely imported from the United States. During the Second World War, a number of powers were transferred from the BBFC to the Film Division of the Ministry of Information. This Ministry was disbanded in 1946, but the BBFC had lost its strong grip on political film censorship ${ }^{214}$. Also, the shifting of priorities in the post-war context entailed that most contentrelated disputes would revolve around sexual or violent content, rather than political messages.

In 1984, the BBFC changed its name into the British Board of Film Classification, reflecting the fact that censorship had lost much of its significance. That same year, Royal Assent was given to the 1984 Video Recordings $\mathrm{Act}^{215}$, which was passed in response to a scare concerning violent films published on videotape. The videotape area had not yet been regulated, but the new Act made it obligatory that all video recordings sold in the United Kingdom carry a classification by a classifying authority designated by the Home Office, using an age-rating system. The BBFC was appointed as classifying authority in $1985^{216}$. The 1984 Act made it an offence to sell video recordings to those under the age of classification, or to sell products that had received no classification at all. As a consequence, the BBFC has broader powers in the area of video products (and some computer games) than it does in the area of films. Local councils are not obliged to heed the BBFC's classifications, and there have been a number of instances where local councils banned films that had been classified, or admitted younger audiences to films where the BBFC had imposed a higher age limit. As in the United States, the British film control system has become increasingly liberal. Where Rebel Without a Cause was cut because of the perceived risk that it could incite a teenager rebellion, the BBFC now concentrates mainly on material

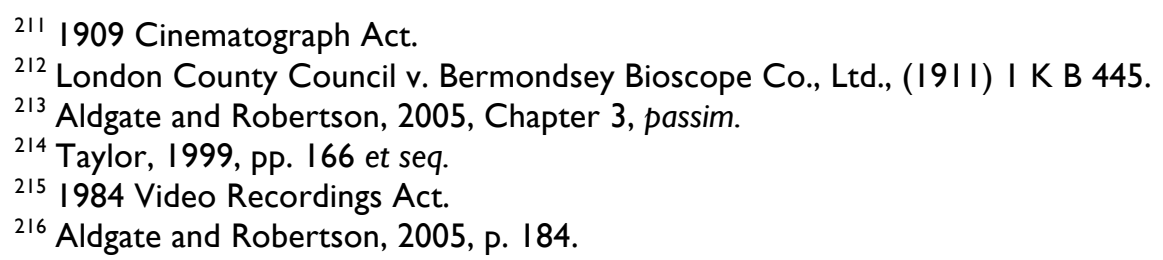


containing strong sexual or violent content $\mathrm{t}^{217}$. It also takes an active stance on racial, sexual and other forms of discrimination ${ }^{218}$. It can issue advice on cuts for cinema films and can impose cuts on video products, in order to lower the age of classification, or making classification possible.

The evolution of broadcast censorship in the United Kingdom has followed a rather complex path. The public broadcaster BBC, established in 1922, enjoyed a monopoly over radio broadcasting, as well as television broadcasting from 1932 onwards, until 1954. During that time, its head sir John Reith strictly worked toward its remit to unite the nation and give the population what the economic and cultural elite thought they should receive ${ }^{219}$. Illustratively, the 1996 BBC Agreement still stated that high standards should be maintained in all respects, particularly in terms of content quality and editorial integrity. Programmes should be offered as a public service, high-quality programmes for children, as well as programmes reflecting lives and concerns of local and national audiences, and programmes made outside the Home Counties should be offered ${ }^{220}$. This role of cultural guardian was taken very seriously. In the 1930s, a Dance Music Policy Committee was established, which strictly controlled the sort of music that was permitted on the airwaves. Throughout its existence, the BBC has at various times banned or censored songs containing foul language, explicit sexual lyrics, drug references, controversial political subject matter, satire, religious content, pop versions of classical music and music supposedly containing advertising. At present, the BBC claims that they no longer ban songs or records, but there have been cases of direct and indirect censorship, such as in the

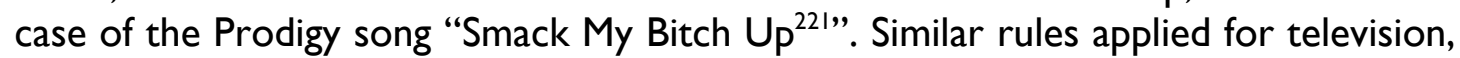
especially where political matters were at issue. Most prominently, programmes relating to Ireland were regularly stopped or postponed during the troubles, and the Irish republicans and loyalists were barred by Government order from appearing on British television.

When the first commercial television station, ITV, was established in 1954, supervision of a tough regulatory authority was deemed necessary. As a result, the Independent Television Authority was established. This was responsible for making sure that political coverage was balanced, and that good taste prevailed on Britain's television screen ${ }^{222}$. Ironically, when the liberalization wave of the Sixties caused the BBC to become more liberal in its programming, it was obliged by the government to bind itself to accept obligations identical to those imposed by the ITA ${ }^{223}$. Nonetheless, during the late Sixties and Seventies, socially conservative audience groups such as the National Viewers and Listeners Association attacked the ITA and BBC, and regimes of institutional censorship were developed, through internal codes and guidelines. The advent of commercial radio in 1972 caused the ITA to be redubbed Independent Broadcasting Authority (IBA). The IBA took a very robust approach to regulation, setting guidelines on the quantity and timing of advertisement, and insti-

\footnotetext{
217 lbid.

${ }^{218}$ BBFC Student Guide, pp. 6 et seq.

${ }^{219}$ Robertson and Nicol, p. 770.

2201996 BBC Agreement.

${ }^{221}$ BBC, 2002

222 Robertson and Nicol, p. 783.

${ }^{223}$ Id., p. 770.
} 
tuting monitoring mechanisms for programme content quality and technical quality, amongst others.

The advent of the Thatcher era brought a complex relationship between the Government and broadcasters. Coverage of sensitive political issues, especially those relating to Ireland, led the Government to seek further control over news media. Also, while it sought to bring about greater commercial freedom, leading to the development of cable and satellite television services, but also aimed to control sexual content (which led to the BBFC being appointed as video regulator). A commission, the Broadcasting Complaints Commission, was instituted to deal with complaints of unfair treatment in radio or television programmes, and another commission, the Broadcasting Standards Commission, was established in 1988 to monitor sex and violence. At the same time, support for cable and television services helped to bring about the increased choice in channels that was available by the early Nineties.

In 1990, a new Broadcasting Act - which still is the centrepiece of radio and television legislation, replaced the IBA with two new bodies: the Independent Television Commission and the Radio Authority ${ }^{224}$. These were to regulate with a lighter touch. A system of punishments from warnings to fines was instituted, with the ultimate sanction being loss of the television licence. The legislative process of this Act was quite difficult, as a large debate arose around a new requirement of "due impartiality", by which the Government hoped to deter programmes too critical of the government, especially where Irish matters were concerned. Hence, under this law, freedom expression was bound by imprecise codes, "drafted and interpreted by Government appointees on a number of bodies whose jurisdiction overlapped and whose decisions could not be appealed or attacked no their own merit ${ }^{225 "}$. Judicial review was theoretically possible, but judges tended to defer to the alleged expertise of these appointed political appointees, regardless of whether this was warranted or not. Codes were instituted by the ITC, BBC, Radio Authority, the Broadcasting Standards Council and the Broadcasting Complaints Commission. As a result, complainants failing to succeed in one forum could easily move their complaint to another, exposing broadcasters to double or even triple jeopardy. In 1996, the BSC and $\mathrm{BCC}$ were merged under a Broadcasting Act amendment ${ }^{226}$, but other arrangements remained the same.

In 2000, the Labour government proposed to amalgamate all censorship bodies into a new organization, Ofcom. This organization was formalized in December 2003, and has nearly complete regulatory powers in all fields of radio and television, even over the $\mathrm{BBC}$, although this is nominally still independently regulated by its Board of Governors. In 2005, Ofcom presented its own highly detailed Broadcasting code ${ }^{227}$, outlining provisions on protecting minors, harm and offence, crime, religion, due impartiality and accuracy, elections and referendums, fairness, privacy, sponsorship and commercial references.

\footnotetext{
${ }^{224}$ Part I Chapter I and Part III Chapter I, 1990 Broadcasting Act.

${ }^{225}$ Robertson and Nicol, p. 77I.

226 I996 Broadcasting Act, Part V.

${ }^{227}$ Since revised regularly. Ofcom, 201 I.
} 
In France, the Ministry of Culture is in charge of film rating. All films must be granted a visa by the Ministry, which decides on a rating based on the advice of the Film Classification Commission (Commission de classification cinématographique) ${ }^{228}$. Cinemas are required by law to prevent underage viewers from watching certain films, and are subject to fines if they fail to do so. The Commission cannot impose cuts on a film, but it can refuse classification, although this happens rarely. In comparison with other rating systems, the Commission seems to pay less attention to strong language and sexual content, but more to violence. The Commission is housed within the National Centre for Cinema and the Moving Image (Centre National du Cinéma et de l'Image Animée - (NC), which was established in 1946 as a public administrative organization. It has regulatory powers over approval of film investment and production, operating licences, regulating cinematographic heritage, keeping public records of film and television, administering the film rating commission, and regulating the relationship between film and television ${ }^{229}$.

Television and other electronic media are administered by the Higher Audiovisual Council (Conseil Supérieur de l' Audiovisuel - CSA). It was created in 1989, replacing the National Commission of Communication and Liberties (Commission Nationale de la Communication et des Libertés), which in turn replaced the High Authority for Audiovisual Communication (Haute Autorité de la Communication Audiovisuelle) ${ }^{230}$. The latter organization was established to supervise attribution of radio frequencies to private radios, in response to the mushrooming of "free radio stations". The CSA is primarily responsible for monitoring respect of the principles of pluralism and honesty of information; organizing radio and television electoral campaigns; allocating frequencies, regulating broadcast content, guaranteeing the respect of human dignity and protecting children. Furthermore, the CSA aims to make television accessible to all, especially the impaired, and making sure that audiovisual media "reflect the diversity of French society ${ }^{231 !}$."

One interesting aspect of French media policy is its emphasis on the French language, which is also one of the CSA's responsibilities, and is exemplified in the 1994 Toubon Law" ${ }^{232}$. This law, considering the French language to be a "fundamental element of the personality and patrimonium of France ${ }^{233}$,", amongst others requires the use of French in all audiovisual programmes, with exception of music works and original versions of films ${ }^{234}$. Related legislation concerns quota for European and Frenchlanguage television content. Concretely, minimum sixty per cent of televised films and television series must be produced in Europe, and 40 per cent in Francophone countries $^{235}$. These rules apply to both overall broadcasting time and prime time. Other legislation imposes a minimum quota for French-language songs in radio broadcast ${ }^{236}$.

\footnotetext{
${ }^{228} \mathrm{CNC}$ Visas and Qualifications.

${ }^{229}$ CNC Mission. See also, CNC Code.

${ }^{230}$ CSA Role and Missions.

${ }^{231}$ Id.

2321994 Toubon Law.

233 Id., Article I.

${ }^{234}$ Id. Article 12.

${ }^{235}$ CSA TV Quota.

${ }^{236}$ CSA Radio Quota.
} 
In Germany, freedom of expression and censorship have a chequered history. The Imperial Press Law (Gesetz über die Presse ${ }^{237}$ ) of 1874 abolished the government's right of pre-publication censorship, and ended the requirement of a government printing licence by stating that no judicial or administrative action could revoke authorization to operate any type of press-related business. Nonetheless, publishers, except for publications "exclusively serving the purposes of the sciences, the arts, business, or industry ${ }^{238}$," were still required to deliver one free copy of every publication to the local police station. The requirement of licensing was maintained for entertainment venues, such as cabarets, music halls, theatres and later cinemas and subject to direct police control.

After the First World War, a liberal constitution was drafted for the new Weimar Republic, which provided that "Every German has the right within the limits of the general laws, to express his opinion orally, in writing, in print, pictorially, or in any other way. No circumstance arising out of his work or employment shall hinder him in the exercise of this right, and no one shall discriminate against him if he makes use of such right.

No censorship shall be established, but exceptional provisions may be made by law for cinematographs. Moreover, legal measures are permissible for the suppression of indecent and obscene literature, as well as for the protection of youth at public plays and exhibitions ${ }^{239}$."

The exceptional provisions for cinematographs took the form of a new Cinema Law (Lichtspielgesetz), promulgated in May $1920^{240}$. This law also created film review offices (Filmprüfstellen) in Berlin and Munich, under direction of a higher review office (Oberprüfstelle), also in Berlin. These offices carried out mandatory film review procedures. Review panels were appointed by the directors of the offices, who were in turn appointed by the Interior Minister. The procedure was secret, and applied to both domestic films and foreign films. However, the scope of censorship was limited, as it was conceived as a security measure. Films could only be refused approval on the basis of danger to state interests, or threats to public order and security, not on the basis of morality.

In 1934, the new Nazi regime changed the film law. The broad powers given to Adolf Hitler through the Enabling Act were, amongst others, to be used for a "vigorous moral sanitization" (durchgreifende moralische Sanierung) ${ }^{241}$ of German culture. As a result, the new law made it possible for films contradicting Nazi ideology to be removed from the public sphere. "Undesirables", such as Jews or leftists, were banned from the film sector, and censorship procedures were changed. The Munich film office was closed, and all films had to be submitted to the Berlin office, which was made subordinate to the Reich Ministry of Propaganda. Pre-production censorship was instituted, and all scripts and projects had to be personally approved by Propaganda Minister Joseph Goebbels ${ }^{242}$.

\footnotetext{
237 I 874 Press Law.

238 Id. $\$ 9$.

${ }^{239} 1919$ Weimar Constitution, Article II8.

2401920 Cinema Law.

241 Hitler, 1933.

${ }^{242}$ Silberman, 1995, p. 52.
} 
After the war, the new German Constitution (Grundgesetz) guaranteed freedom of expression, and prohibited censorship ${ }^{243}$. This was limited, however, by provisions concerning the protection of minors and personal honour, as well as provisions of general laws. Censored materials tend to fall into two categories: works that are considered offensive, indecent or morally objectionable in other ways, and works that are considered dangerous to the state politically ${ }^{244}$. Hence, media works extolling authoritarian or totalitarian ideology are prohibited in Germany.

To administer the moral side of the media, the Federal Examination Department for Media Harmful to Minors (Bundesprüfstelle für jugendgefährdende Medien) was established in 1954. This department examines media works that are deemed harmful to younger persons, and compiles lists (the Index). Works listed in the Index are then subject to limits to circulation defined by different statutes. They cannot be sold or shown to minors, may only be sold in shops (and hence not through mail-order, except where the recipient can produce valid identification), may not be rented out, may not be imported by mail order, or advertised in a location where it can be seen by minors. The period of indexing is 25 years $^{245}$. Works still deemed dangerous to minors after 25 years have to be re-entered. Decisions are made by a panel of twelve members, consisting of the presiding officer, and representatives of the arts, literature, the book trade, suppliers of video products and the telecommunications industry, voluntary youth organizations, teaching staff, churches and the Bundeslandlevel youth protection ministries ${ }^{246}$. Where harm to younger people is obvious, a panel of three members can index a work through unanimous vote.

Apart from indexing, works can also be subject to confiscation if they violate criminal law provisions. The most obvious examples of these are works or denying the Holocaust or advocating totalitarian ideology. Ironically, as indicated above, copyright law supplements these measures in some cases, such as Mein Kampf. Furthermore, $§ 13 \mid$ of the German Criminal Law prohibits dissemination of works glorifying violence ${ }^{247}$, and $\$ 184$ prohibits most forms of dissemination of pornographic material ${ }^{248}$.

Apart from this, Germany also has a rating system, the Freiwillige Selbstkontrolle der Filmwirtschaft (FSK) that, as in the United States, is voluntarily organized by the film industry. It rates movies and DVDs, and issues an age rating, which is not legally binding, but all members of the German film industry association SPIO have committed to implement the rating system ${ }^{249}$.

Similar film and audiovisual broadcasting regulations exist in other developed economies, some of which are even more sophisticated than just providing for age limitations. In the Netherlands, for example, the Netherlands Institute for the Classification of Audiovisual Media (NICAM) manages a system called Kijkwijzer (Viewing

\footnotetext{
${ }^{243}$ Article 5, 1949 Basic Law.

244 The German concept of streitbare Demokratie (combative democracy) implies that the trias politica have extensive powers to protect the liberal democratic state against those who would seek to overturn it. Thurich, 2006, p. 48.

${ }^{245} \S 18$ Youth Protection Law.

${ }^{246}$ BPJM Procedure.

${ }^{247}$ §I 3 I German Criminal Law.

${ }^{248}$ §I84 German Criminal Law.

${ }^{249}$ FSK Mission and Structure.
} 
Guide $)^{250}$ which are used for both films and television programmes. The age ratings have certain consequences, as programmes rated for 12 years may not be broadcast before 20.00, and those rated for 16 years may not be broadcast before 22.00 . Cinemas may not allow those under 16 to view films rated 16 or higher, and retailers may not sell audiovisual products rated 16 to those under 16. Furthermore, the system includes icons reflecting the specific content of the programme, making it possible for parents and guardians to make a more informed decision. These icons indicate violence, horror, sex, discrimination, drug and alcohol abuse, and foul language. In principle, broadcasting stations and distributors are responsible for applying the Kijkwijzer icons to their own products, but NICAM provides for a complaints procedure.

\section{Conclusion}

The relationship between copyright and freedom of expression is complicated but intertwined. The early forms of control over the press, and the contestation against that control during the period of the Enlightenment, led to the establishment in England of an economic mechanism that created a property right over works for authors. This broke the power of the printer's guilds and other distributors, and their cosy relationship with the Crown. Revolutionary France expanded the rights covered by copyright to also include moral rights. Most importantly, the right of paternity and the right of integrity protected works against State censorship, by giving authors the right to identify themselves with their works, and to prohibit any change to the work.

Continuing technological progress resulted in the evolution of an entire commercial industry based on the exclusive rights granted through copyright, and the copyright system evolved in step with this, through the creation of related rights, protecting certain rights and interests of distributors, and clarifying the position of a number of intermediaries and third parties in relation to the Internet.

At the same time, copyright is not the only regulatory framework governing the distribution of audiovisual media products. Content management structures and systems, access structures for international media based on competition principles, as well as culture-related media support policies, also shape the market for audiovisual media products, which is characterized by two concurrent streams of globalization and localization, as well as the increasing volume and value of international trade in cultural products.

Content management structures have known a significant evolution throughout the twentieth century. In the beginning, authorities were concerned about the potential influence of the new-fangled forms of entertainment on public morality. This led to a number of situations where it was held that films were not entitled to the right of freedom of expression. As a response, in a number of countries, self-regulation bodies were set up to pre-empt strict government regulation. Since the Second World War, however, in conjunction with increasing moral liberalism, audiovisual media regulation has become increasingly open. This does not mean that freedom of expression is absolute. Countries still continue to limit the freedom of expression or steer the public debate in a number of ways, related to national characteristics. Most

\footnotetext{
${ }^{250}$ Kijkwijzer Classification.
} 
of these relate to political matters. Germany, for example, places strong emphasis on the maintenance of pluralist democracy and avoiding a resurgence of extreme or authoritarian tendencies. France on the other hand, aims to realize the ideals of the republic - liberty, equality and fraternity - through the audiovisual media system, as well as to safeguard French language and culture. The United Kingdom has perhaps the strictest limits of freedom of expression in audiovisual media in Europe today, although these limits mainly comprise politically sensitive items, rather than morally sensitive items. As a result, this is more an issue for news media than it is for entertainment products.

Where morality is concerned, most developed economies have moved to a system based on age rating to balance between the commercial interests of filmmakers, the interest of the audience in having as wide a range of products as possible, and concerns relating to the protection of minors. The advantage of such systems is that they moderate and structure the way in which certain content can be offered, rather than banning it outright. There is a wide variance in the kind of bodies deciding on content control. In the United States and Germany, for example, ratings are decided through voluntary sector mechanisms, supplemented in Germany by an organization explicitly composed to reflect societal consensus. In other countries, such as France and the United Kingdom, bodies affiliated with the state or given statutory powers by the state decide on ratings. While these are less explicitly composed with the aim to represent the interests of society, they have nonetheless evolved to with evolutions in the film market, and - especially where mainstream material is concerned it rarely happens that materials are banned or that significant differences exist between film ratings across different regions.

To conclude, the evolution of copyright and content regulation in the area of film was driven by both consumer and industry demand for a wider scope of permissibility. As a result, increasingly sophisticated rating structures were established. This was made possible through political and social contestation and debate and the economic incentive of copyright (which is value neutral), which drove producers to expand into as many niches as can be made commercially successful. The next two chapters respectively sketch the evolution of copyright law and media regulation in China, arguing that both of these factors are much less present. This has hindered the evolution of a strong, commercially successful audiovisual entertainment sector in China, while at the same time creating demand for pirated products. 


\section{Chapter III: China's Copyright Legislation}

In comparison to the European and American copyright systems, the evolution of Chinese copyright law proceeded in a markedly different manner. Until the late 19th century, China did not experience the progressive change in power redistribution, nor did a debate on press freedom arise. On the contrary, the idea of legislating copyright was introduced to China from abroad, after the troubles around the turn of the century, including the Boxer Uprising. During this time, foreign powers gained a greater foothold in China as the ailing Qing Dynasty became increasingly powerless and was ultimately overthrown in $191 \mathrm{I}$. While a number of copyright statutes were promulgated, China's subsequent period of political division, internal strife and war precluded copyright law from being implemented nationwide. The complete abolition of pre-Communist law in 1949 marked the provisional end for copyright on the Chinese Mainland. After the reforms began at the end of the Seventies, copyright legislation quickly moved to the legislative agenda.

There were four major reasons for introducing copyright law in China: first, culture expenditure had elevated to such a level that it became impossible to maintain fiscal funding of this sector. Copyright was one part of a broader move of introducing market-based mechanisms to generate income and build better economic incentives for creativity. Second, it was envisaged that copyright would be instrumental in enlisting the support of the intelligentsia for the newly established Dengist administration. Third, copyright was part of broader efforts to reform the Chinese economy. Last but certainly not least, the Chinese government - amongst others because of the increasing piracy problem - became subject to increasing international scrutiny and pressure to better protect foreign intellectual property. As the prime lowhanging fruit, legislation was the prime answer to this pressure. As a result, China's copyright law increasingly converged with international norms as outlined in the previous chapter. Moreover, the institutional framework surrounding copyright, both State and semi-State, has expanded significantly, and now includes an administrative body, special judiciary organs, sector organizations, collecting rights societies, etc.

This chapter argues that, in order to explain piracy, a textual analysis based on the black letter of copyright legislation, and a simple programme evaluation of the surrounding institutions, is incomplete. China lifted the economic mechanism of copyright - the technicalities of the rights granted - from international and national legal systems, seemingly without considering its relationship with other legal, political and social norms governing the production and distribution of audiovisual media. Apparently, the leadership - as well as foreign institutions continuing to press legislative copyright reform - expected the existence of copyright legislation to result in similar business models, industry structures, practices and product diversity as present in countries with a longer copyright history. This has not happened. Rather, the concept of copyright could better be described as a legal or policy irritant. In the legal sphere, a "legal irritant" has been described by Teubner as:

"express[ing] things better than "legal transplant". To be sure, transplant makes sense in so far as it describes legal import/export in organismic, not in mechanistic, terms. Legal institutions need careful implementation and cultivation in the new environment. But transplant creates the wrong impression that after a difficult surgical operation the transferred material will remain identical with itself, playing its old role 
in the new organism. Accordingly, it comes down to the narrow alternative: repulsion or integration. However, when a foreign rule is imposed on a domestic culture, I submit, something else is happing. It is not transplanted into another organism, rather it works as fundamental irritation which triggers a whole series of new and unexpected events ${ }^{25 !}$."

To expand the surgical metaphor, the question here effectively is about whether a transplanted (clean) lung will cause a smoker to kick his habit, whether the lung will itself be harmed by continued smoking, or whether something in between will happen. It is therefore necessary to look at the whole body, as well as behaviour, and broaden the scope of irritation beyond the purely legal sphere. Chinese law is instrumental in nature, and therefore, should be considered also in the light of policy related to media, but possibly also to other political issues - and implementation. Copyright cannot be considered separately from media regulation, nor can it be taken out of the context of ongoing Chinese political reform. This Chapter aims to outline the factors influencing copyright in China, and contrast them with the evolution of international copyright of the previous Chapter.

\section{Evolution and internationalization of the Chinese copyright system}

The evolution of copyright legislation in China can be divided into four parts. First, before 1979, there were different attempts at establishing a copyright regime, which never were successfully implemented. During the pre-Communist era, this was due to the failure of successive governments to exercise effective control over the Chinese territory. After 1949, copyright was abolished altogether, and media regulation became an administrative matter ${ }^{252}$. Second, after 1979, tentative economic reform measures included copyright-like protection for a number of products, with the aim of off-loading fiscal expenditure for the cultural sectors, stimulating research and coopting the interests of the intelligentsia. However, by 1990, media piracy had become a sizeable problem, the Tiananmen Incident had brought China on the brink of collapse, and under strong international scrutiny. The pressure on China to promulgate copyright legislation became increasingly severe, resulting in the 1990 Copyright Law. This law heralded the third period of copyright legislation, as it was perceived as grossly inadequate to protect the interests of China's international trading partners, predominantly the United States. Three near trade wars and China's objective to join the WTO pushed copyright legislation forwards. Criminal enforcement was introduced, China became a member of most important international copyright treaties, and in 200I, a new Copyright Law was promulgated. This new law had been drafted to be more consistent with international standards and China's commitments ${ }^{253}$. Nonetheless, piracy remained a problem, and after a number of years, the US audiovisual media lobby had re-amassed sufficient political capital to move the United States Trade Representative (USTR) to file two cases with the WTO. At the same time, China became increasingly concerned with the damage piracy inflicted on the domestic creative sectors, and started to introduce policies aimed at developing IPR industries. Hence, the fourth, post-WTO, period is characterised by both continuing foreign pressure, that increasingly becomes futile, and China's own desire to move its development model higher up the value chain.

\footnotetext{
251 Teubner, 2000.

${ }^{252}$ Although some steps were taken to create copyright-like incentives to create, see also Chapter IV.

${ }^{253}$ See also later this Chapter.
} 


\section{Before 1979}

Although copyright-like provisions in Chinese books already appeared in the Tang (AD 618-907) and Song Dynasties (AD 960-1279) ${ }^{254}$, codification of copyright in law only started taking place at the end of the 19th century. First, a 1903 trade treaty with the United States provided amongst others for copyright protection of American works. Furthermore, as the Imperial Qing government tried to adapt to Western and Japanese legal models in its reform effort of the late $19^{\text {th }}$ century, copyright was one of many matters taken over and integrated into Chinese law for the first time, in the form of the “Great Qing Copyright Code” (大清著作权律 Daqing zhuzuoquan lü) of $1910^{255}$. After the fall of the Empire, the warlord Beiyang government in Beijing promulgated the “Beiyang Copyright Law” (北洋著作权法 Beiyang zhuzuoquan $\mathrm{fa}$ ) in $1915^{256}$. In turn, after the Guomindang (GMD) took over control of the China, it also promulgated a Copyright Law in $1928^{257}$. This law, although modernized, still serves as the Copyright Law of the Republic of China, in Taiwan.

When the Communists conquered the Chinese mainland in 1949, they abolished all GMD legislation, with the intention of rebuilding the legal system on a socialist basis. The work of intellectuals was recognised in the China People's Political Consultative Committee (CPPCC)'s "Common Programme", which provided for freedom of opinion and of the press ${ }^{258}$, and which stated that the State rewards excellent social science writings $s^{259}$ and rewards excellent literary and artistic works ${ }^{260}$. At the same time, the first copyright legislation drafting work was started in the field of publishing. The first text, the "Decision Concerning Improving and Developing Publication Work" of $1950^{261}$, set out that the publication system needed to protect authors, readers, and publishers, and remuneration for authors was to be based on the "nature, quality and number of characters of a work". It also provided that "copyright and the right to publication must be respected, i.e., plagiarism, manuscript changes, and printing without prior consent should be prohibited ${ }^{262}$." In 195I, a working group was set up to draft copyright legislation inside the State Publications Administration (SPA), which merged into the Ministry of Culture in 1954. This group produced the "(Draft) Temporary Regulations on the Protection of Copyright of Publications" 263 , which was submitted to the State Council in 1957. This document would have protected written and oral works, written translations, music scores, artistic images, scientific images and maps. There was no copyright-like protection yet foreseen for audiovisual media. The term of protection would be 20 years after the author's death. However, the anti-Rightist campaign had begun by that time, and copyright was perceived as bourgeois. Hence, these Regulations were never passed $^{264}$. Only after the Cultural Revolution, during the reform and opening up pe-

\footnotetext{
${ }^{254}$ Zheng and Pendleton, 1991, Pp. 15-16.

255 1910 Qing Copyright Code.

256 1915 Beiyang Copyright Law.

2571928 Republican Copyright Law.

2581949 CPPCC Common Programme Art. 5.

${ }^{259}$ lbid., Art. 44.

260 lbid., Art. 45.

${ }^{261}$ Chinese title: 关于改进和发展出版工作的决议 Guanyu gaijin he fazhan chuban gongzuo de jueyi, quoted in Shen, 2008.

${ }^{262}$ Sgambati, 1992, p. 143.

${ }^{263}$ Chinese title: 保障出版物著作权暂行规定(草案) Baozhang chubanwu zhuzuoquan zanxing guiding (qicao).

264 lbid.
} 
riod (改革开放 gaige kaifang) did work on copyright legislation begin anew. The abortive attempt at copyright legislation also thwarted attempts at internationalization.

Some aspects of this abortive attempt to institute copyright would foreshadow and inform later developments. First, the association of copyright with the publications sector would lead to the later National Copyright Administration (NCA) to be set up inside the publications administration, leading to enforcement problems where other sectors of content works would be concerned. Second, copyright did not primarily protect the interests of authors, but also publishers and readers, much more limited the position of authors vis-à-vis other parties ${ }^{265}$.

Copyright work restarted in 1979, when Deng Xiaoping won the brief power struggle that erupted after the death of Mao Zedong and started his economic reform programme. This included reopening China's doors to the outside world. Yet although one of the earliest mentions of copyright appears in Sino-American trade agreements, adherence to international norms only gradually came to fruition. Three periods can be distinguished when looking at the development of China's copyright legislation and its integration with international norms. In the first period, which encompasses most of the ' 80 s, the international dimension of copyright was not a priority and was treated with suspicion. International law and foreign national laws were studied as an example for potential copyright legislation, but integration into the international system was not yet the immediate goal. During the second period, starting around the publication of the 1990 Copyright Law, political pressure from the US strongly increased, which resulted in three trade agreements in the 90's and deep changes to copyright law. The third period, starting roughly in the half of the ' 90 s, is characterized by a growing strive for multilateralism, as China concentrated its efforts on first becoming a part of the WTO, and being seen as a responsible Member afterwards.

\section{9-1990: autonomous development}

The prime priorities for the creation of a copyright regime at the time of the reform and opening up policy lay mainly in the nature of post-reform politics. Authors, scientists and intellectuals, who had heavily suffered in the Cultural Revolution, were to be rehabilitated and given incentives to become productive again. This was deemed necessary for both developmental and political reasons. The prime goal of the reforms was to stimulate economic growth, embodied in the "Four Modernizations" policy. Scientific knowledge, the policy of "seeking truth from facts" and development was seen as indispensable in this process. At the same time, the culture/propaganda bureaucracy was reformed as the pre-Cultural Revolution leadership was put back into place and the most extremist Maoists removed, with the objective of introducing market mechanisms into the cultural sector. This did not entail that it was the objective to liberalize the media market, and throughout the Eighties, the cultural sector vacillated between more openness and more clampdown against "bourgeois tendencies" ${ }^{266}$. At the same time access to foreign materials, such as books and scientific journals, was deemed important for China's development, but foreign copyright fees were expensive. Another concern in this first period was therefore how to promote domestic intellectual production, whilst at the same time

\footnotetext{
${ }^{265} \mathrm{Qu}, 2002$, pp. 44-69, passim.

${ }^{266}$ Kraus, The Party and the Arty, Chapter I, passim.
} 
making it possible for foreign copyright material to be distributed in China as cheaply as possible.

Progress in copyright protection legislation was slow and difficult, because of different factors. First, contemporary Chinese ideas concerning authorship, private property, media control and intellectual labour did not mix well with Western individualized notions of copyright protection in a market characterized by freedom of speech, leading to misunderstandings and misgivings about copyright ${ }^{267}$. Second, sorting out the division of labour between publishing control and copyright protection led to protracted struggles between different factions ${ }^{268}$. Third, a number of science and development bureaucracies were opposed to copyright protection, stating that it would make importing knowledge very expensive ${ }^{269}$.

The first steps towards establishing the doctrines copyright law were in international agreements. Article 6 of the Sino-American agreement on High Energy Physics ${ }^{270}$ stated that: "the parties recognized the need to agree upon provisions concerning protection of copyrights and treatment of inventions or discoveries made or conceived in the course of or under this Accord." More explicitly, Article 6 of the 1979 Agreement on Trade Relations between the United States and China ${ }^{271}$ stipulates that:

"I. Both Contracting Parties in their trade relations recognize the importance of effective protection of patents, trademarks and copyright. [...]

5. Both Contracting Parties agree that each Party shall take appropriate measures, under its laws and regulation and with due regard to international practice, to ensure to legal or natural persons of the other party protection of copyrights equivalent to the copyright protection correspondingly accorded by the other Party."

However, foreign relations did not remain the main driver in the copyright law development process at that time. The Third Plenary Session of the Eleventh Central Committee in 1978, which initiated the reforms, rehabilitated the intellectual class ${ }^{272}$. The next step was the establishment of an organization, the China Publishers Association Copyright Research Small Group, which took over the responsibility of drafting China's first copyright law. This was very much supported by then-Secretary General and propaganda chief of the CCP, Hu Yaobang, who had overseen the reform of the Central Propaganda Department after the Cultural Revolution ${ }^{273}$.

In December 1979, the Small Group submitted their first draft of the copyright law. This draft combined the publishing and copyright, as it was argued that the publishing rights included the rights of broadcasting, recording and performance. However, it was decided to split both areas with the result was that a second dispute arose around sequencing. Some argued that good legislation on publishing already existed, such as the Decision on Dealing with Illegal Books and Magazines of 1955 274; others

\footnotetext{
${ }^{267}$ Feng, 2003, pp. 5-6 and 80-82.

268 Mertha, 2005A.

269 Ibid.

2701979 High Energy Agreement, Art. 6.

${ }^{271} 1979$ US - China Trade Agreement, Art. 6.

${ }^{272} 1978$ Party Congress Report.

${ }^{273}$ Brady, 2010 , p. 40.

${ }^{274}$ I 955 Illegal Books and Magazines Decision.
} 
posed that the publications regulation should get priority, in order to standardize control over the media. The GAP put forward more drafts in 1980 and 1982 that circulated in the different circles of the government. The debate continued unabated for the next years, with numerous issues needing to be resolved ${ }^{275}$. These included the question whether or not an individual's rights should have precedence over those of that person's work unit ${ }^{276}$, protection of folk literature and computer software, transferral and inheritance of copyright, the balance between rights and obligations for copyright holders and the question of neighbouring rights, i.e. the rights of those being involved in audio and video media production ${ }^{277}$. Nonetheless, China did become a member of the World Intellectual Property Organization on January $3^{\text {rd }}$, $1980^{278}$.

A first breakthrough arrived in June 1984, when the "Trial Regulations on Books and Magazines Copyright Protection" 279 were circulated. The "Trial Regulations" concentrated mainly on regulating the right to remuneration of authors, whilst only tangentially including other economic and moral rights. They also did not protect foreign works, and only protected works of foreigners if these were first published in China ${ }^{280}$. Audiovisual products were not protected under the Regulations, although adaptation of a work was mentioned in Article 17 as a fair use exception. As these Regulations would be unacceptable to foreign copyright holders, they remained classified. A later notice stated that the document could not be disclosed to foreigners, and that its existence was not to be hinted $\mathrm{at}^{281}$. On I January 1985, the Implementing Rules to these Regulations came into effect. These further clarified a number of terms of the original document, and provided more concrete guidance of enforcement in cases of infringement ${ }^{282}$. Also in 1984, it became permitted to import Hong Kong and Taiwan music products, with the proviso that such import would have to respect international existing copyright arrangements ${ }^{283}$.

Inspiration for copyright legislation was found in international law and foreign legal systems. In a speech ${ }^{284}$ before the London Conference for the Centenary of the Berne Convention, Guo Shoukang, a member of the Copyright Law drafting committee, evaluated the possibility of Chinese accession to the Convention. He stated that there were some provisions were not advantageous to the Chinese situation. The

\footnotetext{
${ }^{275}$ During this period, a number of interim regulations on the production and distribution of literary and artistic works were implemented as a stopgap measure, more often than not only indirectly related to copyright protection, such as the "Provisional Audio and Video Product Management Regulations" of 23 December $1982^{275}$.

${ }^{276}$ The work unit 单位 danwei is a form of organizational structuring in the PRC. Before the reforms, a danwei controlled most of an individual's private life, since it organized social care, education, etc. Workers also needed their work unit's permission to get married or have children. After the reforms, the danwei system lost much of its social functions. However, the term is so typically Chinese that it is still regularly used in legislation. Hereafter in this study, we will use the translation work unit.

277 Shen, 2008, p. 30.

${ }^{278}$ Cornish, 2006.

279 I984 Trial Copyright Regulations.

280 This compares unfavourably with the French Shostakovich case, in which even works of authors not party to any copyright agreement with France were deemed to enjoy copyright protection. See also Chapter II.

${ }^{281} 1987$ Notice Concerning Copyright Regulations.

2821985 Copyright Regulation Implementation Rules.

2831984 Hong Kong and Taiwan Import Report, Para. I.

${ }^{284}$ Guo, 1986, pp. I2I-127.
} 
scope of protected works, for example, was a point of discussion at that point, with some committee members favouring a two-stage arrangement in which at first only books and periodicals would be protected, other members were more in favour of a comprehensive approach. The specific nature of software was also a matter of discussion, as were the ideas of national treatment and copyright formalities.

In 1985, the State Council decided to establish an administrative body to deal with copyright matters, the National Copyright Administration. This was to be embedded into the newly-independent General Administration of Press and Publications, as “one organ with two name plaques” (一个机构两个牌子 yige jigou liangge paizi), with the responsibility to continue copyright legislation drafting. Two years after the publication of the "Trial Regulations", and with the authorization of the NCA, the Ministry of Radio, Film and Television (MRFT) issued the "Provisional Regulations on Copyright Protection of Audio and Video"285, which took effect on I January 1987. These "Provisional Regulations" again did not explicitly protect foreign works. Moreover, they mainly concerned the obligations of audiovisual publishing and trading work units vis-à-vis authors, performers and other work units, rather than creating and protecting individual rights. While it indicated that audiovisual works were to be protected for 25 years after first publication, it was relatively vague on the precise scope of the protected rights. In effect, the only explicit rule was the provision that no commercial duplication of audiovisual products may be made without authorization. However, this is exactly the fundamental rule that piracy in China breaks.

By that time, the United States had become increasingly concerned with the piracy of computer software and books, as well as with the slow evolution of copyright legislation in China, and started negotiations over the promulgation and implementation of copyright in China. In 1989, this resulted in the "Memorandum of Understanding on the Enactment and Scope of the Chinese Copyright Law". The MOU included, amongst others, the provision that computer software was to be included in the Copyright Law, where China was aiming at a sui generis regime for software protection, but was never ratified due to the Tiananmen incidents of June $1989^{286}$. It did, however, provide further impetus to quickly finish the drafting of the Copyright Law. Moreover, it was a first shot across the bow concerning IPR in China. In the economically protectionist environment in the Unites States of the 1980, the US only wished to deal with countries they could trade with on equal terms. This attitude also resulted in the creation of Section 30I of the US Trade Act. Also known as "Special 30l", it requires the United States Trade Representative to conduct an annual review of the intellectual property practices of US trade partners. Countries designated as "Priority Foreign Countries" are investigated by the USTR, which may then impose trade sanctions ${ }^{287}$.

In the end, the first Copyright Law was promulgated in 1990. It signalled a major upgrade over earlier regulations. First, it protected a wide range of subject matter, being written works, oral works, musical, dramatic, quyi, and choreographic works, fine art and photographs, cinema, television and video works, engineering and product

\footnotetext{
2851986 Temporary Audiovisual Copyright Regulations.

${ }^{286}$ Mertha, 2005A, p. 124.

${ }^{287}$ For a contemporary evaluation of Special 30I, see Bello and Holmer, 1989.
} 
design drawings, maps and sketches, and computer software ${ }^{288}$. It extended these rights to Chinese citizens or works first published in China, as well as to citizens of countries with which China had mutual protection treaty commitments ${ }^{289}$. It protected five main rights: the right of publication, the right of paternity, the right of alteration, the right of integrity, and the right of exploitation and remuneration. The first three rights were granted without time limitation, the latter two were limited to fifty years after the death of the author, except for photographic and film works, which would be protected for fifty years after publication ${ }^{290}$.

Nonetheless, concerns of foreign copyright holders remained. A first problem was the denial of copyright protection to works of which publication was prohibited, outlined in Article 4, which stated that "Works the publication or distribution of which is

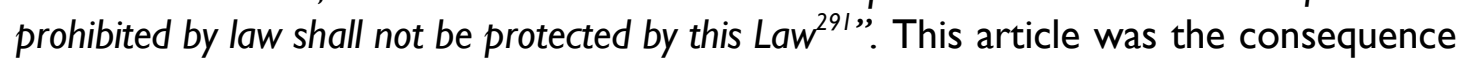
of a compromise between different factions within the drafting group of the copyright law, as some felt it would be unacceptable for the Copyright Law to protect sensitive content. In the case of audiovisual media, however, this meant that foreign works not submitted for circulation approval in China would theoretically not be protected under the Copyright Law.

Article 22, which outlined the limitations on rights, contained some provisions that were found problematic. First, Article 22(7) allowed state organs to use published works in the fulfilment of their duties without permission from and payment or remuneration to the owner, requiring only that the author and title of the work were mentioned. As state-owned enterprises could also be considered state organs, concerns arose that these enterprises could use unauthorized copyrighted material with impunity, and would not have to pay royalties. Second, Article 22(9) held that a free of charge live performance of a work did not need the permission from and payment to the author. This was deemed to conflict with the rights of adaptation as outlined in Article II Berne ${ }^{292}$.

Moreover, a number of provisions would not be consistent with TRIPS requirements, which became an issue during China's GATT/WTO accession process. Articles $32^{293}, 35^{294}$ and $37^{295}$ contained voluntary statutory licences that were not compliant with Article I3 TRIPS, which incorporated the Berne three-step test. Also,

\footnotetext{
${ }^{288}$ Article 31990 Copyright Law.

${ }^{289}$ Article 21990 Copyright Law.

${ }^{290}$ Article 101990 Copyright Law.

291 Article 41990 Copyright Law.

${ }^{292}$ Article 221990 Copyright Law.

${ }^{293}$ (...) Except where the copyright owner has declared that reprinting or excerpting is not permitted, other newspaper or periodical publishers may, after the publication of the work by a newspaper or periodical, reprint the work or print an abstract of it or print it as reference material, but such other publishers shall pay remuneration to the copyright owner as prescribed in regulations. lbid., Art. 32.

294 (...) A performer who for a commercial performance exploits a published work created by another does not need permission from, but shall, as prescribed by regulations, pay remuneration to, the copyright owner; such work shall not be exploited where the copyright owner has declared that such exploitation is not permitted. Ibid., Art. 35.

295 (...) A producer of sound recordings who, for the production of a sound recording, exploits a published work created by another, does not need permission from, but shall, as prescribed by regulations, pay remuneration to, the copyright owner; such work shall not be exploited where the copyright owner has declared that such exploitation is not permitted. Ibid., Art. 37.
} 
Article 42 contained a compulsory licence in violation of the same TRIPS article ${ }^{296}$. For example, computer databases were not protected under the Copyright Law, in violation of Article 10 TRIPS.

Moreover, a number of TRIPS-mandated enforcement provisions were absent from the law, including the possibility of injunctions provided for in Art. 44 TRIPS, and the disposition of goods as stipulated in Art. 46 TRIPS. Finally, although Articles 46 and 47 of the law created civil and administrative liability in cases of copyright infringement, criminal punishment measures were absent.

In short, the 1990 Copyright Law contained a number of provisions that did not comply with the Berne Convention or which became problematic when China wanted to join the GATT. This non-compliance was partly the consequence of a tendency within the leadership to treat copyright as a national - rather than international - matter. Too much foreign influence in the Chinese copyright and publications regime was unwanted. Also, drafting of the Law was constrained by different factors, such as the internal bickering between different government departments that characterizes Chinese political culture. Zhang describes the goal of this legislative process as: "first making sure there is a law, so it can be revised later ${ }^{297 " . ~ A ~ n o t e ~}$ slipped to NCA chairman Song Muwen by NPC Legal Committee chairman Song Rufen read: "Do not lose the big over the small, do not delay in order to reach perfection $^{298, "}$.

\section{2-1996: foreign pressure and cycles of futility}

The copyright law was immediately subject to controversy at home and internationally. Chinese artists and composers found that the law did not adequately reflect their interests. Internationally, American reaction to the law was swift, even though the Implementation Regulations of the Copyright Law took the edge off some provisions, for example by making Art. 22(6) and (7) subject to a three-step test literally copied from the Berne Convention ${ }^{299}$. Nonetheless, the USTR, under influence from American industry groups, announced trade sanctions under Special 301 on December $2^{\text {nd }}, 1991$, to take effect on January $17^{\text {th }}, 1992^{300}$.

An intense round of negotiation followed, in which the US succeeded in making the TRIPS agreement, which was still in the drafting stage at that time, into a basis for better protection of American IPR in China. China's reward would be American support for China's bid to be a founding member of the WTO. Nonetheless, there was strong resistance from the Ministries having jurisdiction over software, as they argued that the $C L$ did not cover software ${ }^{30 !}$. Mere hours before the sanction deadline, the US and China reached an agreement and signed a Memorandum of Understanding. In this MOU, China agreed to accede to the Berne Convention and the

\footnotetext{
${ }^{296}$ Zheng, 1998, p. 223.

297 Zhang, 2002.

298 Ibid.

${ }^{299}$ Article 21,1991 Implementation Regulations.

${ }^{300}$ Sgambati, 1992, p. 140.

${ }^{301}$ Mertha, 2005A, p. 127. The American efforts can also be considered in the light of the objective to integrate trade and IPR issues, as these had been considered separate until the end of the Eighties. Also, However, the Copyright Law itself limited the possibilities for adjustment. Revoking the law itself, would have been a huge political risk, in view of the political capital that was spent and the concessions made by the different administrative units during its drafting.
} 
Geneva Phonograms Convention ${ }^{302}$, which would prevail over Chinese domestic laws and regulations in cases of inconsistency, under Art. 142 of the General Principles of the Civil Code ${ }^{303}$. It also committed to implement a number of new regulations and amendments to the Copyright Law that would bring it more in line with the Berne Convention. Most importantly, the MOU stipulated that the rights guaranteed by the Berne Convention must be extended to all Berne Union member nationals, but also to works created in China by these nationals, effectively extending the Berne Convention protection to foreigners, but not to Chinese nationals. Consequently, Chinese nationals enjoyed less protection under their own law, where foreigners enjoyed super-national treatment ${ }^{304}$. Around the same time, another MOU was signed regarding market access, which did not include explicit mention of audiovisual media. At that time, market access was regarded by the U.S. administration as a separate matter from intellectual property rights.

According to the terms of the $1992 \mathrm{MOU}$, China duly acceded to the Berne Convention. This was confirmed by new regulations ${ }^{305}$ as required by the MOU that also confirmed pre-existing bilateral copyright treaties, as well as other provisions. Foreign software was to be protected as literary works, rather than sui generis, foreign databases were protected, and foreign copyright holders gained the right to prohibit import of pirated copies of their work, reduced the impact of the statutory licences present in the Copyright Law on foreign rights holders, and the international copyright treaties China was a party to expressly gained superiority over Chinese domestic law. China also acceded to the Universal Copyright Convention, although this was not stipulated in the MOU. In 1993, China joined the Geneva Phonograms Conventions. However, the software lobby in the US remained worried about rampant piracy in China, stating that in 1993, 94 percent of packaged software sold in China was counterfeit, leading to a business loss of $\$ 322$ million $^{306}$. In June 1994, China once more found itself designated as a priority foreign country under Special $30 \mathrm{I}$.

The month after, China made infringing reproduction and distribution a criminal offence ${ }^{307}$, but in February of 1995, the United States announced US\$1.08 billion worth of trade sanctions. The Chinese announced retaliatory sanctions of the same amount, but these were both again averted by an agreement reached at the last minute $^{308}$, consisting of an Exchange of Letters and an Action Plan. The focus sharply differed from the $1992 \mathrm{MOU}$. Where the emphasis previously was placed on legislative

\footnotetext{
${ }^{302}$ Article 3, 1992 Memorandum of Understanding.

303 "Any international treaty concluded or acceded to by the People's Republic of China contains provisions differing from those in the civil laws of the People's Republic of China, the provisions of the international treaty shall apply, unless the provisions are ones on which the People's Republic of China has announced reservations", 1986 General Principles of the Civil Law, Article 142. However, since judicial and constitutional reviews are absent in China and there is no constitutional stipulation on direct effect of international treaty, the exact scope of this obligation remains unclear. For a detailed discussion of the status of treaties in the Chinese domestic legal order, see Li and Guo, 20II. ${ }^{304}$ Super-national treatment - being a violation of the principle of national treatment - is not expressly forbidden by TRIPS or by the Berne Convention. As there are as of yet no cases on this, it remains to be seen whether or not the WTO regards it as permissible or not. Friedmann, 2007, p. 153.

3051992 Copyright Treaty Implementation Regulations.

${ }^{306} \mathrm{Hu}, 1996$, p. 84.

3071994 Copyright Criminal Punishment Decision.

308 I 995 IPR Agreement.
} 
enhancement, the main thrust of this agreement centred on enforcement. In the letter to Trade Representative Michael Kantor, Trade Minister Wu Yi outlined the recent actions that Chinese authorities took to enforce intellectual property rights, including the closing of seven offending factories, the seizure and destruction of two million infringing products and further engagements to continue the struggle against copyright piracy ${ }^{309}$. The Action Plan consisted of two main parts: the first part called for China to institute an Intellectual Property Rights Working Conference at the national and sub-national levels and different task forces to better enforce IPR laws. Moreover, it stipulated that there should be a "special enforcement period" during which IPR enforcement should be heavily funded. The Action Plan veered very much towards copyright-related issues, with these taking up twelve pages. Patent-related matters, on the other hand, were dealt with in only three pages.

The MOU of 1992 and the Action Plan of 1995 increasingly drifted away from "standard" bilateral negotiations based on national sovereignty. Both agreements heavily interfered with China's domestic IPR policy. Paradoxically, although China's IPR policy had been partly designed to "keep foreigners at bay", it now had to allow increasing foreign interference in internal processes and had to extend increasingly more protection towards foreign nationals than Chinese nationals. This state of affairs had become unacceptable to the leadership and different steps had already been taken to overcome the problems of the 1990 Copyright Law. In 1994, the State Council promulgated the "Intellectual Property Rights Customs Protection Regulations 310 ", and a lack of criminal punitive mechanisms had been remedied with the aforementioned Decision Concerning Punishment of Copyright Infringement Crimes of 5 July 1994, which laid down maximum prison sentences and fines for cases of production and sale of infringing products. It also allowed the confiscation of the infringing products, as well as the materials used to produce them, and the infringing party could be made to pay damages to the copyright holder. The revised Criminal Law, which came into force in 1997, converted the stipulations of this Decision into law ${ }^{311}$. Article 217 Criminal Law provides a maximum of three years of detention or imprisonment as well as the possibility of fines for copyright infringement for the purpose of making profit leading to "grave" consequences. In case of "huge" consequences, the prison sentence can be between three and seven years. Article 218 of the Criminal Law provides a maximum of three year's imprisonment or criminal detention for the sale of infringing materials. However, no guidelines were given for the interpretation of "grave" and "huge", leaving it to the discretion of judges as to how to apply these articles. This was only remedied in 2004, with the promulgation of a related Supreme People's Court Judicial Interpretation ${ }^{3 / 2}$.

\section{6-current: international integration and the Internet}

After the 1995 Agreement, the pressure from the United States began to shift. China was again designated a Priority Foreign Country, but negotiations did not lead to a new agreement. Instead, a report mainly reiterating China's previous commitments was presented as a face-saving measure. Hereafter, the United States lessened IP pressure on China, due to different reasons. First, although some intellectual property industry associations, such as the International Anti-Counterfeiting Coalition,

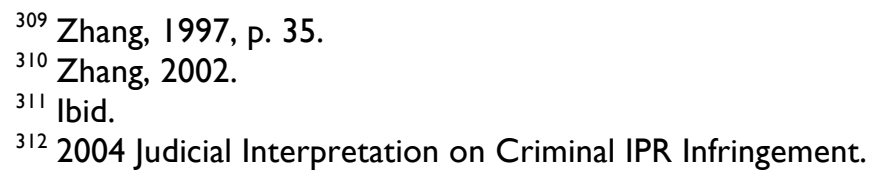


called for the renewal of China's Priority Foreign Country designation, a sort of intellectual property fatigue had taken hold in the USTR. Non-intellectual property intensive industries started to become vocal about the intellectual property debate overshadowing other trade-related issues, such as market access. Second, considerable political capital had already been expended, and the American government was loath to keep investing in the intellectual property front rather than in other trade or strategic issues ${ }^{3 / 3}$. Moreover, the preferred trade strategy changed, as the United States started to focus on the deal necessary to get China into the WTO, rather than on bilateral action.

In order to join the WTO, China faced two challenges. First, it needed to ensure that all domestic law and regulation was WTO-consistent. Second, it had to strike a deal with the major trading blocs on the terms under which China would be allowed to join. As a result, the entirety of China's copyright sector-related legislation and regulations was overhauled, and a number of provisions clarified. For example, in 2000, the National People's Congress Standing Committee reiterated criminal liability for intellectual property infringement via the Internet ${ }^{314}$. The Copyright Law itself would need to be updated both to respond to TRIPS obligations and to remove the discriminatory situation created after the 1992 MOU and the 1995 Agreement. Consequently, in 1997, a "Copyright Law Revision Small Group" was formed, which worked together with the NCA in assembling opinions from institutions such as universities, government organs and industry associations regarding the revision of the Copyright Law. They submitted a draft version of a revised Copyright Law to the State Council Legislative Committee, aiming to enact the new law in 1999.

However, the process was delayed again. First, the draft law contained some passages that did not comply with the WIPO Copyright Treaty and the World Phonograms and Performances Treaty ${ }^{315}$. Although China at that time was not a contracting party of these treaties, it aimed to make the law as compliant with international standards as possible, both in order to avoid the problem of double standards again, and to make it possible to join these treaties later. Second, the draft law still contained unsolved problems, such as the permission for television and radio stations to use copyrighted material without remuneration and permission for non-profit goals present in Article 43. Third, the Committee took a dim view of some of the changes suggested, believing these to be "too foreign" or "not adapted to Chinese circumstances". Some went even further and described IPR as "people in white shirts and suits who sell things to China that cost many tons of rice, and which are too expensive $^{316 "}$. This led to the withdrawal of the draft law by the end of 1999.

The State Council, recognizing that the current system was untenable as well, and that the clock was ticking for WTO accession, pushed Copyright Law reform through. It charged the NCA with the drafting of a new copyright law. It took three more years of discussion and debate to come to a general conclusion, but in $200 \mathrm{I}$ the revised Copyright $\operatorname{Law}^{317}$ was promulgated. This contained significant updates

\footnotetext{
${ }^{313}$ Mertha, 2005A, p. 47.

${ }^{314} 2000$ Internet Safety Decision.

${ }^{315}$ Zhang, 2002.

${ }^{316}$ Mertha, 2005A, p. 130.

317200 I Copyright Law.
} 
making the law more compliant with international treaties, and reflecting the evolved state of technology. The new Copyright Law contained sixty articles, up from fifty-six in the 1990 version. Eleven articles were new, five articles were deleted and four articles were merged into two. Enforcement became a more important part of the Law, with Section 5 - "Legal Liability" being renamed "Legal Liability and Enforcement Measures".

Article 2 provides increased protection of the rights of stateless persons, as well as works first issued in China by stateless persons or citizens of countries with which China does not have an agreement or that are not party to an international treaty of which China is a member if those works are issued first in China or in a country which is party to an international treaty with China. Article 3 updated and clarified the list of works that could be protected under copyright law to include acrobatics, buildings and model works. Article 7 of the 1990 version, which stipulated that works being protected by the Patent Law could not enjoy copyright protection, was deleted. Article 8 introduced the possibility of the organization of bodies for collective management of copyright, allowed to claim rights for copyright owners and participate in litigation or arbitration related to copyright in their own name. This provision was already outlined by article 54 of the Implementation Regulations of 1991, which entitled the copyright owner to exercise their rights by way of collective registration, but its incorporation into the law strengthened the legal basis for these organizations.

The list of personal and property rights outlined in Article 10 was substantially enlarged and clarified. Most importantly, Article 10(12) confirms the right of communication of information on networks, clearly incorporating the Internet into the law. A second point is that the right of rental present in Article 10(7) was expressly created in response to international standards, as it was originally part of the provisions on distribution ${ }^{318}$. Lastly, the article provided for transfer of copyright, something that was not clearly present in the 1990 law. The protection of works created by compilations present in Article 14 of the old law did not comply with Article 10(2) TRIPS, as it specified only works could be protected. This was amended to include parts of works, data that do not constitute works and other materials.

Film copyright was amended in the new law to be enjoyed by the producer of the film, although scriptwriters, directors, cameramen, lyricists, composers and other authors retained the right of authorship of their work, and the right to remuneration pursuant to their contract with the producer. The section on limitations on rights was also amended. Article 22(3) concerning citation of a published work for the purpose of reporting current events was specified with the phrase "for any unavoidable reason". Article 22(4) was updated by on the one hand specifying the scope of articles that can be reproduced, and on the other hand by including the right of the author to disallow such reproduction. This right was already present in Article 22(5) concerning publication of speeches.

A very controversial part of the 1990 Copyright Law, Article 22(7) outlined that a state organ could use a published work for the purpose of fulfilling its official duties. This article was amended to include the phrase "within proper scope".

${ }^{318}$ Zhang, 2002. 
Article 22(9), which in the 1990 law stipulated that free-of-charge live performances of published work fell under a no-remuneration statutory licence was amended to stipulate that it could not collect fees from the public, but also not pay remuneration to the performers.

Article 22(I I) concerning the translation of published works into minority languages was narrowed in scope. Authors concerned needed to be Chinese citizens, legal persons and other organizations. This specification reflected the dichotomy between domestic political needs on one hand and the wish not to prejudice legal rights of foreigners.

A new article 23 made it possible to use certain works to be compiled into educational textbooks unless the author declares in advance that his use is not permitted. Authors retain the right of remuneration and authorship. Remuneration standards for the exploitation of works in the 1990 law were stipulated as being fixed by relevant authorities, unless the contracting parties decided otherwise in a contract. The idea was that the government would fix remuneration standards, and contracting would be used in specific cases and exceptions. As it transpired, only standards for the remuneration of republication of periodical articles and for performers of musical works were instituted. Book and periodical writers continued to use the Provisional Regulations Governing Remuneration for Book Manuscripts ${ }^{319}$ of 1990. The new law recognised that this system did not correspond well with the market system and reversed the arrangement by putting the contract option first, and only then referred to administration-established standards. However, these standards were never made concrete. Only in the case of the statutory licence for broadcast of music works on radio or televisions were remuneration standards published in $2009^{320}$. A new provision established protection for the typographical arrangement of books and periodicals in Article 35.

The duties of performers when exploiting published works have also been strengthened. Article 35 of the 1990 law stipulated that a performer did not need to obtain permission from the author of a public work to use it in performance only requiring him to pay remuneration. In the $200 \mathrm{I}$ law, performers need to obtain this permission. The protection of performers was strengthened as well in Article 37. Performers gained the right to authorize public transmissions of performances, as well as receive remuneration regardless of the commercial goal of performance recording. This commercial goal was still a requirement in the 1990 law. Moreover, performers also received the explicit right to authorize the dissemination of performances on the Internet, once again confirming the increased role of Internet-related copyright. In article 38, the duration of the economic rights of performers was confirmed to be fifty years after the performance.

Producers of sound and video recordings exploiting a work created by another person did not need their express permission according to Article 37 of the 1990 law. As long as the author did not forbid the use of the work, permission was not necessary. Article 39 of the $200 \mathrm{I}$ law amends this by stating that such adaptation requires express consent from the copyright owner. A statutory licence stipulation was also added, under which record producers do not need to obtain permission from prior

\footnotetext{
${ }^{319} 1990$ Provisional Manuscript Remuneration Regulations.

${ }^{320} 2009$ Broadcasting Remuneration Rules.
} 
producers. This licence is limited by the possibility of the copyright owner to expressly prohibit such exploitation.

The new law provided for the protection of the rights of sound and video recording producers. In Article 4I, they are accorded the right to authorize others to reproduce, distribute rent and communicate records on the Internet, with the term of protection being fixed at fifty years after production.

The rights and obligations of radio and television stations were clarified in Articles 42 and 43. The first article was revised by dropping the provision that copyright owners could prohibit broadcasting of their works. On the other hand, radio and television stations were obliged to always pay remuneration, as the provisions that provided for non-remuneration were dropped as well. The latter article provides that remuneration needs to be paid for the broadcasting of sound recordings, unless another agreement is made between the interested parties. In the old law, remuneration did not need to be paid for non-profit broadcast. This was a very controversial topic, as radio stations were considered to be "mouthpieces of the party", but also a public good. As they did not work commercially, they also did not need to pay remuneration to use published audio works under the fair use doctrine. However, during the drafting of the $200 \mathrm{l}$ law, it was pointed out that this was not compliant with international treaties, as well as being a rarity in the world ${ }^{321}$. Article 4I of the 1990 law, obliging radio and television stations to conclude a contract with performers when producing a programme was deleted.

The most important update included in the 200I law was the substantial revision of the provisions on law enforcement. The name of chapter 5 of the law was changed from "Legal Liabilities" to "Legal Liabilities and Enforcement Measures". In Articles 46 and 47, the following infringing actions were added to the list present in the 1990 law: plagiarizing another person's work, unauthorized exploitation of typographical arrangements, unauthorized broadcasting or recording of performances, unlawful renting of copyrighted works and unauthorized communication of works on the Internet. The law also provided for new remedies. Article 47 states that unlawful incomes and infringing copies of works may be confiscated. Under "serious" circumstances, the materials, tools and equipment used for copyright infringements can be confiscated and the infringer can be prosecuted criminally if his infringement constitutes a crime.

Also under Article 47, technological measures implemented by the copyright holder to protect his copyright may not be intentionally circumvented without authorization, unless otherwise specified. This mirrors Article II WCT and Article I8 WPPT. Secondly, electronic right management information of a work is protected and may not be deleted or altered intentionally, pursuant to Article 12 WCT and Article 19 WPPT.

Provisions for damages of copyright infringements are new in the 200I law. Before, judges would apply Article II 8 GPCC, which provides for "complete compensation". Under Article 48, damages have to be computed in first instance on the basis of the actual injury of the copyright holder. If that is not possible, it shall be paid on the basis of the illegal income of the infringer. If neither of these options is possible, the

${ }^{321}$ Zhang, 2002. 
maximum fine is set at $500.000 \mathrm{RMB}$. Damages can also include the reasonable cost the copyright holder incurred to stop the infringement.

Articles 49 to $5 \mathrm{I}$ introduce a procedural element in the Copyright Law, which was not present in the 1990 version. Until then, the Copyright Law did not expressly provide for evidence preservation measures and preliminary injunctions, although the Civil Procedure Law provided for these. In order to expressly comply with TRIPS requirements, detailed provisions for civil copyright cases were incorporated into the Copyright Law. More specifically, Article 49 instituted the possibility for copyright and related right owners may apply to the Court to order cessation of the related act and take property preservation measures before legal proceedings commenced, if the act would cause irreparable injury to his legitimate rights if not stopped immediately, invoking Articles 93 to 96 and 99 of the Civil Procedure $\mathrm{Law}^{322}$. Article 50 provides for evidence protection, obliging the relevant People's Court to take a decision within 48 hours. Also, the applicant may be ordered to submit a bond. Article $5 \mathrm{I}$ allows the People's Courts to confiscate unlawful income, infringing copies and materials used in copyright and related right infringements.

The burden of proof in infringement cases was reversed in Article 52. It is up to the publisher, producer, distributor or renter of a reproduction to prove that his actions are lawful. However, it could be argued that this goes against the presumption of innocence present in the Criminal Law ${ }^{323}$.

Lastly, Articles 48 and 49 of the old copyright law containing provisions on mediation and arbitration were merged. However, the new law is less clear than the 1990 Law in terms of possible action if either of the parties is not content with mediation and arbitration, or does not comply with the verdict. Most importantly, the sequencing of legal actions was reversed in the new Law. The 1990 Law provided that the Courts should be addressed in cases of infringement only if the parties did not wish to settle the dispute by mediation. In case of copyright contract disputes, the same sequence applied. In the $200 \mathrm{I}$ Law, enforcement of rights through litigation became the prime option, with mediation and arbitration relegated to a supplementary status.

The revised Copyright Law of 200 I was as a substantial update on the 1990 law, with only 13 of the original 54 articles remaining unchanged. It not only amended a number of inconsistencies and loopholes from the 1990 version, it also responded to international requirements, on one hand by legal instruments as TRIPS, the WCT and other treaties, and on the other hand by the development of digitalization and globalization. In its wake, a number of administrative regulations concerning management of amongst others publications and audiovisual products were updated as well. The Law was supplemented by Implementing Regulations in 2002, and some provisions were further clarified by administrative regulations and judicial interpretations. Amongst others, they clarified the thresholds of Art. 217 Criminal Law in 2004 at 50.000 CNY in business volume, 30.000 CNY in gain or 1000 copies for "serious" infringements and 250.000 CNY in business volume, 150.000 CNY in gain and 5000 copies for "huge" infringements. These values apply to individuals. When applicable

\footnotetext{
${ }^{322}$ Civil Procedure Law.

${ }^{323}$ Zhang, 2002.
} 
to "work units", these numbers need to be multiplied by three ${ }^{324}$. The thresholds concerning the number of copies were halved in 2007 to 500 copies $^{325}$.

Piracy remained rampant, however, and so did the resulting pressure of the media conglomerates on the USTR. In April 2007, the US launched a WTO case against China concerning intellectual property rights. The case contained two copyright claims: Article $4 \mathrm{CL}$ and the criminal enforcement thresholds. In January 2009, the WTO Panel ruled January Article 4 was not compliant with China's WTO obligations under Art. 5(I) Berne, as it constitutes a formality to copyright grant ${ }^{326}$. Concerning enforcement thresholds, the Panel ruled that thresholds in themselves may or may not comply with the requirements of Art. 6I TRIPS, as long as they fulfil all the conditions present in that Article. It then found that the US did not present enough evidence to prove that this was the case ${ }^{327}$, leaving the legality of these specific thresholds in limbo. The importance of this should not be overstated as in any case, the legal text could easily be upgraded to include the exact wording of the TRIPS article, and the effect of a lowered or deleted threshold in the fight against media piracy would likely be very low ${ }^{328}$.

Ironically, while DS362 found that some specific parts of China's copyright legislation did not comply with TRIPS requirements, it confirmed implicitly that the rest does. As can be deducted from the detailed nature of the case, the US has been very methodical in looking for holes in China's entire IP legislation. It can safely be assumed that if more possible inconsistencies existed, they would have been incorporated into the case. Moreover, the USTR has dubbed Chinese IP law as "largely satisfactory". The Chinese and American governments negotiated that the findings of the Panel would be executed by March 2010. Consequently, on 26 February 2010, the updated copyright law was duly promulgated, with Article 4 changed to "Copyright holders, when exercising their copyright, may not violate the Constitution and laws, and may not damage the public interest. The State implements supervision and management over publishing and dissemination of works according to the law ${ }^{329}$." Assuming this update is WTO compliant, this ensures that China's copyright legislation is basically consistent with its international commitments ${ }^{330}$. In other words, foreign pressure on copyright legislation as an anti-piracy strategy may have reached the end of the road. Moreover, another revision of the Copyright Law is currently in process. The main points of this update are on copyright management and trade, as well as on further confronting the effects of modern technology on the copyright sector.

Copyright-related legislation is now appearing in other laws. The first Tort Law of the People's Republic of China, promulgated in December 2009, contains provisions on copyright, together with other intellectual property rights, as a basic civil right to be protected, but does not bring many new substantial upgrades. However, it does

\footnotetext{
${ }^{324} 2004$ Judicial Interpretation on Criminal IPR Infringement; Ranjard, 2005.

${ }^{325} 2007$ Judicial Interpretation on Criminal IPR Infringement.

${ }^{326}$ DS362, Report of the Panel.

${ }^{327}$ DS362, Report of the Panel.

${ }^{328}$ Creemers, 2009.

${ }^{329} 2010$ Copyright Law.

${ }^{330}$ Although a number of niggles remain. For example, he Criminal Law articles on intellectual property infringement contain the test "with the aim of profit". This might therefore not include "all instances of wilful copyright piracy on a commercial scale" as provided in Article 6I TRIPS.
} 
foreground a number of procedural aspects that could improve the position of infringed parties in copyright disputes. First, it raises the position of civil litigants in respect of fines, by stating that if for one act, administrative or criminal liability is found together with civil liability; the civil liability should be compensated with priority ${ }^{33 !}$. Second, the tort law incorporates joint liability for aiding and abetting infringing activities ${ }^{332}$. As a result, it might very well be possible for landlords of premises where infringing activities take place, to be found liable for copyright infringement ${ }^{333}$, increasing rights holders' power when confronting infringement. Third, the Tort Law includes the protection of civil rights on the Internet, and defines user and ISP liability for internet-related infringement of rights. This converts the provisions of earlier Judicial Interpretations into law, and widens the scope of these provisions to include all civil rights included in the Tort Law, rather than only intellectual property rights.

\section{$\underline{\text { Related developments }}$}

Rulemaking work has not been limited to doctrinal copyright matters. Collective copyright management was regulated in the early Nineties, and the Music Copyright Society of China was set up ${ }^{334}$. After a long period of silence, collective management got a new boost the second half of the Noughties, by the foundation of the China Audiovisual Copyright Association (CAVCA) in $2008^{335}$ and the China Film Copyright Association (CFCA) in 2009. CAVCA mainly collects royalties for the use of audiovisual works in karaoke, and represents rights holders in litigation suits. It is also developing capacities to operate on-line. CFCA started collecting fees for display of film works on the Internet, flights and public transport on I January 20II. In support, the State Council published remuneration benchmarks for the broadcast of music works for the same time ${ }^{336}$. In 2010, NCA followed suit with standards for film display in certain spheres ${ }^{337}$.

Technological measures were considered as well. In 1996, regulations were promulgated that require all legally produced audiovisual media products to carry identification logos ${ }^{338}$. From 200 I onwards, disc reproduction plants had to etch SID codes on their products ${ }^{339}$.

As an indication of China's administration-based form of legal implementation and enforcement, a number of documents were promulgated which regulated the administrative punishment of copyright infringement ${ }^{340}$, including on the Internet ${ }^{341}$ and or-

\footnotetext{
${ }^{331}$ Article 4, 2009 Tort Law.

332 lbid.

${ }^{333}$ Wang, 2010.

${ }^{334}$ For a broad analysis of the function of collective management organizations, see Rechardt and Misonne, 2008.

335 Id.

${ }^{336} 2009$ Provisional Broadcasting Remuneration Rules.

${ }^{337}$ Film Work Copyright Collective Management Use Fee Collection Standards, NCA, 20I0, outlining remuneration standards for dissemination on the Internet, in Internet cafés, through video ondemand, in means of transportation, non-commercial local area networks and through rental.

3381996 Anti-Counterfeit Symbol Notice.

${ }^{339} 200$ I Audiovisual Product Regulations.

${ }^{340} 2003$ Administrative Punishment Rules, revised in the 2009 Administrative Punishment Rules.

${ }^{341} 2005$ Administrative Internet Protection Rules.
} 
dered a number of specialized anti-piracy campaigns ${ }^{342}$. Provisional rules for rewarding information on piracy were promulgated in $2006^{343}$. Moreover, the Supreme Court clarified a number of matters on legal implementation in a number of judicial implementations, dealing with matters such as the applicable law in Internet Copyright Disputes ${ }^{344}$, applicable law in criminal copyright cases $^{345}$, and the procedure for copyright cases in civil litigation ${ }^{346}$.

Furthermore, as the creative industries rose to the forefront of China's development policy after 2006, an increasing number of policy and regulatory documents relating to creative industry development explicitly included copyright protection. In 2006, in the framework of the $\mathrm{II}^{\text {th }}$ Five-Year Plan, a dedicated planning document for development of the cultural industries was included for the first time ${ }^{347}$. This emphasized strengthening of copyright protection as a necessity for further development. In 2008, the National IPR Strategy was published, with the aim to support the development of IP-intensive industries, amongst others by the institution of specialized intellectual property courts. A derivative of this Strategy, aimed at the radio and television industries, was published in $2010^{348}$. Currently, a law for the promotion of the film industry is in the legislative process, and this will include stronger copyright protection as a prime means of supporting further development of this industry. A draft for a law protecting intangible cultural heritage through intellectual property is also in the works. In these documents, we see that the new trend in China relates much less to substantive improvement of the IPR environment per se, and more to the instrumental questions of how these legal instruments can be applied to reach socio-economic objectives.

Conclusion: Limits of copyright law analysis and linkages to the corresponding chapters

Although China has created a copyright law system that conforms to international norms and commitments in a very brief time, there is evidence that it has turned into a legal irritant. Philosophically, it has been divorced from its Enlightenment basis and its connection to political and economic liberalization. Rather, the Chinese leadership turned it into an instrument for development, and as a reaction against foreign pressure in the trade area. Furthermore, piracy has remained rampant, even as the quality of copyright legislation has steadily improved. Hence, to explain piracy, it is necessary to step beyond the black letter of copyright law. On the one hand, it is necessary to analyze the broader media regulation framework, while on the other

\footnotetext{
${ }^{342}$ Such as the 2010 World Expo Campaign, the 2008 Olympic Games Campaign, 2004 Winter Campaign, 2002 Hero Campaign, etc. See also Chapter VI.

${ }^{343} 2007$ Provisional Reward Rules.

${ }^{344} 2000$ Internet Copyright Interpretation, revised in the 2003 Internet Copyright Interpretation and the 2006 Internet Copyright Interpretation.

${ }^{345} 2004$ Judicial Interpretation on Criminal IPR Infringement. This Interpretation amongst other established the controversial enforcement thresholds that were at issue in DS 362. Updated in the 2007 Judicial Interpretation on Criminal IPR Infringement Interpretation, lowering a number of the thresholds.

${ }^{346} 2002$ Civil Copyright Interpretation, stipulating amongst others that copyright cases must be heard at the Intermediate People's Court level or higher, that administrative enforcement may not stand in the way of filing civil suits, that copyright suits must be filed at the location of infringement, infringing copies or the defendant, and defining a number of terms present in the Copyright Law.

${ }^{347} 2006$ Cultural Five Year Plan.

${ }^{348} 2010$ Radio and Television IPR Strategy, based on the 2009 Audiovisual Industry Growth Opinions.
} 
hand, an analysis of whether and how the black letter provisions are implemented and enforced is indispensible.

\section{Limits of copyright}

In the West, copyright law is the prime legal framework governing the production and dissemination of audiovisual media products. In China, this is not the case. As the original wording of Article 4 and the original broad exemptions for state organs imply, and the institutional arrangement whereby the NCA essentially is a department of the GAPP, the increasing inclusion of copyright in cultural industry policy confirm, copyright is only one part of a broader regulatory framework surrounding audiovisual works which not only includes the traditional aspects of copyright, but also matters of industry and development policy, state power, censorship and other forms of media control. This has consequences for the legal position of piracy, as it is not considered only - or even primarily - as a violation of copyright law, but potentially of other laws and regulations, which in turn will have consequences for enforcement. Moreover, when piracy is a violation of media regulation, it is necessary to analyze whether and how regulation and policy create incentives for piracy. This regulatory structure will be analyzed in the next Chapter, while its political and economic roots will be the subject of Chapter $\mathrm{V}$.

\section{Limits of textual analysis}

In the West, copyright law is regarded as private law. It confers rights and obligations on private persons, and in case of dispute, a court will judge the case on the basis of the merits in combination with statutory and/or case law. In other words, parties to a dispute are faced with a relatively predictable situation and a stable base on which to argue their claims. Because of this, textual analysis is important, as it clarifies the state of the law, and creates predictability. If an analysis of Chinese law is limited to the text, it is implicitly assumed that the Chinese legal system can provide similar enforcement quality and predictability. This seems not to be the case, and hence, understanding piracy will also require an analysis of the Chinese enforcement systems to provide high-quality enforcement, consistency and predictability. This in turn raises complex questions on the incentives on State and private actors, different enforcement methods, capacity and governance. These will be addressed in Chapter VI. 


\section{Chapter IV: The mechanics of China's media control}

As already outlined in the Chapter II, the core characteristic of the present international copyright system is that it grants creators the exclusive right to exploit their works, or allow others to do so, in whatever way they choose. While there are legal boundaries to such exploitation, these tend to be limited in their scope and application. Furthermore, governments dispose of a number of policy tools giving financial support to certain media works outside of the market place, but in general these serve to broaden consumer choice, rather than limit it.

In China, this broad freedom of exploitation is absent. Instead, the audiovisual sector is subject to tight control by the Party-State. This limits the role of copyright significantly, as it decreases the kind of works that can be exploited, in which way, and by whom. Furthermore, the convoluted way in which the system works significantly raises transaction costs, further decreasing potential return on investment, and inducing convergence in the kind of works that are made. Where public support is available, it does not serve to maximize consumer choice. Rather, support is given to works that carry out the Party-State's message. As a consequence, copyright loses much of its significance as an ordering principle in the audiovisual product market. Furthermore, this Chapter will argue that by reducing the space for legitimate media, space for piracy is opened. .

While the rationale underpinning this system is analyzed in depth in the next Chapter, it should be kept in mind that the regulation of audiovisual media production and distribution serves a number of major policy objectives, which can be divided under two broad headings: public opinion control and development. The first stems from the political imperative in a one-party system to monopolize the public debate, as any space not controlled by the Party-State may become a rallying point for dissent or opposition. This monopolization goes further than simple censorship, which is barring information from the public sphere. In China, the objective of media control is broader: it is to create and maintain a vision of reality as conceived by the PartyState. This vision is not only limited to the more obvious political aspects, but also includes broader ethic and moral aspects.

The second springs from two consecutive needs: at first, the State wanted to offload the costs of media production and distribution by raising funds through introducing market mechanisms. In other words, making the cultural sector subject to market dynamics would make the propaganda machine self-sufficient, and more capable to spread the Party's message. By the mid-Noughties, however, the cultural industries became a crucial development point themselves, as a driver for raising the technological level of the Chinese economy, in an effort to move into higher value-added economic sectors. In turn, industrial development of the audiovisual sector supports the media control objective, as it broadens the communication channels between the rulers and the ruled, and allows stricter control over what the average Chinese citizen can see and hear.

For a long period of time, this method of managing the media sector was only aimed at domestic audiences. But following China's increased prominence on the international stage, increasing attention has been paid to using Chinese media in support of 
improving China's image abroad. Increasing China's "soft power" abroad has become an increasingly important objective for the media sector, with corresponding attention paid to making sure that the message foreign audiences receive, is the PartyState's message.

This chapter concentrates on the regulation of China's domestic entertainment media market. It is argued that these different objectives often are at odds with each other, and that in the aspiration to realize both sets of objectives, the wishes of the public - domestic and international - are insufficiently taken into account. In other words, the top-down structuring of China's media negates bottom-up demand, with media producers stuck in the middle. As a consequence, supply of legitimate products - remembering Wang Shujen's argument - is reduced both in range and in speed. It will be less able to fulfil public demand, leading to incentives for piracy.

The chapter contains three parts. First, the regulatory actors charged with governing the audiovisual media market are identified. The second part outlines the complex and intricate legal and regulatory system the Party-State has put in place. Third, the consequences of this system are discussed by analyzing how incentives are reshaped and costs are distributed because of this system.

\section{The institutional structure - the propaganda system}

The Chinese audiovisual media market is governed by a complex set of both Party and State actors, all with their own functional jurisdictions. In order to understand the internal functioning of and relationships between these actors, it is necessary to first take a slightly broader look at how China's administrative Party-State complex is structured. Due to its large size and population, China is politically not the monolith it is sometimes thought of as in the West. Rather, it is governed by a very complex administrative system with many vertical layers and horizontal departments, each controlled by a corresponding Party body ${ }^{349}$.

At the top political level, “leadership small groups” (lingdao xiaozu 领导小组) are often set up to coordinate work and policy in broad functional fields, in both Party and State hierarchies. These groups work between different ministries and organs, and thereby perform vertical as well as horizontal command between these groups. Such groups may be temporal, but some are more permanent. The more permanent groups become gateways through which the Party elite controls a functional area within the state system ${ }^{350}$. Control over these gateways means access to specific functions of power as well as power over specific policy areas. Because of this, jostling over access control is a relatively common occurrence.

Saich states however, that these gateways have declined in importance during the ' 90 s, except for party affairs and propaganda ${ }^{351}$. Below these small groups administrative units form the different "systems" of administrative policy implementation. These "systems", or xitong 系统 coordinate policy and monitor implementation. The word has a narrower and a broader definition. In the narrow sense, a xitong can refer to the totality of bodies and organs within the jurisdiction of a specific ministry; in

\footnotetext{
${ }^{349}$ Although it is the task of the State sector to realize Party policy, this policy can be distorted in many ways and in many places. Chapter VI, on enforcement, will go deeper into these issues.

${ }^{350}$ Saich, 2004, p. 122.

${ }^{351}$ Saich, 2004, p. 124.
} 
the broad sense, it defines a broader group of functionally related bureaucracies that cross individual ministry or industry lines. Lieberthal identifies 6 major xitong ${ }^{352}$ : party affairs, organization and personnel, propaganda and education, political and legal affairs, finance and economics and the military.

The problems of bureaucratic coordination on the local level result in tensions between the horizontal and vertical directions of administrative power, something the Chinese call "branches", tiao 条 and “areas" kuai 块. The dominance of one over the other will decide how central policy is implemented. A predominance of tiao means that the ministry on the national level is in form control over its lower-level entities. Power runs mainly vertically up and down the system and policy implementation is relatively uniform throughout the country. When kuai take the upper hand, the party committee at each local level is the decision -making authority in that area. The factor that most of all decides which dimension - vertical or horizontal - predominates, is the relationship between the different authority relationships, of which there are two sorts. "Leadership relationships" or lingdao guanxi 领导关系 are relationships in which one body can issue binding orders to a subordinate organ. "Functional relationships" or yewu guanxi 业务关系 exist between two bodies when one body can advise the subordinate organ, but not issue binding orders. In a kuai-based environment, the lingdao guanxi run between the administrative organs and the Party Committee of that level, with the higher-level administrative units exercising yewu guanxi, whereas in a tiao-based environment, it is the related administrative body of a higher level which exercises the lingdao guanxi, whereas the Party Committee sees its role relegated to exercise yewu guanxi ${ }^{353}$. These relationships can shift, based on factors such as the political climate, personal relations between incumbents, relative position of political bodies or institutions, etc., but they depend most of all on who has the power to appoint official posts and who holds the budget.

Audiovisual media policy is governed in the propaganda and education xitong, at different levels in the Party-State's administrative system. The most important Party institution is the Central Propaganda Department, which in turn maintains Party control over the State Council, the Ministry of Culture (MoC), the State Administration of Radio, Film and Television (SARFT), and the General Administration of Press and Publications (GAPP). These ministries each have a different function in the media hierarchy. This structure is replicated at the provincial and local level: every Party Committee contains a Propaganda Department, which is responsible to both the Central Propaganda Department and the provincial Party Committee. Similarly, People's Governments contain culture bureaus, radio, film and television departments and press and publications departments, which are answerable to both their higherlevel counterparts and the local Party Committee.

\section{Central Propaganda Department}

The CPD was first established in 1924, shut down during the Cultural Revolution, and re-established in 1977. It is a Party organ, rather than a State organ, and while it is not explicitly granted authority in law or regulation, has broad powers in deciding, defining and enforcing media censorship and control. It guides theoretical research and propaganda work nationwide, guides social and public opinion, has control over

\footnotetext{
${ }^{352}$ Lieberthal, 2003, pp. 219 et seq.

${ }^{353}$ Saich, 2004, pp. 122-124.
} 
all news outlets, and production of all spiritual products. It outlines all culture policy and directs legislation in this area ${ }^{354}$.

As one of the five commissions directly responsible to the Central Party Committee, the Central Propaganda Department carries the leading role in overseeing the translation of Party policy to propaganda guidelines and the transmission of these guidelines to the administration for implementation. It has been a continuous part of CCP organization since 1922, except for a brief period during the Cultural Revolution, when its duties were taken over by a comparable organ. At present, its chairman is Liu Yunshan (刘云山), who has been in charge since $2002^{355}$. He oversaw amongst others the propaganda concerning the implementation of the Three Represents ${ }^{356}$, harmonious society, and the scientific development view. He is also a member of the Politburo. Liu reports to Li Changchun (李长春), the fifth-ranked member of the Central Committee, who is chairman of the Central Spiritual Civilization Construction Guiding Committee (中央精神文明建设指导委员会 zhongyang jingshen wenming jianshe zhidao weiyuanhui) ${ }^{357}$, of which Liu is the vice-chairman.

Due to the CPD's secretive nature ${ }^{358}$, its internal organization is not publicly known. Shambaugh offers two descriptions, the first listing its constituent components as five directly administered units, two indirectly managed organizations and eight functional departments. The second description lists two offices and six bureaus ${ }^{359}$ :

I: General Office (bangongting 办公厅)

2: Policy and Law Research Office (zhengce fazhi yanjiushi 政策法制研究室)

3: Theoretical Bureau (lilun ju 理论局)

4: Propaganda and Education Bureau (xuanchuan jiaoyu ju 宣传教育局)

5: Press and Publications Bureau (xinwen chuban ju 新闻出版局)

6: Literary and Art Bureau (wenhua yishu ju 文化艺术局)

7: Training Bureau (peixun ju 培训局)

8: Cadre Administration Bureau (ganbu guanli ju 干部管理局)

The CPD supervises the Ministry of Culture, GAPP, SARFT, the Chinese Academy of Social Sciences, the Xinhua News Agency and a number of lower-ranked administrative organs at provincial and sub-provincial level. At the same time, senior State personnel are also appointed to the CPD, reinforcing the connection between Party and State. For example, past SARFT director Wang Taihua ${ }^{360}$ and current director Cai Fuchao ${ }^{361}$, Wang Chen, current director of the State Council Information Office $(\mathrm{SClO})$ and editor-in-chief of the People's Daily ${ }^{362}$, and Cai $\mathrm{Wu}^{363}$, Minister of Cul-

${ }^{354}$ CPD Website, visited on 24 January 20II, translation in annex. See also Brady, 2008, pp. 9 et seq.

${ }^{355} \mathrm{CV}$ available on http://politics.people.com.cn/GB/I024/64 I6890.html

${ }^{356}$ The Three Represents is a political theory developed in the Jiang Zemin era, which holds that the Party represents advanced social productive forces, the progressive course of China's advanced culture and the interests of the overwhelming majority of the people.

${ }^{357}$ Brady, pp. 25-26.

${ }^{358}$ Its premises on Chang'an Avenue in Central Beijing, opposite the Zhongnanhai leadership compound, don't indicate their occupant, the CPD website also does not contain address or contact details. Id. p. I5. See also Qiao, 2010, for an account of a visit to the CPD.

${ }^{359}$ Shambaugh, 2007, p. 37.

${ }^{360} \mathrm{CV}$ Wang Taihua.

${ }^{361}$ CV Cai Fuchao.

${ }^{362}$ CV Wang Chen.

${ }^{363}$ CV Cai Wu. 
ture are all CPD vice-directors. However, the CV of Cai Fuchao - appointed as SARFT director, CPD vice-director and party secretary in March $201 \mathrm{I}$ - indicates a new sort of movement. He started out as an economic journalist in the Beijing Daily, and worked his way up through the ranks until 1998, when he left his post of viceeditor to pick up a post in the Beijing municipal Propaganda Department, and pursue Master and Doctoral degrees in media studies. By 2008, he led the Beijing Municipal Propaganda Department, and had become a vice mayor. To a certain extent, Cai Fuchao's background may indicate a slight shift of appointment policy. His colleagues in the media administration have experience in Party-political bodies, rather than in professional practice. His predecessor, Wang Taihua, had made his career in the provincial government of Anhui, reaching the consecutive top posts of governor and party secretary, rather than in the capital. Cai Wu, of the Ministry of Culture, has a background in the Communist Youth League and the International Department of the Central Committee. Liu Binjie, who leads the GAPP, also came through the Youth League, and then spent some time in Sichuan, ending up heading the provincial propaganda department ${ }^{364}$. It remains to be seen whether Cai Fuchao remains an outlier, or whether his appointment signals a slight shift to increased expertise of staff at the central level.

The CPD exercises its authority directly through different means. As indicated earlier, it influences all policies, laws and regulations in its sphere of competency. However, in keeping with the policy to keep the Party in the background ${ }^{365}$, these are all promulgated through State institutions. Directly, it has authority over the Party cells that are mandatorily present in all lower-level State institutions, but also in large media outlets. The members of these cells therefore are not only subject to administrative punishment, but also to Party discipline ${ }^{366}$.

\section{The State media system}

\section{State Council}

The State Council is the highest organ of State administration, and is the executive organ of the National People's Congress, China's legislative body. It governs the various central-level ministries, administrations and commissions that form China's administrative structure, decides on their powers, personnel allotment and internal structuring. As such, it sometimes acts as the ultimate arbiter in turf battles between the different administrations, such as the Ministry of Culture and GAPP spat over on-line gaming responsibilities. In the audiovisual media sphere, it promulgates central policies and regulations that cross the boundaries of constituent ministries, and regulatory documents with high political priority.

\section{Ministry of Culture}

The Ministry of Culture was founded under the Central People's Government immediately upon the Communist takeover in October 1949, and moved to the jurisdiction of the State Council after its foundation in 1954. In 1970, the Central Committee decided to close the Ministry, replacing it with a culture group in the State Council. It was re-established in 1975, during the $4^{\text {th }}$ NPC, and merged with a number of smaller culture bureaucracies in 1980.

\footnotetext{
${ }^{364}$ CV Liu Binjie.

${ }^{365}$ Saich, 2004, p. 121.

${ }^{366}$ More about this in Chapter VI on enforcement.
} 
Until 2008, it had significant powers in the distribution of audiovisual media. It guided film distribution and screening, which was transferred to SARFT. Its responsibility over audiovisual product wholesale, retail, rental, screening and import management was transferred to GAPP ${ }^{367}$. In both cases, this ended a situation whereby SARFT and GAPP were responsible for the production segment of audiovisual media distribution, and the Ministry of Culture for the downstream part, which led to bureaucratic wrangling, as the Ministry of Culture would derive much more income from overseeing the media market.

However, the Ministry of Culture is still important, as it has a leading role in coordinating industry-wide policies and plans, has powers in on-line distribution of network music and cartoons, Internet café licensing and is responsible for foreign cultural exchange. In the field of enforcement, it has the authority over the comprehensive culture market enforcement teams that were created by consolidating the administrative enforcement staff of the different propaganda xitong bureaucracies ${ }^{368}$.

\section{State Administration of Radio, Film and Television}

SARFT is a State Council ministry-level entity, which presides over China's radio, film and television sector. It was formed in 1986 as the Ministry of Radio, Film and Television, through the merging between the Ministry of Culture Film Bureau and the Ministry of Radio and Television, and demoted to Administration rank in 1998.

It has administrative jurisdiction over the entire Chinese radio, film and television industry. Its current president is Cai Fuchao, who is also a deputy director of the CPD. Concretely, it is responsible for drafting policies, laws and regulation for radio, film and television propaganda, drafting technical standards, organizing public services and projects, managing entry into and exit from the system, examining content and quality of all audiovisual products, supervising broadcast and transmission, guiding foreign cooperation, and leading CCTV and National Radio ${ }^{369}$.

\section{General Administration of Press and Publications.}

In 1949, administrative authority over press and publication matters was vested in a News Administration and a Publications Administration. These were abolished successively in 1952 and 1954, and until 1982, administration of publications was subject to a number of structural changes. In 1982, a "Publications Undertaking Management Bureau" was instituted in the Ministry of Culture, which became the independent State Publications Administration in October 1986. At the beginning of 1987, it was renamed into Administration of Press and Publications and into General Administration of Press and Publications in 200I. In 1986, the National Copyright Administrations was established as a department under the publications administration. This situation still persists, with the NCA internally being treated as a GAPP department, while externally, it operates under its own name. Its current head is Liu Binjie, and it has powers and responsibilities that parallel those of SARFT, in the press and publications area. It drafts policies development plans, laws and regulations, oversees implementation, supervision and administrative law enforcement, examines content of publications, Internet publications and on-line games, is responsible for coordinating saohuang dafei activities against obscene and illegal publications, regulates the publica-

\footnotetext{
${ }^{367} 2008$ Ministry of Culture Structure.

${ }^{368}$ Id.

${ }^{369} 2008$ SARFT Structure.
} 
tions market, and is responsible for copyright management work, foreign publications and copyright-related exchange and import ${ }^{370}$.

\section{The rules of media control}

With the exception of copyright and advertising, China's audiovisual media sector is not governed by law, but by administrative regulation. This subtle difference indicates the control the Party-State wants to maintain over the media sector. Under administrative regulation, the primary means of enforcement will be vested within the administrative organs. Moreover, any law or law revision must be approved by the NPC, whereas the administrative organs retain a free hand for any change they would like to make in their administrative regulation. Furthermore, they remain responsible for interpreting the regulations.

Audiovisual media regulation is complex and multi-layered. It is controlled by both Party and State documents, with the State documents being widely published and open. The internal policy-making processes, which mostly take place in or through consultation with the CPD, as well as the internal Party documents, remain hidden. The State documents can be classified hierarchically. At the top, there are the guiding opinions, plans and policy documents outlining the direction media regulation will take in the future. These outline objectives, list tasks and policy steps, and as such form the basis for the drafting of further regulations. At the next level, there are the “Management Regulations” (guanli tiaoli 管理条例). These are directly promulgated by the State Council. In the field of audiovisual media, the most important are the Radio and Television Management Regulations, the Film Management Regulations and the Audiovisual Product Management Regulations. On the basis of these, the individual ministries and administrations then formulate more detailed management rules and regulations, each further detailing and interpreting the rules of higher-level regulations. At the lowest step, there are the Notices (tongzhi 通知), that are used to deal with ad hoc issues, publish administrative decisions, or bring attention to enforcement of specific regulation.

Moreover, further orders are distributed internally or orally, and local administrative entities are often entitled to draft regulations for their specific jurisdictions as well. Also, the Party has its own parallel command structure that reaches into all administrative entities, but also all media enterprises. As a result, it is difficult for potential actors to get a comprehensive overview of the state of the legal field concerning audiovisual media. In the words of Anthony Fung, there is no "Blue Book" for the media $^{371}$, which would contain all information a budding entrepreneur would need to set up shop.

In part, this signals the struggle the administration is facing in adapting to continuous processes of reform and evolution, against the background of technological innovation and globalization. More than anything else, the continuous fine-tuning, tentative progression and occasional tightening demonstrate how the Party-State endeavours to reconcile often mutually conflicting goals related to economic development, control and resistance against domestic and foreign challenges to its predominance. Furthermore, the ethically conservative media administration - which still considers all

\footnotetext{
${ }^{370} 2008$ GAPP Structure.

${ }^{371}$ Fung, 2007, p. 8.
} 
audiovisual media as being politically significant - is still vacillating in how to cope with programmes or films solely meant for entertainment purposes, rather than political propaganda, the increasing presence of racy content, addressing social and moral issues explicitly in television programmes, and allowing for increased audience participation.

The Party-State has come to recognize a number of these problems. Around the time of WTO accession, SARFT outlined a legislation plan aimed at broadly improving the regulatory structure for radio, film and television, although this remained limited to administrative regulation ${ }^{372}$. In 2004, the Radio and Television Development Opinions already called for the swift promulgation of a Radio, Film and Television Transmission Guarantee Law, a Radio and Television Law and a Film Law ${ }^{373}$, which would lay down a framework of legal principles in the media sector. However, at the time of writing, none of these propositions have come to fruition. New legislative measures may be afoot. In the 2010 Rule of Law Plan, SARFT identified a number of issues to be addressed. Predominantly, it called for the construction of a clean, corruption-free and service-oriented government that conducted administration to the law, in order to fully support the further development of radio, film and television. However, the Opinions do not seem to address a number of systemic issues with media governance ${ }^{374}$, such as corruption, bottlenecks in the media structure and the insecurity that comes with broad State discretion. Rather, they opt for incremental change, for example by calling for increased legal study by legal cadres, formulation of better work plans, revising present regulations on the basis of scientific knowledge, abolishing regulations no longer necessary, improving performance in administrative services and procedures, improving law enforcement capacity, and applying newer technology. These Opinions, aiming to reconcile government accountability and openness on the one hand and maintain Party leadership and control on the other, do not address the deep paradox between both of these objectives, but only scratch the surface of the fundamental tensions present in China's media sector today. These tensions are endemic to the way in which China's Party-State is constructed, the media sector may be one way in which China's reform trajectory is becoming increasingly "trapped".

Substantively speaking, administrative regulation covers the complete audiovisual media value chain, constructing an intricate web of prohibitions, obligations, procedures and responsibilities. While many observers tend to concentrate on content censorship - the removal of information from the public sphere - this system also contains product, process and personnel licensing measures, investment and ownership restrictions, screening and broadcasting rules, subsidies and in-kind benefits. Moreover, additional safeguards were put in place for foreign products, including denial of trading rights for foreign enterprises, import and screening restrictions for foreign products, foreign investment and ownership controls and foreign personnel controls. Conversely, rules have been instituted in recent years to attract foreign capital and expertise in areas where this was lacking in China.

\footnotetext{
${ }^{372} 200$ I Radio, Film and Television Legal System Rules.

${ }^{373} 2004$ Radio and Television Development Opinions, Para. 5.

${ }^{374} \mathrm{~A}$ number of these issues will be analyzed in depth in the next chapter.
} 


\section{Content restrictions}

For reasons further analyzed in the next chapter, the Party-State exercises strict control over the content of audiovisual media work. While this control is less strict than it has been during some periods in the past - especially the Cultural Revolution - relaxation is not a given, and the Hu-Wen leadership has notably tightened control over media outlets. This is especially clear during politically tense periods, such as the anniversary of the Tiananmen incidents, but also the Olympic Games and the Shanghai World Expo, when control is strengthened and preventive measures taken.

In regulatory documents, content control appears as a prerequisite for obtaining licensing, subsidies or material support. But it does not work in one direction. Instead of only using censoring criteria to remove certain content categories from the public sphere, the regulatory documents also proactively encourage works to be made that reflect the views of the Party-State, which are then granted subsidies, facilities, favourable screening treatment and other benefits.

The list of prohibited content has been relatively stable over the years, but has been expanded to become at the same time more concrete, but also more blurry, as the propaganda administrations have sought to create incentives to move as far into the safe side as possible.

The 1982 Audiovisual Product Regulations stated that

"All audiovisual products carrying anti-China, anti-communism, anti-socialist and pornographic or obscene content, as well as audiovisual products engaging in religious propagation activities, shall be confiscated without exception. Import shall not be allowed of audiovisual products of which the content is extremely unhealthy ${ }^{375}$."

In 1985, the Obscene Goods Prohibition Regulations reiterated that:

I, Of all sorts of obscene goods, regardless of whether or not being for the purpose of making profits, import, production (including duplication), sale and broadcast must all be strictly forbidden.

II, The scope of prohibited obscene goods is: videotapes, audiotapes, films, television programmes, slides, photographs, images, books, periodicals and transcripts concretely describing sexual acts or undisguisedly propagating sexual and obscene images, toys and appliances printed with this sort of image as well as obscene medicines and obscene appliances ${ }^{376}$.

More detailed regulations on punishment for trading in these goods were promulgated in 1990377. In 1986, the Ministry of Public Security published detailed guidelines for films and television programmes containing public security-related themes ${ }^{378}$. Also, the special status of films with revolutionary or history themes was confirmed in 1990, when it was confirmed these films needed extra examinations ${ }^{379}$.

By that time, the Ministry of Radio, Film and Television had introduced a rating system, whereby some films containing sexual, criminal or violent content, but also "social deformation phenomena" could be designated as "unsuitable for children" (shao'er bu yi 少儿不宜) ${ }^{380}$. Unfortunately, it turned out that marking films with this label significantly increased their attractiveness, leading to situations where unrated

\footnotetext{
3751982 Audiovisual Product Regulations, Para. 10.

3761985 Obscene Goods Prohibition Regulations, Para. I, II.

3771990 Obscene Goods Punishment Decision.

3781986 Public Security Film Questions.

3791990 Revolutionary and History Drama Notice, Para. I-III.

3801989 Film Classification Notice; 1989 Unsuitable for Children Rules.
} 
films were marketed as unsuitable for children to boost attendance numbers. Consequently the scheme was dropped quietly by the mid-Nineties ${ }^{381}$.

The first wave of broad media regulations in the early Nineties brought more structure to content regulation. An excerpt of the regulations for import of foreign television dramas ${ }^{382}$ (1990) gives a fascinating insight in the mindset of the leadership at that point, listing respectively desired criteria, criteria for editing, and criteria for prohibiting circulation.

Article 2: Under all the following circumstances, broadcast may be permitted:

(I) having vigorous and solemn subjects, and with advanced thoughts,

(2) giving first place to entertainments, and are able to shape the audiences' sentiments, and have aesthetic appeal, and conform to the moral standards of our country, and have a certain educational significance;

(3) disseminating scientific knowledge, enlightening people's intelligence;

(4) realistically re-enacting history, and reveal the inexorable laws of social development;

(5) beneficial to the youth's healthy growing up in the aspects of virtue, knowledge, body and beauty, etc.;

(6) of which the theme thought can be accepted, and have a relatively high artistic value, and are able to provide exquisite art appreciation and learning to the audience.

Article 3: All those falling under the circumstances listed in Article 2, but having the following content in specific plot details, may be broadcasted after deletion or revision:

(I) male-female kissing and fondling scenes of relatively long duration not having a close connection with the story plot;

(2) scenes directly showing male or female genitals and sexual activities'

(3) scenes with frontal exposure of female body below the breasts (including the breasts) not having a close connection with the story plot;

(4) scenes meticulously explaining criminal activities;

(5) strongly stimulating scenes of acrobatic fighting, murder, violent activities with excessive bloodiness and brutality;

(6) scenes propagating superstition, supernatural beings, and horror;

(7) scenes inserting product advertisement in the whole programme;

(8) other scenes that my lead to social harmful effects.

Article 4: Under all the following circumstances, broadcast is prohibited:

(I) opposing the socialist system, opposing communism and China, dividing China, defaming and discriminating the Chinese;

(2) those having themes of propagating bourgeois values of "human rights" "democracy", "liberty", "equality".

(3) embellishing capitalist oppression, plundering of backward ethnicities and the rise of nations;

(4) embellishing superpower choking the independence of the peoples of the Third World and interference in domestic political affairs;

(5) propagating ethnic, sexual and geographic discrimination;

\footnotetext{
${ }^{381}$ Zhang, 2008, pp. 27-30.

${ }^{382} 1990$ Foreign television Programme Import Regulations. See also 1990 Foreign Television Drama Import Standards.
} 
(6) propagating obscenity and pornography, falling under the content listed in the "Provisional Regulations Concerning Establishment of Obscene and Sexual Publications" promulgated by our country's press and publications administration.

(7) playing up criminal acts such as murder, brutality, drug use, gambling, visiting of prostitutes, prostitution, etc.,

(8) publicizing youth criminality;

(9) publicizing superstition and calamities;

(I0) publicizing and advocating religious supremacism;

(I I) displaying destruction of the natural world and the ecological balance, ravaging, catching and killing of valuable and rare wildlife and overdeforestation;

(I2) having mediocre themes and crude artistry;

(I3) possibly leading to international, ethnic or religious controversies;

(I4) violating our country's Constitution, laws and regulations.

The 1993 Film Examination Regulations included a shorter list, including content violating laws, harming State interest, social stability, major State policies, social public moral norms, violating science, having sexual or violent aspects, and violating the spiritual and mental health of youth ${ }^{383}$. The highly politicized nature of this list was toned down a bit for the 1994 Audiovisual Product Regulations. These Regulations prohibited content that endangers the unity and territorial integrity of the nation and sovereignty of the State; content that incites the division of the ethnicities and undermines national solidarity; content that divulges State secrets; content that propagates obscenity and superstition or glorifies violence; content that slanders or insults others; other content of which the publication and dissemination are prohibited by State provisions ${ }^{384}$. This list was to be the blueprint for the definitive blackletter list still present in regulation today. In 1995, a similar list was included in management rules for television drama co-productions ${ }^{385}$.

The 1996 Film Regulations added content harming the security, honour and interests of the State ${ }^{386}$ and the following 1997 Film Examination Regulations and the Radio and Television Management Regulations expanded the moral scope of the list by including improper sexual content, feudal superstitions and a positive depiction of crime, murder and violence. ${ }^{387}$ Moreover, Article 10 of these Regulations included guidelines on content to be edited out of films, including sexual, violent and superstition-related content ${ }^{388}$.

The 1990 list was reused in the 1998 Television Drama Distribution Permit Notice $^{389}$, including the procedural requirement of licensing. The 1999 Television Drama Examination Regulations condensed the 1997 Film Examinations prohibited content list $^{390}$ as well as the 1997 Film Examination Regulations provisions on editing and revision $^{391}$. The list was furthermore included in the 2000 Television Drama Regula-

\footnotetext{
3831993 Film Examination Regulations.

3841994 Audiovisual Product Regulations.

3851995 Television Drama Co-Production Rules.

3861996 Film Management Regulations, Article 24.

3871997 Film Examination Regulations, Article 9, 1997 Radio and Television Regulations, Article 32.

${ }^{388}$ Id., Article 10, see Annex.

3891998 Television Drama Distribution Permit Notice, Para. II.

3901999 Television Drama Examination Regulations, Article 10.

${ }^{391}$ Id., Article II.
} 
tions $^{392}$, the 2001 On-demand Broadcasting Rules and 2001 Hotel On-demand Broadcasting Rules ${ }^{393}$. Also in 200I, the Film Management Regulations laid down the definitive list of prohibited content ${ }^{394}$ :

(I) content that violates the basic principles of the Constitution;

(2) content that endangers the unity of the nation, sovereignty or territorial integrity;

(3) content that divulges secrets of the State, endangers national security or damages the honour or benefits of the State;

(4) content that incites ethnic hatred or discrimination, ethnic unity, or infringes upon ethnic customs and habits;

(5) content that propagates evil cults or superstition;

(6) content that disturbs the public order or destroys the public stability;

(7) content that propagates obscenity, gambling, violence or instigates crimes;

(8) content that insults or slanders others, or infringes upon the lawful rights and interests of others;

(9) content that endangers public ethics or excellent folk cultural traditions;

(10) other content prohibited by laws, regulations or State provisions.

The same list is present in the 2002 Audiovisual Product Regulations ${ }^{395}$, the 2003 Foreign Satellite TV Rules ${ }^{396}$, the 2004 On-demand Radio and Television Regulations $^{397}$, the 2004 Television Drama Examination Regulations ${ }^{398}$, the 2004 Radio and Television Business Management Regulations ${ }^{399}$, the 2004 Internet Audiovisual Programme Dissemination Rules, ${ }^{400}$ the 2006 Film Script (Outline) Filing, Film Management Regulations ${ }^{401}$, the 2006 Audiovisual Products Wholesale, Retail and Rental Management Rules ${ }^{402}$, the 2007 Internet Audiovisual Programme Regulations ${ }^{403}$, the 2009 Internet Content Management Notice ${ }^{404}$ and the 2009 Reproduction Regulations ${ }^{405}$. The 2010 Television Drama Content Regulations added a last item to the list, namely content endangering the lawful rights and interests of minors or harming the physical or mental health of minors ${ }^{406}$.

The 2009 Internet Content Management Notice ${ }^{407}$ furthermore included provisions on content that should be edited out of films, including amongst others content distorting Chinese and foreign culture and history, derogating historical heroes and the Army, display of criminal methods, religious extremism, superstition, large natural or man-made catastrophes, sexual content, scary content, content violating privacy, abuse of animals, content promoting a "negative view of life" and content violating

\footnotetext{
${ }^{392} 2000$ Television Drama Regulations, Article 22.

${ }^{393} 200$ I On-demand Broadcasting Rules, Article 9, and 200 I Hotel On-demand Broadcasting Rules, although the latter does not include the provision on racial, sexual and regional discrimination.

${ }^{394} 200$ I Film Management Regulations, Article 25.

395200 I Audiovisual Product Regulations, Article 3.

${ }^{396} 2003$ Foreign Satellite TV Rules, Article 12.

${ }^{397} 2004$ On-demand Radio and Television Regulations, Article 2I.

${ }^{398} 2004$ Television Drama Examination Regulations, Article 20.

${ }^{399} 2004$ Radio and Television Business Management Regulations, Article 22.

${ }^{400} 2004$ Internet Audiovisual Dissemination Rules, Article 19.

4012006 Film Script (Outline) Filing, Film Management Regulations, Article I 3.

4022006 Audiovisual Products Wholesale, Retail and Rental Management Rules, Article 4.

4032007 Internet Audiovisual Programme Regulations, Article 16.

${ }^{404} 2009$ Internet Content Management Notice, Para. I.

4052009 Reproduction Regulations, Article 3.

${ }^{406} 2010$ Television Drama Content Regulations, Article 5.

4072009 Internet Content Management Notice, Para. II., see annex.
} 
the spirit of laws and regulations. Moreover, works with sensitive content also need to be approved by relevant administrative authorities.

Apart from the minimum standards laid out in this notice, SARFT also intervenes on an ad hoc manner. In 2004, for example, television dramas with judicial and gangster themes could only be broadcasted after 23.00. In 2007, the SARFT reacted against popular talent show Super Girl, by requiring that "mass-participation"-type programmes are "positive and upward, healthy and elegant, cheerful in body and mind, moulding noble sentiments, reflecting a correct world view, view of life and value system ${ }^{408 \text { " Later }}$ that year, these programmes were prohibited ${ }^{409}$. In 201 I, SARFT made headlines when it prohibited, amongst others, television dramas containing time travel ${ }^{410}$.

\section{Licensing}

In short, content requirements are the central pillar of the media control regime. They outline what is desired and what is prohibited. To implement content policies, the Party-State maintains control over access to and presence in the media system through licensing procedures. The evolution of licensing followed the structural transformation of the media sector, whereby operators increasingly became subject to market conditions and regulatory frameworks. Licences became present in some of the most sensitive sectors - such as import of audiovisual products, first, and in 1994, the Central Committee ordered the establishment of licensing programmes in all segments of the audiovisual media market ${ }^{4 \prime \prime}$.

Licenses can apply to the product, the process and personnel involved. In other words, a film, television programme or song must be licensed itself, produced by a licensed company, sometimes even by people who are licensed to do so. This monopoly over market access gives the Party-State tremendous space and discretion for interference in media production and distribution. To a certain extent, and allowing for technological progress, this echoes the royal charters and privileges for printers and books mentioned in the second chapter. The essential policy mechanism at work is the same: companies are allowed to bring their product to market if they commit to cooperate with the regime, and hence are co-opted into supporting the Party-State's political interest. The significant difference is that new technologies have allowed for quicker communication and new media products, borders have become more porous and it is much easier to learn and obtain what is available abroad.

\footnotetext{
${ }^{408} 2007$ Mass Participation Programme Notice.

${ }^{409} 2007$ Make-over and Sex Change Prohibition Notice.

${ }^{410} 2011$ March Television Drama Notice.

4 II 1994 Market Improvement Notice.
} 


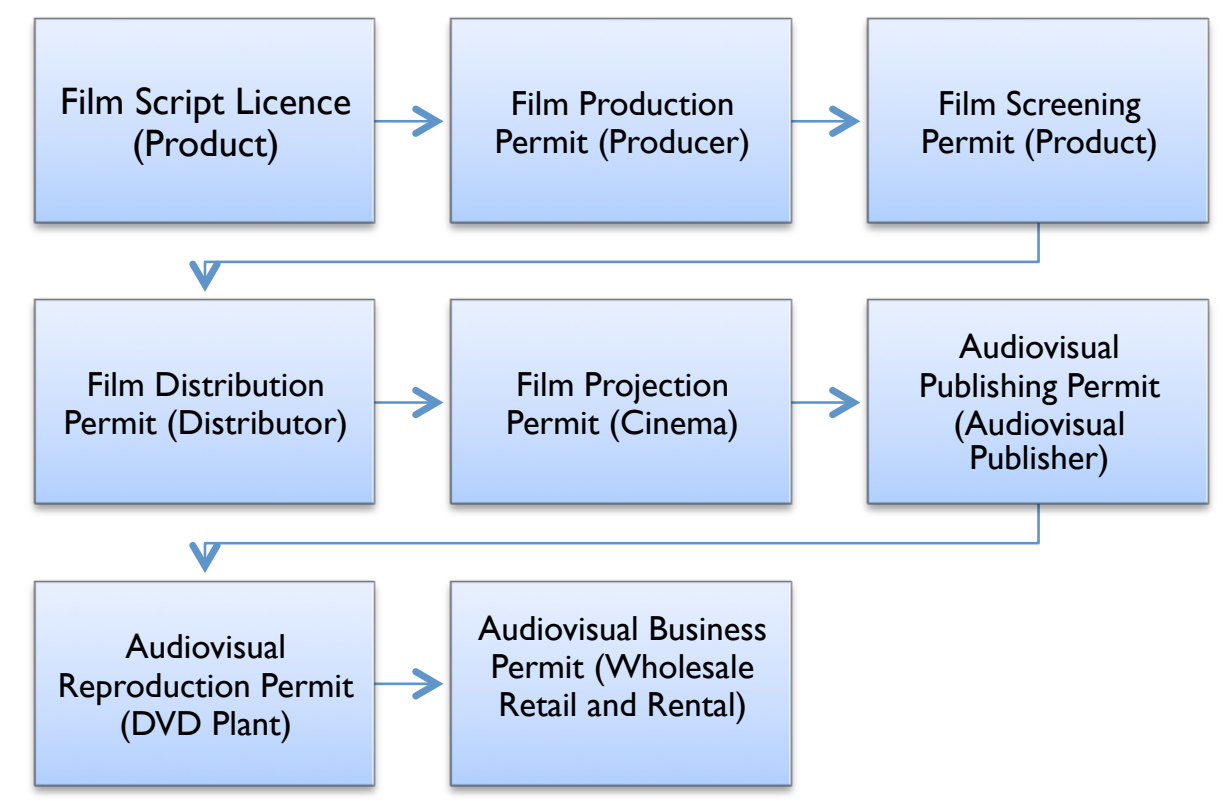

Figure 3: 8 licences are required before a film can be made, shown in a cinema, and be distributed on a DVD.

However, this creates problems of its own: as any form of policy enforcement in China, enforcement of media control runs into de facto federalism problems, which materialize as principal-agent problems. The centralization of nearly all final licensing powers over production and dissemination at the central level, where provincial and lower authority have little or no deciding role to play, is partly aimed at avoiding deviant behaviour by lower-rank organs.

\section{Film}

During the planned economy phase, film production distribution was organized along administrative lines: film studios and distribution companies were de facto departments of the culture departments, and the China Film Corporation was in charge of distribution nationwide ${ }^{4 / 2}$. When the reforms gained speed, access to audiovisual media production, import and distribution became increasingly regulated through administrative approval and licensing. In other words, a command sector ruled through administrative fiat increasingly became a marketized sector, governed through administrative regulation, reflecting the Dengist slogan of "ruling the country according to the law".

On I August 1979, the State Council approved the Ministry of Culture and Ministry of Finance "Instruction Report Concerning Reforming Film Distribution and Screening Management Systems". The implementation of this document brought about the renewal and development of film distribution and screening networks, which had broken down during the Cultural Revolution. The document not only confirmed the leading position of China Film Company in film distribution and screening, but also regulated financial aspects. Seventy per cent of distribution income would go to CFC, 30\% remained with the provincial-level film companies. Of that proportion, $20 \%$ was paid in taxed, while $80 \%$ could be retained by the local film distributor ${ }^{413}$.

\footnotetext{
${ }^{412}$ Zhu, 2002, pp. $907-908$.

413 Tang, 2009.
} 
Furthermore, the document called for paying attention to both urban and rural population, and for both deepening and improving the film distribution and screening structure. In 198I, the 198I Imported Film Management rules also confirmed the China Film Company monopoly over importing films for public showing ${ }^{414}$, and its subsidiary China Film Co-Production Company for foreign-related film coproduction.

In June 1993, the first open film examination regulations were promulgated. The Ministry of Radio, Film and Television decreed it would set up an examination organ, which was given ten days to write an examination opinion per film. Films were to be examined for content quality and technological quality ${ }^{415}$. In January 1995, the Film Shooting Regulations instituted ${ }^{416}$ that all scripts had to be approved by the local provincial-level Propaganda Department. Simultaneously, social groups could be named as joint producer for films in which they invested, but these had to be made in cooperation with approved film studios. Three weeks later, a permit system for film distribution and screening was introduced. Distribution permits were issued at the central and provincial level, screening permits at all government levels ${ }^{417}$. At the same time, an annual examination system was implemented. Film distributors and cinemas would be evaluated on their performance in implementing film policies and regulations, supporting State funding projects, legality of distributed films, and meeting minimum quantity targets set by the State ${ }^{418}$. Those not meeting conditions could have their permits revoked.

The 1996 Film Regulations comprehensively codified requirements for film production companies. These had to have suitable articles of associations, a well-defined scope of business, suitable funding, premises and equipment, and a satisfactory organizational structure ${ }^{419}$. Furthermore, they had to submit a list of their funding sources. The maximum period before an approval decision had to be taken was limited to I 80 days, and where successful, a "Film Production Permit" would be granted. Again, any significant change to the script required further approval, and postproduction work had to be completed in PRC territory. After further examination, films would be granted a "Film Screening Permit", which permitted for domestic distribution, as well as for export. Film import was limited to approved work units, without further approval criteria. This essentially meant that, import work units would be State-picked. Approval would also need to be sought for organizing international film events. For establishing a distribution work unit, approval had to be sought at the provincial level, or at the central level, where interprovincial activities were intended. Establishment of screening work units had to be approved at the county-level. But not only sector access was regulated: approval also had to be obtained for terminating a film distributing work unit.

\footnotetext{
${ }^{414}$ Other governmental departments were allowed to import foreign films for "work purposes" with State Council or local People's Government approval. It would not be unimaginable that these powers would have resulted in foreign film copies ending up on the black screening market.

415 I993 Film Examination Regulations.

4161995 Film Shooting Regulations, Para. I.

4171995 Film Distribution and Screening Regulations, Article 4.

${ }^{418}$ Id., Article 8, see Annex.

${ }^{419} 1996$ Film Management Regulations, Article 8.
} 
In the beginning of 1997, the examination procedure for films was further clarified and institutionalized ${ }^{420}$. MRFT would set up a film examination committee and a reexamination committee. Film would be submitted to the examination committee, which would rule on the matter within fifteen days of receipt. In case a film was not approved, the re-examination committee would look into the matter again. Also, MRFT provided a legal basis for withdrawing films from the market "under special circumstances.

The 200I Film Regulations aimed to shorten film production business approval time, by delegating the responsibility for preliminary approval to the Provincial level, and lowering the maximum time limit to 90 days $^{421}$. Also, approval for closing down of a film production work unit became required. It introduced the possibility for independent entities to apply for a one-off film production permit. These were, however, barred from foreign-related cooperation, but were allowed to produce films abroad upon SARFT approval. Foreign organizations and individuals were not permitted to engage in film production.

Furthermore, approval requirements were introduced for processing foreign films, with the added proviso that all films, copies and other materials had to be transported out of the country after completion. Also, distribution and screening approval limits were fixed at sixty days.

In 2003, in an effort to address calls from the United States pressing for broader market access in China, a second distribution company, Huaxia, was established and granted approval to distribute imported films. However, the ownership of Huaxia is divided among 19 State-owned or State-operated media groups, and supposed large competitor China Film Group is its second largest shareholder ${ }^{422}$. China Film also maintains the import monopoly, implying that this is more a window-dressing operation rather than a systemic change.

The 2004 Film Access Regulations yet again revised matters. New film production companies could not directly apply for a film production permit, but were obliged to produce their first film under a one-off permit. While foreign investment became permitted, the Chinese side had to have obtained either a long-term production permit or two short-term production permits. Approval procedures were instituted for the establishment of film technology companies. While the Regulations encouraged establishment of film distribution companies, this encouragement was limited to domestic films.

\section{Television}

Television in China was quite a limited phenomenon until 1982. There were one central and only about 30 television channels nationwide, which fell under the responsibility of either central or provincial governments. The sector was governed through internal administrative orders - the so-called "red-headed document" (红头 文件 hongtou wenjian) ${ }^{423}$. However, in 1983, the newly-established MRT took a num-

\footnotetext{
${ }^{420} 1997$ Film Examination Regulations.

${ }^{42 !} 200$ I Film Regulations.

${ }^{422}$ China Daily, 2003.

${ }^{423}$ Guo, 2003, p. 8.
} 
ber of steps to expand television network coverage. A four-tiered structure, following the structure of local government, was established, and local governments were encouraged to establish television stations based on local needs ${ }^{424}$. Very quickly, however, the appetite of these local television stations for the large income potential of advertising led to problems of insubordination and broadcast of pirated television programmes. A year later, production of entertainment programmes by the lowestlevel television stations was prohibited ${ }^{425}$. Nevertheless, China's television sector expanded dramatically during the Eighties.

The first steps towards a more systematized television licensing structure were taken in the wake of the Tiananmen incident. Unsurprisingly, the first area to be regulated concerned the programmes considered most sensitive: news programmes and television dramas. The 1990 Television Drama Production Permit Regulations outlined that a permit would be required for producing television dramas. A longterm permit and a temporary permit, valid for one programme series, would be made available. Long-term permits required higher personnel capacity, equipment capacity and financial strength, while for a temporary permit, an approved script had to be submitted. Any drama produced by a non-approved work unit would be considered an illegal publication. For identification purposes, producers were required to list their Permit number in the titles of every episode. Any producer who would lose the capacities required for a Permit, would also lose the Permit, as would those producing "inferior" programmes and having "chaotic internal management". This Permit had provincial validity, and work units shooting outside of their regions, had to first notify the administrative departments at their destination ${ }^{426}$. Also, a special permit was required to produce television dramas with major historical or revolution themes ${ }^{427}$

In February 1994, the Television Programme Import and Broadcast Regulations stipulated that only MRFT-appointed work units were allowed to import foreign television dramas, that had to seek approval for all imported programmes ${ }^{428}$. strengthened rules over television drama planning made it obligatory for all television drama producers to submit annual theme production plans to the China Television Art Committee ${ }^{429}$. By that time, county-level television station establishment applications were no longer approved, and in 1995, no more new television stations were permitted at all ${ }^{430}$.

Also in 1995, the regulations on television drama permits were revised. These strengthened the requirements for obtaining a long-term permit by including a minimum production amount of four drama programmes or two drama series per year. A number of requirements for a temporary permit were also strengthened. The final responsibility for all permits was raised from the provinces to the central level, and an extra approval process was instituted for television dramas concerning revolu-

\footnotetext{
${ }^{424}$ Huang, 2003, p. 30.

${ }^{425}$ Guo, 2003, p. 10.

4261990 Television Drama Production Permit Supplementary Regulations.

${ }^{427} 1990$ Revolution and History-Themed Television Drama Notice.

${ }^{428} 1994$ Television Drama Import and Broadcast Regulations, Article 4.

4291994 Provisional Television Drama Theme Rules.

${ }^{430}$ Guo, 2003, p. 10.
} 
tionary and history themes. Lastly, television drama producers became subject to annual examination, the failing of which would lead to permits being revoked.

A related ministerial decree regulated the broader question of licensing television programme producers. Here the conditions were, amongst others, that a higherlevel controlling work unit would be responsible for annual production planning and conducting content examination. Private participation in this sector was not permitted.

In 1996, existing television channels and broadcast structures became subject to increasing scrutiny. With the aim of rationalizing the broadcast structure, the Central Committee and State Council stipulated that all new broadcast and transmission mechanisms needed to be approved, all unauthorized channels needed to be transformed into relay stations or regularized ${ }^{43 !}$.

A year later, the State Council promulgated the first comprehensive regulations on radio and television management ${ }^{432}$. Given the great political sensitivity of radio and television media, the provisions this document contained on licensing were correspondingly detailed and restrictive. Concretely, only government entities were allowed to apply for permission to establish radio and television stations. Approval had to be sought to change names, broadcasting logos, or programming scope, and to withdraw from the sector. Furthermore, these Regulations contained specific provisions on infrastructure management. Radio and television infrastructure was subject to central planning. MRFT would be in charge of allocating frequencies and bandwidths, as well as authorizing broadcast stations, relay stations, microwave stations and satellite upstream stations. Localities were only permitted to construct one radio and television network, signal jamming was explicitly prohibited, and approval had to be obtained to set up terrestrial satellite receiving equipment. Furthermore, radio and television stations were only permitted to broadcast approved programmes, produced by approved production entities or by themselves. Standard Putonghua spoken and written language was compulsory, as was broadcasting according to pre-approved programme schedules. Lastly, approval was necessary for organizing television programme trading.

In the wake of these Regulations, all radio and television producers were obliged to re-register, with all applications having to be approved at the provincial level, and television drama producers being approved by the MRFT ${ }^{433}$. The television production permit system was reformed shortly after. All old permits were cancelled and new permits would be issued to organs meeting the new conditions of the 1997 Regulations. For dramas, two new permits were provided: an A-level permit, replacing the old long-term permit, and a B-level permit valid for only one drama ${ }^{434}$.

In 2000, the renewed Television Drama Management Regulation included new provisions on requiring approval to go abroad for filming, and to participate in foreignrelated television exhibitions. A year later, export approval procedures were further clarified, as all important matters pertaining to media landing abroad, and negotiation

\footnotetext{
4311996 Strengthening Press and Publications Management Notice, Para. II.

432 I 997 Radio and Television Regulations.

4331997 Radio and Television Re-registration Notice.

${ }^{434}$ I 998 Radio and Television Permit Notice.
} 
with foreign media, had to be approved by SARFT. Local channels negotiating time slots, channels or establishing stations abroad had to obtain provincial Propaganda Department and SARFT approval, as well as "foreign propaganda department and radio and television bureau" approval ${ }^{435}$.

At the end of 200I, in response to China's WTO accession and a Central Propaganda Department document ${ }^{436}$ calling for broad reform in a number of audiovisual media sectors, a flurry of trial rules were promulgated. Amongst these, the Radio and Television Access Implementation Rules reiterated the previous Permit rules, but emphasised that programme producers needed a "professional controlling work unit", and that legal representatives in this sector needed appropriate professional qualifications.

A new flurry of television regulations came along in 2004. Most importantly, SARFT issued a new decree on radio and television programme production management. These Regulations changed the official requirement of a diploma for legal representatives into a requirement to submit their $\mathrm{CV}^{437}$.

There were new examination regulations for television dramas, making the previous trial rules definitive. These established application procedures for television drama planning and project establishment, with a decision period of fifty days. Furthermore, examination was broadened to examination of foreign drama scripts and engaging foreign personnel. At the same time, the provisions on content to be edited out were dropped ${ }^{438}$.

Rules were laid down for on-demand cable television broadcast and on-demand video in hotels and restaurants. In these rules, provision of all these services became subject to licensing, and a list of $3 \mathrm{I}$ foreign satellite television channels for broadcast in three-star and more hotels was made ${ }^{439}$. The period of approval of a programme production business - still at provincial and central level - was now established at twenty days ${ }^{440}$. A year later, a joint notice of the CPD and a number of Ministries indicated that after these $3 \mathrm{I}$ channels, no other channels would be admitted in principle ${ }^{441}$.

Provisional regulations were made for the establishment of Sino-foreign television production joint ventures. Wary of foreign influence, the Regulations provided that the Chinese side had the power to appoint the legal representatives, and that there must be one Chinese shareholder. Furthermore, these companies were obliged to use independent logos, so they could not be associated with their foreign investors. The period of approval - by both SARFT and MOFCOM - was limited to twenty

\footnotetext{
435200 I "Marching Out” Rules, Para. IX.

436 "Central Propaganda Department, State Administration of Radio, Film and Television and General Administration of Press and Publication Some Opinions Concerning Deepening Press and Publications and Radio, Film and Television Sector Reform", internal document, not translated. Hereafter referred to as Document 17.

4372004 Radio and Television Business Management Regulations.

4382004 Television Drama Examination Regulations.

${ }^{439}$ Outside of this scope, broadcast of foreign television stations in China remains nearly completely prohibited, with the exception of Rupert Murdoch's Star Television, which has landing rights in Guangdong Province, and a number of joint ventures with Chinese television stations. See also next Chapter.

4402004 On-demand Radio and Television Rules.

4412005 Cultural Product Import Rules.
} 
days each. These joint companies could not produce news programmes, and were obliged to dedicate two thirds of their annual production to Chinese-themed radio and television programmes ${ }^{442}$. A corresponding Implementation Notice warned that this did not mean that joint companies could engage in any way in running television channels ${ }^{443}$.

2010 saw new Regulations on television dramas. Evolutionary rather than revolutionary, they shortened the examination and approval period for television dramas from fifty to twenty days ${ }^{444}$.

\section{Audiovisual Products}

The first regulations on audiovisual products came out in 1982. In these, it was stipulated that any audiovisual product sold on the market had to be published by a Stateapproved publisher, and that industrial and commercial work units were prohibited from engaging in audiovisual publication. In order to become an audiovisual publisher, approval had to be sought with MRT, and in the case of local work units, after obtaining approval from the provincial broadcasting department. Establishment of audiovisual publishers was prohibited at lower than provincial levels. In order to obtain approval, applicants had to show that they had corresponding technological capacity, preserving quality of the products, define their publishing scope and provide annual publication planning - which had to be approved separately. But more importantly, they were required to support the Four Cardinal Principles ${ }^{445}$ and the mission statement provided for them ${ }^{446}$. But also, the lawful rights and interests of authors and performers were to be safeguarded, on the basis of MRFT payment methods $^{447}$. Furthermore, these Provisional Regulations also stipulated that audiovisual production plants had to be approved in the same way as publishers, and had to show they had a good relationship with audiovisual publishers, had to pledge not to engage in "private reproduction and sale" and to produce high-quality products. Exporting work units had to be approved by MFRT and MOFTEC. The publication of foreign-related co-productions remained the province of State-approved work units, and all projects and agreements had to be approved by the relevant ministries, or local People's governments ${ }^{448}$. The import of foreign audiovisual products for commercial purposes was prohibited ${ }^{449}$. Import for "work purposes" by other work units would be handled by State Council departments, and the MRFT would handle import for broadcasting purposes itself. Also, the China National Publications Import and Export Corporation (CNPIEC), was made responsible for checking imported publications.

When import of Hong Kong and Taiwan music products became allowed in 1984, all already approved audio publishers could apply for MRT import permission ${ }^{450}$. In

\footnotetext{
4422004 Joint Venture Radio and Television Production Regulations.

4432005 Joint Venture Implementation Notice, Para. (4).

${ }^{444} 2010$ Television Drama Content Regulations.

445 The principles of (I) upholding the socialist path, (2) upholding the democratic dictatorship of the people, (3) upholding CCP leadership and (4) upholding Marxism-Leninism and Maoism.

4461982 Audiovisual Product Regulations, Para. 5, see Annex.

447 Id. Para. 6.

${ }^{448}$ Id. Para. 9.

${ }^{449}$ Id. Para. 10.

450 I 984 Hong Kong and Taiwan Import Report.
} 
1985, the Videotape Distribution Management Rules ${ }^{451}$ reiterated that China Film Company remained the sole importer and publisher of foreign videotapes ${ }^{452}$, while all distribution and screening companies were permitted to distribute them.

In 1986, as a response to increasing levels of videotape piracy, the Audio and Video Market Rectification Notice ${ }^{453}$ emphasized also that all videotape retail and rental outlets needed approval from local radio, film and television departments. This included existing distributors wishing to sell or rent their distributed products. In order to aid identification, all audiovisual publications needed to clearly indicate the publisher's name and logo. Also in 1986, clearer rules became available for videotape publishing ${ }^{454}$ and distribution, with China Film Company remaining the prime publisher and distributor. Lower-level publishers wanting nationwide distribution of their products were encouraged to do this through CFC. Income sharing rules were provided for, with CFC deciding how much the lower level distribution companies would receive. Furthermore, lower-level film companies were encouraged to participate in drafting regulations, and conduct supervision over film screening points, echoing the close relationship of CFC and governmental institutions at the central level ${ }^{455}$.

During the Eighties, videotape regulations did also not only address videotapes for home use. The new technology was also used for public film screenings. In I985, according to the Commercial Video Notice ${ }^{456}$, there were more than thirty thousand screening work units, screening more than two thousand programmes. However, the Notice also reported the showing of significant numbers of obscene videos, or "unhealthy" martial arts films. The leadership was not happy with this, and would like to see this replaced with "outstanding, healthy programmes loved by the masses". As a consequence, private persons were prohibited from engaging in video screening. Similarly, commercial video screenings by work units and other organizations were prohibited. Only propaganda and culture work units were permitted to organize video screening, and could only charge ticket prices in order to cover costs, not to make commercial profit. In 1986, a related Notice ${ }^{457}$ argued for caution in approving more video screening points, as the leadership preferred film over video as a method of public screening.

In 1992, with the post-Tiananmen Incident retrenchment in full swing, a clean-up operation of the audiovisual publishing sector was ordered in response to the growing problem of piracy, publication of obscene videos, the preponderance of (illegally) imported films in cinemas and screening stations, and the perceived lowering of moral standards for the purposes of profit. All audiovisual work units in which these problems were present, would be closed ${ }^{458}$, and all other audiovisual publication, repro-

\footnotetext{
451 I985 Film Videotape Distribution Rules.

452 Videotapes, at that time, were mostly used for screening, rather than home entertainment. Hence, there was no conflict with the CNPIEC mandate, which dealt with audiovisual publications in the nonfiction sphere.

453 I 986 Audiovisual Rectification Notice.

4541986 Provisional Audio and Video Publishing Work Regulations.

455 I 986 Provisional Film Videotapes Distribution Management Rules.

4561985 Commercial Video Notice.

457 I 986 Video Tape Supply Notice.

4581992 Audiovisual Compression and Rectification Notice, see Annex.
} 
duction, distribution and screening work units had to re-register with the central authorities.

The 1994 Audiovisual Product Management Regulations were the first of a new batch of more comprehensive and systematized State Council regulations. It clarified the licensing requirements and procedures for audiovisual product publishers, and limited the term of response to 90 days from the receipt of application. Requirements included conformity to the audiovisual product development plan, lawful articles of association, having a well-defined scope of business, having funding, equipment, personnel and expertise for the envisaged business. Any significant business change required re-approval. Similarly, all works had to be approved of themselves, and could only be brought onto the market after receiving the "Audiovisual Product Distribution Permit" ${ }^{459}$.

These Regulations also included provisions on reproduction work units, who had to conform to similar conditions as publishers, and subject to the same approval time limit. Reproduction entities were not allowed to edit product content. Downstream, wholesalers, retail, rental and screening outlets also had to apply for an "Audiovisual Product Wholesale Business Permit" an "Audiovisual Product Retail Business Permit", an "Audiovisual Product Rental Business Permit", or an "Audiovisual Product Screening Business Permit", respectively. These permits would be issued at the provincial level, apart from the retail and rental permits, which were issued at the county level. Related regulations on Sino-foreign television drama co-productions reiterated that MRFT approval - a "Television Drama (Video) Co-Production Permit"- must be obtained, and that the period of examination was limited to sixty days. The Audiovisual Product Regulations also shortened the approval period for audiovisual product publisher and reproduction plant establishment from ninety days to sixty days, and permitted independent work units to apply for approval to produce audiovisual products. It clarified import procedures and limited the approval period to 30 days. Approval procedures for wholesale and retail operations were simplified, by instituting a single "Audiovisual Products Dealing Permit", which would be applied for at the provincial or county-level, depending on the business scale of the applicant.

In 1999, a wider list of approved audiovisual publishers was promulgated. CNPIEC remained the only enterprises allowed to import finished audiovisual products, but a number of other State-owned publishing enterprises were permitted to publish certain categories of foreign products, including "literature and art, cultural and socialtype audiovisual products ${ }^{460}$,"

In 2004, the Audiovisual Product Publishing Rules were revised. Also here, the approval time was lowered from ninety days to sixty. It became obligatory to use the China Standard Audiovisual Product Code, and publication planning and reporting requirements were clarified. These Rules also contained expanded provisions on reproduction outsourcing, including the use of State-provided outsourcing letters. Records of all outsourcing would need to be kept for two years. In 2005, the CPD imposed a moratorium on new approvals of cultural import companies ${ }^{461}$.

\footnotetext{
4591994 Audiovisual Product Regulations.

4601999 Importing Qualification Notice.

46I 2005 Cultural Product Import Rules, Para. IV.
} 
In, 2009, the GAPP promulgated the first dedicated regulations for reproduction of tapes and discs ${ }^{462}$. The push for sector organizations in charge of self-regulation also reached reproduction. Furthermore, reproduction work units became subject to a licensing scheme, although the requirements were quite low. GAPP would examine reproduction of read-only discs, within a period of 60 days. Recordable discs and tapes were delegated to the provincial level. Furthermore, detailed provisions on reproduction equipment were included. For example, import of second-hand reproduction equipment was prohibited. All new reproduction equipment had to be examined and approved by the administrative department, with GAPP in charge of approving read-only compact disc reproduction equipment. Reproduction equipment belonging to companies being found guilty of piracy would be sold to other companies. All other transactions concerning reproduction equipment had to be registered with the provincial-level press and publications department.

\section{Internet}

China's first connection to worldwide information networks became was realized in 1987, but it would take until the second half of the Nineties until the Internet became a widespread phenomenon connecting the large cities throughout the countries. In 1997, China had more than 290.000 computers connected to the Internet, with about 640.000 users, growing to 1.47 million computers and 4 million users in 1999. It says something about the leadership's perception of this new phenomenon that already in 2000, the first regulations on audiovisual programme dissemination through the Internet were promulgated.

These Regulations instituted a permit system for on-line audiovisual dissemination. Apparently, the leadership was concerned enough about the open nature of the Internet to restrict distribution rights of the two categories deemed most sensitive news programmes and film or television dramas - to radio and television work units already having at least three years of experience in that sector. Programmes to be broadcasted could only be chosen from a special catalogue, compiled by SARFT. Enterprises would be subject to annual examination. Failure to meet required targets would result in loss of the permit. Also, work units engaging in on-line media dissemination were obliged to set up internal examination mechanisms, and State organs were to provide "public supervision reporting mechanisms ${ }^{463}$ ". The related Implementation Rules clarified the earlier Rules, and limited the scope of news and drama programmes that could be broadcasted online to programmes that had been broadcasted to provincial or central television stations.

Shortly after, the Internet café business came into focus, as problems related to unhealthy content and Internet criminality became increasingly worrisome. A clean-up campaign of all Internet surfing venues was mandated, and all venues had to re-apply for registration ${ }^{464}$. At the same time, audiovisual product retail points were also targeted, with the aim of closing offending businesses.

The Internet Audiovisual Dissemination Management Rules were slightly revised in $2003^{465}$. Operators were now obliged to establish yewu guanxi with the propaganda

\footnotetext{
4622009 Duplication Management Rules.

4632000 Provisional Internet Radio and Television Regulations.

${ }^{464} 200$ I Culture Market Rectification Notice, Para. (I).

${ }^{465} 2003$ Internet Audiovisual Dissemination Management Rules.
} 
departments of their district. These Rules, like the 2000 Rules, were drafted sloppily, and a reworked, clearer version was promulgated the year after.

In the 2004 Rules $^{466}$, the differentiation in programme categories on the basis of content was dropped, and the permit system revised. Permits would cover certain activities divided over three categories: which programmes would be offered, whether these were self-made or relayed, which kind of receiving terminals would be used, and which kind of network would be employed. Any kind of foreign participation was prohibited, and existing radio and television stations were encouraged to start offering content via the Internet. The approval conditions, apart from economic, personnel and equipment requirements, also included that applicants must set up content examination and broadcast management systems, and provide inspection and monitoring plans. SARFT would be in charge of all approval dossiers, albeit only after preliminary examination at the local level where local applications were concerned. Furthermore, content providers were required to maintain data on all broadcasted programmes for thirty days, could not relay foreign website content, and had to provide not only for different supervision methods as in the 2003 Regulations, but also had to make sure that supervisory authorities had signal input connections.

Another Internet reform came in 2007 with the Internet Audiovisual Service Regulations $^{467}$. These not only included provisions on dissemination of programmes, but also on new national-scale social organization. This sector organization was to be responsible for self-discipline, and act as interlocutor for the sector with the leadership. Furthermore, the maximum examination and approval period was fixed at 60 days over two stages: twenty days at the provincial level and forty at the central level. The duration of dissemination permits were lengthened from two years to three. The Ministry of Information Industry was brought into the system as well, as the new regulations made it an obligation to not only have a SARFT permit, but also a MII telecommunication business licence. Lastly, new provisions covered the relationship between audiovisual providers and network operators.

In conclusion, it is hard to overstate the importance of administrative licensing as a mechanism to control access to the media production and distribution sectors. This creates tremendous barriers to entry, and increases transaction costs. Furthermore, the State gives itself considerable discretion in the licensing process. This is exemplified by the "safeguard provisions" present in every licensing process. For company licensing, these usually outline that companies have to conform to the "State plan, distribution and policies" in their area. Furthermore, entities need to fulfil quantitative and qualitative targets production entities in order to maintain their licences, which are subject to annual examination. It follows that it can be safely assumed that this will induce a certain level of convergence towards the centre of the audiovisual media spectrum, rather than creating incentives for "hitting line balls ${ }^{468}$ ".

Nonetheless, the leadership does seem to be aware of the problems caused by licensing, and recently introduced a number of small measures to simplify procedures and broaden access. Since 2006, television drama productions employing Hong Kong of Macau personnel no longer need to be approved at the central level, only at the

\footnotetext{
4662004 Internet Audiovisual Dissemination Management Rules.

4672007 Internet Audiovisual Service Regulations.

${ }^{468}$ Meaning to push the envelope of what is permitted. CMP Dictionary.
} 
provincial level ${ }^{469}$. In 2010, the "One Filing, Two Examinations" system for films experimented with a streamlined licensing procedure for domestic film projects ${ }^{470}$. Similarly, part of the examination responsibilities for television dramas were moved to the provincial level. This does probably not indicate, however, that the leadership aims to abolish significant parts of the licensing system, or wants to move to a completely more localized system. Rather, it should be considered as tweaking the machines, as the objective of licensing centralization is balanced with procedural matters - the rapidly expanding production capacity of China's media means that centralized licensing may become a bottleneck - and governance perception matters.

\section{Ownership and investment}

In 1978, the complete audiovisual production and distribution value chain was and State-run. However, as the reforms deepened, it was realized that these media would need to rely increasingly on revenues from market operations to earn their keep. However, at the same time, the Party-State did not want to surrender this valuable political tool, but rather, increase its efficacy in steering public discourse. The following structural transformation of China's media sector, including the transformation of cultural “undertakings" (shiye 事业), non-profit work units operated by the State for societal objectives into commercial enterprises (qiye 企业), aimed to serve these two goals: developing the industry commercially, while also strengthening its political function.

Essentially, this meant that cultural companies needed to become self-supporting if they were to survive. However, they were not given complete freedom to decide their own commercial policies, but are still beholden to Party-State interests. Also, not all undertakings were transformed into enterprises completely. Rather, a number of media companies were split into an editorial side and a commercial side. The editorial side would be responsible for all matters related to product content, while the commercial side would be responsible for bringing the product to the market. The limited feedback possible between the consumer base and the producers this engendered, limited this sort of company's profit prospects greatly ${ }^{471}$. Furthermore, dependence on market means did not mean the severance of the direct link between media outlet and Party-State. All media enterprises still contain Party cells, which are supposed to follow propaganda discipline. Similarly, State institutions remain the outright owners or controlling shareholders of all important outlets, with private capital limited to the fringes of the sectors and foreign capital even more restricted. Ownership of and investment in media companies have been tough questions for the Party-State. While the apparent benefits of non-State capital inputs into the industry are clear, the leadership remains wary of introducing another potential locus of authority into a sector it would like to keep monopolized. The idea of this locus being foreign would seem even more dangerous. Nonetheless, development objectives have pushed the leadership into a progressively larger acceptance of private and foreign capital in the audiovisual media sector.

\footnotetext{
${ }^{469} 2006$ Supplementary Provisions.

${ }^{470} 2010$ Film "One Filing, Two Examinations System" Announcement.

${ }^{471}$ Fischer, 2008, pp. 184-185.
} 
A first mention of attracting private capital into the media sector came with the 2000 Film Sector Reform Opinions ${ }^{472}$. In this document, SARFT stated that, while film production entities needed to be controlled by State capital, private or foreign capital could be attracted as well. Distribution entities (except China Film Group) could also attract domestic private capital, but no foreign investment. Cinemas and other screening entities could attract domestic and foreign private capital, with domestic capital having the controlling share, and subject to administrative approval ${ }^{473}$. A week later, the 2000 Television Drama Regulations were promulgated. These stated that the State encouraged "all circles of society to participate in television drama production through investment or financial aid methods" ${ }^{\text {"474 }}$, with specific rules to be worked out by SARFT. The 200I Film Management Regulations contained similar provisions with respect to film production and cinema construction ${ }^{475}$

In October, 2000 the Ministry of Culture, MOFTEC and SARFT jointly published the 2000 Foreign Cinema Investment Regulations. These permitted foreign investors to establish cinemas and cinema chains in China, but subject to a number of conditions. Apart from an economic value test, foreign capital had to be brought into a joint venture ${ }^{476}$, where foreign capital could not exceed $49 \%$, and which could not exceed 30 years of duration. Illustratively, the joint venture could not use the brand name of a foreign media or cinema company ${ }^{477}$. Furthermore, any such undertaking would be subject to the catchall provision of "conforming to local cultural facility deployment and planning", and an administrative approval process by the three Ministry-level entities involved. This process was also required in cases where the shareholding structure of the JV changed. Finally it was reiterated that foreign-invested cinemas should apply by Chinese laws and regulations, and only screen licensed films ${ }^{478}$. The 2003 revision of these Regulations, although raising the required registered capital from I million CNY to 6 million, dropped the naming restrictions, and indicated a number of pilot cities (Beijing, Shanghai, Guangzhou, Chengdu, Xi'an, Wuhan, and Nanjing), where foreign participation up to $75 \%$ was allowed ${ }^{479}$. They also included a special provision on Hong Kong and Macau investors ${ }^{480}$. However, as Anthony Fung reports, the push to attract more foreign expertise and capital into the cinema sector backfired. Chinese audiences and Western business culture didn't mix well, there were staff conflicts and communication issues between Western and Chinese sides. By 2005, the joint projects ended, and Chinese majority ownership had become the norm again ${ }^{481}$.

In 2004 , domestic investment in the film sector became firmly regulated with the promulgation of the 2004 Film Entry Regulations. These stated that domestic enterprises - excluding foreign-invested companies - could establish film production companies, subject to SARFT approval. Foreign enterprises could again only establish film

\footnotetext{
4722000 Film Sector Reform Opinions.

4732000 Film Sector Reform Opinions, Para. VII.

${ }^{474} 2000$ Television Drama Regulations, Article 19.

${ }^{475} 200$ I Film Regulations, Articles 17 and 4I.

${ }^{476} 2000$ Foreign Cinema Investment Regulations, Article 3. Minority investment in cinemas was one of the two GATS commitments that China made in its WTO Services Schedule.

477 Id, Article 4.

${ }^{478}$ Id, Article 8.

${ }^{479} 2003$ Foreign Cinema Investment Regulations, Article 3.

${ }^{480}$ Id, Appendix I.

${ }^{48 I}$ Fung 2007, pp. 73-78.
} 
production companies through joint ventures. Significantly, the Regulations explicitly granted private film production companies the same treatment as State-owned companies. Moreover, joint ventures were also permitted for film technology companies. The Regulations were less open where distribution was concerned, with only domestic companies being permitted to establish companies distributing only domestic films. Domestic capital was encouraged to invest in child film distribution and screening, rural film screening and cinema upgrading. The Regulations also reiterated that film import and export remained exclusive territory of SARFT-approved companies $^{482}$. In 2004, foreign access to the radio and television programme production sector became authorized, albeit under strict restrictions and the obligation to enter into joint ventures, as already indicated above ${ }^{483}$.

In 2005, the State Council announced further decisions on private capital entering the cultural sector. Amongst others, private capital would be encouraged to invest in film and television drama production and dissemination, film and television broadcast technology development and application, cinemas and cinema chains, rural film screening and retail of audiovisual products ${ }^{484}$. Moreover, it would also be encouraged to invest in export of cultural products and services, and performance venues. However, except for performance venues, private capital could not have a controlling share. Furthermore, private investment became allowed in compact disc reproduction, and could invest in minority shareholding of radio and television station music, technology, sports and entertainment programming as well as cable television networks. Finally, private capital was allowed into on-demand programming in certain high-level hotels. The State Council also reiterated equal treatment of private and public enterprises. Nonetheless, the Opinions explicitly maintained the prohibition of private investment in news agencies, radio and television stations, broadcasting platforms and satellites, satellite ground stations, cable backbone networks, etc.; furthermore, private capital was not allowed to operate audiovisual programme services online, nor to import foreign media products.

Similar Opinions concerning foreign capital were put forward by the Ministry of Culture, SARFT, GAPP, NDRC and MOFCOM three months later. Foreign investors could establish wholly-owned recordable CD production plants, and have a minority share in companies reproducing read-only discs and audiovisual product retail, the latter with the proviso that the State's power to examine content would not be prejudiced, and with the exclusion of films. Foreign investors were equally allowed to hold minority shares in cinema exploitation, film technology and audiovisual product distribution. Hong Kong and Macau investors were allowed a somewhat wider berth. Foreign investment remained prohibited in radio and television stations, transmission, programme production and broadcast, film production, Internet culture operations, film import and distribution and audiovisual publishing. Again, all investment would be subject to government approval by the correct entity at the correct level. More specifically, the Opinions warned lower-level People's Governments not to exceed their powers in attracting foreign investment, and that foreign investment in

\footnotetext{
4822004 Film Entry Regulations.

${ }^{483} 2004$ Joint Venture Radio and Television Production Regulations.

${ }^{484} 2005$ Private Capital Decisions, Para. I.
} 
certain crucial sectors should be reported to the correct State Council ministry and the $C P D^{485}$.

The Cultural Five-Year Plan of 2006 took the above investment ideas a step further, and called for "Supporting social forces to establish risk investment and guarantee companies, providing services for small and middle cultural enterprise development. ${ }^{486, " ~ B u t ~ a t ~}$ the same time, it also planned to "foster and develop a batch of State-owned or Statecontrolled large-scale cultural enterprises and enterprise groups with solid strength, making them become the leading force of the cultural market and strategic cultural industry investors $^{487}$." Furthermore, the plan reiterated the priority of rural investment and the role of capital markets in developing the culture sector.

As for foreign capital, the 2007 Foreign Investment Catalogue only permitted a few investment possibilities in the media sector. Under the "restricted" category, it included the printing of publications and distribution of audiovisual products (except films) and cinema construction with the obligation of a Chinese-controlled joint venture; radio and television programme production projects and film production projects, with the obligation of cooperation with a Chinese partner; and production of satellite broadcasting reception equipment. The Catalogue prohibited investment in production and import of audiovisual products, operation of radio and television programme production companies, network audiovisual services, video show companies and radio or television stations, channels and transmission ${ }^{488}$. The only aspect of audiovisual media listed in the "encouraged" category, was the development and manufacture of different kinds of media hardware.

The role of investment was touched upon briefly in the 2008 National IPR Strategy. In 2009, the Audiovisual Industry Opinions indicated the importance of investment in the "marching out" strategy for audiovisual products ${ }^{489}$. Later that year, the Ministry of Culture made a first catalogue for domestic investment in sectors under its jurisdiction $^{490}$, echoing the Foreign Investment Industry Catalogue. Again in 2009, the Cultural Industries Promotion Plan called for further centralization of State investment in the culture sector. In 2010, a more detailed plan for the press and publication sector outlined the requirement for more sophisticated investment mechanisms for further development, as well as the controlled entry of private capital. The Film Industry Development Opinions contained similar provisions, as well as - again - requirements for further investment in the rural regions.

The evolving regulatory regime surrounding public, private and foreign capital investment in the audiovisual media production and distribution sphere displays a continuous search for balance between providing finances for industrial development and achievement of certain social objectives on the one hand, and maintaining PartyState control over which products enter the media market and the way in which they are brought to the public on the other. The Party-State recognized that the production of higher-quality films and television programmes, first for the domestic

\footnotetext{
4852005 Foreign Capital Opinions, Article 10.

${ }^{486} 2006$ Cultural Five-Year Plan, Para. (19)3.

${ }^{487}$ Id. Para. (20)3.

${ }^{488} 2007$ Foreign Investment Catalogue.

${ }^{489} 2009$ Audiovisual Industry Growth Opinions, Para. XIII.

4902009 Cultural Industry Investment Catalogue.
} 
market and later also for export, required significant amounts of capital. The strategy they took shows a graduated policy, whereby State capital would maintain control over central points in the distribution channel, while domestic private capital could invest in more peripheral industries, and foreign capital remains limited to some borderline sectors, where access to foreign technology was important to achieve certain goals, such as in cinema development.

\section{Screening restrictions}

Apart from managing media content, there are also a number of restrictions concerning exactly when certain works can be broadcast, and there are specific quota and unwritten barriers for screening foreign content, both on television and in cinemas.

For starters, all television stations are obliged to broadcast CCTV's daily news broadcast and weather forecast. This not only causes significant advertising income lost to these television stations, it also means that they cannot offer a competing programme right in the middle of the prime time. Moreover, there are strict limits on the proportion of foreign content that can be shown in total, and during the "golden hours" (from 18.00 until 22.00). In the 1990 Foreign Television Programme Management Regulations ${ }^{491}$, this proportion was fixed at twenty per cent in total, and fifteen per cent during the golden hours. By 2000, it had become prohibited to broadcast foreign or co-produced television dramas between 19:00 and 21:30492, which was extended to 22:00 in 2002. ${ }^{493}$. Furthermore, the 2000 Notice prohibited the broadcast of the same television drama on more than three provincial-level television stations ${ }^{494}$.

The most famous screening restrictions concern foreign cinema films. Before 1994, import of foreign movies was a discretionary affair of the Ministry of Culture, and was usually limited to Communist propaganda films. In order to boost attendance numbers for the cinema sector, SARFT allowed the screening of 10 foreign blockbuster movies per year. This quota was doubled when China joined the WTO in $200{ }^{495}$. Presently, although both parties explicitly acknowledged that this case in no way called this commitment in question, hopes exist within the American film industry that the post-DS363 negotiations will further increase the quota level. However, these quota are not absolute, as they cover only films imported on a revenuesharing basis ${ }^{496}$. In principle, more foreign films could be imported against payment of a flat fee, but the very low fees (reported at about US $\$ 50.000$ in 2003) make this very unattractive ${ }^{497}$. Furthermore, foreign films may never comprise more than a third of the number of titles playing at any given time in a cinema, and generally run for only ten days. During special periods, such as the Spring Festival period, summer holidays or important propaganda events such as historical anniversaries, foreign

\footnotetext{
491 1990 Foreign Television Programme Regulations, Article 9, maintained in the 1994 Foreign Television Programme Regulations, Article 10 and the 2000 Television Drama Regulations, Article 35.

4922000 Television Drama Notice, Para. II.

4932004 Propaganda Discipline Enforcement Notice, Preamble. See also 2004 Foreign Television Programme Regulations.

${ }^{494} 2000$ Television Drama Notice, Para. II.

${ }^{495}$ China WTO Accession Services Schedule.

${ }^{496}$ Typically, about $13 \%$ of the box office will be passed on to the rights holder. Zhao and Dawson, 2011.

${ }^{497}$ Wang, 2003, p. 70.
} 
films will be not be screened in cinema's, and when an important State-backed main melody film is shown, foreign films are also retired of given less favourable treatment. One very visible example of this was the James Cameron blockbuster film Avatar. This was shown in China in a 2D version, on 1600 screens, and a 3D version, on 900. Days before the State-sponsored main melody film Confucius would hit the screens, Avatar was pulled, allegedly because authorities did not want the runaway success of Avatar to interfere with Confucius ${ }^{498}$. Interestingly, China Film Group, Avatar's distributor, was also a major investor in Confucius.

\section{Personnel matters}

Not only work units can be subject to administrative action and disciplinary sanctions. In 2002, concrete punishment regulations were spelled out for personnel breaking "propaganda discipline". These referred to an internal CPD document on sanctioning breaks of propaganda discipline, again illustrating the close relationship between Party and State institutions. These Regulations again obliged radio and television personnel to follow the Party line. They differentiated infractions in a number of categories. The gravest category contained violations of the Constitution, the Four Basic Principles, the Party line, opposing major State and Party policies, State unity, endangering social and governmental stability, inciting ethnic hatred, disseminating political rumours, propagating sects, divulging State secrets, broadcasting messages counter to China's foreign policy, reporting foreign legal cases if this created a "harmful effect", providing forbidden television programmes to foreigners, inducing unstable incidents, reporting foreign ethnic or religious extremism without approval and other ethnic and religious matters, broadcasting sexual, violent, criminal or gambling-related content, reporting false news, wrongfully reporting major incidents, in violation of regulations reporting legal cases, infringing privacy rights, disseminating programmes without approval, not broadcasting according to the approved schedule and broadcast unapproved programmes ${ }^{499}$. All these infractions, depending on gravity, would be punishable by demotion or dismissal. Dismissal would also entail that the staff member concerned would be prohibited from working in the radio, film and television sector for three years ${ }^{500}$ and CCP members would also be subject to disciplinary sanction in the Party ${ }^{501}$.

Furthermore, since 2000, approval needs to be sought for foreign personnel participating in the production of domestic television dramas ${ }^{502}$, radio and television programmes $^{503}$. In the cartoon sector, attracting foreign expertise was encouraged ${ }^{504}$, as the weakness of the Chinese cartoon industry was diagnosed as being caused by low technological quality, which could be remedied by foreign technology and skill.

\section{Positive incentives}

The above matters severely restrict the space companies have to operate their business. At the same time, however, the State has also implemented a number of car-

\footnotetext{
${ }^{498} \mathrm{LaFraniere,} \mathrm{2010.} \mathrm{There} \mathrm{are} \mathrm{reports} \mathrm{that,} \mathrm{in} \mathrm{the} \mathrm{end,} \mathrm{Avatar} \mathrm{was} \mathrm{reinstated} \mathrm{on} \mathrm{a} \mathrm{small} \mathrm{number} \mathrm{of}$ screens, since Confucius was a critical and box-office flop, and theatres were anxious for the extra income Avatar generated. Magistad, 2010.

4992002 Provisional Personnel Breaking Discipline Regulations, Articles 4 - 12.

500 Id., Article 15.

501 Id., Article 16.

5022000 Television Drama Notice.

${ }^{503} 200$ I Radio and Television Access Regulations, Para. VIII.

${ }^{504} 2006$ Cartoon Development Opinions, Para. (18).
} 
rots in order to stimulate the development of the cultural sectors. These include special funds, subsidies and awards, such as the Golden Rooster, Huabiao and Hundred Flowers awards. However, these forms of support come with political strings attached. Rather than primarily serving to maintain or expand cultural diversity and consumer choice, they aim to reward productions that carry out the Party line and main melody. For example, the National Film Development Fund, established in 1991, was aimed to supporting the production of main melody films ${ }^{505}$. In 1996, Also, recent Hundred Flowers Award winners include Founding of a Republic and the civil war epos Assembly. These are powerful incentives for producers in a market harried by piracy, and it would not be unreasonable to assume that this would also result in convergence around the Party's theme. One could cynically wonder if piracy therefore is not something that the leadership might desire to a certain extent, as it strengthens their position of control over a large extent of potential income for media products.

\section{Mobilizing the Industry: a tale of two campaigns}

All these different control mechanisms come together when the entire propaganda xitong is mobilized for campaigns. These campaigns are organized for important celebrations, such as the Spring Festival; anniversaries of significant historical events, such as the 30th anniversary of reform and opening up in 2008, the 60th anniversary of the PRC's founding in 2009 and the 80th anniversary of the CCP's founding in 20II; or significant events such as the 2008 Beijing Olympics and the 2010 Shanghai World Expo. Since 2006, campaigns to support cultural industry development have also been organized. Given that these matters, both the propaganda campaigns and the industrial development plans tend to be described in much detail, they offer a clear insight in how the Propaganda xitong is constructed, and how it is expected to operate.

At the end of 2008, a film campaign was launched, in order to celebrate the 30th anniversary of China's beginning to open up to the outside world, and, in the words of the SARFT Film Bureau, to:

"enthusiastically celebrate the magnificent spirit of the reform and opening up times, bring about a public opinion atmosphere commemorating and extolling reform and opening up, fully give rein to the important function of film in constructing a harmonious society, unfold the substantial achievements of Chinese film reform and opening up to Party and People ${ }^{506}$."

The campaign would be divided in four parts, of varying length and scope. The shortest campaign, "Excellent Domestic Film Screening Commemorating the 30th Anniversary of Reform and Opening Up", from 24 October until I 5 November, would be organized in the larger cities and mainstream cinemas. The second, "Excellent Domestic Films Commemorating the 30th Anniversary of Reform and Opening Up Entering Communities" would run from 10 November until the end of 2008, in second-tier film markets, and in rural regions, the "Offering Excellent Domestic Films Celebrating the 30th Anniversary of Reform and Opening Up" campaign would be run from 10 November until the end of 2009. Simultaneously, film channels would run a campaign named "Broadcast of a Propaganda Series Commemorating the 30th Anniversary of Reform and Opening Up".

\footnotetext{
5051996 Film Production Fund Notice.

${ }^{506} 2008$ 30th Anniversary Notice.
} 
For each of these four campaigns, a number of films deemed suitable were handpicked, for their merits in celebrating the achievements of the reforms, technical quality and influence.

All film sector institutions were mobilized. Administrative film entities were charged with leadership and coordination functions, facilitating the organization of individual events, as well as with publicizing this campaign through the news media. Film producers were called upon to support the campaign by making their creative personnel available for film promotion work, but also to reach agreements with film distributors. These distributors in turn were expected to concentrate distribution and promotion work on campaign-related films. One of them, the Beijing All-China Screening Digital Cinema Company was called upon to make films available at low prices at second-tier levels, namely in communities, schools, factories, mines, etc. Two others, the China Film New Rural Distribution Company and the Administration Centre of Digital Film Content, were charged with sending film information to the countryside. Hard copy producers were ordered to give priority to campaign films.

At the consumer level, urban cinemas were obliged to provide promotional actions and low-price tickets for campaign films, and to give them priority screening. Secondtier cinemas had to bring their work to communities, schools, factories, mines, etc., and provide free public interest film screenings. In the countryside, screening work units had also to provide as many free screenings as possible. Film channels had to announce their broadcasting of campaign films during the golden hours. They were also expected to further publicize the wider campaign, together with film magazines. The film sector associations were called upon to assist in the campaign by using their clout in guiding and coordination, and providing ideas for further campaign development.

For the 2009 New Year and Spring Festival periods, a similar campaign was developed $^{507}$. Here, the campaign was divided in three parts: rural regions, urban regions and film channels. In the rural region, this campaign called for the continued support for the still-ongoing 2008 campaign. It added to this the provision of 7000 Statepurchased digital film projectors, the practical implementation of subsidy plans, as well as the State-funded provision of 1000 film copies on reels for regions where digital equipment was sparse. Lastly, the campaign aimed to provide a hundred thousand free rural film screenings at "peasant worker transport points and work points".

In the urban region, the Film Bureau was apparently happy with the achievements of the 2008 campaign, calling for the continuation of screening of certain films, as well as giving priority treatment to domestic films newly entering the market and further providing cut-rate tickets. Film channels were required to broadcast only "happy and auspicious films", while the SARFT film channel would initiate a charity campaign to bring films to the grass roots in selected localities. The film industry chain was subject to similar requirements as the 2008 campaign. Furthermore, the campaign included support for film dubbing in ethnic minority languages, and required cooperation with Party and State institutions, social organizations and educational institutes in order to provide special screenings for these groups.

${ }^{507} 2009$ Spring Festival Notice. 
These two connected campaigns clearly show the intricacy of the propaganda machine that has been put in place, and the way in which it can be brought to bear in carrying out its mandated tasks. Main melody films are produced in the certainty that they will be included in these large and highly publicized campaigns. State-owned distribution companies prioritize and organize the distribution of these films, making sure that enough copies are available where they are needed - with the assistance of the film processing industry. Cinemas and other outlets then spread the message to the public.

The main problem, however, is cost. From these two campaign plans, significant public funding seems to be necessary in providing equipment and film copies, especially to rural areas. In urban areas, large-scale cinema complexes have been made possible by lifting the prohibition on foreign and private funding in this sector, providing a better way to spread the Party-State's message. In the rural areas, on the other hand, public financial support is indispensable in order to attain the media distribution objectives the system sets itself. While a certain part of the financial outlay comes out of the public purse, media outlets are essentially required to forgo their commercial interest in order to satisfy political requirements during these campaigns. One could view this public service role as the price of being allowed into the business in the first place, but one might also ask the question to which extent the different requirements put to the audiovisual media industry are contradictory. The recent flurry of development plans for the cultural industries, which outline the different developmental objectives, illustrate the tensions between social interests and economic interests.

\section{Cultural development plans}

The $16^{\text {th }}$ Party Congress in 2002 gave a new impetus to the development of the cultural industries. For the first time, cultural industries were part of the Work Report presented to the Congress, as they were mentioned as an important growth point. They were considered to be significant as a part of the effort to move up in the value chain, instrumental in constructing a xiaokang society, and necessary in support of the national spirit. In the wake of this Report, the propaganda xitong began formulating a cascade of industrial development plans for the cultural industries ${ }^{508}$. Furthermore, in order to support development of the cultural industries, the Chinese Academy of Social Sciences started publishing an annual report, the Cultural Blue Book, from 2002 onwards $^{509}$.

In these plans, a number of recurring terms are used to describe the kind of works that the propaganda xitong aims to create. The "Two Fors" (二为 erwei) is an abbreviation for “serving the people and serving socialism”. The "Double Hundred" (双百 shuangbai), likewise, is short for "letting a hundred flowers bloom and a hundred schools of thought contend". Works are supposed to reflect the "main melody" (主

\footnotetext{
508 Including, amongst others, the 2004 Radio, Film and Television Development Opinions, the 2005 Foreign Capital Opinions, the 2006 Cartoon Industry Opinions, the 2006 Culture Five-Year Plan, the 2008 Cartoon Industry Opinions, the 2009 Audiovisual Industry Growth Opinions, the 2009 Cultural Industries Promotion Plan, the 2010 Press and Publications Industry Development Opinions, the 2010 Film Development Opinions, the 2010 Radio and Television IPR Strategy, etc.

${ }^{509}$ Keane, 2007, p. 6I.
} 
旋律 zhuxuanlü), which is no more than a euphemism for the Party line, and "stick closely to reality, stick closely to life and stick closely to the masses". Furthermore, the creation of works "with Chinese characteristics", that reflect the "traditional excellent virtues of the Chinese nation" 510 aims to improve the standing of the cultural industries domestically, and increase China's visibility as a creator of cultural products abroad. Moreover, a comprehensive set of policy objectives is outlined, including expansion of cultural capacity, providing ideology guarantees and support for economic development, political stability and social progress, production of more and better cultural products, providing better culture products and services to the countryside and other poorer regions and increasing Chinese cultural influence abroad.

In order to achieve these objectives, the plans detail a number of policy steps. At the grass-roots level, public culture facilities would be constructed. A number of focus programmes would be put in place, in order to produce a number of prominent cultural products. The cultural industries would be restructured, product and service markets fostered and input factor markets put in place, distribution structures would be remodelled, and private capital would be allowed to supplement public ownership. Science and technology development in service of the cultural industries would be prioritized, and support would be given to the "Marching Out" policy, which aimed to create a number of programmes and projects geared towards export. Lastly, a large emphasis would be put on education and training of talented personnel to work in the cultural sector.

It is clear that such ambitious plans require the marshalling of significant amounts of resources, personnel, institutional support and cooperation by economic actors. However, a number of these requirements and objectives seem paradoxical. In the words of Miao Di: "television today is like a double-gendered rooster: propaganda departments want it to crow while finance departments want it to lay eggs ${ }^{511}$ ". As with the tension between government openness and maintenance of control outlined earlier, the leadership seems to pursue incompatible goals. The question on how to reconcile economic development strategies, formulated with both the successes and the failures of overseas models in mind, with political imperatives of control and supervision remains open. Certainly, these goals sometimes overlap. Constructing modern, high-quality cinemas, mobile media platforms and enhancing Internet connectivity, cable television networks and satellite television coverage certainly combine the economic objective with providing broader and better distribution channels, with the political objective of providing broader and better propaganda channels. A number of main melody films - such as Founding of A Republic and Feng Xiaogang's Aftershock, have become very successful. On the other hand, it is impossible to find out which films and programmes would have been made absent the different control regulations, or how foreign companies would have engaged the Chinese marketplace if they would not have been limited by investment, ownership and trading restrictions. One thing we do know, we know through piracy: the market displays considerable appetite for a large amount of foreign works that did not pass through censorship, indicating that demand for products is broader than lawful supply.

\footnotetext{
${ }^{510} 2006$ Culture Five-Year Plan, Para. II (6).

${ }^{51}$ Quoted in Shirk, 20II, p. II.
} 


\section{Conclusion}

The media control regime as outlined above creates significant barriers, thresholds and checks all along the production, distribution and market process of audiovisual media. It raises transaction costs through the complete value chain, and significantly limits the content scope of works that can be produced legitimately in China. Foreign players are even worse off, as they often may not participate in a certain market segment, or can only enter under strict conditions, in minority share-holding positions. Often, foreign enterprises have little control how and when their products are brought to the market. Foreign works are subject to step-motherly treatment by the downstream companies taking care of distribution and marketing, and the cinema quota still stand.

It is hard to chart how exactly this impacts the scope of media works legally available in China. Given the mercurial nature of the censorship regime, it is not always clear which works are fit for production or import. Estimating the specific impact on media production would require empirical research, and that is assuming that it would be possible to say something meaningful about works that are not made or imported. Nonetheless, it would not be unreasonable to state that the range and number of audiovisual media products that can be brought onto the Chinese markets is significantly narrowed because of the restrictions. Filmmaker Feng Xiaogang had a number of projects prohibited by the film authorities ${ }^{512}$. In the music sector, Montgomery suggests that market access barriers do more to restrict foreign operators than concerns about piracy ${ }^{513}$. Furthermore, the lengthy censorship process for foreign works, which generally are not released in China first, combined with the screening restrictions outlined earlier, may delay their availability on the Chinese market and open up a further window for piracy.

Remembering the argument that piracy networks are rewarded for speed and product range, this is the point where significant demand for pirated products is generated. Consumers have a strong incentive to turn to pirated products because there are more of them, and they are available quicker. Moreover, it gives piracy networks the competitive advantage against lawful producers, as lawful producers cannot react against piracy by lowering prices or providing better products. It is simply impossible for them to compete. This challenges the conception that media piracy is a simple market failure, a failure of supply and demand to find each other and trade. PartyState policies have brought about that there simply is no market in the first place.

Furthermore, this is the beginning of a vicious circle engendering more piracy. Apart from the fact that they operate outside of the law, piracy suppliers are subject to the same commercial logic that legitimate suppliers are. In other words, it makes sense for them to provide more and better products and services. Hence, there is no reason to confine themselves solely to works that are not available on the Chinese market. As a result, approved works will be pirated as well, causing a further drop in potential income, and a further disincentive to invest to bring media works - domestic or foreign - to the market in China. Consequently, less works will be available, again creating more space for piracy.

\footnotetext{
${ }^{512}$ Zhang, 2008, passim

${ }^{513}$ Montgomery, 2009.
} 
Apart from creating demand for pirated products, the media control system might also enhance piracy in another manner: the continuous involvement of Party-State and semi-Party-State entities means it is much harder for producers to keep works under wraps. The different licensing procedures require a number of hard copies to be submitted to distributors, State entities, etc. Officials in these entities then have ample opportunity to pass them on to the piracy networks ${ }^{514}$.

As the media market is subject to such tight control, copyright loses much of its relevance, and Chinese enforcement agencies often do not consider piracy to be primarily a copyright problem. On the contrary, piracy can be considered as much more a breach of publication discipline - a violation against State order - than the violation of the private rights of another individual. An interesting insight about this is offered in the 2007 Copyright Protection Strengthening Notice. In spite of the title of this document, priority is actually given to concerns relating to broadcast of unapproved materials. Obtaining lawful authorization from rights holders for programme broadcast is relegated to a secondary position ${ }^{515}$.

The Chinese-language terminology illustrates this difference: pirated copies of works allowed on the market are called “unlawful reproductions" (weifa fuzhipin 违法复制 品), whereas pirated copies of prohibited works are referred to as "illegal publications” (feifa chubanwu 非法出版物). This will have significant effects in determining the political economy surrounding piracy, as they may impinge on different policy objectives. Also, especially when the old Article 4 Copyright Law was still in force, this difference led to a number of adjudication problems. As indicated earlier, piracy activities offer a broad range of products, irrespective of whether these are approved works or not. Hence, enforcement raids and activities often uncover that producers, distributors, vendors or websites would have both categories, making it unclear under which regime they should be punished. A number of judicial interpretations were published ${ }^{516}$, but it remained a complicating factor. It remains to be seen whether and how the new Copyright Law will change these matters.

Nonetheless, it is not enough to point to the space in which piracy can exist. For piracy to become as large-scale a phenomenon as it did, there also needs to be an environment in which piracy can survive and thrive. In other words, in order to fully diagnose piracy, it will be necessary to consider why China fails to implement and enforce its media control regime. An important consideration raised in this chapter informs enforcement questions. As piracy concerns media control enforcement at least as much as it does copyright enforcement, different political economy considerations apply, as enforcement would serve different objectives. Rather than being unable to protect the rights of private rights holders looking for relief, the PartyState seems to be unable to maintain control in a sphere generally considered to be of prime political importance. In other words, piracy, if analyzed as a breach of propaganda discipline, impinges on an important policy objective. It would therefore be unwise to only analyze anti-piracy enforcement from the restrictive angle of eco-

\footnotetext{
${ }^{514}$ Fung 2007, p.8.

${ }^{515}$ Only one of the six paragraphs of this Notice relates to right holder authorization, and this is listed after all content and licensing provisions.

${ }^{516}$ See 1998 Supreme People's Court Interpretation of Some Questions Concerning the Concretely Applicable Law in Hearing Criminal Cases Involving Illegal Publications.
} 
nomic damage foreign rights holders and Chinese domestic rights holders suffer, or the relationship with the black letter of international trade commitments. Rather, we must try to understand why the Party-State seems unable to prevent the circulation of works in a way it does not permit and cannot control. This first requires us to understand deeper the legitimacy, objectives and political economy of media control, which will be the subject of the next chapter. This is important because, it lays down the political economy objectives, priorities and considerations on the basis of which law enforcement is organized. Furthermore, the dynamics of the law enforcement institutions themselves, not in the least because of their State-centred nature, are by themselves subject to political economy problems as well, as shall also be shown in the next chapter. 


\section{Chapter V: Understanding the political underpinnings of Chinese media}

The previous chapter concentrated on in the actors in charge of China's audiovisual media sector, and how regulatory measures serve two seemingly conflicting goals: maintaining Party-State control over the complete audiovisual media output and supporting economic development of the audiovisual media sector. In all cases, it is clear that maintaining Party control takes precedence, as media plans and regulations prioritize "integrating social and commercial interests, putting social interest first". To really understand the objective of the Party-State's media policy, a broader understanding of what "social interest" means is necessary. In other words, legal analysis does not explain why the regulatory measures analyzed in the previous chapter are put in place. Rather, we need to examine the objectives of the Party-State in developing these regulations and policies, which means in turn that we must understand the political imperatives to which the Party-State is subject.

There is a significant body of literature in cultural and communication scholarship that addresses different questions concerning China's media system structuring and restructuring ${ }^{517}$, its relationship with the Party-State and audiences ${ }^{518}$, the influence of globalization ${ }^{519}$, the complex relationship between political and economic objectives in audiovisual media ${ }^{520}$, the development of national cinema ${ }^{521}$ and the influence of new technologies ${ }^{522}$. This chapter aims to connect the Party-State's communication strategy with audiovisual media piracy, by highlighting how and where the Party-State requires commercial interest to cede to political interest, which brings about the market failures that are significant drivers of both piracy demand and supply.

This chapter aims to accomplish three goals. First, it provides a theoretical and historical analysis of media control, based on the idea of a single-pillar, monopolistic power system. Second, it provides an overview of the political background of China's current media strategy, based on the choices concerning China's continued development that have been made after the Tiananmen incident, which continues to influence China's politics. Third, on the basis of post- 1989 policy documents, I outline China's increasingly complex and subtle media policy. Here, I concentrate on both content and the underlying industrial structure. On this basis, I will argue that the aims of China's media strategy are conflicting. On one hand, China wants to maximally expose its citizens to its message, which has lead to extremely rapid developments in infrastructure and technology. Conversely, the aim to keep controlling content results in continuing contestation and dissatisfaction from both media enterprises and audiences, and is instrumental in holding back the development of the domestic audiovisual sector, and may drive audiences towards finding their entertainment elsewhere, for example through piracy.

\footnotetext{
517 Zhang, 2008.

${ }^{518}$ Zhao, 2008.

${ }^{519} \mathrm{Wu}, 2008$.

${ }^{520}$ Shirk, 20 I I; Zhu and Berry, 2007.

${ }^{521}$ Zhang, 2004.

522 Keane, 2007.
} 
The single pillar of Chinese political power and media control in history

As we saw in the second chapter, regimes everywhere in the world wished to control the printing press, fearing political opposition and dissidence. However, in Europe's present liberal democracies, power increasingly devolved from the monarch to the nobility, privileged cities, trade guilds, and increasingly to elected parliaments. This brought with it increasing contestation around information openness and the freedom of speech and the press. By the time the United States were founded at the end of the eighteenth century, these values had become so crucial that they were inscribed into the Constitution.

Such an evolution never took place in China. Rather, the Empire was characterized by a remarkable constancy in the way society was constructed and power was distributed. Revolutionary processes - switchovers between dynasties - did not call into question the systemic issues of China's social organization, but rather the perceived loss of virtue - hence, the Mandate of Heaven - of the ruler. Consequently, freedom of information, speech or the press never crystallized into points of contestations where increasingly ambitious new elites challenged the political status quo, and where new forms of social organizations could be developed. Rather, China's political structure has evolved in a different direction. The Chinese empire could be described as having a "single power pillar". The basic tenets of this structure was that the Emperor - the Son of Heaven - ruled his territories with the assistance of a body of officials that would be in charge of translating the Emperor's order into administrative policy. The highest-ranking officials would be in charge of a ministry or other government department. There was no popular representation or other institutionalized representation mechanisms, or division of power ${ }^{523}$. Similarly, the role of law was largely limited to areas where certain activities would upset social order, and directly threaten the legitimacy of the Emperor. This legitimacy - as in contemporary Europe - depended upon divine approval of the ruler. However, as the Mandate of Heaven depended upon the moral character and virtue of the ruler, and could be withdrawn in case the emperor would fail to live up to the required moral standard. The mere fact of a ruler being overthrown signified the loss of the legitimacy to rule, and the new ruler would then be seen to take over the Mandate.

In modern day terms, the imperial political system could be described as a "small state". A few thousands of officials would be in charge of ruling China's vast territory. Districts with thousands of inhabitants would be governed by a single imperial official, who would both be the highest administrator and judge. Hence, State interference into the daily lives of citizens remained limited ${ }^{524}$. However, after the Qin dynasty, China had become effectively centralized in terms of written language, currency measurements and administration.

After the fall of the Empire in 19/2, China fragmented, and was ruled for a time by regional lords. As Frank Dikötter shows, it would be overly negative to call them "warlords", and a number of them introduced very liberal forms of political organiza-

\footnotetext{
${ }^{523}$ For a broad historical overview of the development of China's political system, see Gernet, 2002.

524 This is not to say there was no State interference at all, or to say that the State did not deliver social services. For example, Philip C.C. Huang's research on private law at the end of the Qing dynasty clearly shows how active district magistrates could be in providing adjudication services in private disputes. Huang, 2009. Also, the State was expected to provide public services, such as grain stockpiles for during bad times, and keeping the roads free from highwaymen.
} 
tion, including liberal constitutions, separation of power and democratic election ${ }^{525}$. However, before any of these experiments could come to full fruition, the Guomindang (GMD) had conquered the Chinese mainland, and had re-introduced a single power pillar. Like the CCP after it, the GMD would introduce Leninist mechanisms of social control, aimed at maximizing party control into the society. The problem was, that the GMD - in its efforts to conquer the mainland - had struck deals with previous elites, such as regional lords, but also mafiose organizations, which meant that it never was able to fully assert control over the territory it governed nominally ${ }^{526}$. Later, the Japanese invasion would sweep away any semblance of strong GMD government.

In a sense, it could be argued that the CCP succeeded where the GMD failed. Deriving its power from rural support, rather than support from urban elites, the CCP could afford to sweep away a much larger part of existing social structures in 1949. In contrast with the imperial past, the CCP reconstructed society using Leninist strategies of social penetration ${ }^{527}$, greatly expanding State presence in society. The economy became increasingly nationalized as Party cells were established in all companies, departments and other institutions, all laws and regulations were abolished, and the Party maintained control over the People's Liberation Army, rather than transferring this to the State ${ }^{528}$. After the Cultural Revolution, the Party withdrew from a number of aspects it previously occupied, in a shift from totalitarianism to authoritarianism. Nonetheless, the Party still maintains strict control over the "commanding heights" of economy and society, and does not to tolerate any challenge to this position. Similarly, the way it controls the media still displays continuities with the Cultural Revolution era ${ }^{529}$.

Any single power-pillar system needs to maintain a certain monopoly over potential gathering points for dissent ${ }^{530}$. In theory, pluralist political systems enjoy a "marketplace of ideas". Single-pillar regimes, on the other hand, cannot allow discourse challenging to their power to build up, lest it becomes a locus for the gathering of discontent, which may in turn threaten regime survival. It is clear that public communication is a key aspect of such control, and that therefore, maintaining control over the public debate is a core interest of the CCP, as it would be for any authoritarian ruling party. This interest is so strong, that the Central Propaganda Department can even overrule top leaders.

Control of the public discourse for reasons of political legitimacy is nothing new in China. Already during the imperial era, maintaining the Mandate of Heaven required information flows to be controlled, and publication of books and prints was strictly monitored. One of the crucial acts of the fledgling Qin dynasty to establish their power was the burning of all books that contradicted the Qin's legalist ideology ${ }^{531}$. In later times, only the State could publish certain documents such as almanacs, calen-

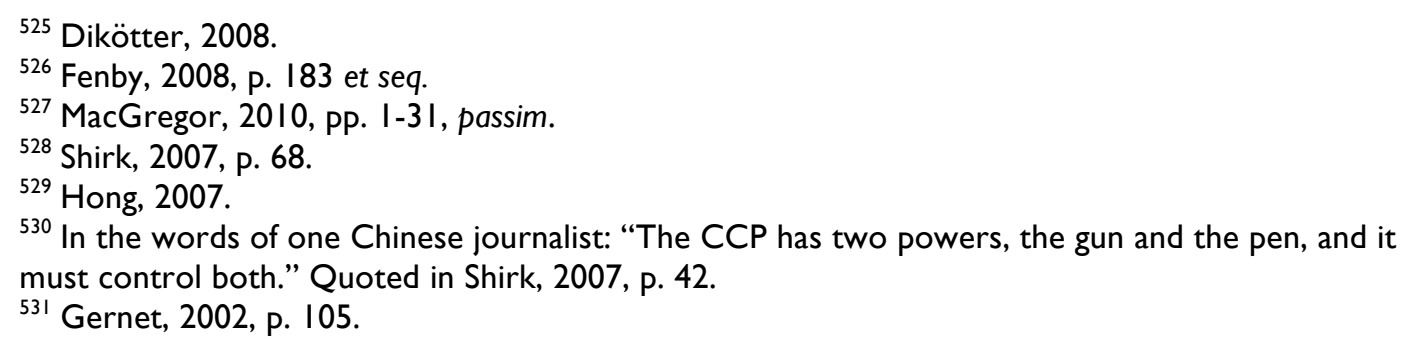


dars and astronomical charts. This was a consequence of the emperor's position as the symbolic ruler of Chinese agriculture ${ }^{532}$. The calculation of the date of Spring Festival was an imperial prerogative, as it was seen part of the function of the emperor to serve as the "father and mother of the people". Therefore, publication of certain charts and calendars by others could be seen as an attempt to usurp imperial power. Moreover, district magistrates would always be on the lookout for books and pamphlets challenging imperial power ${ }^{533}$, especially as such dissent could be expressed in very subtle and artistic fashions ${ }^{534}$. Apart from political concerns, morality also played a large part in imperial media control. As the emperor needed to maintain and promote li - a complex concept encompassing rituals, moral standards and proper conduct - works violating certain aspects of social order could be banned as well. This view in which the government is responsible for the moral education of its subjects has persisted until this day.

Communist concepts of media control were foreshadowed under the Guomindang reign. After the - then new - film technology entered China in the early twenties, some media control steps were discussed, but the weakness of the central government meant that such measures were never comprehensively implemented. At that time, cinematographic technology had already become of age and films had become storytelling works, rather than short novelties, and concern had arisen over their possible "negative" impact on society ${ }^{535}$. The main concern was the impact on film on public morality. In jiangsu, a provincial film approval committee was established, which examined all films shown in provincial capital Shanghai, which was the centre of the Chinese film industry at the time. It especially paid attention to films containing scenes containing sexual or criminal matter, and "deal with them according to the law, or order cessation of showing and closing of business according to the gravity of the circumstances ${ }^{536}$." However, this committee was a civil organization, and lacked the support and assistance of administrative powers needed to enforce their judgments, and effective film control was not enacted in Shanghai's film industry.

After the Northern Expedition, during which the Guomindang established control over the Chinese mainland, it quickly moved to institute censorship and control measures in the field of publishing, but also in the film business. These measures were primarily intended to establish "party rule" (dangzhi 党治), in other words, to make the population identify themselves with GMD ideology. As Chiang Kai-shek wrote: "If the thinking of all Chinese parties is not unifies, the construction of China will be extremely difficult" and "thought unification is more important then anything

\footnotetext{
${ }^{532}$ For example, one of the more important imperial Chinese ceremonies during the Ming and Qing dynasties consisted of the yearly ceremonial ploughing of the first furrow at the Temple of Heaven in Beijing, when praying for a good harvest.

${ }^{533}$ Jonathan Spence has analyzed an extensive account on the background of one of such pamphlets, published during the reign of the Yongzheng emperor. Interestingly, displaying the Confucian ideal of education, the emperor entered into conversation and education of the pamphlet's writer. Spence, 2002.

${ }^{534}$ This aspect of Chinese art has been studied in-depth by art historians. See for example Murck, 2002; Liu and Shek, 2004.

${ }^{535}$ Zhang, 2004.

${ }^{536}$ Wang, 2006.
} 
else $^{537 " .}$ Moreover, the GMD structured the political discourse around the terms “revolutionary” (geming 革命) and “anti-revolutionary” (fangeming 反革命) ${ }^{538}$.

Aware of its possible propaganda impact ${ }^{539}$, the government moved to use film as a medium for ideological transmission. According to the GMD, films should not be seen as pure forms of entertainment, but should have an educational and cultural function as well. Simultaneously, concern remained about the potential negative influence of films on morals. Consequently, local examination committees for film, but also theatre, publications, etc. were set up as GMD rule stabilized, and in 1928, the first preparations were made for the establishment of a national film examination board.

The "Regulations on Examination of Films" (jiancha dianyingpian guize 检查电影片规 则) was passed in September 1928 by the Ministry of the Interior, and were scheduled for implementation on I January 1929. However, implementation was deferred, because of the inconvenience of internal communication, and provinces and municipalities were free to decide when they would implement the measures. Moreover, the Education Ministry found that film censorship also had an educational function, and wanted a say in film examination. Hence, new "Regulations on Examination of Films" were promulgated in April 1929, for implementation on I July of that year ${ }^{540}$. These Regulations stipulated that films could not oppose Party doctrine, undermine public morals and public security, encourage superstition and cults, and feudal thinking $^{541}$. This list is still the kernel of prohibited content in the People's Republic. Separate examination tracks for domestic and foreign content were instituted. The task of examination fell to provincial civil affairs and education department and universities, and municipal or county public security organs, social affairs bureaus and education bureaus. These operated under the guidance of the local GMD Party Committee. However, this decentralization powers caused examination to differ considerably between localities, and films that were approved in the more liberal Shanghai, were often prohibited in the inland. Moreover, examination procedures proved to be an administrative burden, and many disputes arose. As a result, the Regulations were never consistently and comprehensively implemented.

The Examination Regulations were replaced in 1930 by the "Film Examination Law" (dianying jiancha fa 电影检查法), promulgated in November 1930 by the Ministry of the Interior and the Education Ministry Film Examination Committee ${ }^{542}$. It stipulated that all films must undergo examination before being allowed on screens, and that films could not contain content "endangering the honour of the Chinese People, violating the "Three Principles of the People" (三民主义 sanmin zhuyi), harming decent customs or public order, propagating superstition and sects". It also instituted a fine not exceeding $300 \mathrm{CNY}$ for violators. Corresponding implementation regulations were promulgated in February 1932, outlining amongst others that all films had to be

\footnotetext{
${ }^{537}$ Quoted in Wang, 2006.

538 lbid.

${ }^{539}$ Many Guomindang cadres had studied or trained in Soviet Russia, and had first hand experience with Soviet propaganda, including the use of films.

540 Wang, 2006.

541 lbid.

5421930 Film Examination Law.
} 
submitted to the Film Censorship Committee in Nanjing, rather than to local or provincial entities.

After the 3rd National Congress of 1929, in which the Western powers' colonialism, militarism, hegemonism and "false democracy" was decried, and sanmin zhuyi was adopted as the basic principle for state building, the GMD Central Propaganda Department passed the "Document Establishing the Literature and Art Policies of Our Party" ${ }^{153}$, demanding the creation of ideological art, and banning the publication of all works running counter to ideology, such as works reflecting "feudal thoughts" or inciting class struggle. Film policy was derived from this document. As an enormously influential mass medium, film was placed under official control, and became a tool for mastering the population. However, GMD leadership was still unstable at that point, and internal disputes were rife. Hence, the government was not able to control the complete film sector. The foreign influence in the film centres of China, which were predominantly Beijing and Shanghai, was such that foreign films usually were not censored $^{544}$. At the same time, the budding Communist Party was well aware of the propaganda value of entertainment in general and film in specific. Furthermore, a strong Leftist industry developed as the early CCP grouped filmmakers, writers and other cultural producers in cultural criticism groups, and influenced filmmakers to promote Communist political views. ${ }^{545}$.

After the 1949 takeover of the mainland, the Communists quickly asserted control over the film sector. Liberalization in the early fifties culminated in the Hundred Flowers Campaign, which brought criticism of the new regime into the open. By 1957, Mao cracked down heavily on the cultural sector in the Anti-Rightist Campaign. The disastrous, ideology-fuelled Great Leap Forward followed soon after. Gradually, the Chinese film sector became nationalized and put under direct Party control $^{546}$. Similarly, the Communists labelled the Thirties-style Shanghai pop music as vulgar ${ }^{547}$, banned import of all foreign music and promoted communist songs. By the high tide of the Cultural Revolution, entertainment of entertainment's sake had all but disappeared. Films were seen as a tool to educate the masses and a transmission belt for Communist ideology to be spread among the population ${ }^{548}$. Control over the cultural sector was complete, and State production houses were churning out films with uplifting, patriotic and ideological themes, such as resistance against Japan or America. However, the Cultural Revolution had a strong influence on the film sector's vitality. Very few films were made during this period, due to the strict content restrictions of that time. After 1976, control over the audiovisual media was relaxed somewhat, as the totalitarian Maoist doctrine was replaced with Dengist economic reform. Nonetheless, it was made clear very soon that Deng would tolerate no challenge to the Party leadership, in line with the Four Cardinal Principles. Less than a year after the reforms started, the Democracy Wall movement in Beijing was crushed ${ }^{549}$, new propaganda chief Deng Liqun launched a campaign against for-

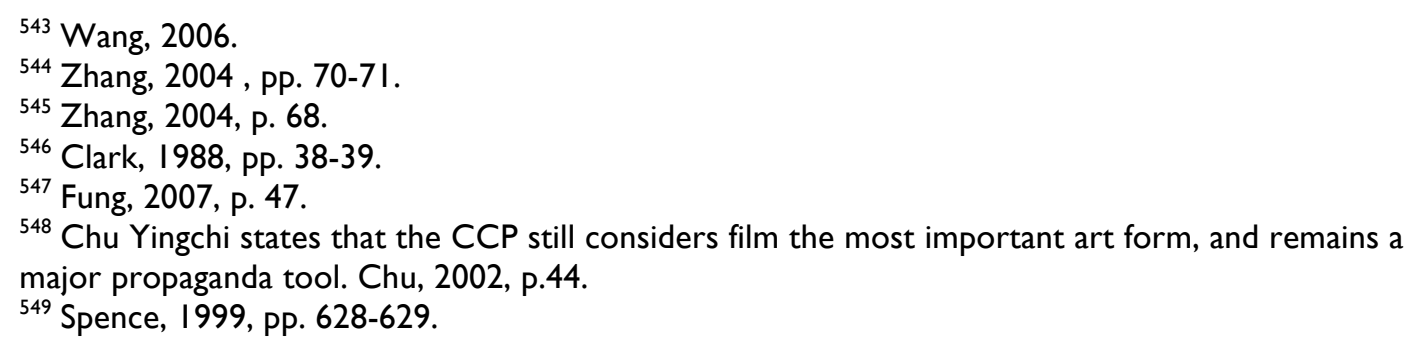


eign spiritual pollution in $1983^{550}$ and another wave of pro-democracy demonstrations in 1986 and 1987 was put down forcefully ${ }^{55 !}$.

In short, the efforts to control the dissemination of ideas display - allowing for technological process - great continuity throughout Chinese history, to a large extent because the basic political imperatives for this did not change. However, not even the staunchest propaganda system is immune from external shocks, and the true test for the CCP's capacity to deal with crises came around in 1989.

\section{Ruling capacity}

1989 was not a good year to be a Communist Party leader. In the space of a few short months, the Berlin Wall fell, Poland, Hungary, Czechoslovakia, Bulgaria and Romania had seen political transitions away from Communism. Two years later, the Soviet Union would cease to exist. China itself was rocked by what became later known as the Tiananmen Incident, but which was actually a nationwide protest movement against rising prices, unemployment and a perceived lack of legitimacy of the CCP leadership ${ }^{52}$. China came to the brink of revolution as deep cracks appeared between top-level leaders, which the protesters attempted to exploit to divide the Party's power, and some army commanders refused to carry out the orders to fire on civilians. In the midst of the crisis, hardliners led by Li Peng convinced Deng Xiaoping to re-assert control by military means. Zhao Ziyang, the then Communist Party Secretary, was removed from office and placed under house arrest, which continued until his death in 2005. Shanghai Party Secretary Jiang Zemin was flown in hastily and under cover to replace Zhao ${ }^{553}$. The consequences of the crackdown were deep. The rural-based reforms of the ' 80 s ground to a halt, and a number of tentative political reform steps had begun to circulate were wiped off the table ${ }^{554}$. A period of political retrenchment followed, which only ended with Deng's Southern Tour of 1992. This Tour echoed imperial inspection trips, and was used as a platform to give a new impetus for further economic development. Throughout the ' $90 \mathrm{~s}$, the leadership committed significant resources to diagnosing the factors that led to the 1989 protests, the demise of the Eastern European socialist governments and the dissolution of the Soviet Union ${ }^{555}$. Furthermore, as the Chinese government further entered political uncharted territory, it also looked to other countries for inspiration on how to reconcile political legitimacy with maintenance of control, and maintaining social and economic prosperity.

Shambaugh posits that the leadership diagnosed factors in four categories that combined to undermine the leading position of Communist parties and the Soviet Union in particular. First, much blame was placed on the failure of Communist regimes to improve material living standards of their citizens, due to the totalitarianism of the command economy and the absence of market mechanisms. The economy lacked flexibility and innovation, and too much emphasis was placed on heavy industry, while light industry and agriculture were neglected. The reforms of Gorbachev were

\footnotetext{
${ }^{550}$ Although, by this time, the effect of this sort of campaigns had visibly diminished. Clark, p. 175.

${ }^{551}$ Spence identifies the creation of the GAPP as a response against these demonstrations. Spence, 685.

552 Id. pp. 696 et seq.

${ }^{553}$ Shirk, 2007, pp.36-38.

${ }^{554}$ Kraus, 2004, p. 93, MacGregor, 2010, 80.

555 Shambaugh,2008, pp. $45-86$.
} 
deemed to come too late and to be too disruptive. Second, the political and coercive strength of Communist parties had deteriorated. The totalitarianism of the Stalinist era still cast its shadow over society. "Propaganda work" was deemed inadequate, as it was tedious and disconnected from reality, only concerned good news, excluded the intelligentsia. With increasing "peaceful evolution" efforts from abroad, Soviet citizens came to further distrust their media, while the CPSU was not able to develop in step with scientific and technological progress in the West. ${ }^{556}$ Against this background Gorbachev's glasnost policy of introducing and advocating pluralist politics further undermined the CPSU's ideological position ${ }^{557}$ and its absolute monopoly of political power. Internally, Communist parties were deemed to have formed an elite class of their own, subject to internal struggles, and increasingly removed from reality. Third, at the social and cultural level, the Soviet Union was deemed to have given too much power to ethnic groups, and that the USSR's federal structure was a prime driver of centrifugal powers. Furthermore, the proletariat had lost belief in the Communist parties, and alienation against State and party was rife. Gorbachev's step of liberating the media was considered catastrophic, because it "both exposed the party's failings and [...] opened venues for 'antisocialist voices' to vent their frustra-

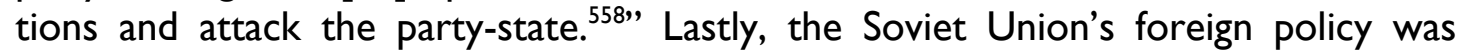
deemed to have become unsustainable by the middle of the Eighties, and Gorbachev's efforts towards détente played right into the "peaceful evolution" strategy of the United States ${ }^{559}$.

The Chinese leadership distilled a number of lessons from this, which are mostly implicit in the diagnosis of what went wrong. As a result, the post-Tiananmen development path differed significantly from the steps taken in the ' 80 s. The earlier reforms were based on rural measures and local entrepreneurialism, but the advent of the Jiang administration heralded the beginning of a new era, in which the lessons of Tiananmen were incorporated, and which also included analysis of what caused the demise of the Eastern European Communist regimes ${ }^{560}$.

The internal process is summarized by Shirk in three basic guidelines: avoid public leadership splits, prevent large-scale social unrest, and keep the military on the side of the Party ${ }^{561}$. The first meant that the way politics were being done inside the Party itself was straitened. Before 1989, there had been gradual tendencies towards the recognition of factions within the Party, but these tendencies were quickly done away with, as it was realized that another leadership split might lead to serious consequences. The second aspect informs the requirement to keep the peace in order to maintain the hold on power. On one hand, it explains a large part of the continu-

\footnotetext{
${ }^{556}$ Id., pp. 66-67.

${ }^{557}$ Shambaugh lists "eight negations" that were deemed to result from these reforms: negation of the CPSU's leadership position; the socialist economic system as the dominant sector of the economy; the public ownership system as dominant in the economy; existence of classes and class struggle; the ultimate goal of realizing communism; the leading position of Marxism-Leninism as the guiding ideology; democratic centralism and negating the international appeal of socialism.

${ }^{558}$ Shambaugh,2008 p. 74.

559 Id. p. 75. Peaceful evolution use a variety of tools such as radio broadcast, promotion of human rights and democracy, economic aid, support for NGOs and autonomous trade unions, spreading the ideology of capitalism and freedom, supporting underground activists, infiltrating Western media publications into closed countries, academic and cultural exchanges, etc.

${ }^{560}$ Shambaugh, 2008, pp. 4l - 87, passim.

${ }^{56}$ Shirk, 2007, pp. 39 et seq.
} 
ing drive towards material development and improving living standards, but on the other hand, it also reflects the increasingly strong responses against all kinds of riots and incidents. Given the potential that every riot and incident - at least in the fearful minds of the leadership - might become a gathering point for popular dissent, the Party-State is making ever larger efforts in building comprehensive and sophisticated systems to prevent and respond to riots by public opinion monitoring, and to actively influence public opinion through different media ${ }^{562}$. Also, depending on the likelihood of protest and the potential impact on social stability, different social groups are subject to differential treatment. This aspect also goes some way in explaining the attitudes against foreign domination - amongst others through culture - since in the past, foreign threats have often caused internal upheavals. The last aspect aims to guarantee that the interests of the Army remain tied to the future of the Party, thereby guaranteeing the obedience of the Army when it is called upon to preserve the maintenance of the CCP.

The result of these processes was that the China's development and reform path was realigned. First, the focal point of the economic reforms shifted away from the countryside and its population, to the urban, better educated and younger population. Second, entrepreneurs, students and the like would be brought into Party circles in greater numbers and at higher positions ${ }^{563}$. Third, control over the military was reasserted, and a professionalization of the forces, as well as a progressive increase of military budgets, was initiated as a trade-off for accepting Party control. In other words, the CCP aimed to co-opt the groups that had rebelled against it or caused problems otherwise in 1989 into accepting its leadership, by promising and providing them with economic opportunities and prospects. Nonetheless, 1989 still reverberates in the way the Party deals with students. These can get away with activities which would be ruthlessly suppressed elsewhere, and are generally treated more gingerly than other sections of the population.

In other words, after 1989, the leadership became very much concerned with maintaining “governance capacity” (执政能力 zhizheng nengli). Of course, direct control of the news media was always important to maintain and increase this capacity, but throughout history, this term has also been closely connected with the management of the cultural sphere. The 2006 Cultural Five-Year plan explicitly mentions strengthening of the Party's governance capacity as one of the core objectives of the policy, together with the commitment to persist in Marxism-Leninism, Maoism, Dengism, and the "Three Represents" to arm the party and educate the people, as well as the objective to implement the scientific development view, and build a harmonious society ${ }^{564}$. In the cultural sphere, standards were tightened after 1989, as the "Sweeping Pornography and Striking Illegality" campaign intensified under the auspices of the leftist hardliners. Under the guise of this campaign, many critical or sensitive works were destroyed as well ${ }^{565}$.

\footnotetext{
${ }^{562}$ In the 12th Five-Year Plan, the budget for maintaining social stability was set at 624.4 billion Yuan, 23.3 billion more than the PLA budget. Lam, $201 \mathrm{I}$.

${ }^{563}$ MacGregor, 2010 p. 31.

${ }^{564} 2006$ Cultural Five-Year Plan, Para I(I).

${ }^{565}$ Kraus, 2004, p. 93. See also Chapter VI.
} 
In the field of cultural studies, much attention has already been paid to the influence of State control over the structuring and content of China's media sector, its relationship with global cultural influences and capital, its relationship with Hong Kong and Taiwan media, the influence of new forms of media, and the relationship with media and public events. The political objectives of the Chinese state, and the economic structuring of the audiovisual media sector, are present as an undercurrent in this body of literature. The next section combines this literature with the orientation in the policy documents to provide better insight in the concerns of the Party-State and the strategies it uses to govern the audiovisual media sector. These are crucial in understanding the different barriers and requirements outlined in the previous chapter, and inform the priorities for law enforcement, also in cases of piracy, which will be addressed in the next chapter. Furthermore, understanding them will provide deeper insight as to why foreign media products are treated differently.

\section{The Party-State's concerns}

Audiovisual media policy is formed on the basis of complex political, economic and social considerations ${ }^{566}$, which are often interlocking, overlapping, mutually conflicting or supporting. The overriding Party-State concern is that audiovisual media must enhance the Party's political legitimacy, and create support for Party-State policies. Developments in the media sector echo broader political evolutions. At the same time, being at the nexus of politics and economy, media are the locus of tensions caused by a development model that combines deep economic reform with political immobilism. While many efforts have been made to turn the media sector from "undertakings" into commercial industries, the leadership still prioritizes maintaining control over the content of all works, programmes and films that are made publicly available. This is especially clear in the field of news media, where daily bulletins from the various propaganda administrations give detailed guidelines on whether and how certain stories are to be reported ${ }^{567}$. In the realm of non-news media, however, a problem arises, as the concept of pure entertainment works does not fit well with the Party idea that audiovisual media should not be there purely for entertainment, but has a pedagogical function ${ }^{568}$. In this logic, films and television programmes should inform and educate, rather than entertain.

There are two main consequences to this. First, propaganda system departments treat entertainment media as an inferior form of culture ${ }^{569}$. Many policy documents, speeches and decisions have been taken to remove "vulgar tastes" from films and television. One well-known example concerns the Wuhan Satellite Television talent show Super Girl. This programme was the first of its kind in China, and was very successful. However, a lot of the success was built on the racy repertoire and dress of the participants, as well as the strong and arguably rude comments given by the judges. SARFT intervened, and by the end of the show, participants were singing patriotic songs, wearing traditional Chinese dress, and the judges had been ordered to

\footnotetext{
${ }^{566}$ Keller, 2000, p. 51.

${ }^{567}$ See CDT, Ministry of Truth.

${ }^{568}$ Zhang, 2008, p. 22.

${ }^{569}$ Putting matters into context: the viewing rates of entertainment programmes reached $10 \%$ in 20I0, prompting SARFT to react even more strongly against these programmes from mid-20II onwards. He and Cao, $20 \mathrm{II}$.
} 
comment constructively ${ }^{570}$. After that, SARFT promulgated stronger regulations on "mass participation-type programmes ${ }^{571}$ ", and further cracked down on similar programmes. In 2007, for example, SARFT issued a Notice cracking down on the Chongqing Television programme The First Heartbeat, another talent show. SARFT found that "the competition sequence design of "The First Heartbeat" is ugly and crude, the jury's words, deeds and bearing are unmannered, its programme design lacks artistic level, content and artistic style is vulgar, the performed songs are philistine and vulgar. Chongqing Television does not take the least responsibility over live broadcasting, has not performed any effective handling of the utter disorder prevailing at the scene, have allowed these disordered performances, and have abandoned the responsibility of the broadcast organ. The Chongqing municipal radio, film and television bureau has not reported this situation to SARFT, to the detriment of management ${ }^{572}$."

Chongqing Television was ordered to implement rectifications, conduct internal examination, and gravely punish the personnel responsible for the programme.

A week later, SARFT promulgated a strict notice prohibiting all "makeover and sex-

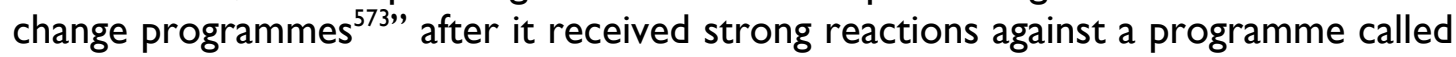
The New Beauty Testament, which contained amongst others graphic scenes of sexchange surgery. A Hunan Satellite Television talk show was cancelled by SARFT after discussing homosexuality during regular programming ${ }^{574}$. Dating television shows became subject of increased scrutiny in 2010. In two internal documents, SARFT banned "fake participants, morally provoking hosts and hostesses, sex-implied comments ${ }^{575, "}$. Programmes such as If You Are the One, Take Me Out and Run For Love, broadcast by Jiangsu TV, Hunan TV and Zhejiang TV respectively, whose popularity partly stemmed from the lively battles between participants and some heated debates touching upon social affairs, were criticized $^{576}$. Also, Anhui Satellite TV was ordered to erase footage from their dating programme You Are My Destiny, after a candidate declared that she'd rather cry in a BMW than smile on a bicycle ${ }^{577}$. In 2008, the film Lost in Beijing was taken off the market because versions containing "pornographic content" were published. The production company's permit was revoked, and the producer Fang Li was stripped of his production credentials for two years ${ }^{578}$. Also in 2008, the actress Tang Wei became subject to a SARFT ban. She had acted in the controversial film Lust, Caution, which became a huge success in an adapted version on the mainland. In the notice, SARFT indicated that "[a]ll television programs, including news, features, entertainment, advertising and live broadcasts, must not cover Tang Wei or stir up issues related to her from now on ${ }^{579}$."

\footnotetext{
${ }^{570}$ At that time, the "Eight Honours and Eight Shames", Hu Jintao's attempt to create a moral yardstick, were heavily promoted in State media. In the Super Girl finals, a contestant sang the "Eight Graces and Eight Shames Song”. Di, 201 I, p. 97.

57I 2007 Mass Participation Management Notice. Super Girl was taken off the air definitively in 201 I. Jacobs, $201 \mathrm{I}$.

5722007 First Heartbeat Notice.

${ }^{573} 2007$ Make-over and Sex Change Prohibition Notice.

${ }^{574} \mathrm{Di}, 20 \mathrm{II}$, p. 97.

${ }^{575}$ Lin, 2010.

${ }^{576}$ Yin, 2010.

${ }^{577}$ Xinhua, 2010B.

${ }^{578} 2008$ Lost in Beijing Circular.

${ }^{579}$ Martinsen, 2008.
} 
Second, propaganda departments are very wary of filmmakers or television programme producers addressing social, political and historical themes ${ }^{580}$. In 2006, filmmaker Lou Ye and producer $\mathrm{Nai}$ An received a five-year ban from filmmaking after entering their film Summer Palace for the Cannes Film Festival. Summer Palace contained both sex scenes and political undertones related to the Tiananmen Incident, which also led to SARFT refusing distribution permission. However, Lou stated that SARFT explained the refusal was due to inadequate technological quality ${ }^{581}$. For Lou, it was already the second ban, after he was barred from making films for two years in 2000, after screening his earlier film Suzhou River at the International Film Festival in Rotterdam. In 201I, SARFT promulgated a ban on television dramas containing time travel plots ${ }^{582}$. SARFT television drama department director Li Jingsheng stated that "Many stories are totally made up and are made to strain for an effect of novelty. The producers and writers are treating serious history in a frivolous way,

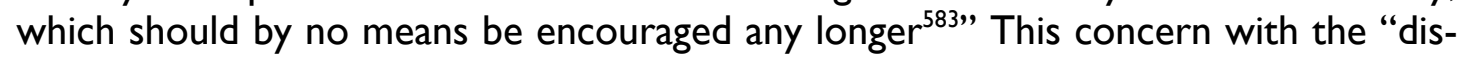
tortion of history ${ }^{584}$, stems from the concern that the use of historical contexts might be a way for subversive criticism of the present.

In an illustration of the increasing sophistication of the media control system, it seems that increasingly, responsibilities over media content is transferred to broadcasters or distributors. For example, at the end of 2009, the television series Narrow Dwellings was taken off the air by Beijing Television (although it kept running on a number of other television stations, such as Dragon TV in Shanghai). Li Jingsheng had criticized it, stating that Narrow Dwellings is popular because "It uses the topics of sex and officials to raise its profile ${ }^{585}$." The series described the life of two sisters coming to study in the large fictional city of Jiangzhou, and wanting to purchase a house after graduation. The narrative outlines how the increasing house prices affect the sisters' relationships; involving topics such as high interest loans, corrupt officials and extramarital affairs.

The conservatism of the censors varies with the political environment. During the latter half of the Eighties, for example, following the first wave of development, entertainment films became more accepted in their own right ${ }^{586}$. All of that changed after the Tiananmen incidents, as the cultural administration led the retrenchment by ordering the production of large numbers of main melody films ${ }^{587}$. Following the increasing commercialization of the film sector in the Nineties, entertainment films became grudgingly accepted as being successful (where main melody films often were not), and hence, efforts were made to include more entertainment aspects into main melody films ${ }^{588}$. By the end of the Noughties however, the political pendulum had swung back in the direction of conservatism, with an ongoing crackdown against po-

\footnotetext{
${ }^{580}$ As indicated in the previous Chapter, such films are subject to stronger content examination procedures.

581 Jones, 2007.

${ }^{582} 201$ I March Television Drama Notice.

${ }^{583}$ Branigan, $201 \mathrm{I}$.

${ }^{584}$ Global Times, $201 \mathrm{l}$.

${ }^{585}$ Liu, 2009.

${ }^{586}$ Zhang, 2008, pp. 2I - 25.

${ }^{587}$ Zhang, 2008, p. 38.

${ }^{588}$ Zhang, 2008, p. 63 et seq.
} 
litical activists and rights defence lawyers. Similarly, controls over the distribution of media in general (and the Internet in particular) were strengthened.

As indicated in the previous chapter, certain parts of the regulatory framework remain vague, and the different administrations have significant power to influence which works can be brought to market, and who can be permitted to do so. At the same time, the decision-making process remains opaque. Different media industry actors have complained about the lack of clarity in approval processes. Furthermore, the impact of regulatory action goes beyond the exact procedure to issue or deny approval. Warnings and statements concerning certain bellwether themes are enough to indicate the prevailing political winds, inducing strategic behaviour from media operators to align more closely with the Party's priorities of the moment. For example, when SARFT issued guidelines on television drama's including time-travel plot details, Professor Nie Wei, of the Shanghai University School of Movie and Television Drama Studies, stated that "a warning - it is not an official ban - from SARFT is already strong enough. [...]The producers of the Palace, the recent popular time travel drama, are changing their scripts [for the next series] ${ }^{589}$. In other words, this means that decisions to produce and distribute are not only dependent on the formal State regulations, which are relatively transparent, but that the true locus of these decisions lie in the much less transparent Party structure. The interplay between these two institutions not only creates a more complex picture about management in the media sector, it also becomes a problem when discussing China's WTO commitments ${ }^{590}$.

Is it good to have friends come from afar? - Mistrusting foreigners and the history of national humiliation

Another important aspect in China's audiovisual media strategy is the limitations that are placed on the entry of foreign products, foreign capital and foreign businesses into the marketplace. This strategy combines political, moral and economic considerations.

Politically speaking, nationalism has become a prime basis for legitimacy after the end of Maoist ideology ${ }^{591}$. A significant part of the nationalist narrative is built on the premise that China, once the greatest power in the world, was subdued by imperialist foreign nations and attacked by an aggressive Japan. It was the Communist Party who in 1949 made an end to this century of "national humiliation" (国耻 guochi ${ }^{592}$ ) and put China on the path to renewed greatness, the story goes. One example of this is the massive anti-Japan campaign that overwhelms China's television cannels and movie theatres every fifth anniversary of the victory over Japan in 1945. During this period, a host of news items, television documentaries and dramas, films and other publications aims to boost the Party's image as national saviour versus the Japanese aggressor. In this period, foreign films are not screened in cinemas ${ }^{593}$.

\footnotetext{
${ }^{589}$ Branigan, 20II.

${ }^{590}$ See Chapter VII.

59l Shirk, 2007, p. 85. See also Rosen, 2006, pp. 97-I 18.

${ }^{592}$ A thorough study of the particular mode of communication influenced by the idea of guochi can be found in Callahan, 2009.

${ }^{593}$ Shirk, 2007, p. I7I.
} 
A second basis for distrusting foreigners is distilled from the diagnosis of the USSR's dissolution. One of the major causes of this in the eyes of the party was the tactic of "peaceful evolution" employed by the West to mobilize the citizenry against the state ${ }^{594}$. The leadership remains wary of this, and perceives foreign - and mainly American - media as a potential Trojan horse, brought into China by fearful or hostile foreign governments in order to stall China's resurgence and Westernize its population. This concern certainly fuelled the dispute about Google's refusal to continue to censor search results as required by the Chinese government. Hence, foreign television channels are unavailable to the general population, and may not be advertised, where they are available, in luxury hotels. Foreign media companies that have been "unfriendly" to China, may be banned from operating on Chinese territory ${ }^{595}$. Related to this, are concerns about the extension of the American cultural dominance ${ }^{596}$.

Third, conservative elements within the propaganda administration feel that foreign media products are often degenerate. This view is shared by a certain part of China's film sector. Leftist intellectuals, for example, find that Hollywood movies are stereotype genre movies, driven by huge investment, developed along standard story lines, featuring popular stars and filled with special effects ${ }^{597}$. According to this view, the commoditisation of films deprives them of aesthetic value and philosophical depth, as they only provide superficial pleasure and satisfaction. In the words of one critic: "Western movies and television shows, represented by the United States, are fraught with pornography, violence and crimes in the name of reflecting social problems and exploring the distorted human life. After giving sensational stimulation, what these films leave for us are only restlessness, fear and lost hearts. Hollywood was once a world art center by praising things genuine, virtuous and beautiful. However, contemporary Hollywood, to a large degree, is immersed in exaggerated depictions of the lost human nature under serious social problems including economic recession, violence, sex crimes, homosexuality, and drug addiction. Among the 10 imported foreign megaproductions last year, seven were from Hollywood. Except for Forrest Gump and Lion King, others are all full of bloody murders, gunfights, and sexual temptations ${ }^{598}$ ". Later, the nationalist book China Can Say $\mathrm{No}^{599}$, lashed out at Hollywood, stating that "Violence comes to Hollywood movies as a natural company of individual acts of heroism, while individual acts of heroism reinforce violence. This is the most common way of expression of Hollywood movies. Accompanying individualism is degraded hedonism. Because of serious social problems, like financial crisis, family crisis, racial discrimination, violent crimes, sex liberation and drug addition, American people are extremely pessimistic, confused and self-abandoned. All these down moods are tapped and exaggerated by Hollywood for profits ${ }^{600}$."

\footnotetext{
${ }^{594}$ See earlier.

${ }^{595}$ For example, the 2005 Sino-Foreign Joint Venture Notice indicated that foreign companies wanting to do business in China could not have a "record of being unfriendly to us within three years before the date of application."

${ }^{596}$ Keane, 2007, p. 20.

$597 \mathrm{Su}, 201 \mathrm{l}$.

${ }^{598}$ Quoted in Su ,201I.

599 This book, published in 1996, was an emotional and disillusioned protest of five young writers against America's posturing against China. Rosen, 2006, p. 107.

${ }^{600}$ Quoted in Su, 20II.
} 
The mistrust of foreign attitudes towards China shows most clearly where foreign films refer to China in some way. For example, the Departed, a 2007 film by Martin Scorcese, was apparently not permitted on the Chinese market because its plot contained mentions of Chinese military acquisitions ${ }^{601}$. Similarly, certain passages in Pirates of the Caribbean: At World's End involving the Chinese pirate character Sao Feng were edited out, because they were deemed to insult Chinese sentiments ${ }^{602}$.

Apart from political and moral concerns about content, there also are economic concerns about China's marketplace being swamped with foreign products, destroying the local film and television industries. The Chinese government is quite aware of the fact that the Chinese film sector lacks the advanced technology and business expertise the large international media conglomerates have. Furthermore, they have seen what happened to Taiwanese and Hong Kong cinema when Hollywood set its sights on the region. From the late Seventies to the early Nineties, the Taiwanese film market was protected by import quotas, which were beneficial to Hong Kong films, as these were considered by Taiwan to be domestic. As a result, Hong Kong and Taiwan films jointly occupied about half of the Taiwanese film market, which was at that time also Hong Kong's largest export market. Increasingly, however, local distributors and cinemas lobbied for lifting of the foreign film import quotas, which were progressively relaxed and finally abolished in 1996. As a result, cinema box office intake more than doubled over three years with the inflow of Hollywood blockbusters. However, this hit the profitability of Hong Kong and Taiwan film hard. In 1997, only three Hong Kong films grossed more than NT\$10 million, and only three Taiwan titles grossed over MT\$I million. By 2000, Hollywood commanded 93 per cent of the film market, with Chinese films relegated to 2.5 per cent ${ }^{603}$. Korea, on the other hand, still has film quota in place, requiring that 73 days per year be reserved for the screening of Korean films ${ }^{604}$. This is considered to have brought about the Korean film sector's resurgence. Between 1996 and 2005, Korean box office intake tripled, while Hollywood's market share halved from 77 percent to 38 percent.

\section{The Party-State's message}

On the basis of the background outlined earlier, the Party-State has developed an elaborate communication strategy, with the goal of confirming and maintaining the Party's political predominance and legitimacy. This strategy has both domestic and international aspects, and relates to content control, technology, infrastructure, as well as economic aspects of the communication sector. These policies have grown ever more sophisticated, aiming to make the media sector economically successful and influential, so it can better fulfil its propaganda function. Technological innovation and import policies can be seen in this regard as making media accessible to wider audiences, as well as providing better quality, which should increase attractiveness. At the same time, maintenance of ownership over infrastructure and strict parallel control through the Party system are guarantees for the continued control over the sector. Most important, however, remains the content. This is built on a number of themes, mainly revolving around nationalism, economic growth and - increasingly China's growing international clout.

\footnotetext{
${ }^{601}$ Reuters, 2007D.

602 BBC, 2007.

${ }^{603}$ Curtin, 2003, pp. $247-269$.

${ }^{604}$ Although Hollywood pressure is present here as well. Choi, 2010.
} 


\section{How the CCP makes the country great.}

Implicitly and explicitly, China's internal communication strategy has transformed from an ideology-driven discourse to emphasizing nationalism. The role of the Party in the discourse has been subtly shifted from the traditional communist discourse based on class struggle, to a nationalist and growth-related discourse in which the Party is the indispensable protector of the Chinese national interest and unity, as well as the international stature of the country, and the driving force of economic development. This message is most clear in news media. During calamities, such as the 2008 Wenchuan earthquake, significant amounts of attention are given statements by Party leaders and rescue efforts by the armed forces. Other groups, such as the Red Cross, or in the case of the 2010 Yushu mudslide ${ }^{605}$, Lama monks, are hidden from view. Similarly, large propaganda efforts are held around large events such as the 2008 Beijing Olympics and the 2010 Shanghai Expo, which demonstrate the Party's success in making China a strong and wealthy nation ${ }^{606}$. Party propaganda is also present in fiction programmes, with the main melody films as the best example. These films have become more sophisticated as time has gone by. Founding of $a$ Republic, the 2009 epos commemorating the establishment of the People's Republic, was praised for its nuanced depiction ${ }^{607}$ of Mao Zedong and Chiang Kai-shek. At the same time, reviewers indicated the revisionism present in the film plot, which could be explained as an attempt to legitimize the economic reform process through fiat by a fictional Chairman $\mathrm{MaO}^{608}$. The dominant dogma of that time, that of class struggle and anti-bourgeois sentiments, cannot be found in the film.

During the ideological retrenchment of $20 \mathrm{II}$, this glorification of past Communist history gained speed. Referred to as "Red Culture", this drive consists of a diversity of subjects. Communist history tourist destinations, such as the wartime base of Yan'an, the birthplace of Mao, the old location of the Jiangxi Soviet, and even a southern region of Hainan province, in which the celebrated "Red Women Detachment" fought, are becoming increasingly popular ${ }^{609}$. In Chongqing, populist Mayor Bo Xilai ordered State media to promote 36 "Red Songs", which praised the CCP, and to drop entertainment programmes from the schedule, in favour of traditional revolutionary plays ${ }^{610}$. In Shandong, revolutionary "Red Games" were organized, where contestants competed in events such as the $40 \mathrm{~m}$ grenade toss, stretcher-carrying races and a minefield steeplechase ${ }^{611}$.

\section{“Marching out”: China's external propaganda}

As China's integration in the international world gained speed, including the China's successful bid for the Beijing Olympics as well as the Shanghai Expo, and WTO accession international attention China increased and criticism of China did not abate. At the same time, China found that it had not yet accrued the necessary political clout to be taken seriously as an important power at the international level, and that it was not able to significantly influence or dominate the international economic structure. As propaganda chief $\mathrm{Li}$ Changchun later outlined in a speech, it was felt in

\footnotetext{
605 Jacobs, 2010.

${ }^{606}$ Polumbaum, 2003. For a broader analysis, see also Price and Dayan, 2008.

${ }^{607}$ Pan, 2009; Davies, 2009.

${ }^{608}$ Davies, 2009; Abdoolcarim, 2009.

${ }^{609} \mathrm{http}: / /$ www.theage.com.au/travel/allfemale-army-unit-lures-red-tourists-201 I 0502- l e3xo.html

${ }^{610}$ Moore, 2011 .

${ }^{611}$ Foster, 2010.
} 
Beijing that "Communication capacity determines influence. In the modern age, whichever nation's communication methods are most advanced, whichever nation's communication capacity is strongest, it is that nation whose culture and core values are able to spread far and wide, and that nation that has the most power to influence the world ${ }^{612}$."

In response, the Chinese government started paying more attention to its international image, its influence and its "soft power". Audiovisual media would play a large role in this. At the end of 200I, this “marching out" (走出去 zouchuqu) project was concretized $^{613}$. The prime objective of the project was defined as "making China's voice being heard all over the world". Concretely, it meant that worldwide audience would be presented with "an authentic China", understand the Chinese position, attitude and point of view in international affairs. The objective was that by 201 I, Chinese radio, film and television would have the same influence as the large Western media conglomerates. Later, the "marching out" project was written into policy documents on radio and television development ${ }^{614}$, cartoons ${ }^{615}$, the press and publications industry ${ }^{616}$ and audiovisual products ${ }^{617}$. The latter document targeted that every year, 100 audiovisual programmes and 20 audiovisual enterprises would be awarded for their merits in supporting the project. However, this project has not been very successful, as indicated later in this Chapter.

\section{Dealing with foreign media enterprises}

As already indicated, the government is very wary to open the doors to foreign media conglomerates, as they fear both the socio-political and economic impact of opening the market. Yet, the leadership also recognises that foreign media conglomerates do possess capital, technology, expertise and other inputs that are considered to be useful for developing the local audiovisual media sector. As a result, the regulations and measures concerning market access for foreign media are structured in such a way that the desired aspects of foreign participation are attracted, while other activities remain restricted. In other words, rather than fully rejecting the interaction with the international media giants, the Chinese government is willing to deal with them, but on its own terms. This explains why the Chinese WTO commitments as to services were extremely limited ${ }^{618}$, allowing SARFT and other departments to maintain restrictive market access measures for operators and products ${ }^{619}$.

The different regulations on investment, outlined in the previous chapter, provide some insight in the leadership's priorities. The government aims to support exactly those inputs that will make it possible for the sector to better fulfil the governmentmandated tasks, while barring potentially destabilizing content. As a result, sometimes even going against some aspects of import regulations, the leadership has permitted and supported a number of selected foreign media enterprises to enter the Chinese market, on the presupposition that they would work together with the gov-

\footnotetext{
612 Bandurski, 2009.

${ }^{613} 2001$ Radio, Film and Television Stepping Out Rules.

${ }^{614} 2004$ Radio and Television Development Opinions.

${ }^{615} 2006$ Cartoon Development Opinions, 2008 Cartoon Development Opinions.

${ }^{616} 2010$ Press and Publications Industry Development Opinions.

6172009 Audiovisual Industry Growth Opinions.

${ }^{618}$ Chinese Services Schedule, see also Chapter VII.

${ }^{619}$ See also Guo, 2003, pp. 5-19.
} 
ernment. In television, Rupert Murdoch was permitted to broadcast to the mainland with the Hong Kong-based station Phoenix TV. Viacom has brought its MTV channel to parts of China in conjunction with CCTV, and also offers part of its Nickelodeon cartoon channel through CCTV ${ }^{620}$. However, MTV is required to include nationalist and patriotic motives in its programming ${ }^{621}$. Soon after WTO accession, Murdoch's News Corporation and AOL Time Warner received approval to air to Southern Chinese audiences, provided that they would offer the English-language channel CCTV 9 to American audiences ${ }^{622}$. Warner Brothers has been very active in China. In 2004, it established a joint venture with China Film Company to produce films in China, and was also the first major Hollywood studio to offer its films through VOD on the mainland, cooperating with a Beijing content distribution company ${ }^{623}$. Fox News - again, owned by Rupert Murdoch - assisted CCTV in setting up a more modern, attractive English-language website for foreign audiences ${ }^{624}$. In 201 I, Warner Bros signed a deal with a CCTV subsidiary to offer Warner movies through cable networks. However, questions remain over the legality and viability of these services $^{625}$.

\section{Reactions, contestation and pushback}

As far as legitimate media goes, the Party-State's media policy seems to be successful in achieving its political objectives. However, it has created a number of conflicts and inconsistencies. Media enterprises are at once exposed to the market logic, as well as Party-State requirements. At the same time, little indication in the media policy document is given on how media reform will be paid for. The assumption seems to be that simply introducing market mechanisms into the media sector might generate the necessary capital. Even if that might be true in the longer run, in the short run investment is necessary. Hence, there are struggles to bring programmes to television and films into the cinema as quickly as possible ${ }^{626}$. Furthermore, there are indications that short-term profits are favoured, given the expectation that the political environment could change relatively rapidly, and that good times may not last ${ }^{627}$. Audiences seem to be dissatisfied with the scope of programmes that the Party-State will permit them to view. Finally, foreign operators, with a few exceptions, have not yet penetrated the market because of market entry restrictions. Those that have, have been able to do so by cultivating good relationships with the government, and bringing technology, skills and know-how that were deemed to be welcome for the domestic media sector. However, these relationships remain unstable and asymmetrical.

\section{Domestic media outlets}

In contrast with the relatively strict censorship framework, a number of provincial and regional satellite channels have been very successful in responding to the opportunities for commercialization that have been brought to the television sector, particularly in sports and drama ${ }^{628}$. These channels have to fill demand for subscribers,

\footnotetext{
${ }^{620}$ Fung, 2007, pp. 66 et seq.

${ }^{621}$ Fung, 2007, p. I0I.

${ }^{622} \mathrm{He}, 2003$, p. 210.

${ }^{623}$ PRNewswire, 2008.

${ }^{624}$ Goldkorn, 2006.

${ }^{625}$ Landreth, 20II.

${ }^{626} \mathrm{Di}, 201 \mathrm{I}$, p. 95.

${ }^{627}$ Shi, 2008, pp. I25-I 26.

${ }^{628}$ Chan, 2003, pp. 165-169.
} 
and have the advantage of being able to use satellite technology to broadcast over very wide areas. This brings them into conflict with the central broadcaster, CCTV, which still enjoys political preponderance ${ }^{629}$. One significant example of this is Hunan Satellite Television. This station has produced a number of highly successful commercial programmes, including the TV talent show Super Girl, first broadcast in 2004. Other challengers come from Hong Kong. The semi-Chinese broadcaster Phoenix Satellite TV - a joint venture between Rupert Murdoch's STAR TV and Chinese interests - broadcasts to urban audiences all over China. While it has had to cultivate its relationships with the government to do so, its scope of broadcasting is much broader than CCTV's, eroding the central dominant voice ${ }^{630}$. At a more grass roots level, there are small public demand-driven illegal television stations in Anhui that respond to popular demand, outside of any regulatory framework ${ }^{631}$.

The other prime beneficiaries of the official system's lacklustre offerings have been on-line media enterprises. While websites such as Tudou and Youku have come under scrutiny for piracy, they are not yet as high on the leadership's radar as television is where content is concerned ${ }^{632}$. Also, they are not subject to the film import quota or the broadcast screen quota. These websites have invested substantially in producing their own content, and licensing foreign films and television programmes $^{633}$. This business is growing rapidly, with advertising income tripling from 83 million USD in 2008 to 346 million in $2010^{634}$. Nonetheless, as these sites grow, displaying the capacity and willingness to self-censor will be crucial for their survival.

\section{Foreign media operators}

Not all foreign experiences of the Chinese media market have been successful. Warner Brothers, for example, pulled out of a number of cinema joint ventures in Shanghai, Nanjing, Guangzhou, Chongqing, Changsha and Nanchang in 2006. While these cinemas were very successful economically, the regulatory environment had shifted $^{635}$. Concretely, the 2005 Foreign Investment Opinions reversed the earlier provisions of the 2003 Foreign Cinema Investment Regulations that permitted 75 per cent foreign participation in mainland cinemas, reducing the participation limit to 49 per cent. After considering different options, Warner decided to end their investment. Hollywood majors remain anxious to enter China's market in full swing. However, all majors also have existing operations on the ground in related areas such as merchandising, apparel, theme parks and the like. Consequently, they tend to prefer to lobby the US Government for increased market access, rather than directly dealing with the Chinese government, as this might jeopardize their existing operations.

\section{Audiences}

Not only media operators themselves react against the Party-State's communication policy. Far from being passive subjects of an authoritarian propaganda steamroller,

\footnotetext{
${ }^{629} \mathrm{Hu}, 2005$, p. 15.

${ }^{630}$ Chan, p. 168.

${ }^{631}$ Pan, 2011.

${ }^{632}$ Part of the reason for this is that on-line audiovisual media did not fall immediately within the core competencies of the existing media bureaucracies, prompting the institution of a new State Internet Information Office, to be responsible for, amongst others, online audiovisual services, gaming and social media. Xinhua, 20IIB.

${ }^{633}$ Einhorn, 2011.

${ }^{634}$ Barboza, 2010B.

${ }^{635}$ Fung, 2007, pp. 73-78.
} 
Chinese audiences are increasingly disillusioned with the official discourse, and demand arises for more diverse offerings ${ }^{636}$. Pang diagnoses this as turning away from the public sphere of political propaganda, into the private sphere of home entertainment ${ }^{637}$. Fung explains how the privately owned Phoenix television channel has turned large viewing numbers away from State-owned competitor CCTV ${ }^{638}$. This has led to increasing tensions between the two channels, with CCTV using its clout to stifle Phoenix, but Phoenix relies on its high standing with the central leadership to fight off the CCTV attacks. In any case, Phoenix' success illustrates the uncompetitiveness of the State-owned television company, while at the same time providing an answer to what a modern, Chinese television station could look like.

Similar problems are arising with another mainstay of Chinese television: the CCTV Spring Festival Gala ${ }^{639}$. While watching the Gala has become a tradition in many households, in recent years, it has come under increasing attack from different sides. Audiences find it increasingly remote from reality, according to a Sina.com poll quoted in the Global Times. In 20I I, reactions indicated that the show is seen as a political tool, and at the same time is also accused of portraying farmers in a disparaging way ${ }^{640}$. Tellingly, other Party-State institutions increasingly criticize the gala. In 2007, Xinhua News Agency reported "Cross-talks and stand-up routings were among the programs that drew most audience since 2000. However, audience expressed their disappointment at the invariable boring pattern and old faces of actors and actresses". In 201 I, six major provincial television stations opted against broadcasting the Gala, citing its "waning influence and CCTV broadcast fees ${ }^{64 l}$ " as reasons. Progressive southern newspaper Southern Metropolis Daily condemned the 201I show by stating that "Even if immortals entered the human world, they would be unable to save the Spring Festival Gala. ${ }^{642 \text {," }}$

The same is true for main melody films. This concept has evolved in lockstep with the increasing sophistication of China's audiovisual media sector, and became entrenched in the Changsha Conference of March 2006, which decided that ideological rectitude should become the basis for further development ${ }^{643}$. However, even with all the financial support and other backing the State issued to these films, many of them flopped. In 1999, the film Guoge (National Anthem), which cost 20 million CNY to make, only took in 15 million in box office, and a large part of this was due to subsidized ticket purchases ${ }^{644}$. In $201 \mathrm{I}$, various means were deployed to make the box office intake - intended to top 800 million CNY - of Beginning of the Great Revival seem higher than in real life. Sometimes cinema tickets were printed for this film, and then overwritten by hand with the title that the viewer really wanted to see. After on-line reviews posted about the film were overwhelmingly negative, film

\footnotetext{
${ }^{636}$ Sometimes, this happens through illegal means. In 2008, over 10 million satellite dishes prepared to receive international signals were reportedly exported to China. In principle, these are prohibited. Fletcher, 2010.

${ }^{637}$ Pang, 2006, p. 108.

${ }^{638}$ Fung, 2007, p. 129.

${ }^{639}$ For a broader evaluation of the Spring Festival Gala's political content and function, see Lu, 2007.

${ }^{640} \mathrm{Fu}, 201 \mathrm{I}$.

${ }^{641} \mathrm{Wu}, 201 \mathrm{I}$.

${ }^{642}$ Zhang, $201 \mathrm{l}$.

${ }^{643}$ Zhang, 2008, p. 63.

${ }^{644}$ Rosen, 2002, p. 75.
} 
review websites were ordered to shut down the review option for this film ${ }^{645}$. For this film, blockbuster Transformers 3 had been postponed ${ }^{646}$. As a result, commercial pressures have pushed main melody filmmakers to become slightly more responsive to audience needs, in diverse ways. For example, during the late Nineties, main melody films turned away from celebrating large events and great personages of Chinese communist history, to re-telling CCP ideology through the eyes of individuals, closer to life and closer to reality, as indicated in a number of policy documents ${ }^{647}$. Also, significant efforts have been made to raise the technological quality of films. To a certain extent, this has paid off. Recent main melody films such as Founding of a Republic and Aftershock boast impressive special effects and backdrops, and the efforts that are made to enhance the visual quality of films are clear. At the same time, however, main melody films are not successful in capturing the top of the box office intake, which remains mostly populated by imported films, and in recent years, by non-main melody films. Illustratively, the Shanghai gangster drama Let the Bullets Fly, directed by Hong Kong film director jiang Wen, became the highest grossing Chinese movie ever. It was lauded for combining a strong plot, high artistic quality and maintaining a clear vision in the face of Chinese censorship ${ }^{648}$. Five days after it started screening, SARFT issued a direct order to cut back screenings of the film and replace it with the Feng Xiaogang film If You Are The One $2^{649}$.

China's cultural export plan also seems to be failing. While China's cultural trade deficit spurred the leadership to formulate the "marching out" policy, they seem not to have taken foreign audiences' demand into account. According to the export plans, exported content should "reflect our country's modernization drive accomplishments and outstanding culture ${ }^{650}$." In other words, Chinese content would foreground socialist ideology and Chinese culture. However, in the international market, these Chinese offerings pale in comparison with other Asian suppliers ${ }^{651}$. They also reinforce the image of China as an authoritarian and controlled state with foreign viewers ${ }^{652}$. In other words, through emphasizing a particular version of Chinese content, media policy seems to alienate the very foreign audiences it aims to attract. Indeed, the few Chinese films that became successful abroad, came from a stream of “cinema of attraction", emphasizing visual aspects, while de-emphasizing storylines ${ }^{653}$.

\section{Conclusion}

An analysis of the history of China's political culture shows that the current political structure of the Chinese state still resembles the power structures developed during the Imperial era, while adding Leninist aspects of social penetration. As a crucial link between the Party leadership and the Chinese population, as well as a carrier of political ideas, media have been imbued with special political significance from very early

\footnotetext{
${ }^{645} \mathrm{Kan}, 201$ I. Kan also indicates that these reviews often contained criticism of the current PartyState, asking why the film glorified past revolution while present revolution was impossible. 
onwards. Hence, they remain a crucial part of the Party-States legitimizing apparatus, and are recognized as such.

The primary mission of the audiovisual media is to enhance the Party-State's legitimacy at home. However, there are other political interests, which sometimes align, but sometimes compete as well. In recent years, developing the cultural sector has become a part of China's economic development priorities, meaning that the sector needs to become more competitive at the international level. Moreover, the crucial tension remains between the economic interest of individual actors and the political interests of the Party-State ${ }^{654}$. Many economic reforms in the sector have been undertaken, which have made China's media enterprises increasingly independent from the State, but also increasingly subject to the market logic. However, this has not been complemented equally with an increasing independence in terms of which films and programmes can be made and broadcast. In the words of a Chinese film director: "We know what our leaders want from a film, we don't know what the market wants ${ }^{655}$ ". As such, China's audiovisual media sector can be seen as a microcosm of the wider society, in which economic development and political reform have not proceeded at the same pace, resulting in similar tensions.

In the media sector, these tensions become manifest as operators have sought to maximize their income, even if that means challenging the boundaries of what is permissible. The commercial success of many of these more controversial problems seems to indicate that the tastes of the Chinese audience are much broader than what the leadership deems fit for broadcast. This supports the central argument of the previous Chapter, namely that a reduction of the permitted scope of works translates in an increased demand for products outside of that scope, which can only be delivered illegally. It also raises questions as to implementation and enforcement of media regulations. Given the already indicated link between media enterprises often State-owned - and the Party-State apparatus, it is not unreasonable to assume these tensions will translate into certain outcomes, in which one side or the other of the tension will prevail over the other. How this happens, must be viewed through the prism of the incentives of individual State officials, media regulators and enterprises, as well as their political stature and how these are played off against each other. Hence, in order to further understand how piracy is enhanced through shortcomings in enforcement and implementation, it is necessary to look into how the regulations outlined in the previous chapter are implemented and enforced in the light of both the policy objectives and the inherent tensions in the media sector.

\footnotetext{
${ }^{654}$ As Laikwan Pang states: "the government holds onto the ideological purity and unity of the national cinema by creating tight restrictions on film production and distribution, but such stringent controls encourage a new form of cinema activity - piracy - which totally evades the control of the government." Pang, 2006, p. 100.

${ }^{655}$ Chu, 2002, p. 44.
} 


\section{Chapter VI: Enforcement}

A number of conclusions can be drawn from the previous chapters: China's copyright law at present is on par with international obligations, and has been mostly so for quite some time. The copyright legislation is part of a broader, intricate and interlocking system of administrative regulation that controls the production and distribution of audiovisual media. The Party-State exercises strict control over the sector because of political reasons directly linked to the legitimacy of the system and its chances of survival. Hence, piracy is at least as much a violation of media regulation as it is of copyright. And yet, pirated works remain widely available on the audiovisual products market and on the Internet, television channels keep broadcasting prohibited programmes and keep pushing the limit of acceptability in terms of entertainment. In other words, there is a paradox between the apparent importance of media control, and the Party-State's capacity to fully realize this control.

In order to resolve this paradox, this Chapter argues that it is necessary to view it in the light of a larger paradox: how is it possible that an organization - the CCP - that has so strong a hold on the Chinese body politic, in combination with the State power over which it has a monopoly, has significant problems with policy implementation? In this sense, copyright piracy is not a stand-alone problem. Rather, it is symptomatic for a system in which the deck is stacked against consistent policy implementation. Given China's size and internal diversity, it is not strange that implementation of different policies or regulatory frameworks differs across regions, but in a number of areas, this seems in spite of rather than because of the stated objectives and claims that the Party-State makes, or institutional design. This chapter proposes that many Chinese social issues, not only anti-piracy enforcement, but also product quality, food safety, environmental protection, etc., are the negative externalities of a dysfunctional social organization structure that is aimed primarily at maintaining the governing position of the Party, at the expense of substantive policy considerations. As a result, policy implementation and law enforcement are hampered by the conflicting incentives created by the Party-State structure itself.

These two paradoxes are addressed in three steps. First, the different kinds of liabilities and enforcement responsibilities are outlined for both copyright and media control laws and regulations. These can be divided in State-based enforcement through administrative or criminal procedures, and civil enforcement, through the courts. Second, in an analysis of State-based enforcement, the question how the alignment of political incentives results in low priority and attention for anti-piracy enforcement, and why the enforcement that does occur is often of low quality and unsustainable, and does not have long-lasting results. This part covers both administrative and criminal enforcement. Third, the question on how the civil judiciary deals with piracy matters and its potential deterrent effect is discussed. In the last section, Internet piracy enforcement is taken as an example of how piracy through different means changes the alignment of enforcement incentives, and the impact of this on piracy activity.

The legal framework of anti-piracy enforcement.

To better understand the dynamics anti-piracy enforcement in China, it is necessary to look beyond copyright law and related enforcement activities and institutions. 
Apart from copyright, audiovisual media piracy is subject to a plethora of laws and regulations, which also include the media control measures outlined in Chapter IV, as well as criminal law articles on smuggling, distributing obscene publications or disturbing market order. In that sense, rather than automatically coupling piracy to copyright, it is more useful to see piracy as an infraction against the media regulation order, of which copyright infringement is only one modality. Because of this, antipiracy is not always conducted under the banner of copyright. Rather, copyright infringement is one of the many justifications used in countering piracy activities, along with matters such as "safeguarding social and political stability, promoting mental and physical health of minors, [...], safeguarding national cultural safety ${ }^{656 ",}$ or "creat[ing] a harmonious and stable social cultural environment for the 60 years of New China's establishment ${ }^{657}$ ". This limited role of copyright is reinforced by the institutional structure responsible for anti-piracy enforcement, where the National Copyright Administration essentially is nothing more than a department of the press and publications administration. The judiciary seems to take the same view, as evidenced by a 1998 Supreme People's Court Interpretation that outlined the legal basis for criminal prosecution of cases involving illegal publications ${ }^{658}$.

Copyright law provides for three different kinds of liability, and hence, three different kinds of procedure ${ }^{659}$. Two of these, the administrative and criminal procedures, are vested in State organs. Interested parties may bring a case to an administrative enforcement body, but they are not entitled to compensation through this procedure. On the other hand, the procedure is much simpler for these parties. Generally, criminal liability arises where administrative enforcement organs find that an infraction meets criminal thresholds. These organs are then supposed to transfer these cases to the procuratorate, for further prosecution.

However, criminal liability can also arise out of other articles, as clarified in the 1998 Interpretation. Illegal publications aimed to destabilize the state or incite rebellion are punishable under Articles 103 and 104 of China's Criminal Law ${ }^{660}$. Article 152 of the Criminal law expressly provides for severe punishments for smuggling of obscene articles. In grave cases, life imprisonment can be imposed ${ }^{661}$. Article 153 provides that those smuggling other articles can also be liable to criminal punishment, depending on the payable tax evaded ${ }^{662}$. Article 363 of the Criminal Law would be applicable in cases of production, dissemination, sale or broadcast of obscene publications $^{663}$. Lastly, until the Copyright Law revision of 2010 , there was a problem of how to deal with criminal enforcement over foreign products that had not been approved on the Chinese market, as these would not enjoy copyright under the provisions of Article 4 Copyright Law. This was solved by making such activities punish-

\footnotetext{
${ }^{656} 2010$ Expo Campaign Notice.

${ }^{657} 2009$ Cultural Market Discipline Notice.

658 I 998 Illegal Publications Interpretation.

${ }^{659}$ In the 2010 Copyright Law, the grounds for civil liability are listed in Articles 47 and 48 . Article 48 also provides for administrative enforcement procedures where public interests are harmed. The basis for the criminal procedures can be found in Articles 217 and 218 of the 1997 Criminal Law, dealing respectively with infringing reproduction and sale of infringing products.

6601997 Criminal Law, Articles 103 and 104.

${ }^{661}$ Id., Article 152.

662 Id., Article 153.

${ }^{663}$ Id. Article 363.
} 
able under the broad provisions of Article 225(3), which concerns disturbing market order $^{664}$.

The regulations on media control are purely administrative or criminal. Given that there are no civil rights or obligations created through the plethora of administrative regulations, the administrative bodies in charge of regulation are also in primary charge of enforcement, the one exception being criminal enforcement. Generally, grounds for administrative punishment can be divided in a number of broad categories, corresponding with the categories of media sector control outlined in Chapter IV. The first one of these is operating without a licence, or outside of one's permit scope. Second, there is the production, distribution or sale of unauthorized products. Third, there is changing important business matters, such as shareholding structures, important personnel, etc. without approval. Fourth, there is unapproved use of certain facilities. This concerns for example television channel operators renting or selling broadcast time, transmission stations inserting commercials, using satellites and other infrastructures, cinema renovation, etc.

Hence, the majority of anti-piracy enforcement is State-based, requires State input, and is initiated and carried out by administrative bodies. While many countries provide for criminal copyright enforcement, China's administrative enforcement system - at least in the audiovisual media sphere - is one-of-a-kind ${ }^{665}$. This has one significant consequence. In Western economies, under the presupposition that piracy is an infringement of a private party's copyright, it is typically up to the party to initiate enforcement proceedings through the courts, in defence of their private intellectual property rights ${ }^{666}$. In China, where piracy primarily infringes publishing discipline, and there is much less of a private rights tradition, administrative enforcement is primarily aimed at protecting the interests of the Party-State, and is also subject to significant administrative political economy issues. Because of this, the large role of administrative governance plays in the organization of audiovisual media production and distribution may in fact enhance piracy action rather than inhibit it. The following section addresses the question of why administrative anti-piracy action seems so ineffective by first outlining the broad conflicts of interests and misaligned incentives that are generally inherent in the way China's administration is constructed. Second, it outlines a number of factors inhibiting enforcement that are specific to the governance of the audiovisual media sector.

\section{Administrative enforcement and its problems}

China seems to have a general problem with both policy implementation, making sure that administrative departments fulfil their obligations according to instructions, and enforcement, State-based punishment of violations against laws or regulations, aimed at bringing about compliance. This in turn results in a low level of internal compliance - State actors fulfilling their tasks and refraining from corruption, power abuse and other misdeeds - as well as external compliance, or non-State actors obeying the law. It would be beyond the scope of this study to offer an exhaustive explanation of this phenomenon, including causal connections and empirical study.

\footnotetext{
${ }^{664}$ Article II, 1998 Illegal Publications Interpretation.

${ }^{665}$ Ranjard, 2005.

${ }^{666}$ Although in recent years, the copyright lobby has been pushing towards stronger criminal enforcement of copyright infringement, partly to offset enforcement costs. For a critique of this evolution, see Moohr, 2003; Lessig, 2004.
} 
Rather, this section aims to identify the main contributing causes of an internal administrative nature. In all this, it is necessary to understand that in the end, the question that must be answered is why administrative enforcement does not seem able to lower piracy numbers. This could be explained broadly in two ways: either there is a lack of enforcement capacity, or individual enforcement personnel are not carrying out their work in such a way as to diminish piracy. In turn, this individual agency arises out of the structural framework in which these officials operate. In case of piracy, it is proposed that both aspects are present to some extent.

\section{Capacity}

In comparison with the long list of duties of all central audiovisual media departments, the number of officials working on audiovisual media regulations is relatively small. In 2008, the staff allotment of SARFT was fixed at 292 posts. A number of these posts deal with retired cadres, and it must be assumed that a further number is tasked with administrative support that does not pertain to substantive duties. These are divided into 12 departments: the General Office, the Laws and Regulations Department, Propaganda Management Department, Film Management Bureau, Television Drama Management Department, Communication Media Organ Management Department, the Network Audiovisual Programme Management Department, Science and Technology Department, Planning and Financial Department, International Cooperation Department, Human Resources Department and Safeguard department ${ }^{667}$.

Similarly, the GAPP, which is the prime entity in charge of law enforcement against pirated hard goods, and which harbours both the National Copyright Administration and the saohuang dafei office, is only allotted 196 posts, also divided over twelve departments: the General Office, Laws and Regulations Department, General Professional Department, Publishing Industry Development Department, Newspapers and Periodicals Department, Publications Management Department, Printing and Distribution Management Department, Science, Technology and Digital Publication Department, Anti-Illegal and Infringing Publications Department ${ }^{668}$, the Copyright Management Department, the Foreign Exchange and Cooperation Department and the Human Resources Department. The Copyright Management Department is nothing other than the National Copyright Administration ${ }^{669}$.

The Ministry of Culture has a somewhat larger staff allotment of 327, divided over eleven departments: the General Office, Policy, Laws and Regulations Department, Personnel Department, Financial Department, Art Department, Culture Science and Technology Department, Culture Market Department, Cultural Industry Department, Social Culture Department, Intangible Cultural Heritage Department and Foreign Culture Contact Department ${ }^{670}$.

At the central level, relatively little capacity is available for administrative law enforcement. Rather, central administration staff is mainly occupied with drafting policies, laws and regulations, providing government input into central market operators and administering the various licensing schemes. The question could therefore be asked whether or not personnel at the central level - outside of day-to-day man-

\footnotetext{
6672008 SARFT Structure.

${ }^{668}$ This department is alternatively known as the National saohuang dafei office, see infra.

${ }^{669} 2008$ GAPP Structure.

${ }^{670} 2008$ Ministry of Culture Structure.
} 
agement of the audiovisual media sector, has time left in which they could concentrate on law enforcement. This is especially acute with the GAPP, given its broad powers in the anti-piracy sphere.

At lower levels of government, less administrative personnel are available. The provincial-level radio, film and television bureaus have around sixty personnel ${ }^{671}$, as do the press and publications departments ${ }^{672}$ and culture departments ${ }^{673}$. In some provinces, competencies are shared. In Shanghai, for example, the culture bureau merged with the radio, film and television bureau. Radio, film and television bureaus have no direct competency to enforce against piracy, as this is the purview of the press and publications, and culture administrations, and hence, have no departments or staff full-time dealing with this.

At lower governmental level, the numbers vary significantly. Jinan, the capital of Shandong province, has 25 posts in the press and publications administration, and Wuhan - capital of Hubei province $-22^{674}$. Jinan also employs 35 personnel in the radio, film and television administration ${ }^{675}$. In Nanjing, the combined culture, radio, film and television, and press and publications bureau employs 136 staff, but in Zhengzhou, the capital of Henan Province, which has a comparable size and population, makes do with 84 posts. In Chengdu, the capital of Sichuan, the combined radio, film and television, and press and publication bureau has 66 employees. Outside of the major cities, staffing numbers seem to be low. In Liangping County, an area with about $\mathbf{8 8 0 . 0 0 0 ~ i n h a b i t a n t s ~ i n ~ C h o n g q i n g ~ M u n i c i p a l i t y , ~ o n l y ~ t e n ~ p e o p l e ~ m a n - ~}$ age the combined culture, radio, film and television, press and publications office. Jiangmen, a city in Guangdong with over four million inhabitants, has only eleven people in the same office.

The totality of numbers mean that, while there are substantial numbers of officials working in cultural sector management, only a small number are engaged in antipiracy work. The leadership has tried to overcome this by ordering the setup of “comprehensive cultural market enforcement teams” (综合行政执法队 zonghe xingzheng zhifa dui) at different levels. These carry out inspections on their own initiative or on request of other cultural market administrations.

The Beijing comprehensive law enforcement team has 67 employees. These are divided over five departments: an administrative department, a legal affairs department, and three law enforcement departments, respectively responsible for the administrative punishment duties of the radio, film and television, culture, and press and publications bodies, the punishment duties of cultural relic bodies and investigation of large interregional cases or cases submitted to it by higher levels of government ${ }^{676}$. In Jinan, the provincial capital of Shandong, 25 personnel have been allotted for comprehensive law enforcement, divided over three departments. The first department deals with entertainment venues, Internet cafés and the like, the second department

\footnotetext{
${ }^{671}$ For example, in 2009, the Beijing Radio, Film and Television Bureau was allotted 69 staff, Jiangsu 57, Yunnan 60, Guangdong 62, Fujian 44 and Sichuan 77.

${ }^{672}$ Fujian 59, Guangdong 58, Sichuan 66.

${ }^{673}$ Sichuan 57, Guizhou 56, Hubei 56.

${ }^{674} 2009$ Wuhan Press and Publications Structure.

${ }^{675} 2004$ Jinan Radio, Film and Television Structure.

${ }^{676} 2008$ Beijing Culture Enforcement Structure.
} 
monitors radio, film and television broadcast and transmission, and the third department is in charge of the publications market ${ }^{677}$. In Chongqing, teams are organized around district lines, with Jinjiang district, for example, being accorded 9 personnel ${ }^{678}$.

The question must be asked on whether these new comprehensive cultural law enforcement teams are capable of bringing about high-quality law enforcement. At present, there are no comprehensive case studies about the efficiency or the effectiveness of these new teams. Press articles remain at the anecdotal level, whilst also touting the effectiveness of individual squads in curbing the presence of illegal publications ${ }^{679}$. Here already, some scepticism is warranted. The Guangming Daily, for example, sings the praise of the Beijing Chaoyang District comprehensive culture market law enforcement team, noting how amongst others the numbers of itinerant pirate disk peddlers and pirated DVD stores have gone down. However, around the Sanlitun area in Beijing, arguably the capital's best known shopping and nightlife area, DVD stores are thriving.

Moreover, the institutional characteristics of the comprehensive law enforcement teams do not seem to entail greater effectiveness. First, in the recent phase of expansion, it seems that in many localities, such as in Beijing ${ }^{680}$, the teams were built on the previous saohuang dafei offices, often while retaining the same plaques on the door. In other localities, such as in Hubei province ${ }^{681}$, the comprehensive enforcement team is just a subordinate department of the culture office. At lower local levels, cultural industry offices had already been combined earlier. In that sense, the comprehensive cultural market law enforcement teams are not new. For the moment, it seems that these administrative law enforcement personnel have limited capacity to enforce, and at the same time meet with strong incentives for corruption and graft. For example, funding for these law enforcement teams and their equipment comes out of the budget of their local government ${ }^{682}$, making them subject to local protectionism ${ }^{683}$. Also, as in the case of communication personnel, the leadership responded to problems by creating new bodies and appointments, issuing orders and regulations, but ignoring the systemic factors that were instrumental in creating the problem in the first place.

\section{Structural aspects of administrative enforcement problems}

While capacity is a first major problem for effective anti-piracy action, as it is in the West, it is not sufficient to explain the low level of enforcement quality. It must be supplemented by identifying the structural incentives causing individual enforcement officers to shirk. A first major problem lies in the organizational structure of China's administration. As already briefly indicated in Chapter IV, China's administrative power is large and fragmented along horizontal and vertical lines. This results in two modes of governance, horizontal and vertical, which in turn have an important impact on the incentive structure of policy implementation and enforcement, which are

\footnotetext{
${ }^{677} 2011$ Jinan Culture Enforcement Structure.

${ }^{678} 2010$ Jinjiang Culture Enforcement Structure.

${ }^{679}$ Guangming Daily, 2007.

${ }^{680} 2005$ Beijing Culture Enforcement Structure.

${ }^{681} 2009$ Hubei Culture Office Structure.

${ }^{682} 2010$ Comprehensive Law Enforcement Allocation Opinions.

${ }^{683}$ See later in this Chapter.
} 
continually in a state of flux and contestation. In Chinese parlance, these two dimensions are named "branches", tiao 条 and “areas" kuai 块. The dominance of one over the other will decide how central policy is implemented. A predominance of tiao means higher-level entities can exert strong vertical control over its lower-level entities. Power runs mainly vertically up and down the system and policy implementation is relatively uniform throughout the country. When kuai take the upper hand, the primary responsibility of administrative organs lies with the local Party Committee and the local government. ${ }^{684}$

The factor that most of all decides which dimension - vertical or horizontal - predominates, is the relationship between the different authority relationships, of which there are two sorts. "Leadership relationships" or lingdao guanxi 领导关系 are relationships in which one body can issue binding orders to a subordinate organ. "Functional relationships" or yewu guanxi 业务关系 exist between two bodies when one body can advise the subordinate organ, but not issue binding orders. In a kuai-based environment, the lingdao guanxi run between the administrative organs and the Party Committee of that level, with the higher-level administrative units exercising yewu guanxi, whereas in a tiao-based environment, it is the related administrative body of a higher level which exercises the lingdao guanxi, whereas the Party Committee sees its role relegated to exercise yewu guanxi. These relationships can shift, based on factors such as the political climate, personal relations between incumbents, relative position of political bodies or institutions, etc., but they depend most of all on who has the power to appoint official posts and who holds the budget ${ }^{65}$. At present, the culture administration is decentralized, meaning that local governments control budgets and appointments ${ }^{686}$.

It logically follows that implementation and enforcement incentives depend on the priorities of the hand holding the purse. In order to maintain budgets and personnel levels, administrative departments tend to deploy strategies that please the decisionmaker, even where this might sometimes contravene the programmatical objectives of that department, hamper implementation of laws and regulations, or cause certain problems to persist. As a result, China is not a monolithic authoritarian state. Its authoritarianism is fragmented ${ }^{687}$. It is a negotiated state ${ }^{688}$ where institutions even in a continuous state of bargaining for power. The invisible hand of the Party and opacity of its internal processes means it is difficult for outsiders to comprehend exactly where certain interests lie, that the power of a certain individual is not only derived from the office he holds, but also the relationship with others in the PartyState apparatus, and that individuals, through these relationship, can wield tremendous power within their geographic or departmental areas.

\section{Fragmented authoritarianism vertically: the deal between the centre and the localities}

The reforms after 1979 went hand in hand with a significant devolution of power to the provincial and lower levels and a realignment of funding and control lines. In a

\footnotetext{
${ }^{684}$ An analysis of this phenomenon can be found in Mertha, 2005B. See also supra Chapter IV.

${ }^{685}$ Dimitrov, 2008, p. 30.

${ }^{686}$ Dimitrov, 2008, p. 50.

${ }^{687}$ For an in-depth analysis of this issue, see Lieberthal and Oksenberg, 1988; Lampton and Lieberthal, 1992.

${ }^{688}$ Saich, 2010, 142.
} 
move to maximize reform experimentation, localities were increasingly permitted to formulate their own economic policies, although it needs to be stressed that many reform initiatives that were touted at the central level were moves that had been tried out successfully but illegally at the local level before ${ }^{689}$. Since that time, local politics have become increasingly important in China's internal governance structure, but this has resulted in a number of significant governance problems as well. While the centre has strived to maintain and sometimes increase control mechanisms over the localities, such as auditing, control over higher-level personnel appointments and disciplinary inspection, policy resistance against and non-compliance of policy decisions remains, leading one retired minister to comment that "policies made by Zhongnanhai sometimes cannot reach outside of Zhongnanhai ${ }^{690 ", ~}$

The reinforcement of local government has led to the emergence of local protectionism. Local governments control their own appointments and budgeting, and also control those of local police and courts ${ }^{691}$. As a result, there is a significant collusion of power at the level of local Party and State institutions. This collusion has significant potential for extractive purposes ${ }^{692}$. As local Party and State organs collectively hold monopoly power over granting administrative permits, access to justice or law enforcement, providing social services and all other powers associated with government, there are strong incentives for graft and other forms of malpractice. Furthermore, the risk of being caught and the risk of punishment is relatively low. While every once in a while, large corruption cases are touted in the press and on television, and numerous anti-corruption drives have been carried out, only a low number of corrupt officials are subject to significant punishment ${ }^{693}$. It is not hard to fathom why: the political imperative for the Party to maintain monopolistic political power overrides all other concerns. As a result: local officials have a very strong power position vis-à-vis higher levels and the Centre. The Party is caught between a rock and a hard place: removing corrupt officials from office would entail destroying the Party base in an entire locality, given how entire local government structures are complicit, and having to rebuild it anew. The subsequent officials would be subject to the same incentives for corruption, and such a solution would at best only bring temporary relief. The other possibility would entail re-centralization of power and the introduction of open and transparent means of checks and balances. However, this would mean fundamental political reform, which does not seem an option that is being considered $^{694}$. Furthermore, such reform can only meet with limited success as long as the primary loyalty of officials is to the Party. In the end, the strength of the Communist Party seems to be maintained at the expense of State capacity to implement policy.

\footnotetext{
${ }^{689}$ For example, there were illegal entrepreneurs in a number of Fujian, Jiangsu and Zheijiang villages even throughout the Cultural Revolution, Huang, 2008, p.62. Also, villages in poorer areas of Anhui and Zhejiang had started experimenting with market-based agricultural models by 1978, Huang, 2008, p. 89-90.

${ }^{690}$ Quoted in Saich, 2010 , p. 187.

${ }^{691}$ Chen, 2008, pp. 686-688.

${ }^{692}$ Pei, 2006.

${ }^{693}$ MacGregor, 2010, pp. 135 - I7I, passim.

${ }^{694}$ In the spring of 2011 , premier Wen Jiabao called for political reform, but was quickly opposed by NPC Chairman and ranking Standing Committee member Wu Bangguo.
} 
This does not mean that there are no checks and balances present in China's political structure. However, these checks and balances are opaque, and are subject to shadowboxing in two arenas: the State arena and the Party arena. Hence, relationships between the centre and the localities are the locus of continuous political contestation, where the balance seems to be that the Centre seems to acquiesce in corruption in a number of areas in exchange for the maintenance of a few key political objectives such as economic growth, social stability and - increasingly - environmental protection.

\section{Fragmented authoritarianism horizontally: why administrative departments do} not like the courts.

While vertical separation divides the centre and regions, there is also significant horizontal separation dividing different State entities and departments. As everywhere, Chinese administrative bodies aim to stake out their turf and defend it $^{695}$. Sometimes, this leads to a concentration tendency, where a department decides to not engage in a certain policy area. Dimitrov gives the example of the copyright administration. One of the reasons this body does not engage in strong anti-piracy enforcement, is that it does not consider this its mission ${ }^{696}$. Rather, it considers itself as charged with providing copyright-related support and expertise to the publishing sector.

On the other hand, where prestige and potential political or financial pay-offs are sufficiently attractive, disputes over turf will take place. In 2009, for example, the GAPP and the Ministry of Culture, who share jurisdiction of the audiovisual games market ${ }^{697}$, fought a high-profile battle over the approval of the popular Internet game World of Warcraft. This was the culmination of a previous build-up of tensions concerning who would have the ultimate authority to issue certain licences, and hence, receive licensing fees. While the Ministry of Culture initially was appointed as the stronger department, the GAPP hit back with a set of regulations stipulating amongst others that required all online operators to obtain a GAPP operating licence, and provide a copyright approval certificate, a game examination certificate and an online game publication certificate ${ }^{698}$. In the end, World of Warcraft was kept off-line for five months. In 2010, the Ministry of Culture issued new regulations that firmly reestablished superiority over GAPP ${ }^{699}$.

These matters hamper coordination between different departments, to the detriment of effective enforcement. Anti-piracy enforcement falls within the purview of the different administrative bodies responsible for audiovisual media, each with their own regulatory mandate. This creates overlap on the one hand and nonenforcement in certain spheres on the other. The lack of coordination is further exacerbated by the different ranks that anti-piracy bodies possess ${ }^{700}$. The Ministry of Culture is a full-ministerial rank component of the State Council, while SARFT and GAPP are at sub-ministerial level. As far as internal organization is concerned, the

\footnotetext{
${ }^{695}$ Keller, 2000.

${ }^{696}$ Dimitrov, 2008.

${ }^{697} 2008$ Ministry of Culture Structure, 2008 GAPP Structure

${ }^{698}$ Foerster, 2009, 2009 Network Gaming Notice.

${ }^{699} 2010$ Provisional Network Gaming Management Rules.

${ }^{700}$ Dimitrov, 2008, p. 51.
} 
NCA is merely a department of GAPP, operating under its own name to the external world. It does not even have an independent personnel allotment ${ }^{70 !}$.

Departmental protectionism at the local level is one of the more significant reasons that criminal enforcement numbers are as low as they are ${ }^{702}$. Transferring a case from administrative to criminal enforcement systems means that the administrative department loses the potential income from fines and enforcement fees ${ }^{703}$. Rather, administrative departments have a strong incentive to maintain fines at such a level that piracy operators can calculate them into the cost of doing business. Often, the losing side in this situation - legitimate rights holders - cannot bring strong pressure to bear on this mutually supporting relationship ${ }^{704}$. Perversely, as administrative departments have a monopoly on providing enforcement, they are in a strong position to play off rights holders versus pirates, and optimizing their income from both sides.

Departmental protectionism also provides a broad scope for corruption. There are reports that in a number of cases, confiscated materials are simply given or sold back to the piracy networks after the political objectives are reached, or are used to extract bribes from both the rights holder and the infringer ${ }^{705}$. In other cases, operators get advance warnings about impending campaigns or raids, so they can close up shop or remove offending articles, and hence can be reported as compliant ${ }^{706}$.

\section{The problem of supervision: quis custodiet?}

Apart from administrative fragmentation, monitoring and communication across geographical and departmental boundaries contribute to implementation problems. Higher levels of administration have to rely on figures, statistics and information provided by the lower levels, which have an interest in presenting the politically desirable image $e^{707}$. Hence, information that is reported upwards is often unreliable or incomplete. This is an old problem in Chinese administration. It echoes the Great Leap Forward, where outrageous production numbers were reported upwards, and sheaves of grain would be brought to the fields around the itinerary of Mao's private train, in an effort to impress the Great Helmsman of the success of the undertaking ${ }^{708}$. However, this should be nuanced. The increasing role of the market has greatly eased the circulation of economic information, and better communication technology has also torn down a number of barriers to acquiring information.

The circulation of information has been the nexus of questions concerning press freedom, the interests of regional governments and the Centre. Theoretically, a free and independent media sector can be a significant check on abuse of official power, and to a certain extent, the Centre has enlisted the news media to increase reporting on local abuses and provide internal reports to the leadership ${ }^{709}$. But these poli-

\footnotetext{
7012008 GAPP Structure.

702 In 2004, 1.1\% of the NCA cases and $2.9 \%$ of the saohuang dafei cases were transferred to the PSB.

Dimitrov, 2008, p. 153.

${ }^{703}$ Mertha, Chen Jianfu, p. 668.

${ }^{704}$ Dimitrov, 2008, p. 214.

705 Id., p. 14.

${ }^{706}$ Mertha, 2005A, p. I44, Dimitrov, 2008.

${ }^{707}$ Even Vice Premier Li Keqiang stated that he did not trust Chinese economic statistics. Moore, 2010.

${ }^{708}$ Lu, 1999, pp. 347-370, passim.

${ }^{709}$ Shirk, Fragile Superpower, p. 90.
} 
tics themselves became subject to contestation. For a while, provincial-level media were permitted and encouraged to publish critical reports about abuses in their provinces. However, the provincial leaders - an increasingly powerful constituency in central policy-making - protested against this practice, which was shifted so that reporters could only report on issues in other provinces ${ }^{710}$. Similarly, journalists reporting in the localities are often subject to threats or harassment ${ }^{711}$.

In recent years, the Internet has provided additional scrutiny. Through bulletin boards, microblogs and other social modes of communication, local problems are often signalled very quickly ${ }^{7 / 2}$. The Party-State tries to control this strictly. It has a 30.000 strong force of monitors permanently checking new on-line developments, and can quickly shut down emerging news stories and online discussions ${ }^{713}$. However, the Party-State is incapable of doing anything but dealing with these issues ad hoc, as they cannot address the systemic causes of many societal problems. In other words, corrupt officials are punished or fired after their stories surface, but the systemic causes of corruption are not changed.

Increasingly, there is popular pushback against these issues. One particular mode of protest is the human flesh search engine, which is an Internet phenomenon, in which massive collective searching takes place to unearth as much information about a given target as possible, usually for the purpose of subjecting them to public humiliation $^{714}$. In an increasing number of cases, the targets of these searches are local officials engaging in certain forms of deviant behaviour that elicit significant response. One famous example of this is Li Gang, a deputy police chief in Baoding, Hebei Province. In October 2010, his son, Li Qiming, hit two students whilst driving under influence on the campus of Hebei University. When arrested, he shouted out "my father is Li Gang", in an effort to frighten the security guards. The resulting outline outrage consecutively resulted in a public apology by Li Qiming, payment of unofficial compensation, and a six-year jail sentence and official compensation ${ }^{715}$.

There are two significant limits to these forms of monitoring with respect to media piracy. First, issues that come to the fore usually are reactions to events that attract strong public reaction. This means on the one hand, this sort of stories usually concerns salient matters such as blatant abuse of official power such as attempted rape or land grabs, environmental pollution, lax labour standards, problems with food or product safety, etc. Compared with this, mere audiovisual media piracy is much less interesting, certainly for the press, which needs sensational stories to sell. Also, there are procedural problems. The government is pushed by populist means to take action against perceived injustice, without necessarily following proper legal procedure, ignoring the legal rights of the parties concerned ${ }^{716}$, or by influencing law en-

\footnotetext{
710 Shirk, Fragile Superpower, p. 90.

711 Reporter Fang Xuanchang, investigating medical fraud, was assaulted in front of his house. Reporter Sun Hongjie was killed in Xinjiang during an investigation of land use for official's residences in 2010. Reporter Li Xiang was killed in Henan following his reporting of a cooking oil scam in $201 \mathrm{I}$.

712 The microblog platform Weibo made it possible to spread news about amongst others the Wenzhou train crash, independent candidates for local elections, the fate of dissident artist Ai Weiwei, etc. 713 Zhang, 2010.

${ }^{714}$ Downey, 2010.

${ }^{715}$ Wines, 2010.

716 This is known as “mass line” justice, Trevaskes, 20II, p. 322.
} 
forcement organs ${ }^{717}$. While this is touted as government responsiveness, it actually weakens law enforcement mechanisms, by making them subordinate to populist pressures.

Second, while it is permitted to blow the whistle on localized, isolated cases of corruption or power abuse, there is a limit to what's possible. Usually, higher-level officials and their relatives and inner circle are off-limits, such as when President $\mathrm{Hu}$ Jintao's son or Premier Wen Jiabao's wife were suspected of shady business dealings ${ }^{718}$. When high-level officials are charged with corruption or similar offences, it is usually the result of a power struggle within the Party that is already completed, such as with Shanghai mayor Chen Liangyu ${ }^{719}$, or in case of problems with very central and visible policies, such as when Minister of Railways Liu Zhijun was fired amid allegations of using sub-standard materials in high-speed railway construction ${ }^{720}$. Similarly, reports are only tolerated of specific cases. Any attempt to delve deeper into systemic causes of power abuse or non-implementation of laws and policies is not permitted.

What does this mean for communication and audiovisual media piracy? As for the first factor, audiovisual media piracy is not perceived as a flashpoint where popular dissent might occur, or that causes riots. Conversely, audiovisual media piracy seems not to be deemed harmful at all, by the largest part of the population ${ }^{721}$. Hence, it will often lose out to other, more salient matters having higher enforcement priority. As for the second point, administrative departments are powerless to investigate media piracy originating from certain sources, especially the Army, neither can the Army be publicly linked to piracy in the Chinese press ${ }^{722}$. Similarly, Chinese press analyses of piracy will not include any discussion about the systemic factors leading to piracy in the first place. Rather, they will concentrate on the money made by arrested individuals and the sentences imposed on them.

The leadership is aware of this problem, and has taken a number of steps to remedy this. In 2004, all important work units within the radio, film and television administration received a SARFT Opinion ${ }^{723}$ aimed at improving internal communication and information exchange. Information work was explicitly tied to providing information both concerning matters internal to the radio, film and television system and social, economic and other newsworthy matter, to higher-level Party and State organs. It outlined quality standards for information reporting, and provided for a number of information points, acting as nodes in a broader information network. Furthermore, SARFT required all the departments and companies concerned to appoint an information officer, who would have to be versed in politics and ideology, and a diligent

\footnotetext{
717 The concept of the Three Supremes (三个至上 sange zhishang), introduced by Hu Jintao in 2007, requires jurists to first consider the supremacy of the Party, then the supremacy of the people, and in last instance the supremacy of the law. CMP Dictionary.

718 MacGregor, 2010, p. 148.

${ }^{719}$ Xinhua, 2008B.

${ }^{720}$ Wong, 2011 .

${ }^{721}$ One 2001 study indicates that more than 70 per cent of urban residents "are not ashamed" to buy pirated products. See also Chapter I. People's Daily, 200 I.

722 MacGregor refers to the army in the Eighties as a state-within-a-state, which ran a substantial commercial network of underground enterprises. Although it has since been forced to professionalize, they still enjoy considerable privileges in Chinese society. MacGregor, 2010, pp. II5 - II8.

${ }^{723} 2004$ SARFT Radio, Film and Television Information Opinions.
} 
worker. These officers would also be subject to biannual training at Party Schools. As an incentive system, information reports would be given points, depending on their utilization by higher-level administrative bodies. Individuals and work units that amassed higher scores would be rewarded with titles and material compensation. On the other hand, failing to provide information on time would result in a punishment of not being eligible for awards, not or falsely reporting information would result in administrative prosecution, and criticism reports.

It is unclear how this system works in daily reality, and more research would need to be done to fully understand how these internal compliance and enforcement systems work in reality. The central question would revolve around how the different incentives combine. Here, SARFT reacted to the problem of bad information circulation by obliging the appointment of a person to deal with this, and creating a concomitant internal reward and punishment system, rather than by more structural or systemic changes that realign existing incentives concerning circulation of information. A deeper understanding of whether and how these new incentives interact with the existing systemic incentives, and whether and how this results in change of behaviour of the personnel subject to them, as well as what that would mean for matters such as type of information that is reported, the speed with which it is reported or regional differences in information reporting, would greatly enhance understanding of the informational aspects of policy implementation and enforcement in China.

\section{Enforcement styles, deckchairs and the Titanic}

The failure of day-to-day administrative enforcement to implement policy - in a number of fields, not only piracy - frustrates the central level ${ }^{724}$. Every once in a while, when the political situation calls for it, the leadership will initiate a centralized campaign in a given field. These campaigns, aimed to break through local protectionism and other interests, are usually highly publicized. They not only serve to implement policy, they also aim to serve the politics of being seen to do something about a problem, to both domestic and foreign audiences. Some of the most well known images relating to China and piracy are bulldozers crushing a pile of confiscated counterfeit goods or discs ${ }^{725}$. Sometimes, these campaigns are organized in the margin of important international events, such as the Beijing Olympics and the Shanghai Expo $^{726}$. Other campaigns protect high-profile works, such as the film $\mathrm{Hero}^{727}$, that need protection for political reasons, even if this protection is only temporary. Another focus can be special kinds of works, such as American films in $200 \mathrm{I}^{728}$ or “compressed discs" in the 2004 Winter Campaign ${ }^{729}$. These campaigns don't always concern copyright infringement. There have been campaigns against "horror and occult" audiovisual products ${ }^{730}$, and products with "vulgar tendencies ${ }^{731}$ ". Most of the time, however, campaigns have a broader focus, and seem to be political responses to foreign pressures for better copyright protection, as well as the administrative

\footnotetext{
${ }^{724}$ Dimitrov, 2008, pp. 6-7.

725 Xinhua, 2010A. See also SIPO 2008; SIPO 2009.

${ }^{726} 2010$ Expo Campaign Notice.

7272002 Hero Notice.

${ }^{728}$ There has been a campaign in 2001 that concentrated on pirated American films. The MPAA had provided the NCA with a list of 784 films that were pirated, against which action was to be taken. 2001 American Film Notice.

${ }^{729} 2004$ Winter Campaign Notice.

${ }^{730} 2008$ Horror Notice.

${ }^{731} 2007$ Vulgar Tendencies Notice.
} 
self-interest of the copyright bureaucracy. These include the $1999^{732}$ and $2001^{733}$ crackdown campaigns, the 2006 Hundred Days Campaign ${ }^{734}$ and the 2009 Cultural Market Campaign ${ }^{735}$.

A number of observers have used these campaigns to argue the point that China is able to engender compliance if and when it chooses to, implying that China simply is unwilling to protect foreign IPR ${ }^{736}$. However, closer observation shows that this is not completely true. During the campaigns with the highest profiles recently, those surrounding the Beijing 2008 Olympics and the Shanghai Expo, counterfeit and pirated products remained readily available throughout the country, and even in the cities where these events were held, close to the venues. Also, the images have not changed. The piles of confiscated goods crushed by bulldozers remain as large as ever.

These campaigns, while sometimes having a measurable short-term effect, generally have little or no influence in the long run. Van Rooij attributes this lack of long-term effect to an oversimplified view of deterrence, and the failure to address structural causes of weak enforcement capacity ${ }^{737}$. He also lists a number of characteristics of campaigns. First, campaigns tend to originate from the leadership. The political prestige these leaders enjoy makes it possible for them to ensure cooperation of different administrative departments that might otherwise - at best - not take place. At worst, these departments obstruct each other. Second, campaigns sometimes follow legislative reform. Third, the focus of the campaign, and therefore the regulatory framework to be used and the institutions involved, are decided by the leadership. For audiovisual media piracy, this will mean campaigns come from different angles, such as intellectual property, anti-pornography, anti-smuggling, etc. Furthermore, as enforcement resources are scarce, it means the leadership needs to decide on priorities and allocations ${ }^{738}$. Fourth, the working procedures in campaigns is standardized and decided at the top. These formalist tendencies also entail the setting of measurable targets. Fifth, campaigns contain a strong public element. Apart from the visibility politics touched upon earlier, citizens are called upon to assist in the campaign by providing information about law breaking. Conversely, campaigns also have an educative objective, and serve to raise consciousness of the legal system. Lastly, at the end of the campaign, the results are announced proudly, and reports are made.

To some extent, campaigns preserve a number of elements of the pre-1978 mass movements, such as the Great Leap Forward, the Cultural Revolution, and less wellknown examples such as the campaign against swallows ${ }^{739}$. These were characterized by their strong political character and their revolutionary nature. Lacking governance capacity, the Party-State saw campaigns as an indispensible tool to implement policy.

\footnotetext{
7321999 Smuggling Notice.

${ }^{733} 200$ I Smuggling Notice.

${ }^{734} 2006$ Hundred Days Campaign Announcement; 2006 Audiovisual and Software Product Piracy Notice.

7352009 Cultural Market Discipline Notice.

${ }^{736}$ See also Chapter I.

${ }^{737}$ Van Rooij, 2009.

${ }^{738}$ Mertha quotes an official saying "there is only one cake and many people want to eat off it". Mertha 2005A, p. 139.

${ }^{739}$ These are illustrated by a poster in Stefan Landsberger's collection. Landsberger.
} 
With the legal reforms, the professionalization of the administration and economic development, campaigns have become more regularized.

Evaluating the impact of campaigns is a tricky affair. On one hand, the impressive results reported at the end of enforcement campaigns, might tempt one to believe in the effectiveness of the campaign. However, Chinese statistical numbers should be approached with caution. Because campaign targets are formulated in a quantitative or measurable way, the numbers are often doctored at the local level. Furthermore, numbers are given in an absolute manner that does not give any indication about proportionality. Lastly, very little reporting is done about the follow-up of such campaigns and their long-term effect ${ }^{740}$. Furthermore, the quantitative objectives lead to changing objectives. The incentive at the local level is to report numbers, not to improve compliance. The infrequency with which campaigns are organised may act as a further brake on their utility. Nevertheless, it would not be illogical to conclude that these factors together do not create consistent enforcement capacity, and do not significantly influence incentives to pirate, when seen in combination with the different causal factors.

\section{Prioritization: politics before copyright infringement}

Another problem of administrative enforcement is that it does not seem to protect the interests of the rights holders, but those of the Party-State. This is particularly clear in the mission of the saohuang dafei offices, which are under the competence of the press and publications administration, and which undertake a significant portion of anti-piracy work. They rose to prominence in the aftermath of the 1989 protests, and aimed to better control potential socially disruptive works ${ }^{74}$. In a speech for the I I th saohuang dafei conference, CPD director Liu Yunshan indicated that the lessons learned from five years of saohuang dafei work could be summarized in "seven persists" ${ }^{, 742}$. These concern first, linking with the larger picture under the leadership of the Party and the State; second, understanding the importance of combating piracy in protecting the broad masses' cultural rights and interests, safeguarding cultural market order, and resolving the problem of "cultural garbage" (文化垃圾 wenhua laji). Third, Liu indicates that protecting intellectual property rights and mobilizing all social forces for saohuang dafei work is aimed at obtaining international understanding and "identification". Points four through seven further deal with institutional and legislative aspects of administrative enforcement. Further in this speech, Liu outlines the focus points and their objectives of saohuang dafei work. In general, saohuang dafei work is aimed at creating a beneficial social environment, cultural environment and social atmosphere, consolidating the leading role of Marxism in the ideological sphere, supporting the establishment of a socialist legal system and the socialist market economy, and protecting the physical and mental health of minors. Investigating illegal publications is aimed at safeguarding social and political stability. Attacking piracy activities is aimed at safeguarding the national image, and providing a desirable public opinion atmosphere and social environment in order to stimulate indigenous innovation and raise national core competitiveness. This speech also underlined the importance of presenting a good image during the 2008 Beijing Olympics.

\footnotetext{
740 IIPA members tracked the effects of the 2006 "Hundred Days Campaign", and did not notice any significant decline in availability of pirated products after the campaign concluded. IIPA, 20I I, p. 67.

${ }^{741}$ Meng, 2006, p. 102.

${ }^{742}$ Liu, 2008.
} 
These tendencies are confirmed in the different enforcement campaigns. Here, piracy is never primarily attacked as an infringement of a private right. Rather, the campaigns aim for a multitude of objectives, of which protecting IPR is only one. As piracy takes place at the nexus of different policy areas, and hence different institutional contexts, the goals of the campaign are shifting, depending on the specific objectives and concomitant administration. One of the first campaigns dealing with piracy, in 1986, outlined problems and objectives as follows: "One sort of situation is pirate recording and sale of audiovisual products imported by smuggling, its content has all not passed examination and approval; another sort of situation is unauthorized pirate recording and selling of products of domestic publications work units, infringing copyright and gravely damaging publications work units' economic interests. These infringing piraterecorded and sold audiovisual products are not only of low quality, but some have unhealthy content. These false and inferior audiovisual products are sold at low prices, overflow the market, gravely impede the development of the audiovisual publications sector, cause consumers' mental and physical health, and economic interest to be directly damaged. In order to rectify and strengthen management over the audiovisual products market, safeguard widespread consumers' personal interests, and benefit the construction of a socialist spiritual civilization, determined stopping of and attack against unlawful actions such as infringing pirate recording and selling, etc. must be undertaken ${ }^{743}$." Another campaign, one year later, was aimed against illegal publication activities that "flooded the market, and not only is content degenerate, and often propagates murder, sex and superstition, but the printing quality is also inferior, the selling price is costly, the harmfulness to mental and bodily health of the masses, especially the youth, is extremely large, and it gravely influences the construction of a socialist spiritual civilization ${ }^{744}$."

The objectives of the large 200 I campaign referred to earlier do not refer to copyright at all: "The culture market is an important component of the socialist market economy system. The Central Committee and State Council, when promoting the socialist material civilization construction, completely striving to promote the construction of a socialist spiritual civilization, forcefully promoted all nationalities ideology and moral level, and scientific and culture level to be raised incessantly. But, because of all kinds of reasons, the chaotic condition of the culture market still exists, which is explicitly reflected in the operational management chaos of Internet on-line service business venues, electronic gaming business venues, song, dance and entertainment service venues, audiovisual product business venues, publications and computer software markets, the printing sector and cultural object markets, unlawful and irregular activities take place repeatedly, and not a little content such as vulgarity, ignorant superstition, violence, obscenity, gambling and even reactionary, etc., has appeared, corrupting social conduct, influencing the unity of the people and social stability, especially gravely endangering the physical and mental health of minors. The popular masses react strongly against this, and it is necessary to forcefully rectify and standardize this $^{745}$."

Similarly, the 2006 Hundred Days Campaign was aimed at safeguarding cultural business order, and stimulating the flourishing and development of the audiovisual com-

\footnotetext{
7431986 Audiovisual Rectification Notice.

744 I 987 Illegal Publications Notice.

${ }^{745} 200$ I Cultural Market Rectification Notice.
} 
puter and software industries ${ }^{746}$. The 2009 Cultural Market Campaign was aimed to rectify and standardize cultural market order, to create a harmonious and stable social cultural environment for the 60 years of New China's establishment ${ }^{747}$. Approaching piracy from another angle, the 2010 Anti-Counterfeiting campaign ${ }^{748}$ aimed to safeguard a fair and orderly market environment, having found that counterfeiting impairs competitiveness and innovation, but also harms China's international image.

Institutional participation in enforcement campaigns also depends on the aims of the campaign. As the 2006 Hundred Days Campaign primarily targeted audiovisual product markets, SARFT did not participate. Similarly, the campaign surrounding the 2010 Shanghai Expo was a matter wholly in the hands of the cultural administration, and also incorporating four comprehensive culture market law enforcement teams. The 2010 Anti-Counterfeiting campaign was spread in a detailed manner across different departments, but the press and publications administration was the only audiovisual media-related department that took part.

\section{Internal conflicts: Administration as judge and party}

The administrative authorities in charge of the audiovisual media sector are closely connected with the companies that they govern ${ }^{749}$. This results in implementation and enforcement problems, but it also means that there is a significant amount of distrust between the regions and the centre, and amongst the regions themselves.

In the area of television, the official and unofficial income of radio, film and television departments and their personnel is closely connected with the commercial income of local broadcasters and cinemas. As a consequence, local departments are often suspicious of SARFT attempts to impose more centralization of CCTV broadcasts ${ }^{750}$. Similarly, publications entities stand to gain significantly from the local publishing and reproduction business. It is therefore not surprising that local administrative organs tend to use their power to keep out non-local operators, whilst at the same time aiming to support the activities of local economic operators, be they legal or illegal.

\section{Personnel: the weakest link}

In the end, implementation and enforcement of policy must be realized by the individual personnel. This concerns not only law enforcement personnel, but also the administration staff in charge of licensing and supervision, and the staff of media companies themselves, who are called upon to self-regulate. However, as indicated in the previous sections, the structural surroundings often do not incentivize these officials to implement and comply with central policy. Furthermore, the Party-State system generates incentives directly towards individual officials that may deter from effective anti-piracy activity.

\footnotetext{
7462006 Hundred Days Campaign Announcement. See also 2006 Unlawful Audiovisual Product Import Notice; 2006 Unlawful Audiovisual Product Import Notice; 2006 Anti-Piracy Construction Notice; 2006 Audiovisual and Software Product Piracy Notice.

7472009 Cultural Market Discipline Notice.

7482010 Anti-IPR Infringement Campaign Notice. See also 2010 Anti-Infringement Small Group Establishment Notice.

${ }^{749}$ The national and local Propaganda Departments consists of the regulators, but also include representatives of media outlets.

${ }^{750}$ See also Chapter V.
} 
Professionally, the most important formal incentive structure for Party and State officials is the cadre assessment system ${ }^{751}$. The Chinese appointment system works top-down, and is combined with an assessment system that ranks cadre performance on a number of indicators. In order to be promoted, cadres must score favourably on these criteria, and it is therefore not surprising that cadres try to improve their promotion chances by working towards ostensible satisfying these indicators. Such evaluation systems are present for all leading Party and State posts, including governments, and the judiciary, but excluding the Army, which essentially governs itself. In 2009, the Central Committee listed the most important cadre evaluation criteria were as follows: population and resources, social security, energy saving, environmental protection, production safety, improvement in the life of citizens, social security, social stability, clean government, cadre appointments and popular satisfaction $^{752}$. Intellectual property protection does not figure on this list, which means that the incentive for local officials to provide strong anti-infringement is subordinate to incentives that directly contribute to the listed criteria.

There are a number of significant problems with this system. First, it creates a dynamic where the politics of being seen to attain certain goals outweigh the way in which these goals are attained. Especially where quantitative targets are concerned, the incentives to cook the books is large, regardless of which target is concerned. Second, it subordinates the consistent applications of law and regulations to attainment of political priorities, thereby opening the door to very selective law enforcement. In other words, if local GDP growth also includes production of infringing goods, chances are that this infringement will not be punished. Conversely, in localities where GDP suffers from IPR infringement, anti-piracy enforcement efforts will be stronger. As a consequence, there is no paradox in some localities implementing stricter enforcement in some areas than other localities. Rather, these differences stem from an incentive system that gives local governments significant leeway to enforce against activities damaging their specific local interest.

What does this mean for enforcement against audiovisual media piracy? For starters, combating IPR infringement does not figure in the examination criteria list. Hence, there is no incentive for local authorities to commit large resources to this that could have been otherwise used in boosting numbers for which local cadres are rewarded. Given that the direct losers of audiovisual media piracy are foreign media conglomerates rather than domestic companies, few localities have a stake in strongly going after media pirates. On the contrary, very often these boost local GDP and create employment. Furthermore, the only other heading in the 2009 list under which the publication of unauthorized works could fall concerns social stability. Again here, local officials often have larger issues on their hands: there were more than 80.000 mass incidents in China in $2010^{753}$, which much more often have to do with matters such as illegal land grabs, pollution, inflation, and the like. Furthermore, the argument could be made that forcefully removing pirated media might cause more social discontent rather than decrease it.

\footnotetext{
${ }^{751}$ For a broad evaluation of the cadre assessment system, see Whiting, 2004, pp. 101 - II9.

7522009 Cadre Evaluation Opinion.

${ }^{753}$ Freeman, 2010.
} 
Different systems are in place for the control over the staff of companies. While the key staff in important distribution points are Party members and still subject to Party-based appointments ${ }^{754}$, the increasing importance of economic incentives weakened control over the behaviour of individual businesspeople. The leadership shows signs of fear that these entrepreneurs lack the necessary political and social consciousness. Hence, in 2005, SARFT responded by making political training obligatory for producers of radio and television programmes. All producers were required to attend one provincial-level training activity on political morals and social importance every two years ${ }^{755}$.

These sorts of trainings have some importance: they keep the sector officially tied to the state, and help market operators keep attuned to the political currents. Furthermore, it is often useful for businesspeople to attend these training groups, as they provide networking opportunities within the media network and with the provincial-level governments. However, attendance of these trainings again has no significant impact on the incentive structure of media producers. It is therefore not unreasonable to assume that producers treat attending these sorts of activities more as going through the motions of accepting the political status quo, while immediately slipping back in their old patterns afterwards.

In short, China's internal structure falls victim to pervasive principal-agent problems. The central Party-State relies on its deep penetration of society for its power position. But pressured by the requirement of maintaining a monopolistic presence in all these areas of society, local officials have tremendous amounts of political power. On the one hand deriving their legitimacy from their Party-State connection, and maintaining Party presence on the other, they have tremendous incentives for personal enrichment, corruption and graft. The appointment structure ensures that protection can be bought off, and that officials are often put in place on the basis of curried favours and a brief list of top-level political priorities, rather than social services, bottom-up support or other accomplishments. The Party's paranoia to enfranchise organizations external to its disciplinary structure further incentivizes this sort of behaviour. This creates an environment for piracy to thrive.

\section{Copyright enforcement through the courts}

There is, however, a world beyond State enforcement. Copyright is a private right, and the Copyright Law provides a legal basis to bring copyright disputes before the civil People's Courts. On the heels of intellectual property's progressive gain in importance, the courts have strengthened their capacity to hear and decide copyright cases. How do the courts then deal with piracy cases?

\section{Court structures}

China has a five-tiered court structure, with the Supreme People's Court at the top. At the provincial level, there are the higher people's courts. Below this, there are intermediate courts at the district level and basic people's courts at the county level. The latter have subdivisions, the People's Tribunals, which operate at township level.

\footnotetext{
754 The Party's Central Organization Department maintains a nomenklatura system that controls toplevel appointments in core sectors and enterprises. Similar systems are in place at the provincial level. MacGregor, 2010. In the media sector, the Party can still remove editors, producers and managers when they displease Party superiors. Keller, 2000, p. 52.

7552005 Radio and Television Business Organ Management Notice, Para. VI.
} 
However, these courts, especially at the lower level, are often badly equipped to deal with the sometimes highly sophisticated nature of IPR cases. The leadership aimed to remedy this by establishing specialized IPR tribunals. In 2007, there were more than 170 intellectual property divisions within Chinese courts, and I40 dedicated collegial panels ${ }^{756}$.

\section{High caseload, but piracy cases?}

The number of copyright cases has risen continuously since the early ' 90 s. In 2008, 1095 I first instance civil copyright cases were initiated, a $50 \%$ rise over $2007^{757}$. However, this number does not necessarily relate to piracy. A more detailed picture is provided by breaking down the number of copyright cases in the Beida Fabao database (see figure 4). Of the circa 24I48 cases present in the database, about half relate to piracy-related matters, such as producer's rights and economic rights. The number of foreign-related cases remains low: in 2008 , of the 23518 concluded firstinstance IPR cases ${ }^{758}$, only II 39 were "foreign-related" cases, while 225 cases involved a party from Hong Kong, Taiwan and Macau.

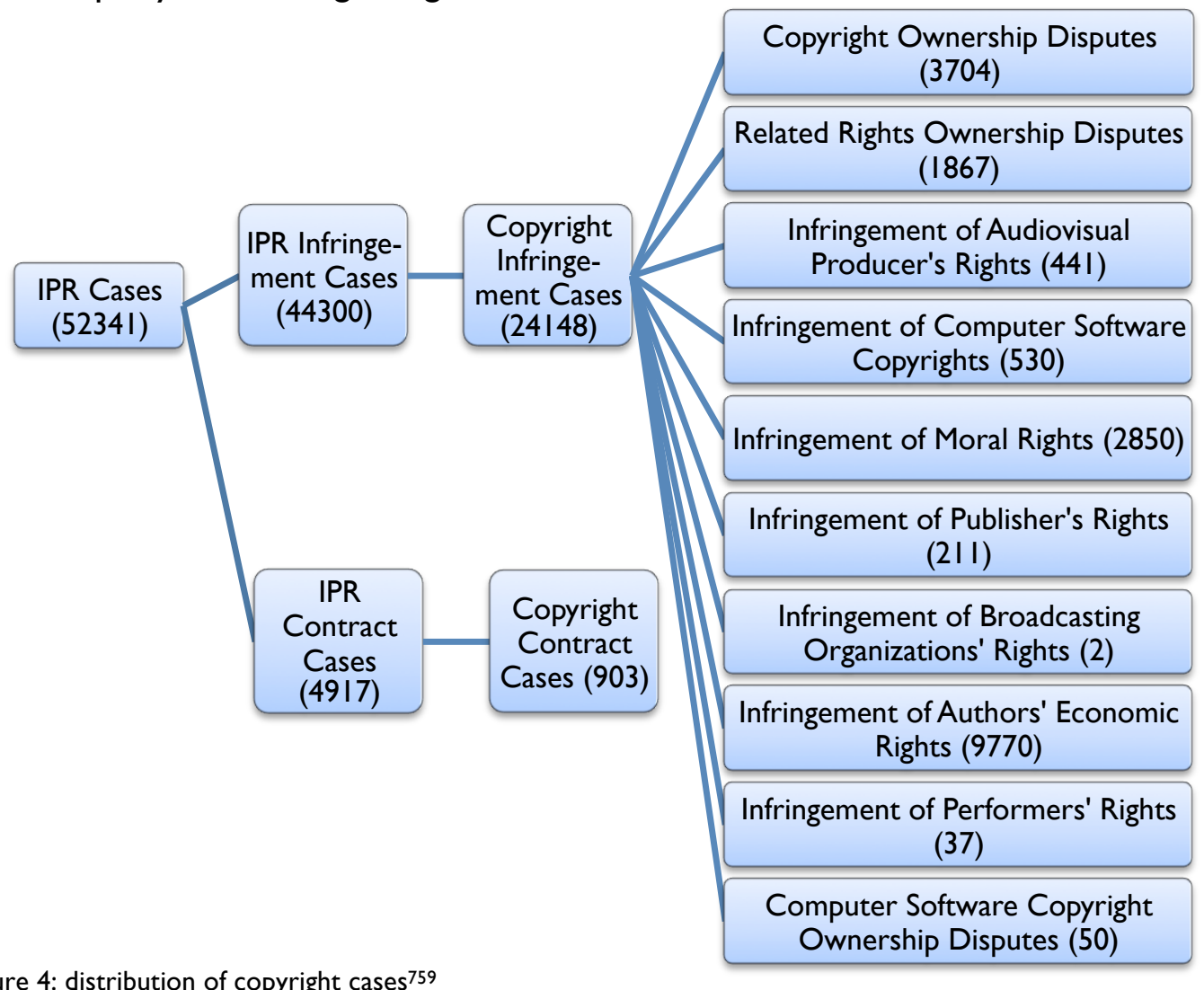

Figure 4: distribution of copyright cases 759

Also, the larger domestic parties seem not to use litigation actively as an enforcement strategy. In the Beida Fabao database, there are only a handful of cases involving China Film Company and none involving Huaxia, the two approved foreign film im-

\footnotetext{
756 Cao, 2007.

757 SIPO, 2009, p. 7I4.

${ }^{758}$ No breakdown is provided for this number, hence, it includes all IPR cases.

${ }^{759}$ Numbers derived from the Beida Fabao database, retrieved on 18 April 201 I, including cases from $1990-201 \mathrm{I}$. The numbers should, however, be treated with caution, as often cases with multiple defendants or concerning different media products are split up into a number of individual judgments, inflating the number of cases.
} 


\begin{tabular}{|c|c|c|c|}
\hline Year & 2007 & 2008 & 2009 \\
\hline $\begin{array}{l}\text { Number of judg- } \\
\text { ments }\end{array}$ & 884 & 2067 & 779 \\
\hline (Partial) win/loss & $89 \% / 11 \%$ & $77 \% / 23 \%$ & $93 \% / 7 \%$ \\
\hline $\begin{array}{l}\text { Average damage } \\
\text { claimed (CNY) }\end{array}$ & 186736 & 202015 & 82251 \\
\hline $\begin{array}{l}\text { Average damages } \\
\text { awarded (CNY) }\end{array}$ & 52,746 & 17,912 & 27,838 \\
\hline $\begin{array}{l}\text { Average costs clai- } \\
\text { med (CNY) }\end{array}$ & 10822 & $447 \mid$ & 5155 \\
\hline $\begin{array}{l}\text { Average costs awar- } \\
\text { ded }\end{array}$ & 4472 & 1853 & 1000 \\
\hline Injunction ratio & $80 \%$ & $69 \%$ & $90 \%$ \\
\hline Apology ratio & $38 \%$ & $56 \%$ & $14 \%$ \\
\hline $\begin{array}{l}\text { Total number of } \\
\text { settlements }\end{array}$ & 246 & 319 & 221 \\
\hline $\begin{array}{l}\text { Average settlement } \\
\text { amount }\end{array}$ & 30589 & 36498 & 29555 \\
\hline
\end{tabular}

Figure 5: Civil copyright case outcomes ${ }^{762}$

porters. Other domestic giants, such as Huayi Brothers, do not file significant numbers of cases. On the basis of the database, between 2000 and 2010, Huayi Brothers was involved in five broad cases (with numerous defendants, with each defendant listed as an individual case). The nature of the defendant is also interesting: often, rights holders sue shopping centres in which pirated products are distributed, rather than the pirates themselves. This may to a large extent be due to the fact that enforcing verdicts is easier with building managers than with pirates. Similarly, online operators are often the target of litigation.

\section{Outcome of cases}

Another important factor influencing enforcement strategies are potential outcomes. In copyright cases, Chinese law provides for different remedies: ceasing the act, eliminating the effects of the act, making an apology and paying compensation for damages $^{760}$. The CIELA database has compiled case outcomes for about 5000 copyright cases since 2006 (see figure 5). From these cases, it is clear that in terms of wins versus losses, plaintiffs are successful in a vast majority of the cases. The ration of injunctions correlates closely with the ratio of wins. In other words, in nearly all cases where the plaintiff wins, an injunction is granted. In terms of damages, however, the picture is not so rosy. The ratio of damages awarded is on the low side. There are a number of reasons for this. First, damages are calculated on the basis of actual losses. The principle of punitive damages does not exist in Chinese copyright law. Consequently, most cases concern a very low number of works, such as one or two films, or one or two records. Second, the sector associations are not yet very active in pursuing their members' rights through the courts. Hence, court cases are often limited to a single plaintiff, rather than an entire class ${ }^{761}$.

\footnotetext{
${ }^{760} 2010$ Copyright Law, Articles 46 and 47. Article 47 further provides for administrative and criminal punishment.

${ }^{761}$ For foreign rights holders, there is an additional problem. Until the 2010 revision of the Copyright Law, they could only claim damages for works that were permitted on the Chinese market, as the Copyright Law would not cover other works. Even with the 2010 amendment, damages are still calculated on the basis of actual losses, and courts cannot include non-permitted works into their damage calculations.
} 
This is borne out by anecdotal evidence. In 2006, two Beijing shops that were sued by five American film conglomerates, were ordered to pay USD 20.100 in compensation for selling "Mr. and Mrs. Smith", "War of the Worlds", and a number of other films $^{763}$. In a 2009 case, the Guangzhou Zhongkai Company was awarded 6000 CNY in a case where a shopping centre had been handing out free - pirated - versions of a Zhongkai film (Fists of Life and Death) with every purchase of a certain DVD player. Zhongkai had demanded 20.000 CNY in damages and $3000 \mathrm{CNY}$ in reasonable costs $^{764}$. Also in 2009, a Hangzhou judge awarded an authorized distributor of the Coldplay record "Viva la Vida" 2000 CNY in damages plus reasonable costs, while at the same time imposing 1467 CNY in court fees on the plaintiff (and a similar amount on the defendant $)^{765}$. In 201 I, Sony Music won an award of 57000 CNY against a Beijing company pirating a number of Michael Jackson songs. However, Sony had incurred nearly 49000 CNY in lawyer's fees, and was charged I 3875 CNY in court fees ${ }^{766}$.

Consequently, damages awarded are often not enough to cover litigation costs. Worse, pursuing cases may often come at a significant cost to the rights holder. Injunctions usually only refer to the work(s) involved in the case. As cases tend to be very limited in scope, enjoining a losing party to cease trading in one particular work can only have a negligible impact on the broader business operation. In comparison, administrative enforcement is simpler and cheaper, and although no damages are awarded in administrative procedures, this generally outweighs the low damages and high costs of civil procedures. Another preferred strategy of American rights holders is to lobby the government to pressure the leadership into better IP protection. While this may lead to a window-dressing new regulation or campaign, the past has shown that foreign pressure has not directly succeeded in reducing piracy rates ${ }^{767}$.

\section{The problem of enforcement of verdicts - the return of the first paradox}

Apart from the low level of damages awarded, enforcing the verdict itself is another problem. Generally speaking, enforcement of civil verdicts is a problem in China, for a large extent due to similar issues that plague administrative enforcement. When a court imposes an injunction or damages on a party outside of that court's jurisdiction, the court of first instance (which normally is responsible for execution of verdicts) may entrust the courts in the locality of that party ${ }^{768}$. However, there are indications that local protectionism also plays a role here, and that enforcement of these verdicts is less than successful ${ }^{769}$. Further study about the execution of verdicts in specific copyright cases is necessary to resolve these questions.

\section{The cases that never happened}

In the area of civil enforcement, a similar problem to the one touched upon at the end of Chapter IV presents itself. In our analysis, we are limited to analyzing the cases that took place. However, to more completely comprehend the potential im-

\footnotetext{
${ }^{762}$ Compiled from CIELA database.

763 AP, 2006.

${ }^{764}$ Guangdong Zhongkai v. Qingdao Weike Cangkou, 2009.

765 Shanghai Busheng Dafeng v. Hanghzou Daziran, 2009.

${ }^{766}$ Sony Music China v. Beijing Yongcheng Chaoliu, 2010.

${ }^{767}$ Dimitrov, 2008, p. 59.

${ }^{768} 2007$ Civil Procedure Law, Article 206.

${ }^{769}$ See Chen, 2008, pp. 668 et seq.
} 
pact of civil litigation on piracy, it is also necessary to comprehend as broadly as possible the incentives that influence rights holders to not use the courts for enforcement. In this sense, the high percentage of cases won does not necessarily reflect the success of court enforcement, but the fact that only rights holders with a clear-cut case and significant interests at stake file cases. These incentives may be found in different areas. Foreign media conglomerates, such as Disney, with a broader agenda in China, may be hesitant to push too hard for strong enforcement, for fear of tarnishing their public image $\mathrm{e}^{770}$. Ironically, broad piracy of media products might act as free advertising for related product in other markets, such as merchandising or appare ${ }^{77 !}$. Foreign rights holders might have a lack of knowledge of or trust in the Chinese court system ${ }^{772}$. Domestic rights holders, acquainted with China's enforcement problems, might be aware that the power of courts to bring about correct judgments and enforce them afterwards is limited. Indeed, courts are financed out of local government budgets, again raising the spectre of local protectionism. And last but not least, the limited scope of works permitted on the market in China further creates a tremendous disincentive for foreign rights holders. Even if a broad injunction against the majority pirated products could be obtained, and successfully enforced, foreign media conglomerates would still be limited in the number of products they could export to the Chinese market. Moreover, they would also still be limited by the Chinese regulations on foreign participation and investment in the media market.

\section{The success story of the Internet}

In comparison with the earlier sections, which mainly concern hard-goods piracy, anti-piracy enforcement with the Internet has become increasingly successful. Chinese audiovisual websites are following their international forerunners in providing mechanisms for rights holders to notify site owners when infringing content is uploaded. A number of popular BitTorrent websites were blocked, while legal Internet-based media services are increasingly becoming available ${ }^{773}$. Internet portal Sohu, for example, is working together with Warner and $A B C$ to provide legitimate and free on-line broadcast of US television programmes ${ }^{774}$. There are a number of reasons for this. Some audiovisual media operators are considering listing on foreign stock exchanges. This would obviously require them to have their legal affairs settled. A number of Internet operators have also become programme creators in their own right, increasing their stake in stronger copyright protection ${ }^{775}$. Their relationship with the State is also different from the traditional media operators - and often pirates. As the Internet is much more a delocalized phenomenon, the locality-based administrative structure is much less of an issue, with many players dealing with the central level directly. Furthermore, with the exception of news services, Internet media operators usually are completely private enterprises. While some of them notably Baidu - may have developed cosy relationships with the Party-State, they are not part of the Party-State system in the same way that traditional media outlets are. As a result, they are also more susceptible to enforcement, as they do not have direct interests within the system that they can bring to bear.

\footnotetext{
${ }^{770}$ Mertha 2005A, p. 58.

771 Swabach, 2007.

772 Although in copyright cases, this situation seems to be improving slightly, see IIPA, 20 I I, p. 67.

${ }^{773}$ Although this caused an increase in the sale of illegal DVD's. China Daily, 2009.

${ }^{774}$ China Daily, 2010.

775 Tudou.com, for example, is developing its own television dramas. Tudou, 2010.
} 
Another difference lies in the way Internet media works. Where hard-goods media requires an intricate system of production and distribution on the ground, the Internet business is more centralized. This again makes top-down enforcement easier, as it decreases the interference from local or departmental protectionism. When the central leadership decides a website is to be taken down, only cooperation from the central-level ministry is required.

Consequently, administrative action against Internet piracy has in many ways been more effective than efforts to combat hard goods. Still, Internet media distribution remains subject to the same content and operator limitations, and hence, there is a limit to the legitimate alternatives that can be offered. Also, some press reports claim that ironically, the success of anti-piracy enforcement online has driven back a number of consumers to pirated hard-goods.

\section{Conclusion}

Enforcement against piracy suffers from different limiting factors. Public enforcement is beholden to issues of political economy. Corruption, local protectionism and lack of effective internal oversight significantly hinder policy enforcement and implementation. Allocation of resources, priority listing on the basis of political preferences and the traditional emphasis on law enforcement through the Party-State system conspire to create a situation where law enforcement is limited to a very limited range of possible interventions. The traditional structure of foreign lobbying, which resolves into intergovernmental bargaining, reinforces this dynamic. Compared with these grave problems, the height of criminal enforcement thresholds is - if anything - of political import, rather than anything else.

On the other hand, the courts - which have been strengthened and professionalized in recent times - remain underused in cases of media piracy. On one hand, they are beholden to some of the same political economy considerations, on the other hand, a number of factors dissuade domestic and foreign rights holders from using the Chinese court system for vindicating their rights.

These factors conspire to create a vicious circle reinforcing the dynamics creating the pirated media market. The range of available works is small and the possibility of making profits are limited within the legal framework, creating an impetus for amongst others - piracy. The piracy market takes hold, and effective enforcement does not take place, further reducing the potential return on investment for media works. This further reduces the available scope of works. As a result, the domestic sector remains weak, and is propped up by government subsidies and investment.

Foreign media conglomerates do not have a strong presence on the Chinese media market. Furthermore, foreign parties have a reduced incentive to sue for copyright infringement, as - even in the absence of piracy - they would be unable to bring their product to the Chinese market anyway, and are banned from operating in the Chinese market by themselves. The advent of the Internet in this situation has shifted some of the enforcement onus towards other administrative bodies. However, the Western experience of dealing with online media piracy, where as of yet, no meaningful response to piracy has been developed, coupled with the Chinese conditions, mean that - if anything - Internet piracy will be even harder to enforce against. 
The dynamics described in the previous chapters are predominantly domestic in nature. However, China's progressive integration in the world economy have brought increasing scrutiny to its' media sector. Not in the least because of the importance attached to human rights in the West, but also as a consequence of the increasing desire of media companies to make money, China's media limitations are subject to more and more criticism. And - at least where trade is concerned - China has subjected itself to international litigation, by joining the WTO. The next chapter will analyze how the State-based causal factors for piracy mesh with China's WTO obligations. 


\section{Chapter VII: the WTO, China and piracy ${ }^{776}$.}

In December 2009, United States Trade Representative Ron Kirk proudly announced that the WTO Appellate Body confirmed an earlier report of the panel deeming a number of Chinese measures restricting import and distribution of certain types of media products to be a violation of WTO law. This AB decision ended more than two years of WTO litigation, through two WTO cases brought by the United States in an effort to curb media piracy in China, and strengthen Hollywood's position vis-à-vis the Chinese market. In Kirk's own words, "[t]he panel and Appellate Body findings ensure that legitimate American products are granted market access so that they can get to market and beat out the pirates. This finding helps to ensure that America's creative ingenuity and innovation are protected abroad ${ }^{777}$."

However, political discourse aside, the question must be asked how exactly the outcome of this case, as well as the China - Intellectual Property case and general WTO discipline impact the two main drivers for media piracy identified earlier. It is very hard to make a definitive statement about the effect of the two US-China media cases, or the general influence of WTO discipline in the real world. A large and complex opening gapes between the black letter of WTO law and a realignment of incentives in the Chinese media sector. The WTO process is one of constant bargaining, contestation and posturing, of which dispute settlement is only one part. Paraphrasing von Clausewitz ${ }^{778}$, one could argue that WTO dispute settlement proceedings often are a continuation of diplomacy by other means, which makes them subject to political considerations and strategic behaviour, for example through leveraging. Furthermore, the WTO lacks enforcement authority beyond naming, blaming and shaming, and permitting a Member to take retaliatory measures. Hence, the implementation of WTO dispute outcomes is subject to complex questions including political and economic factors.

This Chapter therefore does not aim to make broad, sweeping statements about how the WTO eradicates piracy, or opens up China's media market. Rather, having identified the State-based perverse incentives - both in the area of the market restrictions and enforcement - that enable audiovisual media piracy, the more narrow aim is to identify at which points WTO membership can exert influence on the Chinese media policy, and what form this influence can take.

This Chapter answers this question in five steps. First, it analyzes China's rationale for submitting itself to WTO discipline, which entails accepting the jurisdiction of the Dispute Settlement Body. Second, it outlines China's specific commitments and the resulting obligations in relationship to audiovisual media. Third, it evaluates the two US-China media-related cases that were filed in 2007, China - Intellectual Property and China - Audiovisuals. Fourth, on the basis of the judgments that a part of China's media control regime constitutes a violation of its WTO obligations, the

\footnotetext{
776 The section on case DS362 draws on an article the author published earlier in the European Intellectual Property Review.

777 http://www.ustr.gov/about-us/press-office/press-releases/2009/december/wto-appellate-body-

confirms-finding-against-china.

${ }^{778}$ von Clausewitz, 1832.
} 
framework in which the post-litigation bargaining process takes place is analyzed, both in terms of the post-dispute WTO discipline, as well as on the basis of Chinese and American domestic and bilateral policy priorities. Lastly, the potential impact of this process on producers and products on the Chinese media market is sketched.

\section{Why China joined the WTO}

China's accession process to first the GATT ${ }^{779}$ and afterwards the WTO was a protracted affair, and the accession was granted only in exchange for significant commitments and concessions from the Chinese side. WTO entry would open China up to much more foreign influence over its economy, and Beijing would lose a number of policy mechanisms and economic levers both at home and abroad, that it had used in the reform period. China would have to conform to a rules-based trade regime, working on a multilateral basis and dominated by the United States and the European Union. Nonetheless, the Chinese leadership made joining the WTO an important political objective.

The long and twisted road of Chinese WTO membership started immediately after the Second World War. The Republican government had acceded to the GATT Agreement when it was first drafted in 1947, but retracted from the agreement after its 1949 defeat and loss of the Mainland ${ }^{780}$. During the next thirty years, China's ideological position and its difficult foreign relations precluded participation in GATT $^{781}$. After the reforms began, however, China started to view increased participation in the international trading system as beneficial in the light of the open door policy, and formally applied to join GATT in $1987^{782}$. At that time, the procedural requirements were that a working party examining China's application would be established, which would make recommendations to the General Council on the necessary terms of Chinese accession. Afterwards, the General Council would grant permission for accession after a two-thirds approval, representative signature and ratification in China.

As indicated earlier in this study, trade tensions started to develop between the United States and China in the second half of the Eighties, resulting amongst others in the repeated application of the Special $30 \mathrm{I}$ mechanism, and the congressional requirement that China's MFN status should be renewed annually in the light of its human rights record ${ }^{783}$. After the establishment of the WTO in 1995 - which meant that China had to renew its application - the review process moved relatively quickly. China concluded negotiations with all member nations, a Draft Accession Protocol was put forward, which was approved by the General Council and ratified by the National People's Congress, resulting in Chinese WTO accession in $200{ }^{784}$.

\footnotetext{
779 The People's Republic of China never acceded to GATT, as the WTO was established before China became a GATT member.

${ }^{780}$ Gao, 2007. The Republic of China would join the WTO under the name of Chinese Taipei on I January 2002.

${ }^{781}$ The Soviet Union similarly never became a member of GATT. It filed for membership in 1987, but dissolved before membership was approved.

${ }^{782}$ Although, given the Republic of China's presence in the original GATT, China insisted on the term resumption, rather than accession. Gao (2007), p. 6.

${ }^{783}$ Sutter, 2001 , pp. $79-112$.

${ }^{784}$ Gao, 2007, p. 8.
} 
China's size and influence on the world economy, as well as concerns relating to its internal political structure, meant that the major trading partners insisted on high commitments and concession. China had to make separate agreements with the leading WTO members on accession terms before these would countenance its entry. This resulted in a long and detailed Accession Protocol, which included many extra obligations (WTO-plus provisions) and waivers of rights (WTO-minus provisions) ${ }^{785}$. Internally, there was a risk that the powerful administrative entities would strongly oppose accession. Some influential factions within the Chinese leadership opposed WTO membership because of its possible detrimental effects on unemployment, inequality and lack of competitiveness from Chinese companies. President Jiang Zemin and Premier Zhu Rongji were aware of this and kept the WTO accession process from the bureaucracy, working in a very small central group.

Why then, did the Chinese leadership so vigorously pursue WTO membership? Saich identifies five important factors leading to Chinese membership ${ }^{786}$. First, being embedded in a multilateral system afforded the advantage of protection against unilateral action from trade partners. Although this comes at the cost of losing some control over its domestic economy, China was taken aback by the strong reactions of its trading partners in the aftermath of the Tiananmen incident, when it was subjected to trade sanctions and an arms embargo. A second argument was that after the Multi-Fibre Arrangement would run out in 2008, China would have to deal with textile quota. Second, China wanted to be a member of the WTO in order to boost its international image and weigh on global policymaking. Especially at the beginning of the WTO integration process, decisions would be made on several issues that are very important to China, and it wanted to be part of these decisions. Furthermore, internally, entry into the prestigious club of trading countries became an important political legitimating point back home, to the extent that a political crisis loomed when Zhu Rongji came home empty-handed from preliminary negotiations with the Clinton administration. A third factor would be that by firmly positioning China in the international trade regime, the Chinese bureaucracy and future leaders would be obliged to maintain economic reforms. Saich describes this as "a line in the sand of reform that (...) will be almost impossible to retreat behind ${ }^{787 \text { ". }}$. A side benefit would be that the government could blame the foreigners for possible tough decisions. This was also an important matter for a government using nationalism as its guiding principle after the communist ideology left the front stage. Fourth, in the long run, the WTO entry was deemed to provide China with economic benefits, as it would facilitate international trade. As a large part of China's economic growth was - and still is - export-driven, this is not to be understated. Lastly, Saich hypothesizes that an attraction factor also might be that Taiwan was also underway to becoming a WTO member. Given the difficult context in which China and Taiwan find themselves, sharing a forum in which informal contacts and agreements could be made, might be a beneficial matter, especially since China and Taiwan's economic links grow larger rapidly ${ }^{788}$. For the audiovisual media market, it was hoped that China's WTO entry would allow transnational media companies to enter the market, acting as "a driving

\footnotetext{
${ }^{785}$ Although these were limited in the area of IPR, as the majority of legislative reform work had already been undertaken. For a full evaluation of the Chinese Accession Protocol, see Qin, 2003, Pp. 483-522.

786 Saich, 2002.

${ }^{787}$ Saich, 2002, p. 5.

${ }^{788}$ Id., 2002, pp.3-6.
} 
force and an opportunity for Chinese media to realise their own domestic commercialisation and so-called industrialisation ${ }^{789,}$.

\section{China's commitments concerning audiovisual media}

Accession to the WTO for any potential member means mandatory accession to the multilateral trading agreements, which are the agreements in Annex I, II and III of the WTO Agreement ${ }^{790}$. This includes the two major agreements on trade in goods and services, GATT and GATS and related agreements on trade in goods, such as the SPS agreement; as well as TRIPS, the Dispute Settlement Understanding (DSU) and the Trade Policy Review Mechanism. The fact that this package is considered mandatory and hence inseparable, referred to as the "single undertaking ${ }^{79 \mid ",}$ reflects the fact that the WTO is aimed to be comprehensively govern the field of international trade, ending the a la carte approach present in the earlier GATT agreement ${ }^{792}$. Furthermore, Annex IV of the WTO Agreement contains four plurilateral agreements, accession to which is optional, on government procurement; trade in civil aircraft, dairy products and bovine meat.

GATT and GATS provide the basic international legal framework for trade in goods and services, respectively. Both agreements built on two major pillars: national treatment and most-favoured nation treatment. The first means that foreign goods and services must be treated similar to domestic equivalents, the second entails that a benefit extended to one Member must be extended to all. One significant difference between the two, however, is that GATT in principle covers all kinds of goods, whereas the purview of GATS in principle is limited to the services for which commitments have been made in a Services Schedule which is unique to all WTO members $^{793}$.

In recognition of the special characteristics of cultural products and services, the treaties contain a number of provisions pertaining to these products and services, that permit exceptions to Members' general obligations. Article IV GATS 1947 provides that Members are permitted to limit the quantity of foreign films through the form of screen quota, provided that no differentiation is made between foreign films of different origins outside of those quota. This Article reflects the dual concerns of Hollywood's preponderance and the political influence of film ${ }^{794}$. Furthermore, both treaties contain exception clauses (Article XX GATT and Article XIV GATS) that allow for exceptional treatment in a number of areas, amongst others to protect public morals. This has special significance for trade in audiovisual products, because of their specific nature. However, such measures need to be applied in a way that does not "constitute a means of arbitrary or unjustifiable discrimination between countries where the same conditions prevail, or a disguised restriction on international trade" [GATT] or "trade in services" [GATS] ${ }^{795}$.

\footnotetext{
${ }^{789} \mathrm{Hu}, 2005$, p.20.

${ }^{790}$ Article XII, WTO Agreement.

${ }^{791}$ Van den Bossche, 2005, p. 46.

${ }^{792}$ For a broad introduction of WTO requirements, see Van den Bossche, 2005.

${ }^{793}$ At least concerning market access. There are general obligations concerning MFN and transparency in GATS. Van den Bossche, 2005, pp. 50-5I.

${ }^{794}$ Cahn and Schimmel, 1997, pp. 286-287.

795 There are more areas of WTO regulation pertaining to audiovisual media, but these are less relevant for the purposes of this study. For a more detailed overview, see Van den Bossche, 2008; Voon, 2007.
} 
Unsurprisingly, throughout the access negotiations, China tried to ring-fence its domestic cultural market from foreign influence. In the GATS Schedule, for example, China only committed to market access for service providers establishing joint ventures with Chinese partners, with foreign investment of maximum 49 percent, in only two sectors: distribution of audiovisual products - excluding films, and cinema construction and renovation. The Services Schedule also included China's commitment to allow the importation of twenty revenue-sharing films for theatrical release per year ${ }^{796}$.

Furthermore, China is bound by the commitments listed in its Accession Protocol and the Working Party Report. Few provisions in this report directly relate to trade in audiovisual media products and services. However, a number of provisions indirectly covers trade in cultural products and services. First, Paragraph 5.I AP confirms the Chinese commitment to extend trading rights -the right to import and export goods - to all enterprises in China, as well as all foreign individuals and enterprises within three years after accession. Exceptions were made for a number of goods, listed in Annex 2A to the Protocol, which would remain subject to state trading. This Annex contains mostly agricultural products and commodities, and does not contain cultural products. By 2004, China had progressively liberalized trading rights throughout its economy, by eliminating licensing and approval structures and replacing them with registration procedures. Tariffs and non-tariff barriers have also come down ${ }^{797}$. China's failure to extend broader market access and lower barriers to entry to the cultural sector, as illustrated in Chapter IV of this study, caused increasing discontent within the American media conglomerates.

\section{The cases against China}

The American media sector maintained pressure on China to reduce the high levels of piracy, and at the same time to expand market access for their products. When these efforts did not seem to engender sufficient results six years after China's WTO accession, the USTR requested consultations in two interrelated cases against China in April 2007. The first request for consultations, DS362 China - Intellectual Property Rights, dealt with intellectual property matters. It sought to eliminate or reduce the criminal copyright enforcement thresholds, address matters pertaining to the disposal of infringing goods after Customs seizure, and China's denial of copyright to works awaiting Chinese censorship approval. The request for consultations included a fourth matter, relating to a question of translation on the Chinese Criminal Law. Concretely speaking, the United States requested more information on the term 复制发行 fuzhifaxing (reproduction-distribution) in Article 217 of the Criminal Law, which in the Chinese language does not include a conjunction, but was often translated as "reproduction and distribution". The US posited that, if this would indicate that both reproduction and distribution were required for criminal punishment, this might constitute a violation of China's obligations under Articles $4 \mathrm{I}$ and $6 \mathrm{I}$ TRIPS $^{798}$.

\footnotetext{
${ }^{796}$ China Services Schedule.

${ }^{797}$ See Shi, 2005, pp. 23-34.

${ }^{798}$ DS362, Request for Consultations.
} 
The consultations on market access - DS363 China - Audiovisual - were aimed at tackling some of the many barriers inhibiting import and internal distribution of media products. The request focused specifically on the legal structures that denied American companies the right to import media products, instead requiring that all imports be channelled through State-approved, State-authorized and State-run companies. In the eyes of the USTR, these trading rights are a key element of market access, allowing US companies to control when, where and how their products enter China. Furthermore, the request also focused on Chinese rules that impede distribution of publications and home entertainment video products within China, which were deemed to prohibit some distribution activities outright, and apply discriminatory rules to foreign companies in areas where certain activities were permitted ${ }^{799}$. The USTR expressly made the link between market access and piracy, stating that " $[t]$ hese barriers slow down the flow of genuine products within China and give opportunities for IPR piracy and counterfeiting to flourish instead ${ }^{800}$."

\section{DS362/China - Intellectual Property}

The consultations concerning intellectual property only resulted in agreement on the US's fourth point, concerning the translation of Article 217 Criminal Law ${ }^{801}$. Hence, in the panel request, the three American claims were that first, China's thresholds for trademark and copyright infringement were inconsistent with the requirements of Articles 6I and 4I(I) TRIPS; second, that the Chinese Customs regulations, which were alleged to not give Chinese customs authorities the power to order disposal of infringing goods in the way required by Article 46 TRIPS, resulting in the Customs Regulation being inconsistent with Article 59 TRIPS, and third, that Article 4 Copyright Law, allegedly denying copyright protection to works of which publication or distribution was not or not yet permitted, was inconsistent with Article 5 of the Berne Convention, which is incorporated in TRIPS under the provisions of Article 9. As the Customs claim does not relate to audiovisual media, it is not further analyzed here.

The Panel first tackled the alleged denial of copyright. Here, the particular point the US wanted to make that works that had not been authorized for, or of which publication or distribution is otherwise prohibited, are denied copyright protection in China because of Article 4200 I Copyright Law, which read that "Works the publication and/or distribution of which is prohibited by law, shall not be protected by this law." Specifically, the United States made four claims. First, it was claimed that Article 4 Copyright Law violated Article 5(I) Berne, which contains a national treatment clause. Second, Article 4 was deemed to imply that copyright protection would be subject to the successful conclusion of censorship proceedings. This would constitute a formality, which is expressly prohibited under Article 5(2) Berne. Third, it was alleged that Article 4 could be read as denying certain rights that must be extended to producers and performers of sound recordings under Article I4 TRIPS. Fourth, Article 4 would cause the unavailability of the remedies listed in Articles 46 and 47 Copyright Law to authors of prohibited works, and hence be inconsistent

\footnotetext{
${ }^{799}$ DS363, Request for Consultations.

800 USTR 2007.

${ }^{801}$ The 2007 Judicial Interpretation had already laid down that the term should be read as including both and and or. Article 2, 2007 Judicial Interpretation on Criminal IPR Infringement.
} 
with the requirement of making available enforcement provisions present in Articles $4 I$ and $6 I$ TRIPS $^{802}$.

China countered these claims by positing that first, Article 2 Copyright Law guarantees copyright protection in China, and that Article 4 was "extremely limited" ${ }^{803 "}$ " in scope, and second, that China distinguishes between copyright and copyright protection; as a result, Article 4 would only deny "the particularized right of private en-

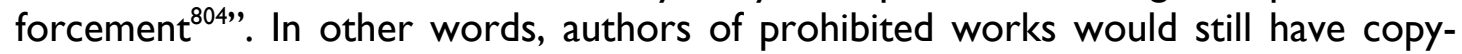
right, but they would not be able to enforce it against infringing parties. The United States rejected this distinction as "artificial" ${ }^{805}$ ".

China also contended that it had the right to exercise control over content through publication licensing under Article 17 Berne ${ }^{806}$, which stipulates that it remains the sovereign right of a Member State to control or prohibit the circulation, presentation or exhibition of works ${ }^{807}$. Furthering this argument, China argued that according to the WIPO guide to the Berne Convention, authors may only exercise their copyright if that does not conflict with public order. As economic rights would be preempted by public prohibition, China alleged that copyright protection would become a legal and material nullity, and become meaningless, as public censorship would render private enforcement unnecessary. Banned content would be removed from the public more securely than would be possible through copyright enforcement ${ }^{808}$.

Responding to the US claim concerning Article 4I TRIPS, China contended that the publication prohibition measures constitute effective actions as required by this Arti$\mathrm{cle}^{809}$. Also, irrespective of having a valid right to enforce, rights holders would still have "access" to enforcement procedures ${ }^{810}$.

The Panel followed the United States' claim that Article 4 is inconsistent with Article 5(I) Berne, finding that "the Copyright Law is sufficiently clear, on its face, to show that Article 4(I) Copyright Law denies the protection of Article 10 to certain works, including those of WTO Member nationals ${ }^{811 " .}$. This includes works that have failed content review and the deleted portions of works edited to pass content review. Concerning works never submitted for or in the process of content review, the Panel did not find that the US made a prima facie case ${ }^{812}$.

Furthermore, the Panel rejected the Chinese argument concerning the difference between copyright and copyright protection, arguing that China did not explain whether and how rights holders would assert ownership of copyright, or license or transfer copyright if protection is denied. This might result in copyright becoming a "phantom right ${ }^{813}$ ". Rebuking China's defence under Article 17 Berne, the Panel ar-

\footnotetext{
${ }^{802}$ DS362 Report of the panel, pp. I-3.

${ }^{803}$ DS362 Report of the panel, p. 13.

${ }^{804}$ DS362 Report of the panel, p. 19.

${ }^{805}$ DS362 Report of the panel, p. 15.

${ }^{806}$ DS362 Report of the panel, pp. $30-33$.

${ }^{807}$ Article 17, Berne Convention.

${ }^{808}$ DS 362 Report of the panel, p. 33.

${ }^{809}$ DS362 Report of the panel, p. 39.

810 lbid.

${ }^{811}$ DS362 Report of the panel, p. 17.

${ }^{812}$ DS362 Report of the panel, p. 27.

${ }^{813}$ DS362 Report of the panel, p. 20.
} 
gues that China does not explain the complete denial of copyright, which is not permitted, and does also not explain why censorship should interfere with rights holders' right to enforce against third parties exploiting works, even if these works are prohibited ${ }^{814}$. The Panel continues by holding that public censorship and private enforcement serve different interests and hence cannot be mutually substituted, and that the assertion that removal from the public is more complete due to censorship is not substantiated, even if relevant ${ }^{815}$.

Concerning the claim under Article 4I TRIPS, the Panel argued that due to Article 4, no enforcement procedures and remedies are available for rights holders of prohibited works to counter infringing acts. The "access" argument was dismissed as "simply [...] not preventing rights holders from filing and pursuing claims in vain ${ }^{816 " . ~ A d d i-~}$ tionally, the Panel stated that Chinese publication prohibition measures might serve as a supplement, but not a substitute, for the minimum standards outlined in Article 4I TRIPS. The Panel ultimately concluded that Article 4 Copyright law is inconsistent with Article 5(I) Berne and Article 9 TRIPS, as well as Article 4I TRIPS. Judicial economy ${ }^{817}$ was exercised in respect of the claims concerning Article 5(2) Berne and Article and 6I TRIPS ${ }^{818}$.

The other part of the case connected with copyright piracy concerns the criminal enforcement thresholds present in Articles 217 and 218 Criminal Law. These provide for criminal enforcement measures in cases of unauthorized reproduction and/or ${ }^{819}$ distribution of copyrighted works (Article 217) and sale of infringing goods (Article 218). These articles contain tests for criminal liability that are drafted relatively broadly. In Article 217, criminal liability exists if "the amount of illegal gains is relatively large, or if there are other serious circumstances". Stricter punishment is possible if "the amounts of illegal gains is huge or if there are other especially serious circumstances 820 ". In Article 218, criminal liability only exists if "the amount of illegal gains is huge ${ }^{82 !}$ ". These thresholds were quantified by judicial interpretations in 2004 and 2007. The 2004 Interpretation put the thresholds of "relatively large illegal gains or other serious circumstances" at illegal gains of at least 30.000 CNY, an illegal business volume of at least $50.000 \mathrm{CNY}$, reproduction and/or distribution of at least 1.000 items, and the catch-all provision of "other serious circumstances ${ }^{822 "}$. The 1.000 item threshold was halved in the 2007 Interpretation ${ }^{823}$. The threshold of "huge illegal gains or other especially serious circumstances was put at unlawful gains of I50.000 CNY, an illegal business volume of at least 250.000 CNY, reproduction and/or distribution of at least 5.000 items, and the catch-all provision of "other seri-

\footnotetext{
${ }^{814}$ DS362 Report of the panel, p. 32.

${ }^{815}$ DS362 Report of the panel, p. 33.

${ }^{816}$ DS362 Report of the panel, p. 39.

${ }^{817}$ In cases where the same measure of one Member is alleged to be inconsistent with a number of different WTO provisions, and panels have already found inconsistency with one provision, they are, under certain conditions, not required to address the other claims, as this would not change the outcome.

${ }^{818}$ DS362 Report of the panel, p. 41.

${ }^{819}$ See above for more explanation about the translation of this term.

${ }^{820}$ Article 217, 1997 Criminal Law.

${ }^{821}$ Article 218, 1997 Criminal Law.

${ }^{822}$ Article 5, 2004 Judicial Interpretation.

${ }^{823}$ Article I, 2007 Judicial Interpretation.
} 
ous circumstances 824 ". The enforcement threshold of Article 218 was set at unlawful gains of $100.000 \mathrm{CNY}$ or more ${ }^{825}$. Also, the 2004 Interpretation stipulated that those violating both Article 217 and Article 218 would be subject to punishment under Article $217^{826}$.

The United States argued that these thresholds are inconsistent with the Article 61 TRIPS requirement of criminal enforcement against wilful copyright infringement on a commercial scale, as well as remedies providing a deterrent to infringement. Also, the thresholds would violate Article 4I TRIPS' requirement that Members provide means for enforcement resulting in effective action. More specifically, the United States alleged that significant quantities of infringing sales in China do not meet the enforcement thresholds, thereby creating a "safe harbour" ${ }^{827}$ " for infringing activities that might be instances of wilful copyright piracy on a commercial scale.

The definition of the term commercial scale then became the measure at issue. The United States interpreted this term as having two elements: on one hand, the term would refer to actors engaging in commercial activities in order to make a financial return in the marketplace, and on the other hand, it would refer to those whose actions, regardless of motive or purpose, are of a sufficient extent or magnitude to qualify as "commercial scale" in the relevant market ${ }^{228}$. China on the other hand argued that the "commercial scale" refers to a significant magnitude of infringement activity, which should be specified according to local conditions, and be subject to national discretion ${ }^{829}$. This connects with Articles I(I) and 4I(5) TRIPS, which allow members to retain discretion of law enforcement. Furthermore, China argued that it uses thresholds for a broader range of commercial crimes, in order to prioritize enforcement and to reflect the significance of a particular infraction. China considers the debated thresholds to be reasonable and appropriate in the context of this legal structure and other laws on commercial crimes. Furthermore, China contended that the thresholds were applicable over a longer period of time, reducing the possible "safe haven" $"$.

The Panel concluded that some acts of copyright infringement might fall below all thresholds and hence are not enforceable through criminal proceedings. However, it would then need to be established whether or not this would violate the commercial scale requirement of Article 6I TRIPS. The Panel defined "commercial scale" as "counterfeiting or piracy carried on at the magnitude or extent of typical or usual commercial activity with respect to a given product in a given market ${ }^{83 !}$." It then set out to first, establish whether or not the level of the thresholds at issue was too high to capture all cases of commercial scale, and second, whether or not the appraisal of China's thresholds should take into account other factors raised by the United States, to encompass all cases on a commercial level, and if not, whether this is required by TRIPS.

\footnotetext{
${ }^{824}$ Article 5, 2004 Judicial Interpretation

${ }^{825}$ Article 6, 2004 Judicial Interpretation.

${ }^{826}$ Article 14, 2004 Judicial Interpretation.

${ }^{827}$ DS362 Report of the panel, p. 123.

${ }^{828}$ DS362 Report of the panel, p. 97.

829 lbid.

${ }^{830}$ DS362 Report of the panel, pp. 93-94.

${ }^{831}$ DS362 Report of the panel, p. II5.
} 
Concerning the first question, the Panel found that the thresholds on their face "do not, in themselves, demonstrate what constitutes a commercial scale for any product in any market in China ${ }^{832}$ ". It also concluded that the United States did not prove that Chinese laws created a situation in which infringing activities meeting the commercial standard norm are excluded from criminal enforcement. In that regard, the Panel especially decried the quality of the evidence brought by the United States, which contained amongst others a number of press articles, which were found to be anecdotal, uncorroborated and unreliable ${ }^{833}$. They concluded that, as a result, the United States did not present a prima facie case under the first sentence of Article 61 TRIPS $^{834}$.

Concerning the second question, the Panel found that none of the other indicia the United States presented was sufficient to prove that China's thresholds violate the first sentence of Article 6I TRIPS. Subsequently, it did not rule on the claims concerning the second sentence of Article $6 \mathrm{I}$ and $4 \mathrm{I}$, exercising judicial economy ${ }^{835}$.

In its conclusion, the Panel recommended that China bring its Copyright law in compliance with TRIPS obligations. It also remarked that its task was not to ascertain the existence or level of piracy in China, nor to review the desirability of strict intellectual property rights enforcement, only to evaluate whether certain Chinese measures violated TRIPS obligations or not ${ }^{836}$.

\section{DS 363/China - Audiovisuals}

Consultations also did not lead to agreements concerning the different import and distribution control mechanisms the US addressed in the request for consultations, leading to the establishment of a second Panel that would have to deal with a case that was much more complex than the comparatively much less complicated IP case. Hence, the Report of the panel was circulated more than half a year later than the China - IP report.

Concretely speaking, the United States challenged more than thirty different Chinese measures, reflecting the haphazard and complicated nature of Chinese media regulation $^{837}$. These challenges can be grouped into four overarching claims. The first claim concerned twelve specific measures that the United States deemed to violate the provisions of China's Accession Protocol relating to grant of trading rights to foreign enterprises ${ }^{838}$, regardless of whether or not these are invested or registered in China. For example, the Foreign Investment Catalogue prohibition of foreign investment in publication, manufacturing and import of audio and video publications was claimed to be inconsistent with the unconditional grant of trading rights. Similarly, Article 4 of the Foreign Capital Opinions prohibits foreign investors to establish amongst others - companies engaging in film import and distribution, import and dis-

\footnotetext{
${ }^{832}$ DS362 Report of the panel, p. 121.

${ }^{833}$ DS362 Report of the panel, p. 124.

${ }^{834}$ DS362 Report of the panel, p. 132.

${ }^{835}$ DS362 Report of the panel, p. 133.

${ }^{836}$ DS362 Report of the panel, pp. 134-135.

${ }^{837}$ DS363, Request for Consultations.

${ }^{838}$ Specifically, these concern Paragraphs 5.1 and 5.2 of the Accession Protocol, and paragraphs 83 and 04 of the Working Party Report, which are incorporated by Para. 5.2. AP.
} 
tribution of books, newspapers and periodicals, import and distribution of audiovisual products or electronic publications.

A more specific claim was filed under a specific requirement of Paragraph 84(b) of the Working Party Report, in which China commits to grant trading rights "granted in a non-discriminatory and non-discretionary way ${ }^{839}$ ". Hence, the United States argued that the Audiovisual Product Management Regulations, while not refusing the grant of trading rights, makes them subject to potential discretionary treatment. Article 5 of these Regulations outlines the requirement of a licence for the publication, production, reproduction, import, wholesale, retail and rental of audiovisual products. However, it does not give further information about the procedure or requirements to obtain such a licence. Similarly, Article 27 of these Regulations stipulates that only audiovisual product import entities designated by the Ministry of Culture are permitted to engage in import of finished audiovisual products, again without giving further information about procedure or requirements for appointment. Related claims were made for similar provisions in the Audiovisual Product Import Regulations and the Film Regulations. In the latter, Article 30 stipulates that only SARFT-appointed entities are permitted to engage in film import.

The second claim was made under the provisions of Article XVI GATS, dealing with market access obligations concerning trade in services. Specifically, the complaint dealt with Article $\mathrm{XVI}(\mathrm{f})$, which stipulates that members may in principle not maintain "limitations on the participation of foreign capital in terms of maximum percentage limit on foreign shareholding or the total value of individual or aggregate foreign investment ${ }^{840}$ ". Here, the Audiovisual Product Sub-Distribution Rules' requirements that the Chinese side must hold at least $51 \%$ equity in Sino-foreign contractual joint ventures sub-distributing audiovisual products was at issue. Also included in the claim were the Foreign Investment Catalogue entry that reiterates this requirement, as well as the Foreign Capital Introduction Opinions provisions that foreign investors are permitted to establish enterprises for sub-distribution of audiovisual products, provided that the Chinese sides holds the "dominant position ${ }^{84 l \text { ". }}$

The third claim concerns Article XVII GATS, which deals with Members' national treatment obligations concerning services and service suppliers. Here again, a number of measures were at issue. Apart from listing claims concerning publications such as books, newspapers and periodicals, the US also filed a number of claims concerning audiovisual products. For example, the refusal to accept applications from foreign-invested internet information service providers to establish Internet cultural entities was deemed to infringe Article XVII, as this would create a disadvantage in comparison with non-foreign-invested enterprises ${ }^{842}$. The Audiovisual Product Subdistribution Rules include the provision that Sino-foreign joint ventures in the field of audiovisual product sub-distribution are limited to a cooperation period of 15 years $^{843}$. Of course, no such term limit is applicable to non-joint ventures. The United States also claimed that a number of abovementioned measures, such as the

\footnotetext{
${ }^{839}$ Para. 84(b) Working Party Report.

${ }^{840}$ Article XVI(f) GATS.

${ }^{841}$ Article 2, 2005 Foreign Capital Opinions.

${ }^{842}$ DS363, Request for Consultations.

${ }^{843} 2004$ Audiovisual Sub-distribution Rules, Article 8(5).
} 
Foreign Investment Guidance Catalogue and the Foreign Capital Introduction Opinions were inconsistent with Article XVII as well ${ }^{844}$.

The fourth claim concerned the requirement of national treatment for goods present in Article III:4 GATT. Concerning audiovisual media, the United States here claimed inconsistency of regulations concerning Internet music distribution, that required that only Ministry of Culture-approved business could import Internet music $^{845}$, as well as regulations outlining licensing requirements for importing Internet cultural products ${ }^{846}$. Most importantly, the US challenged a number of film distribution regulations ${ }^{847}$, arguing that these create a duopoly over film distribution in violation of national treatment requirements.

The Panel found that China acted inconsistently with its WTO obligations in a number of ways. Concerning the first claim, trading rights under the Accession Protocol, the inconsistencies can be divided into three sorts: the "discretion" provisions, comprising Article 4I of the Publications Regulation, Article 27 of the 200I Audiovisual Products Regulation and Article 8 of the Audiovisual Products Importation Rule, which do not provide objective criteria for approval of business entities in their respective fields; the "exclusion" provisions, comprising a condition set out in Article 42 of the Publications Regulation, Articles X.2 and X.3 of the Catalogue and Articles 3 and 4 of the Foreign Investment Regulation, Article 4 of the Several Opinions; and Article 21 of the Audiovisual (Sub-)Distribution Rule, which exclude foreigninvested enterprises from the right to trade in their respective fields, and the "criteria" provision, comprising two conditions stipulated in Article 42 of the Publications Regulation, which are criteria for the grant of trading rights not allowed by the relevant commitments ${ }^{848}$.

Concerning the second claim, market access under Article XVI GATS, the only inconsistency found was China's limitations on the participation of foreign capital in audiovisual products distribution entities ${ }^{849}$. Under the third claim, national treatment under Article XVII, there were more inconsistencies. These can be grouped into two groups: "exclusion" provisions, comprising Article 2 of the Publications (Sub-)Distribution Rule, Article 4 of the Imported Publications Subscription Rule, Articles X:2 and X:7 of the Catalogue of Prohibited Foreign Investment Industries of the Catalogue, Article 62 of the 1997 Electronic Publications Regulation, the Circular on Internet Culture (Article II), the Network Music Opinions (Article 8), and the Several Opinions (Articles I and 4), which either exclude foreign-invested service suppliers from a sector or from the dominant position within joint ventures, where this is permitted for domestic enterprises; and "criteria" provisions, Article 7 of the Publications (Sub-)Distribution Rule and Article 8.5 of Audiovisual (Sub-)Distribution Rule, which differentiate between domestic and foreign-invested enterprises in terms

\footnotetext{
${ }^{844}$ DS363, Request for Consultations.

${ }^{845}$ Article 9, 2006 Network Music Development Opinions.

${ }^{846}$ Article 16, Interim Internet Culture Management Rules.

${ }^{847}$ The 200 I Film Management Regulations, the 200I Film Distribution and Screening Reform Rules and the 2004 Film Entry Regulations.

${ }^{848}$ DS363 Report of the panel, pp. 267-270.

${ }^{849}$ DS363 Report of the panel, p. 352.
} 
of business requirements, in a way inconsistent with national treatment obligations $^{850}$.

Concerning the fourth claim, national treatment under Article III:4 GATS, the only inconsistencies concern the measures dealing with reading materials, which exclude foreign-invested enterprises from wholesaling certain goods, where domestic enterprises face no such barriers. The claims concerning Internet music were rejected, as the Panel found that the US had not demonstrated how the implementation of this measure would influence the distribution of hard copies of sound recordings intended for electronic distribution, as opposed to use of these products ${ }^{851}$. The claims concerning the film duopoly were rejected, as the Panel did not find that these created a de jure monopoly, and that the US did not demonstrate that the application of these measures created a de facto duopoly ${ }^{852}$.

The US did not get the maximum possible out of this case. In the majority of claims where inconsistency was not established, the Panel notes that the US did not adequately establish their argument in the first place, but merely indicated that the alleged inconsistency existed ${ }^{853}$. Moreover, the Chinese succeeded in removing some measures from the Panel's terms of reference on procedural grounds. Some of these measures, concerning audiovisual products, lay at the heart of the economic background of this case, and having them dismissed is unfortunate for the US side. In some cases, the US argument is somewhat sloppy. In the Article III:4 GATT claim concerning sound recordings for electronic distribution, for example, the US muddled the aspects of its argument respectively concerning distribution and use of such products. Moreover, the "use" argument was not present in the Panel Request ${ }^{854}$. This made it possible for China to have the "use" argument dismissed, whilst the "distribution" argument did not demonstrate the alleged inconsistency. The reason for these shortcomings is hard to fathom, but may partly lie in the relatively large number of different claims in this case. If the US had concentrated on a smaller number of cases, this might have been avoided.

The Chinese defence was mainly based on Article XX(a) GATT, which provides for exceptions to GATT discipline in order to protect public order. There was a question of WTO law here, as it wasn't clear whether or not this provision could apply to the Accession Protocol. The Panel accepted this arguendo, and then found that the Chinese media control measures aren't "necessary" to protect public morals, as less trade-restrictive alternatives are available ${ }^{855}$. However, China did manage to defend itself against the claims concerning films for theatrical release under Article III:4 GATT, which was one of the main points in this case.

Both parties appealed against the Report of the panel. China took issue with three decisions of the Panel. First, China appealed against the Panel's finding that China's trading right commitments in the Accession protocol apply to Chinese measures concerning films for theatrical release and unfinished audiovisual products. In the

${ }^{850}$ DS363 Report of the panel, pp. 409-4II.

${ }^{851}$ DS363 Report of the panel, p. 460.

${ }^{852}$ DS363 Report of the panel, pp. 45I-457.

${ }^{853}$ See, for example, DS363 Report of the panel, p. 42.

${ }^{854}$ DS363 Report of the panel, p. 443.

${ }^{855}$ DS363 Report of the panel, pp. 27I-309. 
Chinese view, these measures are considered to regulate services and content, and hence, should not be subject to commitments on trade in goods. Second, China appealed a number of elements, as well as the Panel's conclusion that the standard of "necessity", as meant in Article XX(a) GATT, is not met by the Chinese measures at issue. Lastly, China appealed the Panel's finding that the entry "sound recording distribution services" as present in the Services Schedule includes distribution of sound recording through electronic means, which resulted in a finding of inconsistency with article XVII GATS ${ }^{856}$.

The United States on their side disagreed with the Panel's intermediate finding that China's requirement to conform with the State Plan, as present in Article 42 of the Publications Regulations ${ }^{857}$, could be characterized as "necessary" to protect public morals in China ${ }^{858}$.

The Appellate Body rejected all Chinese claims, although it did make the important point that China Article XX GATT also applies to the Accession Protocol. The Panel had avoided this question by accepting arguendo that this would be the case, and rejecting the argument on the basis of the "necessity" standard. The AB confirmed the American claim, finding that the Panel erred in finding that the State Plan requirement could meet the criteria for "necessity" 859 .

\section{Evaluation of the literal decisions of the cases}

The implementation of DS362 was relatively swift. Less than a year after the Report of the panel was circulated, China had updated both inconsistencies in the Customs Regulations and the Copyright Law ${ }^{860}$. However, both updates could be considered as mere window-dressing operations, and have little operational impact on enforcement against counterfeit products in general and pirated media products in particular. The new Copyright Law Article 4, while no longer denying copyright to prohibited works, confirms the legitimacy of the strict media control regulations. The updated customs articles simply deal with a technicality of counterfeit product disposal that does not directly concern further incentives for the industry.

In this sense, seen on its own, DS362 is a pyrrhic victory at best. While the United States scored some points against China on the low-hanging fruit of Article 4, it was not able to prove the more significant point of the criminal enforcement thresholds. And even if it would have been able to do so, and taking into account the different obstacles that make criminal enforcement so difficult outlined in the previous Chapter, it is difficult to believe that a lowering of criminal enforcement standards would suddenly create a new and strong incentive against audiovisual media piracy.

In this sense, DS 363 is the more meaningful case, as it calls the Chinese media control system into question. It proclaims a number of limits on market access for products and operators, as well as investment barriers against foreign investment in the

\footnotetext{
${ }^{856}$ DS363 Appeal Notification.

${ }^{857}$ This requirement is also present in most administrative regulations governing market access in the audiovisual media sector. However, these measures were not directly at issue in this case.

${ }^{858}$ DS363, Other Appeal Notification.

859 DS363 Appellate Body Report.

${ }^{860}$ For the Copyright Law, Article 4 was changed to provide that copyright holders could not exercise their copyrights in an illegal way. See also Chapter I.
} 
audiovisual media sector, to be inconsistent with China's WTO obligations. In other words, rather than dealing with a simple impediment to trade, the outcome of DS363 potentially has wide-ranging effects on China's domestic regulation ${ }^{861}$. Nonetheless, there is no reason to be too sanguine about the conclusion reached in DS363. For starters, it does not put in doubt the basic right of the Chinese government to regulate the content of media works to be put on the market ${ }^{862}$. Nor does it prohibit the Chinese government from maintaining the core characteristics of the media control regime, as long as this is done in a way that does not discriminate foreign works. While some press observers stated that the case would end the cinema film quota, these are actually part of China's WTO commitments. Hence, they cannot be ended through dispute settlement procedures, only through renegotiation of the Services Schedule.

Legally, both sides score some points in this case. The US has seen it confirmed that China unfairly restricts trading rights and market access in some areas concerning media, as well as not always providing national treatment. China was able to avoid some claims, especially concerning audiovisual media and films for theatrical release, which would have hit relatively hard. However, none of the claims addressed China's much-maligned censorship system dealing with product content, only measures relating to procedures dealing with these products and goods, and the related services. Therefore, this case does not seem to imply that China will open its market to more products, only with more providers dealing with the same number of products.

\section{Implementation and the bargaining framework}

Although it is the objective of the DSB to ensure compliance with rulings ${ }^{863}$, the WTO's power to enforce is limited, It can only conduct monitoring of compliance, and permit the aggrieved complainant to take retaliatory measures in case of noncompliance or both parties failing to agree on compensation. In principle, in case of findings of inconsistency, a reasonable period of time is granted to the respondent to bring their internal measures in line with WTO requirements ${ }^{864}$. In cases where the complainant doubts the existence or WTO consistency of updated measures, they are entitled to request the original panel to decide on this dispute. Panels are given ninety days to complete their compliance reports ${ }^{865}$. Furthermore, the DSB keeps the implementation of adopted recommendations or rulings under surveillance ${ }^{866}$. This means that in principle, the status of implementation is put on the agenda of the DSB meeting after six months following the date of establishment of the reasonable period of time, and it remains on the DSB's agenda until the issue is resolved. Fur-

\footnotetext{
${ }^{861}$ Although the criticism is made that this is outside the scope of what the WTO should be doing. Qin, 2010; Shi and Chen, 2010.

${ }^{862}$ This right is touched upon in the Article 17 Berne Convention, which is part of WTO law, and states that the Convention cannot " in any way affect the right of the Government of each country of the Union to permit, to control, or to prohibit, by legislation or regulation, the circulation, presentation, or exhibition of any work or production in regard to which the competent authority may find it necessary to exercise that right".

${ }^{863}$ See, for example, Article 2I.I DSU, which states that "[p]rompt compliance with recommendations or rulings of the DSB is essential in order to ensure effective resolution of disputes to the benefit of all Members".

${ }^{864}$ Article 21.3 DSU.

${ }^{865}$ Article 21.5 DSU.

${ }^{866}$ Article 21.6 DSU.
} 
thermore, the concerned Members must provide the DSB with status reports on the progress of implementation ${ }^{867}$.

In case of non-implementation of recommendations and rulings, Article 22 DSU provides for compensation and the suspension of concessions. These are temporary measures, and not intended to supplant implementation and compliance. Here again, there is a built-in escalation of strength. Members must start negotiation on mutually acceptable compensation with the side having invoked the dispute settlement procedures if so requested, and no later than the expiry of the reasonable period of time. If no agreement can be reached within twenty days after expiry of the reasonable period, the party having invoked the dispute settlement procedures may request DSB authorization to suspend concessions or other WTO obligations in respect of the obstinate respondent. These retaliatory measures should be aimed first at the same sector covered by the inconsistent measures, second at another sector covered by the same agreement and third, under serious circumstances, at concessions or other obligations under another WTO agreement. The retaliatory measures must be of equivalent level to the nullification or impairment of benefits suffered by the complainant ${ }^{868}$. Furthermore, if the respondent objects to the level of retaliation, the matter must be referred to arbitration, again carried out by the original panel, or by an arbitrator appointed by the Director-General if the original panel is not available. This arbitration must be completed within sixty days after the expiry of the reasonable period. Only after the final arbitration decision, the respondent can no longer delay the imposition of retaliatory measures ${ }^{869}$.

The imposition of retaliatory measures is subject to political and economic considerations. Political bargaining between the parties takes place after the cases, in quite the same way it takes place before and during the case $\mathrm{e}^{870}$. The only significant difference in the weight of the arguments is the DSB verdict. Compliance with DSB decisions remains essentially a voluntary matter, if the responding member is willing to bear the price of remaining non-compliant. As indicated above, that price - directly is either compensation or suffering retaliatory measures. Depending on the relative sizes of the two parties' economies, the nature and volume of trade between them, and the economic interest at stake, this price can be higher or lower. Furthermore, this is complicated by the fact that the imposition of retaliatory measures may be as damaging - or even more damaging - to the economic interests of the complainant than those of the respondent. Lastly, the calculation of the level of retaliatory measures may be a protracted and difficult affair, resulting in further delay ${ }^{871}$. The price of non-compliance can mainly be considered through the political prism. Obstinate members may be subject to shaming and blaming, damaging their international prestige and undermining confidence in their commitment to the international trading system $^{872}$.

\footnotetext{
867 Ibid.

${ }^{868}$ Article 22.6 DSU.

${ }^{869}$ Article 22.7 DSU.

${ }^{870}$ A broad study of retaliatory measures and non-compliance can be found in Bown and Pauwelyn, 2010.

${ }^{871}$ Pauwelyn, 2010.

${ }^{872}$ Still, the importance of this should not be overstated. Compliance remains the norm in the WTO system, proven by the fact that in more than $80 \%$ of the cases, findings of incompliance are rectified.
} 
As a result, a number of DSB findings remain unimplemented, and the Members remain in breach of their commitments. One significant example here is the United States after the US - Copyright case. In this case, the EU challenged a number US measures that exempted certain small business from paying copyright remuneration when playing music if these establishment were smaller than a certain area, or used certain types of equipment. These measures were found to violate WTO provisions. However, because of the interests of specific domestic constituencies, the United States have not brought section II0(5) of the US Copyright Code into compliance. Rather, the EC and US settled by agreeing on a compensation payment. In other cases, sanctions are imposed, such as in the case on hormone beef between the EC and the US, which remains one of the most intractable trade disputes.

\section{Implementation of DS363}

While the findings of inconsistency in DS362 were addressed swiftly and effectively, the same is - at the time of writing - not the case for DS363. This partly stems from the fact that the number of measures found inconsistent in the former case was small, and that they could be revised relatively easily, without significantly changing the legal framework of audiovisual media production and distribution. In the implementation process for DS363, China is faced with two conflicting objectives. On one hand, China has made it a priority to be a responsible member of the World Trade Organization. It went through considerable pains to implement its Accession Protocol, and has hitherto committed significant efforts to implement previous DSB rulings ${ }^{873}$. On the other hand, the leadership might not be ready to relinquish more control over a sector it deems crucial in the internal political system. This is compounded by the political tightening during 201 I, which happened after the Arab uprisings, and in the run-up to the leadership change of the $18^{\text {th }}$ Party Congress ${ }^{874}$.

As a result, at the time of writing, there are double signals concerning the implementation of DS363. When the reasonable period of time ran out in March 20II, China communicated to the DSB that "this dispute involves a number of Chinese administrative measures on cultural products and is embodied with more complexity and sensitivity than other disputes" ${ }^{875 "}$ and that it hoped that "relevant WTO Members could understand the difficult and complicated situation China is facing during the process of implementation ${ }^{876}$." By that time, amendments had been completed in regards to the Publications Management Regulations and the Audiovisual Product Regulations. A month later, China notified the DSB that a draft amendment to the Foreign Investment Guidance Catalogue had been published ${ }^{877}$.

The substance of these regulatory revisions reveals a double picture. In the Foreign Investment Guidance Catalogue, the requirement for Chinese majority shareholding in joint ventures retailing audiovisual products was dropped, although retail in audiovisual products remained in the "limited" section. Similarly, in the prohibited section,

Conversely, this indicates that, as incompliance is the exception, it may be assumed that cases of noncompliance are either too minor or too major for the DSB process. Davey, 2009, pp. 119-128.

${ }^{873} \mathrm{Chi}, 201 \mathrm{l}$.

${ }^{874} \mathrm{http}: / /$ www.chinapost.com.tw/commentary/afp/201 I/I0/I 7/320 I06/p2/Online-lockdown.htm

${ }^{875}$ DS 363 Status Report 2.

876 lbid.

${ }^{877}$ DS363 Status Report 3. 
the entry for books and periodicals, as well as audiovisual products and electronic publications import was removed, although publication and - in case of audiovisual product - production remains prohibited ${ }^{878}$. In response to the ruling on internet distribution of music, a clause was added to the entry prohibiting foreign investment in news web sites, on-line audiovisual programme services, and Internet culture business, which excepted music from this entry ${ }^{879}$.

The revised Audiovisual Product Management Regulations, seemed not to implement the DSB's findings. Article 5, found inconsistent with the requirement of nondiscretion because it implemented a licensing system without providing criteria and procedures for grant of such licences, was only updated to reflect the transfer of administrative authority over parts of the audiovisual product value chain from the Ministry of Culture to GAPP, and to drop the word "rental" from the Article ${ }^{880}$. Article 27 of the 200 I Regulations, which stipulated that only entities appointed by the Ministry of Culture were permitted to import finished audiovisual products, was updated as well, now reading that only entities approved by GAPP are permitted to import these products. ${ }^{881}$ However, this change of wording did not address the underlying concern of introducing discretion into a process where China had committed to act in a non-discretionary manner.

A month later, however, the revised Audiovisual Product Import Regulations provided more detailed criteria and procedures for the establishment of a finished audiovisual product import business. The criteria included amongst others that import business should have a "sponsoring work unit and controlling authority conforming the conditions determined by GAPP" 882 , as well as having the capacity to conduct preliminary content examination. Also, while registration with the industry and commerce authority after obtaining GAPP approval would suffice for importers of finished audiovisual products, those wishing to import audiovisual products for distribution would have to conduct further formalities as required by China's foreign trade laws and regulations ${ }^{883}$.

Also, some questions in the case might leave ambiguities that China might exploit further down the line. For example, the "dominant position" as included in amongst others - requirements for the establishment of Sino-foreign joint ventures has not been expressly deemed a violation of WTO discipline, as the Panel found that the US were not able to prove that the term refers to a shareholding majority, and hence, that the measure would fall under Article XVI(f) GATS.

Outside of the field of audiovisual media, China also updated a number of provisions regulating import and distribution of printed products. However, it is clear that the overriding concern of China in passing these reforms is to combine the objectives of realizing apparent conformity with WTO discipline and maintaining control over import and distribution of content works. More cynically, it could be argued that China aims to maintain a de facto status quo in the barriers to entry of foreign operators in

\footnotetext{
${ }^{878} 201$ I Foreign Investment Guidance Catalogue.

${ }^{879}$ lbid.

${ }^{880} 201$ I Audiovisual Product Management Regulations, Article 5.

${ }^{881}$ Id., Article 27.

${ }^{882} 201$ I Audiovisual Product Import Regulations, Article 8(2).

${ }^{883}$ Id., Article 10.
} 
the media market by moving the black letter of its' laws and regulations closer to conformity.

At the time of writing, this case is not finished. On 19 April 201 I, the United States and China jointly communicated the outline for potential procedures for both the request of a panel under the provisions of Article 2I.5 DSU, as well as the imposition of retaliatory measures under Article 22 DSU $^{884}$. Before that, the United States delegation at the WTO had already indicated that the United States was "troubled by the lack of any apparent progress by China in bringing its measures relating to films for theatrical release into compliance with the DSB recommendations and rulings", and that there were "significant concerns about the incomplete progress relative to China's measures relating to audio visual home entertainment products, reading materials, and sound recordings ${ }^{885}$." It remains to be seen which steps in the end will be taken, what the verdict of a potential panel will be, to what extent this verdict will be in line with the expectations of the United States, and whether or not retaliatory measures will be imposed. One internal problem with retaliatory measures in this case is that the value of such measures will be very hard to calculate, given the complex market situation of audiovisual media products in China ${ }^{886}$.

The trajectory of a compliance panel phase and a retaliation phase will also depend on the internal politics of the United States, and its envisaged consequence on SinoAmerican relations. On the one hand, there is a strong anti-China lobby in Congress, as well as a free-trade lobby bent on seeing the rules of the game maintained. On the other hand, as China's stature on the world stage grows, the range of political issues - not only limited to trade matters - seems only to grow. Hence, the position of audiovisual media in Sino-US relations might become a political bargaining chip, or as already indicated by Peter $\mathrm{Yu}^{887}$ - remains eclipsed by considerations more crucial to United States policy makers, such as currency valuation or cooperation in geopolitical matters.

Results of the WTO process on the audiovisual media market

One measure of the success of both China - Intellectual Property and China Audiovisuals will be their effect on the position of foreign operators in the Chinese media market. In other words, the United States media sector will only consider this case successful if it results in more and easier market access for operators and products on the Chinese market. The US rhetoric after the two cases ended indicated that there was strong hope this would happen. After the publication of the DS362 Report of the panel, acting United States Trade Representative Peter Allgeier announced he would "engage vigorously with China on appropriate corrective actions to ensure that U.S. rights holders obtain the benefits of this decision ${ }^{888 "}$. His successor, Ron Kirk, stated when the DSB accepted this report, that "the United States will not hesitate to use all appropriate tools at our disposal to ensure that our industries, authors and artists are protected - and that our trading partners observe their WTO commitments ${ }^{889}$." When the DS363 Report was announced, Kirk stated

${ }^{884}$ DS363 Sino-US Understanding.

${ }^{885}$ US Geneva Mission, 2011

${ }^{886}$ Qin, 2010, pp. 23-24.

887 Yu, 2008.

${ }^{888}$ USTR, 2009 A.

${ }^{889}$ USTR, $2009 B$. 
that " $[\mathrm{t}]$ hese findings are an important step toward ensuring market access for legitimate U.S. products in the Chinese market, as well as ensuring market access for U.S. exporters and distributors of those products. We will work tirelessly so that American companies and workers can fully realize the market opening benefits that this decision signals."

However, the limitations of China's commitments, combined with the US oversights in this case, reduce the impact on the case in the real world. While the right to import works should be granted to foreign enterprises under China's WTO commitments, such rights are relatively meaningless if it is still required to rely upon domestic State owned distributors. The cinema quota of twenty revenue-sharing films per year is a WTO commitment, and in principle can only be raised through negotiation, for which it might not be unreasonable to expect China would like to receive a reward somewhere else. More broadly, there are no rules in the WTO that are meant to inhibit Members' power to censor their media. Hence, maintaining most of the media control measures outlined in Chapter III may not violate China's WTO commitments, as long as they do not function in a discriminatory manner, and are consistent with specific aspects of WTO discipline and China's Accession Protocol. Any revision to China's international commitment in this field could only be realized through bilateral negotiations with trading partners. Furthermore, it is hard to envisage - especially given the tightening of the political climate inside China after the Tibet riots of 2008 - that there will be a meaningful relaxation of the audiovisual media system rules, including the space for foreign products, anywhere soon.

\section{Conclusion: evaluation of WTO influence on audiovisual media piracy}

China joined the WTO for a number of reasons, but fundamental reform to the audiovisual media sector was not one of those. The prime objective for foreign media conglomerates in China is making money, not toppling the regime, as this might be bad for business ${ }^{890}$. Nonetheless, it is clear that China has aimed to maintain the status quo in this field throughout, while introducing foreign capital, technology and other influences at a rate it controls itself. Nonetheless, a number of the commitments China made have had an effect on its management of the audiovisual media market, and the United States made these the basis of two cases, aimed at opening the Chinese market to American audiovisual media products.

However, in the end, the pressure that can be brought to bear on China through the WTO to increase the presence of these foreign media products is relatively limited. Although a number of violations were found in WTO cases DS362 and DS363, and a number of other, like violations may still exist in laws and regulations not addressed by these cases, removing these violations only scratches the surface of China's media market problems. While Article 4 Copyright Law was deemed to be incompliant, it was updated relatively quickly and easily, without significant altering the rules of the game for foreign products. The instances of WTO violations found in DS363 point to differential treatment between domestic and foreign producers, and to the right to import goods. The consequence is then that China removes this differential treatment and grants importation rights, but this does not in any way bear on all other media control measures that China has in place. In other words, the only real change coming out of DS363, taking the outcome of the case literally, would be that

${ }^{890}$ Fung, 2007, p. 27. 
foreign producers and distributors would be allowed to function on the Chinese market without discrimination within the confined limitations of China's WTO commitments, while still subject to all laws and administrative regulations which otherwise govern this market. It can be envisaged that the outcome of the case could lead to a negotiated settlement, but this then hinges on political priorities between the two parties, and given the state of Sino-US economic relations at the time of writing, it is clear that media piracy does not figure on top of the priority list.

That the WTO has a limited impact on piracy in China does not mean that it is a weak organization as such. It clearly has developed an authoritative position in the field of international trade, and its dispute settlement system has greatly strengthened the impact of the multilateral trading regime in comparison to the GATT-era. Rather, the majority of law-based factors contributing to media piracy are outside of the WTO's purview. There is no legal basis for the WTO to make a decision over content-related aspects of China's audiovisual media system. Only copyright law and regulation of media market access can be subject of a WTO case, and then only where there is a cross-border aspect and - in the case of services - where there has been a Chinese commitment. Furthermore, the WTO has no independent investigative capacity. It is up to member states to make the decision to take a case to the DSB. This reflects the political nature of the organization and its role as a memberdriven and intergovernmental, rather than supranational institution.

Looking more broadly, it might be a subject for further research whether or not the WTO's capacity to bring about tangible change in the real world is more effective depending on the sort of trade measure at issue. China's media control regime - like the United States' gambling laws - are not primarily viewed as a trade matter domestically. Rather, these are issues that are discussed in terms of public morality and political imperatives. Even where there is an obvious international aspect, where the question on how to deal with foreign media products is discussed, the barriers to entry for foreign products are not protectionist measures as narrowly defined. While certainly, Chinese domestic media producers are protected by such measures, they also suffer more than anyone else from China's strict media regime. In other words, rather than a trade issue with domestic political consequences, media control is a domestic political matter with consequences in the trade field. The WTO's power is therefore mainly limited to these consequences in the trade field, and cannot address the heart of the matter, which remains subject to national sovereignty.

In the end, therefore, the treatment of audiovisual media will remain an irritant in Sino-American relations, at least for the foreseeable future, and as China - however minimalistically - implements the findings of DS363, the options for formal legal action against China in this field diminish. It seems likely that from that point onwards, only a politically negotiated solution or increased political liberalization inside China would significantly change this situation. 


\section{Conclusion}

\section{Results of this study}

This research project aims to better understand the State-based factors that bring about audiovisual media piracy in China. It broadens the dominant view based on copyright and its related intuitions, stakeholders and enforcement mechanisms, to a wider understanding that also includes the political imperatives surrounding media production, distribution and consumption that result in increased demand for production outside the legitimate scope, as well as the dysfunctional institutional structures that create perverse incentives for piracy activities. The study argues that piracy emanates from the endemic cracks in the system that cannot be closed - or are even further opened - because of the alignment of political and economic incentives.

On the assumption that piracy occurs whenever it is in the interest of suppliers and consumers, this study foregrounds a model that divides piracy between two kinds: consumers are either unable or unwilling to consume the legitimate product. The State is then introduced as a concerned party in media dissemination, with a potential interest in controlling access to works. After providing a brief overview of the evolution of freedom of expression in Europe and its impact on media, the study then investigates whether and how Chinese state action makes it impossible to bring media products to the market legitimately. In Western economies, markets in media products are governed by two main legal frameworks: a framework concerning market access requirements, which mainly relates to freedom of expression, and copyright, which makes it possible for works to be valuated in the marketplace. While there are certain market restrictions, based on content, language and cultural issues, or technological requirements such as spectrum access, it is in practice nearly always possible to bring a product to the market in some form or through some channel. In China, this is different. While there is a high-quality legislative framework for copyright, the market for media works is severely limited in terms of content and sector access.

Concretely speaking, the conclusion of this study is that audiovisual media piracy in China is a consequence of the limitations on the media market. In other words, the narrow scope of legally available works is not able to meet the public's demand, making piracy the only way to obtain a significant amount of media works. Moreover, when economic structures arise that unlawfully respond to that demand, they are protected against strong enforcement by actors of the same Party-State structure that caused the narrow scope of work in the first place. From there onwards, an economic structure closely resembling legitimate distribution structures dynamically comes into being, which - since it operates outside of the law - can much better respond to public demand than legitimate parties, who are still subject to the PartyState's heavy media control hand. This directly damages the Chinese media industry. The Party-State has aimed to mitigate this through subsidization, favourable support policies and other economic methods, but these measures do not solve the lack of competitiveness of the legitimate sector.

Anti-piracy enforcement is limited by institutional weaknesses, policy design problems and lack of capacities. Institutionally, pervasive principal-actor problems and 
corruption create a situation where piracy networks have been able to develop a relatively stable relationship with enforcement officials. Policy is often aimed at protecting the public interest of media control over the private right of rights holders, is designed in such as way that there are little incentives for effective enforcement, or serves to play the politics of enforcement, rather than enforcement itself. At the same time, private rights holders - especially foreign rights holders - have less of a stake in private enforcement, as it is very hard for them to enter the market legitimately anyway.

This conclusion entails that significant anti-piracy action will require much more than a simple increase in enforcement resources or tightening copyright or media regulation law. As a symptom of a media market that is insufficiently free, combating piracy will be better served by broadening the scope of works on the market and players that trade in them. This would give the legitimate sector a larger stake in fighting piracy, as the legitimate market size would increase. However, this would also mean that the entire current mode of communication in China - which the Party views as crucial to maintain and strengthen its leading position - would need to change. Political control would need to be decreased, regulatory structures and institutions who now are often indirect or even direct stakeholders in piracy - would need to be reformed or abolished. Given recent developments where control measures over media and the Internet have mostly strengthened, this seems highly unlikely.

The influence of the WTO on this can only be described in a very nuanced fashion. In one way, the WTO can be very strong, as it has shown in the DS363 case, which essentially declared a part of China's foreign-related media control regime to be incompliant with WTO requirements. At the same time, WTO powers are limited. If China is willing to bear the burden of retaliatory measures in cases of nonimplementation, it cannot force compliance. Also, the WTO can only make a decision in cases where another member brings a case. It has no right to take initiatives on its own. Lastly, the WTO can only rule within its own trade remit. However, the majority of Chinese media control measures are either outside of the WTO's jurisdiction, or are not inconsistent with WTO discipline and China's commitments. For example, the WTO expressly provides that censorship is permitted, as long as it respects a number of basic WTO provisions such as national treatment. Hence, although DS362 and DS363 did punch a couple of holes in the media control web, it seems that, for the present, the Chinese leadership will still be able to maintain the majority of media polices, guaranteeing their control over the media distribution.

Furthermore, this conclusion does not imply that liberalizing the Chinese media market would suffice to end piracy. While it is a necessary condition, it is in itself not enough to generate a functioning market for media products. The development of a functioning media market in China will depend also on entrepreneurs' vision and creativity in developing products that audiences will consume, through different platforms and under attractive conditions. In other words, the Chinese media control regime causes inability of Chinese consumers to access certain products, which is logically prior to their potential unwillingness to access these under conditions set by rights holders. Making the products legal, but maintaining high prices - as copyright industries have done for quite some time - will still push potential consumers to piracy. This conclusion also does not imply that complete media market liberalization is a desirable matter. Recognizing the importance of cultural diversity, an appropriate 
balance between market mechanisms and other forms of financing would reconcile objectives of economic growth as well as interests of local expressions, cultural products and services.

\section{Piracy in context: substantive, theoretical and empirical implications}

Given that piracy in China is strongly influenced by political interference in the market, some care is required when making normative judgments about the phenomenon. For many Chinese, pirated media is the only way in which they can connect to globalized media, not only for something as mundane as entertainment, but also for news and information. Especially in the interactive sphere of the Internet, advocating for stronger government control over dissemination and distribution risks handing strong coercive tools to the Party-State which it may use to crack down heavily on dissent and communication of information. At the same time, piracy may not only be a political good for citizens, but also for the leadership. By maintaining a certain tolerance for piracy, the government may appease citizens by permitting them access to - primarily foreign - products that are deemed relatively harmless, while steering them away from more radical works.

Studying piracy may also help in achieving a broader understanding of Chinese politics. By using piracy as a diagnostic tool for internal pathologies, it may offer an insight into the deeper workings of State-citizen relations, administrative governance and political change in China. It may enable us to make sense of dynamics in other policy areas, such as environmental protection, food safety and product issues. However, this study also indicates that this would require a broad insight into the sector, which can only come from a combination of empirical and primary source research. As indicated in Chapter I, earlier studies into piracy in China suffered from an overreliance of a copyright-based perspective, which paid little regard to market control dynamics, and which did not consider the complex interrelations between the different actors and structures that are a part of piracy. By concentrating on piracy as a symptom of dysfunctional media regulation, this study was able to shed light on these matters. Furthermore, by including a substantial amount of primary documents, this study was able to study the nuances of Chinese media control policy in depth. However, a primary knowledge gap remains. More empirical knowledge about piracy as a phenomenon, as well as its position in the broader media consumption patterns of Chinese consumers, is required if we are to better understand the dynamics of media production and consumption in China. Similarly, collecting, translating and making available Chinese legal and regulatory texts will help open up the field to theoretization by legal scholars who are not necessarily fluent in Chinese. The Chinese media sector is evolving increasingly quickly and is well worth following up through different domestic and international perspectives.

Further questions remain also in the international dimension of piracy. Having found that it has come to the end of the road as regards both the international compliance level of China's IPR regime and the substantive aspects of media censorship, the question remains whether and how the US will use the trade route to expand market access for their media enterprises. At the time of writing, it seems that the US is pursuing a path based on the intention to challenge the procedural aspects of Chinese censorship, both for its own sake and to leverage it against other policy concerns. Time will tell how these efforts turn out, but they may be quite influential in requiring China to either make its censorship system more transparent or making 
the point at the international level that its commitments to the rule of trade law are limited by national interest. Again, this is a moving target, which merits further monitoring and analysis.

\section{One last thought: where do we go from here?}

Many apocalyptic predictions about China's future have been made ${ }^{891}$, and until now, the People's Republic has survived all of them. It is certainly not the present author's intention to make hard predictions or normative suggestions about China's near future. However, China does face a number of significant problems ahead, some of which connect to media openness and free information. Increasing numbers of riots and other incidents, often caused by local abuses, may endanger popular support for continued Party rule. Maintaining economic growth will become harder as China develops further, its economic make-up changes, world trade patterns realign, and distributive questions will be asked increasingly. Economic development of the media sector may indeed provide higher-value jobs and income for Chinese workers, but this implies that they need increased freedom to produce for markets rather than bureaucrats. It may provide a relatively safe way to address and debate social issues, and enhance communication. China is becoming an increasingly pluralist society, and it is hard to imagine how it can continue its development path if the political level insufficiently reflects this.

At the time of writing, the omens are worrying. In the run-up to the 2012 leadership transition, which bodes to be less smooth than the 2002 one, censorship has been tightened, and Internet communication platforms are subject to increased and stronger regulation. The worst crackdown against dissidents and rights defence lawyers since 1989 also may indicate the limits of China's commitment to domestic rule of law, at least where non-economic matters are concerned. It remains to be seen whether the new leadership will be capable of bringing about political change and reform when the situation requires, or whether they will atrophy, with all the potential consequences this may bring. Taiwan and Hong Kong may be successful examples of democratization with Chinese characteristics, but there seem to be no indications that these are considered as models for the Mainland, which rather looks in the direction of authoritarian Singapore.

This also has consequences for China's international soft power. While China has prioritized acquiring this soft power, the continuing stream of news on crackdowns, handling of sudden news events such as the Wenzhou train crash and enduring abuses of varying kinds ensure that the Chinese reputation abroad remains tarnished. American and European politicians will find still find it easy to demonize China for being an unfair trade partner to domestic electorates, reducing China's diplomatic options abroad. If China truly wants to expand its soft power, it will need to show as well as say that it has a story to rival that of the American dream. While it would be foolhardy to say that piracy could be seen as a bellwether for political change in China, it does indicate that Chinese audiences, not only Chinese enterprises, are ready to internationalize.

\footnotetext{
${ }^{891}$ See, for example, Chang, Gordon, The Coming Collapse of China, Random House, 200I, and Navarro, Peter, The Coming China Wars: Where They Will Be Fought and How They Can Be Won, FT Press, 2008.
} 


\section{ANNEX: Chinese legal texts}

Competences of the Central Propaganda Department:

Being responsible for guiding theory research, study and propaganda work nationwide; being responsible for guiding social and public opinion, guiding and coordinating all central news work units' work; being responsible for guiding spiritual product production at the macro-level; being responsible for planning and deploying overall ideological and political work duties, coordinating with central groups in organizing party member education work, being responsible for writing party member education materials, together with relevant entities researching and improving the masses' ideology education work; with party entrustment, in coordination with central organizations, managing the leading cadres of the Ministry of Culture, General Administration of Press and Publications and Chinese Academy of Social Sciences, together with central organizations managing the leading cadres of news organizations and managing organizations such as the People's Daily, State Administration of Radio, Film and Television, Xinhua Press Agency, etc., raising opinions on provincial, autonomous region and municipal Party Committee Propaganda Department directors; being responsible for raising leading principles for propaganda, ideology and culture undertaking development, guiding formulation of policies, laws and regulations in the propaganda and culture system, according to the uniform work deployment of the Central Committee, coordinating the relations between entities in the propaganda and culture system, completing other tasks handed over by the Central Committee.

\section{Competences of SARFT}

(I) Formulating general and specific policies for radio, film and television propaganda and creation, grasping correct public opinion guidance and creation orientation.

(2) Drafting law and regulation drafts for radio, film and television and information network audiovisual programme services, formulating corresponding technical standards and departmental rules, moving structural reform in the radio, film and television area forward.

(3) Organizing moving forward of public service in the area of radio, film and television, organizing implementation of major radio, film and television projects, assisting the old, ethnic minority, border and poor regions in radio, film and television development, guiding and supervising radio, film and television focal infrastructure construction.

(4) Formulating radio, film and television undertaking and industry development planning, guiding and coordinating radio, film and television undertaking and industry development, managing national-scale major radio, film and television activities.

(5) Being responsible for radio, film and television, and information network audiovisual programme service organ and professional supervision and implementing entry and withdrawal management, guiding supervision work over non-governmental organs engaging in radio, film and television programme production.

(6) Supervising radio, film and television programmes, information network programmes and audiovisual programmes broadcasted public audiovisual media, examining content and quality.

(7) Guiding radio, film and television, and information network audiovisual programme service science and technology work, being responsible for supervising radio, film and television programme's transmission, monitoring and safe broadcasting. 
(8) Guiding and managing radio, film and television foreign and Hong Kong, Taiwan and Macau cooperation, being responsible for radio, film and television programme import and inclusion management.

(9) Leading the China National Radio, China International Radio and China Central Television, conducting guidance, coordination and management over major matters such as propaganda, development, transmission coverage, etc.

(I0) Undertaking other matters assigned by the Central Committee or the State Council.

\section{Competences of GAPP}

(I) Drafting of press and publications and copyright management law and regulation drafts, formulating of general and specific policies for the press and publications sector, formulating of press and publications and copyright management rules and organizing implementation.

(2) Formulating press and publication sector and industry development plans, regulating and controlling objectives and sector policies and guide implementation, formulating national publication, printing, duplication, distribution and publications import work units' total number, structure, deployment planning and organizing implementation, moving forward system and mechanism reform in the press and publication area.

(3) Supervising publication activities, organizing investigation and prosecution of publications gravely violating regulations and major publication activities violating laws and regulations, guiding supervision work of non-governmental organizations engaged in publication activities.

(4) Being responsible for conducting sector supervision over press and publications work units, implementing access and withdrawal management.

(5) Being responsible for publication content supervision, organizing and guiding major Party and State documents and data, focusing on publications and textbook publishing, printing and distribution work, formulating State ancient works arrangement and publication planning and undertaking organization and coordination work.

(6) Being responsible for examination and approval of and supervision over Internet publication activities and opening mobile phone books and periodicals and mobile phone literature sector.

(7) Formulating publications market "Sweeping Pornography and Beating Illegality" planning and organizing implementation, organizing investigation and prosecution of large and major cases of illegal publications and illegal publication activities.

(8) Formulating publications market regulation and control policies and measures and guiding implementation, guiding supervision work over publications market business activities.

(9) Being responsible for national press and publications work units' journalist credentials' supervision and management, being responsible for domestic press publishers and press agencies' branch organs' and journalist stations' supervision, organizing investigation and prosecution of major unlawful news activities.

(I0) Being responsible for supervision over the printing sector.

(II) Being responsible for copyright management work, organizing investigation and prosecution of copyright infringement cases wish a major influence and foreignrelated infringement cases, being responsible for dealing with foreign-related copyright relations and relevant reaction work to international copyright treaties. 
(I2) Organizing development of work relevant to press and publications and copyright foreign exchange and cooperation, being responsible for publications import management work, coordinating and promoting publications import and export.

(13) Undertaking other matters assigned by the Central Committee or the State Council.

1982 Provisional Audiovisual Product Management Regulations, Para. 5.

Audiovisual products publishing work units must support the four cardinal principles, implement the direction of serving the people and serving socialism, implement policies on hundred blooming flowers, removing the chaff to renew, make foreign things serve China, make the past serve the present. Their basic task is to mobilize and organize production and acting resources and record and publish audiovisual products needed by State and people, enriching the people's spiritual and cultural life, propagate and accumulate cultural and scientific knowledge achievements, contribute to the establishment of a socialist spiritual civilization and material civilization.

\section{Audiovisual Compression and Rectification Notice}

All audiovisual publication work, where one of the following circumstances is present, must be cancelled:

(I) those exceptionally proclaiming bourgeois liberalization standpoints or having other grave political errors;

(2) those publishing obscene or sexual audiovisual products;

(3) those publishing low moral quality audiovisual products partly containing obscene or sexual, or murder and violence content, where circumstances are grave;

(4) those selling publication numbers, binding and layout, plates and pirated products under grave circumstances, with loathsome influence.

All audiovisual publishing work units, where one of the following circumstances is present, shall be ordered to cease trading:

(I) those that, after issue of the "Notice Concerning Audio and Video Management Work Division Questions" (COC No. 1989(II) by the Central Organization Committee, have not been approved or established according to the provisions of this document;

(2) those organized by local and city level (not including Special Economic Zones, planned single cities);

(3) "colleague's publishers", in which the competent authority has for a long time not taken responsibility or management or not having a competent authority as a matter of fact, organized by a section of persons;

(4) those not having strong leadership ranks and editing and technological capacity meeting requirements;

(5) those lacking corresponding material production criteria, and cannot product audiovisual master tapes;

(6) those not having a fixed work location and necessary capital guarantees;

(7) those after approval of establishment, basically not having produced audiovisual products or only having imported foreign publications.

All audiovisual publishing work units, where one of the following circumstances is present, shall be merged:

(I) those overlappingly or duplicatingly set up in the same locality or under the same entity;

(2) subdivision organs established by audiovisual publishing work units; 
(3) those of which the sponsoring work unit already has a book publisher, of which it is possible to merge the audiovisual publishing work with the book publisher;

(4) others of which the system or deployment are not reasonable.

(...)

2, Concerning compression and rectification of audiovisual duplication, distribution and projection work units.

All duplication work units, where one of the following circumstances is present, shall be cancelled or cease operations:

(I) those violating publication management regulations, using means such as selling of publication numbers, printing numbers, etc. to publish audiovisual products with exceptional circumstances, shall be cancelled.

(2) those that privately translate and privately duplicate or undertake audiovisual duplication work for unofficial publication work units without authorization with exceptional circumstances, shall be cancelled.

(3) those that do not lack basic duplication equipment and special technical personnel or with low-quality products, shall cease operations.

Towards regions where audiovisual duplication capacity is already gravely superfluous, relevant controlling authorities must according to the principle of preserving the backbone, and compressing ordinary work units, conduct "close, stop, merge, shift" towards a part of duplication production work units, and be responsible for dealing with the aftermath work.

All audiovisual distribution work units, where one of the following circumstances is present, will be cancelled:

(I) those violating publication management regulations, using means such as selling of publication numbers, printing numbers, piracy, etc. to publish audiovisual products with exceptional circumstances;

(2) those selling illegal publications with exceptional circumstances;

(3) collective and individual videotape wholesale work units and individual audio tape wholesale work units.

All audiovisual projection work units, where one of the following circumstances is present, shall be cancelled:

(I) those projecting reactionary, obscene or sexual audiovisual products;

(2) those projecting pirated and other illegal audiovisual publications with exceptional circumstances;

(3) those individually run or contracted as well as entrusted to individuals;

(4) those violating other management regulations with exceptional circumstances.

Moreover, work units not having been approved according to regulations by the relevant entity, illegally dealing in duplication, distribution and projection shall without exception be banned.

Duplication, distribution and projection work units shall simultaneously conduct thought rectification and organization rectification, and the provincial, autonomous region of municipal compression and rectification of audiovisual work units office may organize implementation according to the needs concerning publication work units.

1995 Film Distribution and Screening Regulations, Article 7.

For film distribution and screening work units applying for annual permit examination, all levels' government administrative film management organs according to 
these Regulations, approve annual examination registrations of those conforming to the following conditions.

(I) Implementing general and specific Party and State policies related to film work, abiding by laws and regulations;

(2) according to regulations, timely and accurately reporting all statistical data relevant to film distribution and screening to the government management entity;

(3) according to relevant regulations, turning over State film development special funds;

(4) distributed and screened films must be films to which the Ministry of Radio, Film and Television Film Bureau issued a screening permit;

(5) work units distributing and screening films must have distribution and screening rights for the films they distribute and screen;

(6) every year, distribution and screening of focus films may not be less than the statutory quantity determined by the State management entity (except for specialist new film screening method work units such as ball screen, round screen, movement, etc.).

1997 Film Examination Regulations, Article 10.

Article 10: Where a few of the following content occur in plot, language or pictures in a film, it shall be deleted, revised:

(I) scattered obscene and vulgar content, not conform to moral norms and the public's enjoyment habits:

I: inappropriately recounting or describing sex and stories related to sex, expose the front of the male and female body

2: with a confirming attitude describing extramarital love, unmarried cohabitation and other improper male-female relations;

3: concretely describing corruption and degeneration, possibly inducing people to imitate;

4: relatively long kiss or caress shots creating strong emotional provocation and pictures from on the bed or in the bathroom;

5: concretely describing promiscuity, rape, prostitution, visits to prostitutes, homosexuality, etc;

6: dialogue with vulgar, and low interest content;

7: vulgar, inferior background music and dynamic and sound effects.

(II) scattered murder and violence content:

I: imagery embellishing criminality, leading people to sympathize with and admire criminals;

2: concretely describing criminal tricks and details, possibly inducing and moving people to imitate criminal behaviour;

3: relatively strongly provoking pictures of murder, drug use, gambling, etc.;

4: describing bizarre and absurd, having brutality contrary to human nature, acts of violence.

(III) scattered content propagating feudal superstition:

I: meticulously describing fortunetelling and physiognomy, seeking divine advice, as well as long scenes of incense burning, god worshipping, idol worshipping, etc.;

2: plot advocating the omnipotence of religion, supremacy of religion and displaying religious fanaticism;

(IV) plot possibly leading to international, ethnic, religious strife; 
(V) pictures and plot damaging the environment, devastating and catching and killing valuable and rare wildlife;

(VI) other content that should be deleted, revised.

2009 Internet Content Management Notice, Para. II

(I) those maliciously distorting Chinese culture, Chinese history and historical facts; those maliciously distorting other countries' history, not respecting human culture, other countries' culture and social customs and habits;

(2) those with imagery deliberately derogating or vilifying revolutionary leaders, heroic persons, important historical persons, Chinese and foreign famous books and important characters in famous books;

(3) those with imagery maliciously derogating the People's Army, the Armed Police, Public Security and the judiciary, those having circumstances such as abusing prisoners, extracting confessions by torture from criminals or criminal suspects, etc.;

(4) those with imagery and sounds displaying unlawful and criminal aggressiveness and arrogance, concretely revealing details of criminal activities, revealing special investigation methods, revealing informers and witnesses who should receive protection, etc;

(5) those advocating religious extremism, provoking controversies and conflicts between all religions and religious denominations, and between religious believing masses and non-believing masses, harming the feelings of the masses;

(6) those propagating feudal superstition activities such as physiognomy, fortune telling, geomancy practicing, divination practicing, healing by exorcise, etc.;

(7) those with vile methods depicting calamity scenes such as major natural disasters, accidents, terrorizing incidents, wars, etc.;

(8) those concretely showing circumstances such as promiscuity, rape, incest, necrophilia, prostitution, visiting prostitutes, sexual perversion, masturbation, etc.;

(9) those displaying or obscurely displaying details such as sexual activities, sexual process, sexual methods and excessive bodily contact related to this, etc.;

(I0) those intentionally showing, only using the body to cover or using very little cover to cover human private parts;

(II) those containing sexual suggestions, sexual provocations, etc, which easily cause people to make sexual associations;

(I2) those propagating unhealthy content such as extramarital affairs, group sex, one-night stands, sexual abuse and wife swapping;

(I3) those using adult movies, sexual movies, X-rated movies, voyeurism, indecent exposure, exhibitionism and all sorts of prevocational writing or images to function as audiovisual programme titles or classifications;

(14) those having circumstances such as strongly stimulating murder, blood and gore, violence, suicide, abduction, drug use, gambling, occultism, etc.;

(I5) those having excessive scary and terrifying images, subtitles, background music and sound effects;

(I6) those concretely showing maltreatment and killing of animals, catching, killing and eating animals protected by the State;

(I7) those having content violating individual privacy;

(18) those with an approving and praising tone or in a way that leads people to imitate, showing fights and brawls, humiliation of others, and filthy speech;

(19) those propagating negative or decadent views of life, worldviews and value systems, sedulously playing up and magnifying ethnic ignorance and backwardness or the dark side of society; 
(20) audiovisual programmes and films, television programmes and deleted extracts of which the dissemination was prohibited by the State Administration of Radio, Film and Television;

(2I) those violating the spirit of relevant laws and regulations. 


\section{Bibliography}

\section{Academic sources}

Aldgate, Anthony, James Robertson, Censorship in Theatre and Cinema, Edinburgh U.P., Edinburgh, 2005.

Alford, William, Stealing a Book is an Elegant Offense, Stanford U.P., Cambridge, 2007.

Bai, Jie, Joey Waldfogel, 'Movie Piracy and Sales Displacement in Two Samples of Chinese Consumers', Wharton School University of Pennsylvania Working Paper, 2009

Bello, Judith, Alan Holmer, 'Special 30I: Its Requirements, Implementation, and Significance', Fordham International Law Journal, vol. 13, 1989.

Bertrand, André, 'Shostakovich and John Huston: the French Supreme Court on Copyright, Contracts and Moral Rights', in Heath, Christopher and Anselm Kamperman Sanders (eds.), Landmark Intellectual Property Cases and their Legacy, Kluwer, $201 \mathrm{I}$.

Bian, Xuemei, Cleopatra Veloutsou, 'Consumers' Attitudes Regarding NonDeceptive Counterfeit Brands in the UK and China', Journal of Brand Management, vol. 14, 2007.

Black, Gregory, 'Hollywood Censored: The Production Code Administration and the Hollywood Film Industry, 1930-1940', Film History, vol. 3, 1989.

Bown, Chad and Joost Pauwelyn (eds.), The Law, Economics and Politics of Retaliation in WTO Dispute Settlement, Cambridge U.P., Cambridge 2010.

Brady, Anne-Marie, Marketing Dictatorship: Propaganda and Thought Work in Contemporary China, Rowman \& Littlefield, Lanham, 2010.

Butterton, Glenn, 'Pirates, Dragons and U.S. Intellectual Property Rights in China: Problems and Prospects of Chinese Enforcement', Arizona Law Review, vol. 38, 1996.

Callahan, William China: the Pessoptimist Nation, Oxford U.P., Oxford, 2009.

Cahn, Sandrine, Daniel Schimmel, 'The Cultural Exception: Does It Exist in Gatt and Gats Frameworks - How Does It Affect or is It Affected by the Agreement on Trips', Cardozo Arts \& Entertainment Law Journal, vol. I5., 1997.

Cao Jianming, 'The Recent Development and Current Status of Judicial Protection of Intellectual Property in China', in Torremans, Paul et al. (eds.), Intellectual Property and TRIPS Compliance in China: Chinese and European Perspectives, Edward Elgar, Cheltenham, 2007.

Chan, Joseph Man, 'Administrative Boundaries and Media Marketization: A Comparative Analysis of the Newspaper, TV and Internet Markets in China', in Lee, ChinChuan (ed.), Chinese Media, Global Contexts, Routledge, Abingdon, 2003. 
Chen, Jianfu, Chinese Law, Context and Transformation, Martinus Nijhoff, Leiden, 2008.

Cheung, Wah-Leung and Gerard Prendergrast, 'Exploring the Materialism and Conformity Motivations of Chinese Pirated Product Buyers', Marketing Intelligence and Planning, vol. 24, 2006.

Chi, Manjiao, China's Ten-Year WTO Litigation Experience: Some Salient Systematic Impacts of the WTO Dispute Settlement, Chinese Society of International Law, Working Paper, 20II.

Choi, Jinhee, The South Korean Film Renaissance: Local Hitmakers, Global Provocateurs, Wesleyan U.P., Middletown, 2010.

Chow, Daniel, 'Why China Does Not Take Commercial Piracy Seriously', Ohio Northern University Law Review, vol. 32, 2006.

Chu Yingchi, The Consumption of Cinema in Contemporary China, in Donald et al. (eds.), Media in China, Consumption, Content and Crisis, Routledge, Abingdon, 2002.

Clark, Paul, Chinese Cinema: Culture and Politics since 1949, Cambridge U.P., Cambridge, 1988.

Cohen, Gerald, Marx' Theory of History: A Defence, Oxford U.P., Oxford, 1978.

Cornish, Jordana, 'Cracks in the Great Wall: Why China's Copyright Law Has Failed to Prevent Piracy of American Movies Within its Borders', Vanderbilt Journal of Entertainment and Technology Law, vol. 9, no. 2., 2006.

Curtin, Michael, 'The Future of Chinese Cinema: Some Lessons from Hong Kong and Taiwan', in Lee, Chin-Chuan (ed.), Chinese Media, Global Contexts, Routledge, Abingdon, 2003.

Creemers, Rogier, 'The Effects of WTO Case DS362 on Audiovisual Media Piracy in China', European Intellectual Property Review, vol. 3I, no. I I, 2009.

Davey, William, 'Compliance Problems in WTO Dispute Settlement', Cornell International Law Journal, Vol. 42, 2009.

Davies, Gloria, 'Filmed Founding Myths: 建国大业', China Heritage Quarterly, no. 20, 2009.

Di, Miao, 'Between Propaganda and Commercials: Chinese Television Today', in Shirk, Susan (ed.), Changing Media, Changing China, Oxford U.P., Oxford, 201 I.

Dikötter, Frank, The Age of Openness: China before Mao, California U.P., Berkeley, 2008.

Dimitrov, Martin, Piracy and the State: the Politics of Intellectual Property Rights in China, Cambridge U.P., Cambridge, 2008. 
Evans, Gail, 'Issues of Legitimacy and the Resolution of Intellectual Property Disputes in the Supercourt of the World Trade Organisation', International Trade Law and Regulation, vol. 81, 1998.

Fenby, Jonathan, The Penguin History of Modern China: the Fall and Rise of a Great Power, Allen Lane, London, 2008.

Feng, Peter, Intellectual Property in China, 2nd ed., Sweet and Maxwell Asia, Hong Kong, 2003.

Fischer, Doris, 'Censorship and Marketization: Institutional Change within China's Media', in Heberer, Thomas, Gunther Schubert (eds.), Regime legitimacy in Contemporary China: Institutional Change and Stability, Routledge, Abingdon, 2008.

Fisher, Matthew, 'Darcy v. Allen', Heath, Christopher and Anselm Kamperman Sanders (eds.), Landmark Intellectual Property Cases and Their Legacy, Kluwer, 201 I .

Friedmann, Danny, Paper Tiger or Roaring Dragon? China's TRIPs Implementation and Enforcement, University of Amsterdam, Master Thesis, 2007.

Foerstel, Herbert, Free Expression and Censorship In America, Greenwood, Westport, 1997.

Fung, Anthony, Global Capital, Local Culture, Peter Lang, Bern, 2007.

Gao, Henry, 'China's Participation in the WTO: a Lawyer's Perspective', in Singapore Year Book of International Law, 2007.

Gernet, Jacques, A History of Chinese Civilization, London, Folio, 2002, Ist. ed 1972.

Guo, Shoukang, 'China and the Berne Convention', Columbia-VLA Journal of Law and the Arts, 1986.

Guo, Zhenzhi, 'Playing the Game by the Rules? Television Regulation around China's Entry into WTO', Javnost - the Public, vol I0, no. 4, 2003.

Haber, Jessica, 'Motion Picture Piracy in China: Rated Arrgh', Brook Journal of International Law, vol. 32, no. I, 2006.

He, Zhou, 'How Do the Chinese Media Reduce Organizational Incongruence? Bureaucratice Capitalism in the Name of Communism', in Lee, Chin-Chuan (ed), Chinese Media, Global Contexts, Routledge, Abingdon, 2003.

Hong, Junhao et al., 'CCTV in the Reform Years: a New Model for Television?' in Zhu, Ying, Chris Berry (eds.), TV China, Indiana U.P, Bloomington, 2007.

Horn, Murray, The Political Economy of Public Administration, Cambridge U.P., Cambridge, 1995. 
Hu, Zhengrong, Towards the Public? The Dilemma in Chinese Media Policy Change and its Influential Factors, Joan Sorenstein Center Research Paper, Harvard University, 2005.

Huang, Philip C.C., Chinese Civil Justice, Past and Present, Rowman and Littlefield, Lanham, 2009.

Huang Shengmin 黄升民 et al., Zhongguo chuanmei shichang dabianju [The Greatly Changing Situation of the Chinese Media Market] 中国传媒市场大变局, CITIC Publishing, Beijing, 2003.

Huang, Yasheng, Capitalism with Chinese Characteristics: Entrepeneurship and the State, Cambridge U.P., Cambridge, 2008.

Hugenholtz, Bernd, 'Copyright and Freedom of Expression in Europe', in Rochelle Cooper Dreyfuss, Harry First and Diane Leenheer Zimmerman (eds.), Expanding the Boundaries of Intellectual Property, Oxford U.P., Oxford, 2001.

Johns, Adrian, Piracy: the Intellectual Property Wars from Gutenberg to Gates, Chicago U.P., Chicago, 2010.

Keane, Michael, 'Send in the Clones' in Stephanie Hemelryk Donald et al., Media in China: Consumption, Content and Crisis, RoutledgeCurzon, London, 2002.

Keane, Michael, Created in China: the New Great Leap Forward, Routledge, London, 2007.

Keane, Michael, 'Keeping Up with the Neighbors: China's Soft Power Ambitions', Cinema and Media Studies, vol. 49, no. 3, 2010.

Keller, Perry, 'Rules Without Law: Media Regulation in China', in Barendt, Eric et al. (eds), 2000 Yearbook of Copyright and Media Law, Oxford University Press, Oxford, 2000.

Keller, Perry, European and International Media Law: Liberal Democracy, Trade, and the New Media, Oxford U.P., Oxford, 20II.

Kwong, Kenneth, et al., 'The Effects of Attitudinal and Demographic Factors on Intention to Buy Pirated CDs: the Case of Chinese Consumers', Journal of Business Ethics, vol. 47, 2003.

Kraus, Richard, The Party and the Arty in China: the New Politics of Culture, Rowman \& Littlefield, Lanham, 2004.

Lalouette, Jacqueline, 'Du bûcher au piédestal : Etienne Dolet, symbole de la libre pensée', Romantisme, vol. 19, no. 64, 1989.

Landes, William and Richard Posner, 'An Economic Analysis of Copyright Law', Journal of Legal Studies, vol. 18, 1989. 
Lampton, David and Kenneth Lieberthal (eds.), Bureaucracy, Politics and Decision Making in Post-Mao China, California U.P., Berkeley, 1992.

Lessig, Lawrence, Free Culture: How Big Media Uses Technology and the Law to Lock Down Culture and Control Creativity, Penguin, London, 2004.

Lessig, Lawrence, Free Culture: the Nature and Future of Creativity, Penguin, London, 2005.

Lessig, Lawrence, Remix: Making Art and Commerce Thrive in the Hybrid Economy, Penguin, London, 2008.

Li, Jerry, Sanzhuan Guo, 'China', in Shelton, Dinah (ed.), International Law and Domestic Legal Systems: Incorporation, Transformation, and Persuasion, Oxford U.P., Oxford, $201 \mathrm{I}$.

Lieberthal, Kenneth, Michel Oksenberg, Policymaking in China: Leaders, Structures and Processes, Princeton U.P., 1988.

Lieberthal, Kenneth, Governing China: from Revolution to Reform, 2nd ed., Norton, New York, 2003.

Liu, Kwang-ching and Richard Hon Shun Shek (eds.), Heterodoxy in Late Imperial China, Hawaii U.P., Honolulu, 2004

Lu, Xiaobo, 'From Rank-seeking to Rent-seeking: Changing Administrative Ethos and Corruption in Reform China', Crime, Law and Social Change, Vol. 32, 1999.

Lu, Xinyu, 'Ritual, Television, and State Ideology: Rereading CCTV's 2006 Spring Festival Gala', in Zhu, Ying, Chris Berry (eds.), TV China, Indiana U.P, Bloomington, 2007.

Lu, Yuanzhu, Sougata Poddar, 'Piracy, Entry Deterrence and Intellectual Property Rights (IPR) Protection', Oxford Economic Papers, 2008.

MacGregor, Richard, The Party: The Secret World of China's Communist Rulers, Allen Lane, London, 2010.

Magnuson, William, 'WTO Jurisprudence \& Its Critiques: The Appellate Body's AntiConstitutional Resistance', Harvard International Law Journal, vol. 5 I, 2010.

Meng, Bingchun, China's Copyright Policy in the Era of Globalization: A Chance to Restore the Public's Interest, Ph.D. Dissertation, Pennsylvania State University, 2006.

Mertha, The Politics of Piracy: Intellectual Property in Contemporary China, Cornell U.P., Ithaca, 2005. (Mertha 2005A)

Mertha, 'China's "Soft" Centralization: Shifting Tiao/Kuai Authority Relations', The China Quarterly, no. I84, 2005. (Mertha 2005B) 
Milton, John, Aeropagitica: A Speech for the Liberty of Unlicensed Printing to the Parliament of England, 1644, reprinted by Forgotten Books, 2008.

Murck, Alfreda, Poetry and Painting in Song China: The Subtle Art of Dissent, Harvard U.P., Cambridge, 2002

Moohr, Geraldine, 'The Crime of Copyright Infringement: An Inquiry Based on Morality, Harm, and Criminal Theory', Boston University Law Review, vol.83, 2003.

Montgomery, Lucy, Troubled Waters for the Development of China's Film Industry, Media Technology, Creative Industry and Cultural Significance Conference Proceedings, Taipei, Taiwan, 2004.

Montgomery, Lucy and Michael Keane, 'Learning to Love the Market: Copyright, Culture and China', Intellectual Property Rights, Communication and the Public Domain in the Asia-Pacific Region, Conference Paper, University of Queensland, 2004.

Montgomery, Lucy, 'Space to grow: Copyright, cultural policy and commerciallyfocused music in China, Chinese Journal of Communication, vol. 2, no. I, 2009.

Neigel, Connie, 'Piracy in Russia and China: a Different U.S. Reaction', Law and Contemporary Problems, vol. 63., 2000.

Ochoa, Tyler, 'Copyright Duration: Theories and Practice', in Yu, Peter (ed.), Intellectual Property and Information Wealth, Vol. I, Praeger, Westport, 2007.

Pang, Cultural Control and Globalization in Asia, Routledge, Abingdon, 2006.

Pauwelyn, Joost, 'The Calculation and Design of Trade Retaliation in Context: What Is the Goal of Suspending WTO Obligations?' in in Bown, Chad et al., (ed.), The Political Economy of WTO Retaliation, Cambridge U.P., Cambridge, 2010.

Peerenboom, Randall, China's Long March toward Rule of Law, Cambridge U.P., Cambridge, 2002.

Pei, Minxin, China's Trapped Transition: the Limits of Developmental Autocracy, Harvard U.P., Cambridge, 2006.

Polumbaum, Judy, 'Capturing the Flame: Aspirations and Representations of Beijing's 2008 Olympics' in Lee, Chin-Chuan (ed.), Chinese Media, Global Contexts, Routledge, Abingdon, 2003.

Price, Monroe, Daniel Dayan (eds.), Owning the Olympics: Narratives of the New China, Michigan U.P., Ann Arbor, 2008.

Priest, Eric, 'The Future of Music and Film Piracy in China', Berkeley Technology Law Journal, vol. 21, 2006. 
Qin, Julia Ya, “WTO-Plus" Obligations and Their Implications for the World Trade Organization Legal System: An Appraisal of the China Accession Protocol', Journal of World Trade, vol. 37, no. 3, 2003.

Qin, Julia Ya, 'Pushing the Limits of Global Governance: Trading Rights, Censorship and WTO Jurisprudence - A Commentary on the China-Publications Case', Chinese Journal of International Law, vol. I0, no. 2, $201 \mathrm{I}$.

Qu, Sanqiang, Copyright in China, Foreign Languages Press, Beijing, 2002.

Ricketson, Sam and Jane Ginsburg, International Copyright and Neighbouring Rights: The Berne Convention and Beyond, Oxford U.P., Oxford, 2006.

Robertson, Geoffrey and Andrew Nicol, Media Law, 4th ed., Penguin, London, 2002.

Rosen, Stanley, 'The Wolf at the Door: Hollywood and the Film Market in China', Heikkila, Eric and Rafael Pizarro (Eds.), Southern California and the world, Westport, CT: Praeger, 2002.

Rosen, Stanley, 'Chinese Media and Youth: Attitudes toward Nationalism and Internationalism', in Lee, Chin-Chuan (ed.), Chinese Media, Global Contexts, Routledge, Abingdon, 2006.

Saich, Tony, China as a Member of the WTO: Some Political and Social Questions, Kennedy School of Government Working Paper, Harvard University, 2002.

Saich, Tony, Governance and Politics of China, Palgrave MacMillan, Basingstoke, 2004.

Saich, Tony, Governance and Politics of China, 2nd ed., Palgrave MacMillan, Basingstoke, 2010.

Samuels, Edward, 'The Idea-Expression Dichotomy in Copyright Law', Tennessee Law Review, vol. 56, 2009.

Sgambati, Stephanie, 'China's Accession to the Berne Convention: Bandaging the Wounds of Intellectual Property Piracy in China', Fordham Intellectual Property, Media and Entertainment Law Journal, vol. 3, no. I, 1992.

Shambaugh, David, 'China's Propaganda System: Institutions, Processes and Efficacy', The China Journal, no. 57, 2007.

Shambaugh, David, China's Communist Party, Atrophy and Adaptation, California U.P., Berkeley, 2008.

Shen, Ren'gan 沈仁干, gaige kaifangzhong de zhuzuoquan lifa [Copyright Legislation during Reform and Opening UP] 改革开放中的著作权立法, Editor's Friend 编辑之 友, no. 6, 2008.

Shi, Jingxia, Weidong Chen, The 'Specificity' of Cultural Products 
versus the 'Generality' of Trade Obligations -Reflecting on 'China--Publications and Audiovisual Products', Yale Law School Student Scholarship Papers. Paper 104 (2010).

Shi Miaomiao, 'China's Participation in the Doha Negotiations and Implementation of Its Accession Commitments', in Henry Gao and Donald Lewis (eds), China's Participation in the WTO, Cameron May, London, 2005.

Shi, Wei, Intellectual Property in the Global Trading System: EU-China Perspective, Springer, Berlin, 2008.

Shirk, Susan, China: Fragile Superpower: How China's Internal Politics Could Derail Its Peaceful Rise, Oxford U.P., Oxford, 2007.

Shirk, Susan (ed.), Changing Media, Changing China, Oxford U.P., Oxford, 201 I.

Silberman, Marc, German Cinema: Texts in Context, Wayne State U.P, Detroit, 1995.

Simone, Joseph, 'Copyright in the People's Republic of China: a Foreigner's Guide', Cardozo Arts and Entertainment Law Journal, vol. 7., 1988.

Spence, Jonathan, The Search for Modern China, Norton, New York, 1999.

Spence, Jonathan, Treason by the Book, Penguin, London, 2002.

Stewart, Stephen and Hamish Sandison, International Copyright and Neighbouring Rights, Butterworths, London, 1989.

Su, Wendy, 'Resisting Cultural Imperialism or Resisting Cultural Globalization? China's Extensive Debate on Hollywood Cinema From 1994 to 2007', Asian Journal of Communication, vol. 21, 20II.

Sutter, Robert, 'The U.S. Congress: Personal, Partisan, Political', in Myers, Ramon et al. (eds), Making China Policy: Lessons from the Bush and Clinton Administrations, Rowman and Littlefield, Lanham, 200I.

Swabach, Aaron, Intellectual Property Piracy: Perception and Reality in China, the United States, and Elsewhere, TJSL Legal Studies Research Paper, 2007.

Swike, Erin et al., 'Piracy in China', Business Horizons, 2008.

Tang Rong唐榕, 'Gaige kaifang 30 nian Zhongguo dianying tizhi gaige yanjiu [Researching Film Structural Reform in the 30 Years of Reform and Opening Up] 改革 开放30年中国电影体制改革研究', Xiandai Chuanbo - Zhongguo Chuanmei Daxue Xuebao [Modern Broadcast - Journal of the Communications University of China 现代传 播-中国传媒大学学报, no. 2, 2009.

Taylor, Philip, British Propaganda in the Twentieth Century: Selling Democracy, Edinburgh U.P., Edinburgh, 1999. 
Teubner, Gunther, 'Legal Irritants', in Snyder, Francis (ed.) The Europeanisation of law: the legal effects of European integration, Hart, Oxford 2000.

Thurich, Eckart, Pocket Politik: Demokratie in Deutschland, Bundeszentrale für politische Bildung, Bonn, 2006.

Ting, Oliver, 'Pirates of the Orient: China, Film Piracy and Hollywood', Sports and Entertainment Law Journal, vol. I4, 2007.

Trevaskes, Susan, 'Political Ideology, the Party, and Politicking: Justice System Reform in China', Modern China, vol. 37., $201 \mathrm{I}$.

Treverton, Gregory, et al. Film Piracy, Organized Crime and Terrorism, RAND, Santa Monica, 2009.

Van den Bossche, Peter, The Law and Policy of the World Trade Organization: Text, Cases and Materials, Cambridge U.P., Cambridge, 2005.

Van den Bossche, Peter, Free Trade and Culture, A Study of Relevant WTO Rules and Constraints on National Cultural Policy Measures, Boekman Studies, Amsterdam, 2008.

Van Horn Melton, James, The Rise of the Public in Enlightenment Europe, Cambridge U.P., Cambridge, 200I.

Van Rooij, Benjamin, The Politics of Law in China: Enforcement Campaigns in the PostMao PRC, Leiden University, Working Paper, 2009.

Voon, Tania, Cultural Products and the World Trade Organization, Cambridge U.P., Cambridge, 2007.

Wang, Shujen, Framing Piracy: Globalization and Film Distribution in Greater China, Rowman \& Littlefield, Lanham, 2003.

Wang, Chaoguang 王朝光, Jiancha, kongzhi yu daoxiang - Shanghai shi dianying jiancha weiyuanhui yanjiu [Censorship, Control and Guidance - Researching the Shanghai Municipal Film Examination Committee] 检查、控制与导向 一上海市电影检查委员会研究, CASS Working Paper, 2006.

Wang, Chih-Chien, 'Factors that Influence the Piracy of DVD/VCD Motion Pictures', Journal of American Academy of Business, vol. 6., 2005.

Whiting, Susan, 'The Cadre Evaluation System at the Grass Roots: The Paradox of Party Rule', in Naughton, Barry et al. (eds), Holding China Together: Diversity and National Integration in the Post-Deng Era, Cambridge U.P., Cambridge, 2004.

Williamson, Patricia, Ratings and their reasons: An investigation of the efficiency, application and unintended consequences of the Motion Picture Association of America's film rating system, Ph.D. dissertation, Michigan State University, 2007. 
Wu, Doreen (ed.), Discourses of Cultural China in the Globalizing Age, Hong Kong U.P., Hong Kong, 2008.

Wu, Xiaohui, 'Case Note: China - Measures Affecting Trading Rights and Distribution Services for Certain Publications and Audiovisual Entertainment Products (WT/DS363/AB/R)', Chinese Journal of International Law, vol. 9, no. 2, 2010.

Yang, Deli et al.,' Anti-piracy Effectiveness and Managerial Confidence: Insights from Multinationals in China', Journal of World Business, vol. 43 no. 3, 2008.

Yonehara, Brent, 'Enter the Dragon: China's WTO Accession, Film Piracy and the Prospect for the Enforcement of Copyright Laws', UCLA Entertainment Law Review, vol. 9., 2002.

Yu, Peter, 'From Pirates to Partners: Protecting Intellectual Property in China in the Twenty-first Century', American University Law Review, vol. 50, 2000.

Yu, Peter, 'The Copyright Divide', Michigan State University Public Law \& Legal Theory Working Paper Series, no. 0I-2I, 2003.

Yu, Peter, 'Three Questions that Will Make You Rethink the US-China Intellectual Property Debate', John Marshall Review of Intellectual Property Law, vol. 7, 2008.

Yu, Peter, 'Key Legal Findings and Implications of the US. China Panel Report', presentation for The WTO US -China Panel Report: Findings and Implications for the Future of IPRs Enforcement, UNCTAD and ICTSD, Geneva, 2009.

Yu, Peter, 'Moral Rights 2.0', in Heath, Christopher and Anselm Kamperman Sanders (eds.), Landmark Intellectual Property Cases and Their Legacy, Kluwer, $201 \mathrm{I}$.

Zhang, Jing, 'Pushing Copyright Law in China: a Double-Edged Sword', DePaul Journal of Art, Technology and Intellectual Property Law, vol. 18, 2007.

Zhang, Naigen, 'Intellectual Property Law Enforcement in China: Trade Issues, Policies and Practices', Fordham Intellectual Property, Media and Entertainment Law Journal, vol. 8, no. I, 1997.

Zhang, Rui, The Cinema of Feng Xiaogang: Commercialization and Censorship in Chinese Cinema after 1989, Hong Kong U.P., Hong Kong, 2008.

Zhang, Yingjin, Chinese National Cinema, Routledge, London, 2004.

Zhang, Zhongxin 章忠信, 'Dalu xin gaizheng zhuzuoquanfa gaishu [An overview of the newly-revised Copyright Law of Mainland China] 大陆新修正著作权法概述', Zhihui caichan quan yuekan (Intellectual Property Rights Monthly) 智慧财产权月刊, 2002.

Zhao, Xin 赵金金, 'DVD yasuodie chuxian de chengyin fenxi [Pirated Audiovisual Products - An Analysis of the Contributing Factors of the Appearance of 
Compressed DVD Discs] 盗版音像制品-DVD压缩碟出现的成因分析, Liaoning Jingji [Liaoning Economics], 2007.

Zhao, Yuezhi, Communication in China: Political Economy, Power, and Conflict, Rowman \& Littlefield, Lanham, 2008.

Zheng, Chengsi, Michael Pendleton, Copyright in China, CHH International, Sydney, I991.

Zheng, Chengsi, 'The TRIPS Agreement and Intellectual Property Protection in China', Duke Journal of International and Comparative Law, vol. 9, 1998.

Zhu, Ying, 'Chinese Cinema's Economic Reform from the Mid-1980s to the Mid1990s', Journal of Communication, no. 52., 2002.

Zhu, Ying, Chris Berry (eds.), TV China, Indiana U.P, Bloomington, 2007.

Reports and parliamentary hearings

Center for American Economic Studies, Institute of World Economics and Politics, Chinese Academy of Socia ISciences, Study on the Impact of Movie Piracy on China's Economy, 2006. (CEAS 2006)

China National Network Information Center, di 28 ci Zhongguo hulianwangluo fazhan zhuangkuang tongji baogao [28th Report of the China Internet Development Situation Statistics] 第23次中国互联网络发展状况统计报告, 20II. (CNNIC 20II)

Congress Hearing on Piracy of Live Sports Broadcasting over the Internet, Ser. No. III-94, 2009.

Envisional and Net Result, Background Report on Digital Piracy of Sports Events, 2008.

International Intellectual Property Association, 2009 Special 301 Report on Copyright Protection and Enforcement, 2009. (IIPA 2009A)

International Intellectual Property Association, People's Republic of China (PRC) International Intellectual Property Alliance (IIPA) 2009 Special 30I Report on Copyright Protection and Enforcement, 2009. (IIPA 2009B)

International Intellectual Property Association, People's Republic of China (PRC) International Intellectual Property Alliance (IIPA) 20II Special 30I Report on Copyright Protection and Enforcement, 20I I. (IIPA 20I I)

Karagianis, Joe (ed.), Media Piracy in Emerging Economies, SSRC Books, New York, 2011 .

Liu Yunshan 刘云山, 'Zai dishi'erci quanguo saohuang dafei gongzuo dianshi dianhua huiyi shang de jianghua [Speech at the 12th Sweeping Pornography and Striking Illegality Teleconference] 在第二十次全国扫黄打非工作电视电话会议上的讲话, in State Intellectual Property Organization, 2008 Zhongguo zhishichanquan nianjian 
[2008 China Intellectual Property Rights Yearbook] 2008中国知识产权年鉴, Zhishichanquan chubanshe [Intellectual Property Rights Publishing] 知识产权出版社, 2008.

Motion Pictures Association of America, The Cost of Movie Piracy, 2005.

Organization for Economic Cooperation and Development, The Economic Impact of Counterfeiting and Piracy, 2008. (OECD 2008)

Ranjard, Paul et al., The Legislation Protecting Intellectual Property Rights and its Enforcement in the European Union and the People's Republic of China: A Comparative Study, EUChina Trade Project, 2005.

Rechardt and Misonne (eds.), Collective Management of Author's Rights and Related Rights in the EU and the PRC, EU-China Trade Project Report, 2008.

State Intellectual Property Organization, 2008 Zhongguo zhishichanquan nianjian [2008 China Intellectual Property Rights Yearbook] 2008中国知识产权年鉴, Zhishichanquan chubanshe [Intellectual Property Rights Publishing] 知识产权出版社, 2008.

State Intellectual Property Organization, 2009 Zhongguo zhishichanquan nianjian [2009 China Intellectual Property Rights Yearbook] 2009中国知识产权年鉴, Zhishichanquan chubanshe [Intellectual Property Rights Publishing] 知识产权出版社, 2009.

United Nations Economic and Social Commission for Asia and the Pacific, Statistical Yearbook for Asia and the Pacific, 2009. (UN 2009)

\section{Internet sources}

Abdoolcarim, Zoher, Reshooting History in a New China Film, 2009, retrieved 30 September 20II, Time,

<http://www.time.com/time/world/article/0,8599,1928956,00.html>

AFP, All-female Army Unit Lures 'Red' Tourists, 20II, retrieved 5 July 20I I, The Age, $<$ http://www.theage.com.au/travel/allfemale-army-unit-lures-red-tourists-20I I0502le3xo.html>

Associated Press, 5 U.S. Film Studios Win Piracy Case, 2006, retrieved on 5 May 20II, USA Today, <http://www. usatoday.com/life/movies/news/2006-12-19-dvdpiracy_x.htm> (AP 2006)

Associated Press, Chinese Director Coy on 'Let The Bullets Fly' Message, 20II, retrieved 5 August 20I I, Hollywood Reporter, <http://www.hollywoodreporter.com/news/chinese-director-coy-bullets-fly-70524> (AP 20II)

Barboza, David, Booming Demand for TV on the Internet in China, 20I0, retrieved 5 November 201 I, New York Times, <http://www.nytimes.com/2010/07//9/business/global//9chinavideo.html?_r=1> (Barboza 20I0A) 
Barboza, David, For Chinese, Web Is the Way to Entertainment, 2010, retrieved 5 November 20I I, New York Times,

<http://www.nytimes.com/2010/04/I9/technology/I9chinaweb.html?src=busln> (Barboza 20IOB)

Barlow, Joel, Letter to the Continental Congress, I783, digitized version, retrieved 4 July 201 I, Copyright History, <http://www.copyrighthistory.org/cgibin/kleioc/0010/exec/showTranscription/\%22us_I783b\%22/start/\%22yes\%22> (I 783 Letter from Joel Barlow)

Bandurski, David, Li Changchun on the Media and China's “Global Influence”, 2009, retrieved 5 November 20II, China Media Project, <http://cmp.hku.hk/2009/0I//9//457/>

BBC, An Agreement Between Her Majesty's Secretary of State for Culture, Media and Sport and the British Broadcasting Corporation, 1996, retrieved I2 November 20II, BBC,

$<$ http://www.bbc.co.uk/bbctrust/assets/files/pdf/about/how_we_govern/agreement.pd f> (1996 BBC Agreement)

BBC, Banned Songs, 2002, retrieved 5 July 201 I, BBC,

<http://www.bbc.co.uk/totp2/features/top5/banned_songs.shtml>

BBC, China Censors Cut 'Pirates' Film, 2007, retrieved 17 November 2010, BBC,

<http://news.bbc.co.uk/2/hi/entertainment/6744245.stm>

Buckley, Chris, Helped by Technology, Piracy of DVDs Runs Rampant in China, 2003, retrieved 4 October 20I I, New York Times,

<http://www.nytimes.com/2003/08/I8/business/media-helped-by-technology-piracy-

of-dvd-s-runs-rampant-in-china.html?pagewanted=all\&src=pm>

Bundesprüfstelle für jugendgefährdende Medien, Verfahren vor dem I 2er-Gremium [Procedure for the Committee of I2], SD, retrieved 21 October 20II, $<$ http://www.bundespruefstelle.de/bpjm/Jugendmedienschutz/Indizierungsverfahren/v erfahrensarten, did=32934.html> (BPJM Procedure).

Branigan, Tania, China Censors Want to Consign Time Travel Dramas to Past, 20I I, retrieved I0 May 20II, Guardian,

<http://www.guardian.co.uk/world/20I I/apr/ I4/china-time-travel-dramas>

British Board of Film Classification, Student Guide 2005/2006, 2005, retrieved I5 September 20II, BBFC,

$<$ http://www.sbbfc.co.uk/Assets/documents/sbbfc_online_new.pdf> (BBFC Student Guide)

Centre National du Cinéma et de l' Image Animée, Visas et classification : activité de la commission de classification, SD, retrieved 20 October 201 I, CNC,

$<$ http://www.cnc.fr/web/fr/activite-de-la-commission-de-classification> (CNC Visas and Classification) 
Centre National du Cinéma et de l' Image Animée, Les missions du CNC conforme $\square$ ment $a \square$ l'ordonnance $n^{\circ} 2009-90$ I du 24 juillet 2009, 2009, retrieved 20 October 20I I, CNC, http://www.cnc.fr/web/fr/missions. (CNC Missions)

Centre National du Cinéma et de l' Image Animée, Code du Cinéma et de l' Image Animée, 2009, retrieved 20 October 201 I, CNC, http://www.cnc.fr/web/fr/missions. (CNC Code)

China Daily, Film Sector Monopoly Broken Up, 2003, retrieved on 5 May 20I I, China Daily, <http://www.chinadaily.com.cn/en/doc/2003-06/I0/content_244I33.htm>

China Daily, More Downloading Websites Going Down, 2009, retrieved on 4 April 2010, China Daily, <http://www.chinadaily.com.cn/china/2009-

I2/|4/content_9|70331.htm>

China Daily, Free and Legal US Dramas set to Stream on Sohu Website, 20I0, retrieved on 5 March 20II, China Daily, <http://www.chinadaily.com.cn/usa/20I009/I4/content_II299492.htm>

China Digital Times, Ministry of Truth, regularly updated, retrieved on 10 November 20I I, China Digital Times, <http://chinadigitaltimes.net/china/ministry-of-truth/> (CDT Ministry of Truth)

China Media Project, Media Dictionary, regularly updated, retrieved on 8 August 20I I, China Media Project, <http://cmp.hku.hk/ /media-dictionary/> (CMP Dictionary)

Conseil Supérieur de l' Audiovisuel, Rôle et missions du CSA, SD, retrieved 20 October 20I I, CSA <http://www.csa.fr/conseil/role/role_csa.php> (CSA Role and Missions)

Conseil Supérieur de l' Audiovisuel, Les quotas d'œuvres audiovisuelles et cinématographiques à la télévision, SD, retrieved 20 October 201 I, CSA, <http://www.csa.fr/infos/controle/television_quotas_diffusion.php> (CSA TV Quota)

Conseil Supérieur de l' Audiovisuel, Quotas de chansons francophones à la radio, SD, retrieved 20 October $201 \mathrm{I}, \mathrm{CSA}$, <http://www.csa.fr/infos/controle/radio_quotas_accueil.php> (CSA Radio Quota)

Davis, Joshua, The Decline and Fall of Randolph Guthrie III, 2005, retrieved 17 November 2010, Wired, <http://www.wired.com/wired/archive//3.I0/guthrie.html>

Downey, Tom, China's Cyberposse, 2010, retrieved 8 May 20II, New York Times, <http://www.nytimes.com/2010/03/07/magazine/07Human-t.html?pagewanted=all>

Einhorn, Bruce, The YouTube of China Goes Legit, 20 I I, retrieved 30 November 20 I I, Bloomberg Businessweek, <http://www.businessweek.com/magazine/content/II_I5/b4223044746I64.htm> 
Economist, Beware the Middle-Income Trap: China's Roaring Growth Cannot Last Indefinitely, 20II, retrieved 9 October 20II, Economist, <http://www.economist.com/node//8832106>

Elster, Jon, Explaining Social Behaviour: More Nuts and Bolts for the Social Sciences,

Faison, Seth, China Appears To Crack Down On CD Pirating, 1997, retrieved 17 November 2010, New York Times, <http://www.nytimes.com/I997/04/07/world/chinaappears-to-crack-down-on-cd-pirating.html?pagewanted=all\&src=pm>

Fletcher, Owen, Illegal Satellite TV in China Brings CNN to the Masses, 20I0, retrieved 5 November 2010, PCWorld,

$<$ http://www.pcworld.com/businesscenter/article//94755/illegal_satellite_tv_in_china _brings_cnn_to_the_masses.html>

Freeman, Will, The accuracy of China's 'mass incidents', 2010, retrieved on 5 May 20I I, Financial Times, <http://www.ft.com/intl/cms/s/0/9ee6fa64-25b5-I I df-9bd300I44feab49a.html\#axzz IdOKbdU2b>

French, Howard, Chinese Market Awash in Fake Potter Books, 2007, retrieved 9 September 201 I, New York Times, <http://www.nytimes.com/2007/08/0I/world/asia/0I china.html>

Fu, Wen, Flat \& Dull, 20I I, retrieved 10 November 20I I, Global Times, <http://www.globaltimes.cn/china/society/20I I-02/624387.html>

Foster, Peter, China Holds "Red Games”, 2010, retrieved 9 November 201 I, Telegraph, <http://www.telegraph.co.uk/news/worldnews/asia/china/7970568/Chinaholds-Red-Games.html>

Freiwillige Selbstkontrolle der Filmwirtschaft, Aufgaben und Strukturen, SD, retrieved 22 October 20I I, <FSK, http://www.fsk.de/index.asp?SeitID=504\&TID=473> (FSK Mission and Structure)

Global Times, Popularity Does Not Always Rhyme with Quality, 20I I, retrieved 17 May 20 I I, Global Times, <http://opinion.globaltimes.cn/editorial/20 I I-04/644320.html>

Guangming Daily, Beijing Chaoyang Qu chuangxin wenhua shichang zonghe guanli [Beijing District Innovates Comprehensive Cultural Market Management] 北京朝阳区创新文化 市场综合管理, 2007, retrieved 5 May 20II, Guangming Daily, <http://www.gmw.cn/0 I gmrb/2007-05/28/content_613383.htm>

Goldkorn, Jeremy, Arnold and Bubugao, 2003, retrieved 16 November 2010, Danwei, <http://www.danwei.org/advertising_and_marketing/arnold_and_bubugao.php>

Goldkorn, Jeremy, CCTV and Fox Launch Boring Website, 2006, retrieved 22 September 20II, Danwei,

<http://www.danwei.org/media_and_advertising/cctv_and_fox_launch_boring_web.p hp> 
He, Dan; Cao, Yin, Officials Look to Raise Content of TV Programs, 20I I, retrieved 8 August 20II, China Daily, <http://www.chinadaily.com.cn/china/20II-

05/03/content_12432597.htm>

Hitler, Adolf, Die Tagung des Reichstags in der Krolloper am 23. März 1933 [The Reichstag Session in Kroll Opera on 23 March 1933], 1933, retrieved 21 October 20 I0, Internet Archive,

<http://www.archive.org/stream/ACollectionOfSpeechesInGerman/RedesammlungAdolfHitler I57S._djvu.txt>

Jacobs, Andrew, An Official Mourning in China for Quake Victims, 2010, retrieved I5 January 20I I, New York Times,

<http://www.nytimes.com/2010/04/22/world/asia/22quake.html>

Jacobs, Andrew, Popularity May Have Doomed Chinese TV Talent Show, 20I I, retrieved 20 September 201 I, New York Times,

$<$ http://www.nytimes.com/20I I/09/20/world/asia/popularity-may-have-doomed-

chinese-tv-talent-show.html?_r=|>

Jones, Arthur, 'Banned Filmmaker' Is a Relative Term: China's Authorities Still Maintain

Hold on Directors, 2007, retrieved I 2 July 20I I, Variety,

<http://www.variety.com/article/VR I I 1 7958975? refCatld=2484>

Kan, Michael, Web Ratings Disabled for Chinese Communist Party Film, 20I I, retrieved 5 July 20 II, PCWorld,

$<$ http://www.pcworld.com/businesscenter/article/230858/web_ratings_disabled_for_ chinese_communist_party_film.html>

Kijkwijzer, Kijkwijzer uitgelegd [Kijkwijzer Explained], SD, retrieved 2 October 20II, Kijkwijzer, <http://www.kijkwijzer.nl/index.php?id=74>

Lam, Willy, China Has a Blueprint for Social Order, 20I I, retrieved 4 April 20I I, Asia Times, <http://www.atimes.com/atimes/China/MC3 I Ad02.html>

Lin, Qi, SARFT Cracks Whip on 'Immoral' Shows, 2010, retrieved 6 May 20I I, China Daily, <http://www.chinadaily.com.cn/china/20 I0-06/I I/content_9963730.htm>

Magnus, George, China Can yet Avoid a Middle-Income Trap, 20I I, retrieved 9 October 20I I, Financial Times, <http://www.ft.com/intl/cms/s/0/2 I73923c-a286-I l e0-9760$00 \mid 44$ feabdc0.html>

Mission of the United States, Geneva, Statements by the United States at the March, 25, 20I I DSB Meeting, 20I I, retrieved on 5 April 20I I, <http://geneva.usmission.gov/20 I l/03/28/mar-25-20l I-dsb-meeting/> (US Geneva Mission, 20II)

Moore, Malcolm, Wikileaks: Top Chinese Official Doesn't Believe GDP Figures, 2010, retrieved on 23 May 20I I, Telegraph, <http://www.telegraph.co.uk/finance/chinabusiness/8183389/Wikileaks-Top-Chinese-official-doesnt-believe-GDP-figures.html> 
Moore, Malcolm, China Launches 'Red Culture' Drive, 20I I, retrieved 5 November 20II, Telegraph,

<http://www.telegraph.co.uk/news/worldnews/asia/china/8489484/China-launchesRed-Culture-drive.html>

Morrison Foerster, GAPP Issues Notice Further Restricting Foreign Participation in China's Internet Gaming Industry, 2009, retrieved I 2 March 20I I,

<http://www.hkvca.com.hk/hkvcpea/files/ChinaUpdate.pdf>

Motion Pictures Association of America, Types of Content Theft, 20I I, retrieved 7 August 20II, MPAA, <http://www.mpaa.org/contentprotection/types-of-contenttheft>

Kahn, Joseph, The Pinch of Piracy Wakes China Up on Copyright Issue, 2002, retrieved I8 November 2010, New York Times,

$<$ http://www.nytimes.com/2002/I I/0 I/business/0 IPIRA.html?scp= I 2\&sq=china\%20dv $\mathrm{d} \% 20$ piracy\&st=cse\&pagewanted=print $>$

LaFraniere, Sharon, China Curtails Run of 'Avatar' as It Fills Theaters, 2010, retrieved 5 February 20II, New York Times,

<http://www.nytimes.com/2010/0I/20/world/asia/20china.html>

Landreth, Jonathan, Warner Bros. Movies to Be Available in China Via Video On Demand, 20I I, retrieved 5 November 20I I, Hollywood reporter,

<http://www.hollywoodreporter.com/news/warner-bros-movies-be-available$20 \mid 467>$

Landsberger, Stefan, Eliminate the Four Pests, S.D., retrieved I6 June 201 I, Chinese Posters, <http://chineseposters.net/themes/four-pests.php>

Li Chen, Communist Party Drags China to Propaganda Film Flop, Netizens React, 20II, retrieved 17 November 20II, Penn-Olson, <http://www.pennolson.com/20 I I/07/06/communist-party-drags-china-to-propaganda-film-flopnetizens-react/> (Li 20IIB)

Liu, Alice, Narrow Dwellings: a TV Series that Slipped Through SARFT's Guidelines, 2009, retrieved 2 October 2010, Danwei,

$<$ http://www.danwei.org/tv/narrow_dwellings.php>

Liu, Ren 刘韧, Zhongguo fan daoban, daoban diepian zhao mai (China Combats Piracy, a Look on the Sale of Pirated Discs) 中国反盗版, 盗版碟片照卖, 2005, DoNews, $<$ http://www.donews.com/Content/200504/913653ca5be64d4ca5c77ccc73cl f8d5.sht $\mathrm{m}>$

Magistad, Mary Kay, Confucius vs. Avatar: And the Winner is..., 2010, retrieved $5 \mathrm{Fe}-$ bruary 20I I, Yale Global, <http://www.yaleglobal.yale.edu/content/confucius-vsavatar> 
Martinsen, Joel, Tang Wei Too Hot For TV, 2008, retrieved 6 June 20I I, Danwei, <http://www.danwei.org/media_regulation/tang_wei_too_hot_for_tv.php>

National Copyright Administration of China, 版权统计 Banquan tongji [Copyright Statistics], last updated 2008, retrieved 2 October 20I I, NCAC,

<http://www.ncac.gov.cn/GalaxyPortal/inner/bqj/include/list_column_bqtj.jsp?Boardl $D=304 \&$ boardid $=11501010111610 \&$ bqgbid $=11501010111610>$

Ofcom, The Ofcom Broadcasting Code, 201 I, retrieved 6 June 20II, Ofcom, <http://stakeholders.ofcom.org.uk/broadcasting/broadcast-codes/broadcast-code/>

Pan, Kai, The Founding of a Republic Not Overwhelmed By Propaganda!, 2009, retrieved on 30 September 201 I, CN Reviews, <http://cnreviews.com/life/dining-shoppingentertainment/the-founding-of-a-republic-not-overwhelmed-bypropaganda_20090920.html>

Pan, Yan, Village Pirates, 20II, retrieved 5 August 20II, Global Times, <http://china.globaltimes.cn/society/20I I-03/63788I.html>

People.cn, Liu Yunshan tongzhi jianli [CV of Comrade Liu Yunshan] 刘云山同志简历, SD, retrieved 22 September 20I I, People.cn, <http://politics.people.com.cn/GB/I024/64I6890.html> (CV Liu Yunshan)

People.cn, Wang Taihua tongzhi jianli [CV of Comrade Wang Taihua] 王太华同志简历, SD, retrieved II October 20 II, People.cn, <http://politics.people.com.cn/GB/shizheng/252/9667/9683/3455869.html> (CV Wang Taihua)

People's Daily, Qichengduo chengshi jumin dui shiyong daoban chanpin 'zhiyan buhui' [More than 70 Per Cent of Urban Residents “Aren't Sorry” to Use Pirated Products] 七成 多城市居民對使用盜版產品“直言不脢”, 200I, retrieved I October 2010, People's Daily, <http://www.people.com.cn/BIG5/jinji/38/I56/200 I I 204/6 I8440.html>

People's Daily, China Cracks Down on Internet Piracy Operations, Youku.com and Tudou.com May Face Heavy Loss, 2010, retrieved on 18 november 2010, People's Daily, <http://ip.people.com.cn/GB/I52255//2424640.html>

PRNewswire, Warner Bros. Becomes First Hollywood Studio to Make New Release Movies Available Through Video-On-Demand in China, 2008, retrieved 201 I, PRNewswire, <http://www.prnewswire.co.uk/cgi/news/release?id=24l622>

Qiao, Mu, My First Meeting with the Central Propaganda Department, 2010, retrieved I2 November 201 I, China Digital Times, <http://chinadigitaltimes.net/2010/12/dumuqiao-独木乔-my-first-meeting-with-the-central-propaganda-department/>

Rabinovitch, Simon, Beijing Visitors Feast on Fakes Despite Crackdown, 2008, retrieved 9 November 2010, Reuters,

$<$ http://www.reuters.com/article/reutersComService_2_MOLT/idUSPEK2393872008 0807> 
Record Industry Association of America, Parental Advisory, SD., retrieved 10 September 20II, RIAA,

<http://www.riaa.com/toolsforparents.php?content_selector=parental_advisory> (RIAA Parental Advisory)

Reuters, Sony Says China Pirated Spider-Man DVDs Are Fakes, 2007, retrieved I5 November 2010, Reuters, <http://www.reuters.com/article/2007/04/26/film-piracyspiderman-dc-idUSN244574I 420070426> (Reuters 2007A)

China cracks down on Internet piracy operations, Youku.com and Tudou.com may face heavy loss

Reuters, China Says Pirated DVD Production Lines Smuggled In, 2007, retrieved 15 November 2010, Reuters, <http://www.reuters.com/article/2007/07/26/industrychina-piracy-dc-idUSPEK27I 28920070726> (Reuters 2007B)

Reuters, China TV Airs "Prison Break" for English Study, 2007, retrieved I6 November 2010, Reuters, <http://www.reuters.com/article/2007/03/I 6/television-china-tvprison-break-dc-idUSPEK 102860200703 I6> (Reuters 2007C)

Reuters, China Blocks Entry to Scorsese's “Departed”, 2007, retrieved 16 November 2010, Reuters, <http://www.reuters.com/article/2007/0I/I7/us-china-departedidUSPEK26843020070 I I > (Reuters 2007D)

Robson, Wayde, Blu-Ray Pirates: a Few Lines Short of 1080p, 2008, retrieved 8 November 2010, Audioholics, <http://www.audioholics.com/news/industry-news/bluray-pirates>

Shen, Jingting, Cyber Cafe Business Suffers Slowdown, 2010, retrieved on 28 December 20II, China Daily, <http://www.chinadaily.com.cn/business/2010-

I0/I8/content_I|423810_2.htm>

Sherwin, Adam, DVD Industry in Crisis as Sales Slump, 2010, retrieved on 8 May 201 I, Guardian, <http://www.guardian.co.uk/media/20I0/nov/29/dvd-industry-sales-slumpblu-ray>

Snider, Mike, DVD Continues Spinning Success, 2005, retrieved on 19 November 2010, USA Today, <http://www.usatoday.com/life/movies/news/2005-0I-05-dvd-salesinside_x.htm>

Tudou, A Closer Look At Tudou's "Orange Box" - Original Content Production Initiative, 2010, retrieved 5 May 20I I, Tudou, <http://www.tudouchina.com/20I0/07/a-closerlook-at-tudous-orange-box-original-content-production-initiative/>

United States Trade Representative, United States Files WTO Cases Against China Over Deficiencies in China's Intellectual Property Rights Laws and Market Access Barriers to Copyright-Based Industries, 2007, retrieved on 5 May 20I I, USTR,

<http://www.ustr.gov/about-us/press-office/press-releases/archives/2007/april/unitedstates-files-wto-cases-against-china> (USTR 2007) 
United States Trade Representative, United States Wins WTO Dispute Over Deficiencies in China's Intellectual Property Rights Laws, 2009, retrieved on 5 May 20I I, USTR, <http://www.ustr.gov/about-us/press-office/press-releases/2009/january/unitedstates-wins-wto-dispute-over-deficiencies-c> (USTR 2009A)

United States Trade Representative, World Trade Organization Adopts Panel Report in China - Intellectual Property Rights Dispute, 2009, retrieved on 5 May 20I I, USTR, $<$ http://www.ustr.gov/about-us/press-office/press-releases/2009/march/world-tradeorganization-adopts-panel-report-china-i> (USTR 2009B)

Von Clausewitz, Carl, On War, original publication 1832, digital version 2006, retrieved on 16 December 201 I, Project Gutenberg, <http://www.gutenberg.org/files/1946/I946-h/1946-h.htm>

Wang, Jingliang, <Qinquan zerenfa> yu zhishichanquan qinquan zeren [The "Tort Law" and intellectual property rights infringement liability, 2010, retrieved on 5 May 20II, Zhejiang IP Lawyers, <http://www.zjiplawyer.com/caseandreserach/TheoreticalStudy/201001/620.html>

Wines, Michael, China's Censors Misfire in Abuse-of-Power Case, 2010, retrieved on 6 January 20I I, New York Times,

<http://www.nytimes.com/2010/I I/I8/world/asia//8li.html>

Wong, Edward, China's Railway Minister Loses Post in Corruption Inquiry, $201 \mathrm{I}$, retrieved on 20 March 20I I, New York Times,

<http://www.nytimes.com/20I I/02/I3/world/asia/I3china.html>

Wu Dan 吴丹, Si da weishi queren bu chuanbo yangshi chunwan, Anhui cheng yin qi yinxiangli zai xialuo [Four Major Satellite Stations Confirm They Will Not Broadcast the CCTV Spring Festival Gala, Anhui States Due to Decreasing Influence] 四大卫视确认不转 播央视春晚 安徽称因其影响力在下降, 201 I, retrieved 5 March 20II, Ifeng, <http://ent.ifeng.com/tv/news/mainland/detail_20II_0I/3 I/4535048_0.shtml>

Xin, Guoqi 辛国奇, Daoban DVD de “Fangwei” Naoju [The Farce of "Preventing Faking” of Prated DVD's] 盗版DVD的“防伪”闹剧, 2006, retrieved 10 November 2010, Zhongguo Zhicha Wang [China Quality Network],

<http://www.cqn.com.cn/news/zgzlwlx/88955.html>

Xinhua, Cai Fuchao jianli [CV of Cai Fuchao] 蔡赴朝历, SD, retrieved 10 October 20I I, Xinhua, <http://news.xinhuanet.com/ziliao/20II-03/3I/c_I2I 253787.htm> (CV Cai Fuchao)

Xinhua, Cai Wu jianli [CV of Cai Wu] 蔡武简历, SD, retrieved 10 October 201 I, Xinhua, <http://news.xinhuanet.com/ziliao/2005-08/I9/content_3374695.htm> (CV Cai Wu)

Xinhua, Liu Binjie jianli [CV of Liu Binjie] 柳斌杰简历, SD, retrieved 10 October 201 I, Xinhua, <http://news.xinhuanet.com/ziliao/2007-04/25/content_6024270.htm> (CV Liu Binjie) 
Xinhua, Wang Chen jianli [CV of Wang Chen] 王晨简历, SD, retrieved 10 October 20II, Xinhua, <http://news.xinhuanet.com/ziliao/2002-I I/20/content_635495.htm> (CV Wang Chen)

Xinhua, Police Pluck Bird Flu Research Base to Find DVD Pirates, 2007, retrieved on 17 November 2010, Xinhua, <http://news.xinhuanet.com/english/2007-

04/27/content_6032973.htm>

Xinhua, Police Seize 7 Illegal DVD Production Lines, 2008, retrieved I 5 October 20 I0, People.com, <http://english.people.com.cn/9000 I/90776/63584I I.pdf>

Xinhua, China Destroys over 26 Mln Pirated Publications to Mark World Intellectual Property Day, 2010, retrieved 9 May 2010, Xinhua,

<http://news.xinhuanet.com/english20I0/china/20II-04/22/c_I384I553.htm>

Xinhua, Former Shanghai Party Chief Gets I8-year Term for Bribery, 2008, retrieved 6 May 20I I, Xinhua, <http://news.xinhuanet.com/english/2008-

04/I I/content_7959627.htm> (Xinhua 2008B)

Xinhua, l'd Much Rather Weep in a BMW, 2010, retrieved 6 June 201 I, Xinhua, <http://news.xinhuanet.com/english2010/indepth/2010-06/04/c_I3332993.htm> (Xinhua 20I0A)

Xinhua, Zhongguo daoban DVD Shichang qunian da 400 yi, dianying piaofang jin po 60 yi [The Chinese Pirated DVD Market reached 40 billon last year, film box office only reaches 6 billion] 中国盗版DVD市场去年达400亿 电影票房仅破60亿, 2010, retrieved 18 May 20I I, Xinhua, <http://news.xinhuanet.com/society/20I006/16/c_I2224944.htm>

Xinhua, Will China Fall into the "Middle Income Trap"?, 20I I, retrieved 9 October 20 I I, Xinhua, <http://news.xinhuanet.com/english20l0/indepth/20 I I04/09/c_13820679.htm> (Xinhua 20 I IA)

Xinhua, China Sets Up Office for Internet Information Management, 20I I, retrieved I8 September 20II, <http://news.xinhuanet.com/english20I0/china/20II 05/04/c_|38579 I I.htm> (Xinhua 20 I IB)

Yin Xiaoyu 尹晓宇, "Wei shoushilü" youdao zhuli luanxiang, xiangqin jiemu disuhua, dang zhi! ["Only Viewing Rates" Leads to Pursuit of Material Gain and Chaotic Images,

Connected Programmes are Vulgarized and Should be Stopped!] “惟收视率”诱导逐利乱 象 相亲节目低俗化，当止! People’s Daily, 2010, retrieved 4 May 20II, <http://cpc.people.com.cn/GB/64093/82429/83083/I I 93 I577.html>

Zhang, Lei, Invisible Footprints of Online Commentators, 20I0, retrieved 22 March 2010, Global Times, <http://special.globaltimes.cn/2010-02/503820.html>

Zhang Ming 张鸣, Chunqan zenyang cai neng tiejin minzhong? [How Can the Spring Festival Gala Stick Close to the Masses?] 春晚怎样才能贴近民众? , 20I I, retrieved 5 February 20II, QQ, <http://view.news.qq.com/a/20I I0205/000004.htm> 
Zhao, Yanrong and Kelly Chung Dawson, Opening-up of Movie Industry Urged, 20I I, retrieved 6 July 20I I, China Daily, <http://www.chinadaily.com.cn/china/20I I02/I0/content_II977999.htm?>

\section{Cases}

\section{China}

Guangdong Zhongkai v. Qingdao Weike Cangkou, Qingdao Intermediate People's Court, 2009.

Shanghai Busheng Dafeng v. Hanghzou Daziran, Hangzhou Xihu District Court, 2009. Sony Music China v. Beijing Yongcheng Chaoliu, Beijing First Municipal Intermediate Court, 2010.

\section{England}

London County Council v. Bermondsey Bioscope Co., Ltd., (I9I I) I K B 445.

Edward Darcy Esquire v Thomas Allin of London Haberdasher (I599) 74 ER II 3 I.

\section{United States}

Eldred v. Ashcroft, 537 U.S. I86 (2003)

Freedman v. Maryland, 380 U.S. 5 I (1965).

Joseph Burstyn, Inc. v. Wilson, 343 U.S. 495 (1952)

Mutual Film Corporation v. Industrial Commission of Ohio, 236 U.S. 230 (I9I5).

\section{France}

Arrest du Conseil d'Etat privé du Roi, Qui déclare nulle l'opposition faite par les Libraires de Paris au privilège accordé par Sa Majesté aux demoiselles de la Fontaine ; \& enjoint aux Syndic \& Adjoints d'enregistrer sans délai les privilége \& permissions accordés par Sa Majesté, I76I. (I76I La Fontaine Case)

\section{WTO}

DS362, China - Measures Affecting the Protection and Enforcement of Intellectual Property Rights

Related Documents:

Request for Consultations, WT/DS362/I, 2007.

Report of the Panel, WT/DS362/R, 2009.

Second Submission of the United States of America, 2008. (DS 362 - US Second Submission)

DS363, China - Measures Affecting Trading Rights and Distribution Services for Certain Publications and Audiovisual Entertainment Products

Related Documents:

Request for Consultations, WT/DS363/I, 2007. (DS363 Request for Consultations). Report of the Panel, WT/DS363/R, 2009. (DS363 Report of the Panel) 
Notification of an Appeal by China, WT/DS363/I0, 2009. (DS363 Appeal Notification)

Notification of an Other Appeal by the United States, WT/DS363/II, 2009. (DS363

Other Appeal Notification)

Report of the Appellate Body, WT/DS363/AB/R, 2010. (DS 363 Appellate Body Report)

Status Report by China, WT/DS363/I7/Add.2, 20I I. (DS363 Status Report 2)

Status Report by China, WT/DS363/I7/Add.3, 20I I. (DS363 Status Report 3)

Understanding between China and the United States Regarding Procedures under Articles 21 and 22 of the DSU, WT/DS363/I8, 20II. (DS 363 Sino-US Understanding)

\section{Legal documents}

\section{Multilateral treaties}

Berne Convention for the Protection of Artistic and Literary Works, 1886 (last revised 1979). (Berne Convention)

1952 Universal Copyright Convention, revised in 1971.

Convention for the Protection of Producers of Phonograms Against Unauthorized Duplication of their Phonograms, 197I, World Intellectual Property Organization. (197I Geneva Phonograms Convention).

World Intellectual Property Organization Copyright Treaty, 1996. (WIPO Copyright Treaty)

World Intellectual Property Organization Performances and Phonograms Treaty, 1996. (1996 WIPO Performances and Phonograms Treaty)

\section{Bilateral treaties}

Implementing Accord on Cooperation in the Field of High Energy Physics, 1979, I8(2) I.L.M. 346. (1979 High Energy Agreement).

Agreement on Trade Relations Between the United States of America and the People's Republic of China, Presidential Proclamation 4697, I979, 3I U.S.T. 465I. (1979 US-China Trade Agreement).

Memorandum of Understanding between the Government of the United States of America and the Government of the People's Republic of China on the Protection of Intellectual Property, 1992, 34 I.L.M. 676. (I 992 Memorandum of Understanding).

Agreement Regarding Intellectual Property Rights, I995, 34 I.L.M. 88I. (I995 IPR Agreement).

\section{WTO Legal Texts}

Agreement Establishing the World Trade Organization, 1994. (WTO Agreement)

General Agreement on Trade in Services, 1994. (GATS)

Agreement on Trade Related Aspects of Intellectual Property Rights. 2004. (TRIPS) 
Protocol on the Accession of the People's Republic of China, WT/L/432, 200I. (Accession Protocol)

Report of the Working Party on the Accession of China, WT/ACC/CHN/49, 200 I. (Working Party Report)

\section{English statutes}

Royal Charter of the Company of Stationers, I557. (I557 Stationers' Charter).

Ordinances decreed for reformation of divers disorders in printing and uttering of Bookes, I566. (I566 Star Chamber Decree)

The newe Decrees of the Starre Chamber for Orders in Printinge, I586. (Star Chamber Decree)

A Decree of Starre-Chamber Concerning Printing, 1637. (1637 Star Chamber Decree)

An Act concerning Monopolies and Dispensations with penall Lawes and the Forfeyture thereof, 1624. (I624 Statute of Monopolies)

Ordinance for the Regulating of Printing, 1643.

An Act for the Encouragement of Learning, by vesting the Copies of Printed Books in the Authors or purchasers of such Copies, during the Times therein mentioned, 17I0. (Statute of Anne, 1710).

Cinematograph Act (9 Edw.7, c.30), 1909.

An Act to make provision for regulating the distribution of video recordings and for connected purposes, 1984. (1984 Video Recordings Act)

Broadcasting Act, 1990.

Broadcasting Act, 1996.

\section{European Union Documents}

Directive amending Council Directive 89/552/EEC on the coordination of certain provisions laid down by law, regulation or administrative action in Member States concerning the pursuit of television broadcasting activities, 97/36/EC, 1997. (1997 Television Without Frontiers Directive).

Directive on the term of protection of copyright and certain related rights, 2006/I I6/EC, 2006. (2006 Copyright Term Directive)

\section{French statutes}

Edict fait par le Roy très-chrestien Henry deuxieme de ce nom, sur les livres censurez par la faculté de Theologie de Paris, I547. (I547 French Censorship Act) 
Arrest du Conseil d'Etat du Roi, Portant Règlement sur la durée des Priviléges en Librairie, 1777. (I777 Decree on the Duration of Privileges)

Arrêt du Conseil d'Etat du Roi, Qui établit un Bureau de Timbre pour la Musique, I786. (I786 Decree on Music).

Décret de la Convention Nationale du dix-neuf juillet 1793 relatif aux droits de propriété des Auteurs d'écrits en tout genre, des Compositeurs de musique, des $\mathrm{Pe}-$ intres et des Dessinateurs (avec le rapport de Lakanal), 1793. (I793 French Literary and Artistic Property Decree).

Loi n $94-665$ du 4 août 1994 relative à l'emploi de la langue française, 1994. (I 994 Toubon Law)

\section{German statutes}

Reichsgesetz über die Presse, 1874. (1874 Press Law)

Verfassung des Deutschen Reichs, 1919. (1919 Weimar Constitution)

Lichtspielgesetz, 1920. (1920 Cinema Law)

Grundgesetz für die Bundesrepublik Deutschland, 1949. (1949 Basic Law)

Strafgesetzbuch, 1989. (1989 German Criminal Law).

Jugendschutzgesetz, 2002. (2002 Youth Protection Law)

\section{United States statutes}

An Act for the Encouragement of Learning, by securing copies of maps, charts, and books, to the authors and proprietors of such copies, during the times therein mentioned, 1790. (I 790 Copyright Act).

\section{Chinese legal and regulatory documents}

Note: except for documents marked with an asterisk, a translation of all documents is available at the author's website: http://chinacopyrightandmedia.wordpress.com

\begin{tabular}{|c|c|c|c|c|c|}
\hline Long English Title & Short English Title & Chinese Title & Year & Issuing Institution & \\
\hline $\begin{array}{l}\text { Provisions on the Main Du- } \\
\text { ties, Internal Organization } \\
\text { and Personnel Allotment of } \\
\text { the Jinan Municipal Com- } \\
\text { prehensive Cultural Market } \\
\text { Law Enforcement Bureau }\end{array}$ & $\begin{array}{l}20 \text { I I Jinan Culture En- } \\
\text { forcement Structure }\end{array}$ & $\begin{array}{l}\text { 济南市文化市场 } \\
\text { 综合行政执法局 } \\
\text { 主要职责内设机 } \\
\text { 构和人员编制规 } \\
\text { 定 }\end{array}$ & 2011 & $\begin{array}{l}\text { Jinan People's } \\
\text { Government }\end{array}$ & $*$ \\
\hline $\begin{array}{l}\text { Notice Concerning the } \\
\text { Nationwide Television } \\
\text { Drama Shooting Filing An- } \\
\text { nouncement for March } \\
201 \mathrm{I}\end{array}$ & $\begin{array}{l}\text { 20I I March Television } \\
\text { Drama Notice }\end{array}$ & $\begin{array}{l}\text { 广电总局关于 } \\
\text { 20II年3月全国拍 } \\
\text { 摄制作电视剧备 } \\
\text { 案公示的通知 }\end{array}$ & 2011 & SARFT & \\
\hline $\begin{array}{l}\text { Announcement Concerning } \\
\text { Complete Implementation } \\
\text { of the "One Filing, Two }\end{array}$ & $\begin{array}{l}2010 \text { Film "One Filing, } \\
\text { Two Examinations Sys- } \\
\text { tem" Announcement }\end{array}$ & $\begin{array}{l}\text { 关于电影全面实 } \\
\text { 行“一备二审制”的 }\end{array}$ & 2010 & SARFT & \\
\hline
\end{tabular}




\begin{tabular}{|c|c|c|c|c|c|}
\hline $\begin{array}{l}\text { Examinations System" for } \\
\text { Films }\end{array}$ & & 公告 & & & \\
\hline $\begin{array}{l}\text { Provisional Network Gam- } \\
\text { ing Management Rules }\end{array}$ & $\begin{array}{l}2010 \text { Provisional Net- } \\
\text { work Gaming Manage- } \\
\text { ment Rules }\end{array}$ & $\begin{array}{l}\text { 网络游戏管理暂 } \\
\text { 行办法 }\end{array}$ & 2010 & $\begin{array}{l}\text { MoC, NCA, PSB, } \\
\text { SPC, GAPP }\end{array}$ & $*$ \\
\hline $\begin{array}{l}\text { Provisions on the Main Du- } \\
\text { ties, Internal Organization } \\
\text { and Personnel Allotment of } \\
\text { the Chongqing City Jinjiang } \\
\text { District Comprehensive } \\
\text { Cultural Market Law En- } \\
\text { forcement Team }\end{array}$ & $\begin{array}{l}2010 \text { Jinjiang Culture } \\
\text { Enforcement Structure }\end{array}$ & $\begin{array}{l}\text { 庆市黔江区文化 } \\
\text { 市场行政执法大 } \\
\text { 队主要职责内设 } \\
\text { 机构和人员编制 } \\
\text { 规定 }\end{array}$ & 2010 & $\begin{array}{l}\text { Jinjiang People's } \\
\text { Government }\end{array}$ & $*$ \\
\hline $\begin{array}{l}\text { Guiding Opinions Concern- } \\
\text { ing Strengthening Compre- } \\
\text { hensive Cultural Market } \\
\text { Law Enforcement Equip- } \\
\text { ment Allocation Work. }\end{array}$ & $\begin{array}{l}2010 \text { Comprehensive } \\
\text { Law Enforcement Allo- } \\
\text { cation Opinions }\end{array}$ & $\begin{array}{l}\text { 文化部关于加强 } \\
\text { 文化市场综合执 } \\
\text { 法装备配备工作 } \\
\text { 的指导意见 }\end{array}$ & 2010 & MoC & $*$ \\
\hline $\begin{array}{l}\text { Television Drama Content } \\
\text { Management Regulations }\end{array}$ & $\begin{array}{l}2010 \text { Television Drama } \\
\text { Content Regulations }\end{array}$ & $\begin{array}{l}\text { 电视剧内容管理 } \\
\text { 规定 }\end{array}$ & 2010 & SARFT & \\
\hline $\begin{array}{l}\text { Guiding Opinion on Further } \\
\text { Stimulating Press and Publi- } \\
\text { cations Industry Develop- } \\
\text { ment }\end{array}$ & $\begin{array}{l}2010 \text { Press and Publica- } \\
\text { tions Industry Devel- } \\
\text { opment Opinions }\end{array}$ & $\begin{array}{l}\text { 新闻出版总署关 } \\
\text { 于进一步推动新 } \\
\text { 闻出版产业发展 } \\
\text { 的指导意见 }\end{array}$ & 2010 & GAPP & \\
\hline $\begin{array}{l}\text { Guiding Opinions Concern- } \\
\text { ing Stimulating Flourishing } \\
\text { and Development of the } \\
\text { Film Industry }\end{array}$ & $\begin{array}{l}2010 \text { Film Develop- } \\
\text { ment Opinions }\end{array}$ & $\begin{array}{l}\text { 关于促进电影产 } \\
\text { 业繁荣发展的指 } \\
\text { 导意见 }\end{array}$ & 2010 & State Council & \\
\hline $\begin{array}{l}\text { Opinions on the Implemen- } \\
\text { tation of the Radio and } \\
\text { Television Intellectual Prop- } \\
\text { erty Rights Strategy }\end{array}$ & $\begin{array}{l}2010 \text { Radio and Televi- } \\
\text { sion IPR Strategy }\end{array}$ & $\begin{array}{l}\text { 广播影视知识产 } \\
\text { 权战略实施意见 }\end{array}$ & 2010 & SARFT & \\
\hline $\begin{array}{l}\text { Notice Concerning Launch- } \\
\text { ing the "Safe Expo" Cultural } \\
\text { Market Special Safeguard } \\
\text { Operation }\end{array}$ & $\begin{array}{l}2010 \text { Expo Campaign } \\
\text { Notice }\end{array}$ & $\begin{array}{l}\text { 文化部关于开展“ } \\
\text { 平安世博”文化市 } \\
\text { 场专项保障行动 } \\
\text { 的通知 }\end{array}$ & 2010 & MoC & \\
\hline $\begin{array}{l}\text { Copyright Law of the Peo- } \\
\text { ple's Republic of China }\end{array}$ & 2010 Copyright Law & $\begin{array}{l}\text { 中华人民共和国 } \\
\text { 著作权法 }\end{array}$ & 2010 & NPC & \\
\hline $\begin{array}{l}\text { Notice Concerning Printing } \\
\text { and Distributing the Cam- } \\
\text { paign Plan for Attacking } \\
\text { Intellectual Property Rights } \\
\text { Infringement and Produc- } \\
\text { tion and Sale of Fake and } \\
\text { Inferior Products }\end{array}$ & $\begin{array}{l}2010 \text { Anti-IPR In- } \\
\text { fringement Campaign } \\
\text { Notice }\end{array}$ & $\begin{array}{l}\text { 打击侵犯知识产 } \\
\text { 权和制售假冒伪 } \\
\text { 劣商品专项行动 } \\
\text { 方案 }\end{array}$ & 2010 & State Council & \\
\hline $\begin{array}{l}\text { Film Work Copyright Col- } \\
\text { lective Management Use Fee } \\
\text { Collection Standards }\end{array}$ & $\begin{array}{l}2010 \text { Collective Film } \\
\text { Management Standards }\end{array}$ & $\begin{array}{l}\text { 电影作品著作权 } \\
\text { 集体管理使用费 } \\
\text { 收取标准 } \\
\end{array}$ & 2010 & $\mathrm{NCA}$ & \\
\hline $\begin{array}{l}\text { Notice Concerning the Es- } \\
\text { tablishment of a Leading } \\
\text { Small Group for the } \\
\text { Nationwide Special Cam- } \\
\text { paign Attacking Intellectual } \\
\text { Property Rights Infringe- } \\
\text { ment and Production and } \\
\text { Sale of Fake and Inferior } \\
\text { Products }\end{array}$ & $\begin{array}{l}2010 \text { Anti-Infringement } \\
\text { Small Group Establish- } \\
\text { ment Notice }\end{array}$ & $\begin{array}{l}\text { 国务院办公厅关 } \\
\text { 于成立全国打击 } \\
\text { 侵犯知识产权和 } \\
\text { 制售假冒伪劣商 } \\
\text { 品专项行动领导 } \\
\text { 小组的通知 }\end{array}$ & 2010 & State Council & \\
\hline Television Drama Content & 2010 Television Drama & 电视剧内容管理 & 2010 & SARFT & \\
\hline
\end{tabular}




\begin{tabular}{|c|c|c|c|c|c|}
\hline Regulations & Content Regulations & 规定 & & & \\
\hline $\begin{array}{l}\text { Notice Concerning Further } \\
\text { Strengthening of the Admin- } \\
\text { istration of Pre-examination } \\
\text { and Approval of Internet } \\
\text { Games and the Examination } \\
\text { and Approval of Imported } \\
\text { Internet Games }\end{array}$ & $\begin{array}{l}2009 \text { Network Gaming } \\
\text { Notice }\end{array}$ & $\begin{array}{l}\text { 关于有关解释, } \\
\text { 进一步加强网络 } \\
\text { 游戏前置审批和 } \\
\text { 进口网络游戏审 } \\
\text { 批管理的通知 }\end{array}$ & 2009 & GAPP & $*$ \\
\hline $\begin{array}{l}\text { Provisions on the Main Du- } \\
\text { ties, Internal Organization } \\
\text { and Personnel Allotment of } \\
\text { the Wuhan Municipal Press } \\
\text { and Publications Bureau } \\
\text { (Wuhan Municipal Copy- } \\
\text { right Office) }\end{array}$ & $\begin{array}{l}2009 \text { Wuhan Press and } \\
\text { Publications Structure }\end{array}$ & $\begin{array}{l}\text { 武汉市新闻出版 } \\
\text { 局（武汉市版权 } \\
\text { 局）主要职责内 } \\
\text { 设机构和人员编 } \\
\text { 制规定 }\end{array}$ & 2009 & $\begin{array}{l}\text { Wuhan People's } \\
\text { Government }\end{array}$ & $*$ \\
\hline $\begin{array}{l}\text { Opinion Concerning Estab- } \\
\text { lishing and Stimulating a } \\
\text { Party and State Leadership } \\
\text { Ranks and Leading Cadre } \\
\text { Appraisal and Evaluation } \\
\text { System for Scientific Devel- } \\
\text { opment }\end{array}$ & $\begin{array}{l}2009 \text { Cadre Evaluation } \\
\text { Opinion }\end{array}$ & $\begin{array}{l}\text { 关于建立促进科 } \\
\text { 学发展的党政领 } \\
\text { 导班子和领导干 } \\
\text { 部考核评价机制 } \\
\text { 的意见 }\end{array}$ & 2009 & $\begin{array}{l}\text { Central Commit- } \\
\text { tee }\end{array}$ & $*$ \\
\hline $\begin{array}{l}\text { Tort Law of the People's } \\
\text { Republic of China }\end{array}$ & 2009 Tort Law & $\begin{array}{l}\text { 中华人民共和国 } \\
\text { 侵权责任法 }\end{array}$ & 2009 & NPC & $*$ \\
\hline $\begin{array}{l}\text { Provisions on the Main Du- } \\
\text { ties, Internal Organization } \\
\text { and Personnel Allotment of } \\
\text { the Hubei Provincial Cul- } \\
\text { ture Office }\end{array}$ & $\begin{array}{l}2009 \text { Hubei Culture } \\
\text { Office Structure }\end{array}$ & $\begin{array}{l}\text { 湖北省文化厅主 } \\
\text { 要职责内设机构 } \\
\text { 和人员编制规定 }\end{array}$ & 2009 & $\begin{array}{l}\text { Hubei People's } \\
\text { Government }\end{array}$ & $*$ \\
\hline $\begin{array}{l}\text { Some Opinions Concerning } \\
\text { Stimulating Our Country's } \\
\text { Audiovisual Industry's Heal- } \\
\text { thy and Orderly Growth }\end{array}$ & $\begin{array}{l}2009 \text { Audiovisual In- } \\
\text { dustry Growth Opin- } \\
\text { ions }\end{array}$ & $\begin{array}{l}\text { 关于促进我国音 } \\
\text { 像业健康有序发 } \\
\text { 展的若干意见 }\end{array}$ & 2009 & GAPP & \\
\hline $\begin{array}{l}\text { Cultural Industry Invest- } \\
\text { ment Guidance Catalogue }\end{array}$ & $\begin{array}{l}2009 \text { Cultural Industry } \\
\text { Investment Catalogue }\end{array}$ & $\begin{array}{l}\text { 文化产业投资指 } \\
\text { 导目录 }\end{array}$ & 2009 & MoC & \\
\hline $\begin{array}{l}\text { Notice Concerning } \\
\text { Strengthening and Improv- } \\
\text { ing Network Music Content } \\
\text { Examination Work }\end{array}$ & $\begin{array}{l}2009 \text { Internet Content } \\
\text { Management Notice }\end{array}$ & $\begin{array}{l}\text { 关于加强和改进 } \\
\text { 网络音乐内容审 } \\
\text { 查工作的通知 }\end{array}$ & 2009 & MoC & \\
\hline $\begin{array}{l}\text { Reproduction Management } \\
\text { Rules }\end{array}$ & $\begin{array}{l}2009 \text { Reproduction } \\
\text { Management Rules }\end{array}$ & 复制管理办法 & 2009 & GAPP & \\
\hline $\begin{array}{l}\text { Copyright Administrative } \\
\text { Punishment Implementation } \\
\text { Rules }\end{array}$ & $\begin{array}{l}2009 \text { Administrative } \\
\text { Punishment Rules }\end{array}$ & $\begin{array}{l}\text { 著作权行政处罚 } \\
\text { 实施办法 }\end{array}$ & 2009 & $\mathrm{NCA}$ & \\
\hline $\begin{array}{l}\text { Notice Concerning Doing } \\
\text { Well Film Distribution and } \\
\text { Screening Work in the } 2009 \\
\text { New Year and Spring Festi- } \\
\text { val Period }\end{array}$ & $\begin{array}{l}2009 \text { Spring Festival } \\
\text { Notice }\end{array}$ & $\begin{array}{l}\text { 关于做好2009年 } \\
\text { 元旦、春节期间 } \\
\text { 电影发行放映工 } \\
\text { 作的通知 }\end{array}$ & 2009 & SARFT & \\
\hline $\begin{array}{l}\text { Notice Concerning Launch } \\
\text { of a Cultural Market Cen- } \\
\text { tralized Discipline Oper- } \\
\text { ation }\end{array}$ & $\begin{array}{l}2009 \text { Cultural Market } \\
\text { Discipline Notice }\end{array}$ & $\begin{array}{l}\text { 文化部关于开展 } \\
\text { 文化市场集中整 } \\
\text { 治行动的通知 }\end{array}$ & 2009 & MoC & \\
\hline $\begin{array}{l}\text { Cultural Industries Promo- } \\
\text { tion Plan }\end{array}$ & $\begin{array}{l}2009 \text { Cultural In- } \\
\text { dustries Promotion } \\
\text { Plan }\end{array}$ & $\begin{array}{l}\text { 文化产业振兴规 } \\
\text { 划 }\end{array}$ & 2009 & State Council & \\
\hline $\begin{array}{l}\text { Provisional Radio and Tele- } \\
\text { vision Station Broadcasting }\end{array}$ & $\begin{array}{l}2009 \text { Provisional } \\
\text { Broadcasting Remu- }\end{array}$ & $\begin{array}{l}\text { 广播电台电视台 } \\
\text { 播放录音制品支 }\end{array}$ & 2009 & State Council & \\
\hline
\end{tabular}




\begin{tabular}{|c|c|c|c|c|c|}
\hline $\begin{array}{l}\text { Audio Recording Remu- } \\
\text { neration Payment Rules }\end{array}$ & neration Rules & 付报酬暂行办法 & & & \\
\hline $\begin{array}{l}\text { Provisions on the Main Du- } \\
\text { ties, Internal Organization } \\
\text { and Personnel Allotment of } \\
\text { the Beijing Municipal Com- } \\
\text { prehensive Cultural Market } \\
\text { Law Enforcement Team } \\
\text { (Beijing Municipal "Sweeping } \\
\text { Pornography and Striking } \\
\text { Illegality" Office }\end{array}$ & $\begin{array}{l}2008 \text { Beijing Culture } \\
\text { Enforcement Structure }\end{array}$ & $\begin{array}{l}\text { 北京市文化市场 } \\
\text { 行政执法总队 ( } \\
\text { 北京市“扫黄打非” } \\
\text { 办公室) 主要职 } \\
\text { 责、内设机构和 } \\
\text { 人员编制规定 }\end{array}$ & 2008 & $\begin{array}{l}\text { Beijing People's } \\
\text { Government }\end{array}$ & $*$ \\
\hline $\begin{array}{l}\text { Circular Concerning the } \\
\text { Situation of Dealing with the } \\
\text { Problem of the film "Lost in } \\
\text { Beijing" Violating Regula- } \\
\text { tions }\end{array}$ & $\begin{array}{l}2008 \text { Lost in Beijing } \\
\text { Circular }\end{array}$ & $\begin{array}{l}\text { 广电总局关于处 } \\
\text { 理影片《苹果》 } \\
\text { 违规问题的情况 } \\
\text { 通报 }\end{array}$ & 2008 & SARFT & \\
\hline $\begin{array}{l}\text { Some Opinions Concerning } \\
\text { Supporting Our Country's } \\
\text { Cartoon Industry Develop- } \\
\text { ment }\end{array}$ & $\begin{array}{l}2008 \text { Cartoon Devel- } \\
\text { opment Opinions }\end{array}$ & $\begin{array}{l}\text { 文化部关于扶持 } \\
\text { 我国动漫产业发 } \\
\text { 展的若干意见 }\end{array}$ & 2008 & MoC & \\
\hline $\begin{array}{l}\text { Notice Concerning Investi- } \\
\text { gating and Prosecuting } \\
\text { "Horror and Occult-Type" } \\
\text { Audiovisual Products }\end{array}$ & 2008 Horror Notice & $\begin{array}{l}\text { 关于查处“恐怖灵 } \\
\text { 异类”音像制品的 } \\
\text { 通知 }\end{array}$ & 2008 & GAPP & \\
\hline $\begin{array}{l}\text { Provisions on the Main Du- } \\
\text { ties, Internal Organization } \\
\text { and Personnel Allotment of } \\
\text { the General Administration } \\
\text { of Press and Publication } \\
\text { (National Copyright Admin- } \\
\text { istration) }\end{array}$ & 2008 GAPP Structure & $\begin{array}{l}\text { 国务院办公厅关 } \\
\text { 于印发国家新闻 } \\
\text { 出版总署(国家版 } \\
\text { 权局)主要职责内 } \\
\text { 设机构和人员编 } \\
\text { 制规定的通知 }\end{array}$ & 2008 & State Council & \\
\hline $\begin{array}{l}\text { Provisions on the Main Du- } \\
\text { ties, Internal Organization } \\
\text { and Personnel Allotment of } \\
\text { the Ministry of Culture }\end{array}$ & $\begin{array}{l}2008 \text { Ministry of Cul- } \\
\text { ture Structure }\end{array}$ & $\begin{array}{l}\text { 国务院办公厅关 } \\
\text { 于印发文化部主 } \\
\text { 要职责内设机构 } \\
\text { 和人员编制规定 } \\
\text { 的通知 }\end{array}$ & 2008 & State Council & \\
\hline $\begin{array}{l}\text { Notice Concerning Launch- } \\
\text { ing Screening Activities of } \\
\text { Excellent Films Commemo- } \\
\text { rating the 30th Anniversary } \\
\text { of Reform and Opening Up }\end{array}$ & $\begin{array}{l}2008 \text { 30th Anniversary } \\
\text { Notice }\end{array}$ & $\begin{array}{l}\text { 关于开展纪念改 } \\
\text { 革开放30周年优 } \\
\text { 秀影片展映活动 } \\
\text { 的通知 }\end{array}$ & 2008 & SARFT & \\
\hline $\begin{array}{l}\text { Provisions on the Main Du- } \\
\text { ties, Internal Organization } \\
\text { and Personnel Allotment of } \\
\text { the State Administration of } \\
\text { Radio, Film and Television }\end{array}$ & 2008 SARFT Structure & $\begin{array}{l}\text { 国务院办公厅关 } \\
\text { 于印发国家广播 } \\
\text { 电影电视总局主 } \\
\text { 要职责内设机构 } \\
\text { 和人员编制规定 } \\
\text { 的通知 }\end{array}$ & 2008 & State Council & \\
\hline $\begin{array}{l}\text { SARFT Prohibits Broadcast } \\
\text { of Mass-Participation Make- } \\
\text { over and Sex Change Pro- } \\
\text { grammes }\end{array}$ & $\begin{array}{l}2007 \text { Make-over and } \\
\text { Sex Change Prohibition } \\
\text { Notice }\end{array}$ & $\begin{array}{l}\text { 广电总局禁止播 } \\
\text { 出群众参与的整 } \\
\text { 容、变性节目 }\end{array}$ & 2007 & SARFT & \\
\hline $\begin{array}{l}\text { Notice Concerning Launch- } \\
\text { ing a Special Clean-Up } \\
\text { Campaign against Audiovis- } \\
\text { ual Products with "Vulgar } \\
\text { Tendencies" }\end{array}$ & $\begin{array}{l}2007 \text { Vulgar Tenden- } \\
\text { cies Notice }\end{array}$ & $\begin{array}{l}\text { 关于开展音像制 } \\
\text { 品“低俗之风”专项 } \\
\text { 治理活动的通知 }\end{array}$ & 2007 & GAPP & \\
\hline $\begin{array}{l}\text { Civil Procedure Law of the } \\
\text { People's Republic of China }\end{array}$ & $\begin{array}{l}2007 \text { Civil Procedure } \\
\text { Law }\end{array}$ & $\begin{array}{l}\text { 中华人民共和国 } \\
\text { 民事诉讼法 }\end{array}$ & 2007 & NPC & \\
\hline
\end{tabular}




\begin{tabular}{|c|c|c|c|c|c|}
\hline $\begin{array}{l}\text { Internet Audiovisual Pro- } \\
\text { gramme Service Manage- } \\
\text { ment Regulations }\end{array}$ & $\begin{array}{l}2007 \text { Internet Audio- } \\
\text { visual Programme } \\
\text { Regulations }\end{array}$ & $\begin{array}{l}\text { 互联网视听节目 } \\
\text { 服务管理规定 }\end{array}$ & 2007 & SARFT, MII & \\
\hline $\begin{array}{l}\text { Foreign Investment in In- } \\
\text { dustry Guidance Catalogue }\end{array}$ & $\begin{array}{l}2007 \text { Foreign Invest- } \\
\text { ment Catalogue }\end{array}$ & $\begin{array}{l}\text { 外商投资产业指 } \\
\text { 导目录 }\end{array}$ & 2007 & $\begin{array}{l}\text { MOFCOM, } \\
\text { NDRC }\end{array}$ & \\
\hline $\begin{array}{l}\text { Notice Concerning } \\
\text { Strengthening Mass- } \\
\text { Participation Selection-Type } \\
\text { Radio and Television Ac- } \\
\text { tivity Management }\end{array}$ & $\begin{array}{l}2007 \text { Mass Participation } \\
\text { Programme Notice }\end{array}$ & $\begin{array}{l}\text { 关于加强群众参 } \\
\text { 与的选拔类广播 } \\
\text { 电视活动管理的 } \\
\text { 通知 }\end{array}$ & 2007 & SARFT & \\
\hline $\begin{array}{l}\text { Provisional Rules on Re- } \\
\text { warding Reporting, Investi- } \\
\text { gating and Punishing In- } \\
\text { fringement or piracy Activi- } \\
\text { ties }\end{array}$ & $\begin{array}{l}2007 \text { Provisional Re- } \\
\text { ward Rules }\end{array}$ & $\begin{array}{l}\text { 举报、查处侵权 } \\
\text { 盗版行为奖励暂 } \\
\text { 行办法 }\end{array}$ & 2007 & NCA & \\
\hline $\begin{array}{l}\text { Interpretation by the Sup- } \\
\text { reme People's Court and } \\
\text { the Supreme People's Pro- } \\
\text { curatorate on Several Issues } \\
\text { of Concrete Application of } \\
\text { Laws in Handling Criminal } \\
\text { Cases of Infringing Intellec- } \\
\text { tual Property }\end{array}$ & $\begin{array}{l}2007 \text { Judicial Interpre- } \\
\text { tation on Criminal IPR } \\
\text { Infringement }\end{array}$ & $\begin{array}{l}\text { 最高人民法院、 } \\
\text { 最高人民检察院 } \\
\text { 关于办理侵犯知 } \\
\text { 识产权刑事案件 } \\
\text { 具体应用法律若 } \\
\text { 干问题的解释 }\end{array}$ & 2007 & SPC, SPP & \\
\hline $\begin{array}{l}\text { SARFT Circulates the Acts } \\
\text { Gravely Violating Regula- } \\
\text { tions of Chongqing Televi- } \\
\text { sion Station's "The First } \\
\text { Heartbeat" Nationwide }\end{array}$ & $\begin{array}{l}2007 \text { First Heartbeat } \\
\text { Notice }\end{array}$ & $\begin{array}{l}\text { 广电总局全国通 } \\
\text { 报重庆电视台《 } \\
\text { 第一次心动》严 } \\
\text { 重违规行为 }\end{array}$ & 2007 & SARFT & \\
\hline $\begin{array}{l}\text { Internet Audiovisual Pro- } \\
\text { gramme Service Manage- } \\
\text { ment Regulations }\end{array}$ & $\begin{array}{l}2007 \text { Internet Audio- } \\
\text { visual Service Regula- } \\
\text { tions }\end{array}$ & $\begin{array}{l}\text { 互联网视听节目 } \\
\text { 服务管理规定 }\end{array}$ & 2007 & SARFT & \\
\hline $\begin{array}{l}\text { Some Opinions Concerning } \\
\text { Network Music Develop- } \\
\text { ment and Management }\end{array}$ & $\begin{array}{l}2006 \text { Network Music } \\
\text { Opinions }\end{array}$ & $\begin{array}{l}\text { 文化部关于网络 } \\
\text { 音乐发展和管理 } \\
\text { 的若干意见 }\end{array}$ & 2006 & MoC & * \\
\hline $\begin{array}{l}\text { Audiovisual Products } \\
\text { Wholesale, Retail and } \\
\text { Rental Management Rules }\end{array}$ & $\begin{array}{l}2006 \text { Audiovisual Pro- } \\
\text { ducts Wholesale, Retail } \\
\text { and Rental Management } \\
\text { Rules }\end{array}$ & $\begin{array}{l}\text { 音像制品批发、 } \\
\text { 零售、出租管理 } \\
\text { 办法 }\end{array}$ & 2006 & $\begin{array}{l}\text { MoC, NCA, PSB, } \\
\text { SPC, GAPP }\end{array}$ & \\
\hline $\begin{array}{l}\text { Supplementary Provisions } \\
\text { to the "Television Drama } \\
\text { Examination Management } \\
\text { Regulations" }\end{array}$ & $\begin{array}{l}2006 \text { Supplementary } \\
\text { Television Drama Pro- } \\
\text { visions }\end{array}$ & $\begin{array}{l}\text { 《电视剧审查管 } \\
\text { 理规定》补充规 } \\
\text { 定 }\end{array}$ & 2006 & SARFT & \\
\hline $\begin{array}{l}\text { Notice Concerning Launch- } \\
\text { ing a Concentrated Cam- } \\
\text { paign Attacking Pirated } \\
\text { Audiovisual and Computer } \\
\text { Software Products }\end{array}$ & $\begin{array}{l}2006 \text { Audiovisual and } \\
\text { Software Product Pi- } \\
\text { racy Notice }\end{array}$ & $\begin{array}{l}\text { 全国“扫黄打非”工 } \\
\text { 作小组办公室、 } \\
\text { 中央宣传部、中 } \\
\text { 央政法委等关于 } \\
\text { 开展集中打击盗 } \\
\text { 版音像和计算机 } \\
\text { 软件制品行动的 } \\
\text { 通知 }\end{array}$ & 2006 & $\begin{array}{l}\text { GAPP, MoC, } \\
\text { CPD }\end{array}$ & \\
\hline $\begin{array}{l}\text { Notice Concerning Strictly } \\
\text { Attacking Unlawful Import } \\
\text { of Audiovisual Products }\end{array}$ & $\begin{array}{l}2006 \text { Unlawful Audio- } \\
\text { visual Product Import } \\
\text { Notice }\end{array}$ & $\begin{array}{l}\text { 文化部关于严厉 } \\
\text { 打击违法进口音 } \\
\text { 像制品的通知 }\end{array}$ & 2006 & MoC & \\
\hline $\begin{array}{l}\text { Film Script (Outline) Filing, } \\
\text { Film Management Regula- } \\
\text { tions }\end{array}$ & $\begin{array}{l}2006 \text { Film Script (Out- } \\
\text { line) Filing, Film Man- } \\
\text { agement Regulations }\end{array}$ & $\begin{array}{l}\text { 电影剧本 (梗概 } \\
\text { ) 备案、电影片 } \\
\text { 管理规定 }\end{array}$ & 2006 & SARFT & \\
\hline Announcement concerning & 2006 Hundred Days & 全国“扫黄打非”工 & 2006 & MoC, NCA, PSB, & \\
\hline
\end{tabular}




\begin{tabular}{|c|c|c|c|c|c|}
\hline $\begin{array}{l}\text { Launching the Anti-Piracy } \\
\text { Hundred Days Campaign }\end{array}$ & $\begin{array}{l}\text { Campaign Announce- } \\
\text { ment }\end{array}$ & $\begin{array}{l}\text { 作小组关于印发 } \\
\text { 《关于开展反盗 } \\
\text { 版百日行动的公 } \\
\text { 告》的通知 }\end{array}$ & & SPC, GAPP & \\
\hline $\begin{array}{l}\text { Some Opinions Concerning } \\
\text { Promoting Our Country's } \\
\text { Cartoon Industry Develop- } \\
\text { ment }\end{array}$ & $\begin{array}{l}2006 \text { Cartoon Devel- } \\
\text { opment Opinions }\end{array}$ & $\begin{array}{l}\text { 关于推动我国动 } \\
\text { 漫产业发展的若 } \\
\text { 干意见 }\end{array}$ & 2006 & $\begin{array}{l}\text { Ministry of Finance, } \\
\text { Ministry of Educa- } \\
\text { tion, Ministry of Sci- } \\
\text { ence and Technol- } \\
\text { ogy, MII, MOFCOM, } \\
\text { MoC, General Ad- } \\
\text { ministration of Cus- } \\
\text { toms, SAIC, SARFT, } \\
\text { GAPP }\end{array}$ & \\
\hline $\begin{array}{l}\text { Notice Concerning Con- } \\
\text { ducting "Anti-Piracy Hun- } \\
\text { dred Days Campaign" De- } \\
\text { ployment Work }\end{array}$ & $\begin{array}{l}2006 \text { Anti-Piracy Con- } \\
\text { struction Notice }\end{array}$ & $\begin{array}{l}\text { 建设部办公厅关 } \\
\text { 于进行“反盗版百 } \\
\text { 日行动”工作部署 } \\
\text { 的通知 }\end{array}$ & 2006 & $\begin{array}{l}\text { Ministry of Con- } \\
\text { struction }\end{array}$ & \\
\hline $\begin{array}{l}\text { Outline of the National } \\
\text { "I I th Five Year Plan" Pe- } \\
\text { riod Cultural Development } \\
\text { Plan }\end{array}$ & $\begin{array}{l}2006 \text { Cultural Five-Year } \\
\text { Plan }\end{array}$ & $\begin{array}{l}\text { 国家“十一五”时期 } \\
\text { 文化发展规划纲 } \\
\text { 要 }\end{array}$ & 2006 & State Council & \\
\hline $\begin{array}{l}\text { Interpretation Concerning } \\
\text { Some Issues Concerning } \\
\text { Applicable Law in Cases } \\
\text { Involving Computer Net- } \\
\text { work Copyright Disputes }\end{array}$ & $\begin{array}{l}2006 \text { Internet Copy- } \\
\text { right Interpretation }\end{array}$ & $\begin{array}{l}\text { 关于审理涉及计 } \\
\text { 算机网络著作权 } \\
\text { 纠纷案件适用法 } \\
\text { 律若干问题的解 } \\
\text { 释 }\end{array}$ & 2006 & SPC & \\
\hline $\begin{array}{l}\text { Provisions on the Main Du- } \\
\text { ties, Internal Organization } \\
\text { and Personnel Allotment of } \\
\text { the Beijing Municipal Cul- } \\
\text { tural Law Enforcement } \\
\text { Team (Beijing Municipal } \\
\text { "Sweeping Pornography and } \\
\text { Striking Illegality" Office) }\end{array}$ & $\begin{array}{l}2005 \text { Beijing Culture } \\
\text { Enforcement Structure }\end{array}$ & $\begin{array}{l}\text { 北京市文化市场 } \\
\text { 行政执法总队 ( } \\
\text { 北京市“扫黄打非” } \\
\text { 办公室) 主要职 } \\
\text { 责、内设机构和 } \\
\text { 人员编制规定 }\end{array}$ & 2005 & $\begin{array}{l}\text { Beijing People's } \\
\text { Government }\end{array}$ & $*$ \\
\hline $\begin{array}{l}\text { Implementing Rules for Re- } \\
\text { form of Film Distribution } \\
\text { and Screening Mechanisms }\end{array}$ & $\begin{array}{l}2005 \text { Film Distribution } \\
\text { and Screening Reform } \\
\text { Rules }\end{array}$ & $\begin{array}{l}\text { 关于改革电影发 } \\
\text { 行放映机制的实 } \\
\text { 施细则 }\end{array}$ & 2005 & SARFT & $*$ \\
\hline $\begin{array}{l}\text { Rules Concerning Strength- } \\
\text { ening Cultural Product Im- } \\
\text { port Management }\end{array}$ & $\begin{array}{l}2005 \text { Cultural Product } \\
\text { Import Rules }\end{array}$ & $\begin{array}{l}\text { 关于加强文化产 } \\
\text { 品进口管理的办 } \\
\text { 法 }\end{array}$ & 2005 & $\begin{array}{l}\text { CPD, MoC, SARFT, } \\
\text { GAPP, MOFCOM, } \\
\text { General Administra- } \\
\text { tion of Customs }\end{array}$ & \\
\hline $\begin{array}{l}\text { Notice Concerning Matters } \\
\text { Related to Implementing the } \\
\text { "Provisional Sino-Foreign } \\
\text { Joint Venture and Cooper- } \\
\text { ation Radio and Television } \\
\text { Programme Production } \\
\text { Business Enterprise Man- } \\
\text { agement }\end{array}$ & $\begin{array}{l}2005 \text { Joint Venture } \\
\text { Implementation Notice }\end{array}$ & $\begin{array}{l}\text { 关于实施《中外 } \\
\text { 合资、合作广播 } \\
\text { 电视节目制作经 } \\
\text { 营企业管理暂行 } \\
\text { 规定》有关事宜 } \\
\text { 的通知 }\end{array}$ & 2005 & \begin{tabular}{l|l} 
SARFT \\
\end{tabular} & \\
\hline $\begin{array}{l}\text { Some Decisions Concerning } \\
\text { Non-Public Capital Entering } \\
\text { the Cultural Industry }\end{array}$ & $\begin{array}{l}2005 \text { Private Capital } \\
\text { Decisions }\end{array}$ & $\begin{array}{l}\text { 国务院关于非公 } \\
\text { 有资本进入文化 } \\
\text { 产业的若干决定 }\end{array}$ & 2005 & State Council & \\
\hline $\begin{array}{l}\text { Notice Concerning Further } \\
\text { Strengthening Radio and } \\
\text { Television Programme Pro- } \\
\text { duct Business Organ Man- } \\
\text { agement }\end{array}$ & $\begin{array}{l}2005 \text { Radio and Televi- } \\
\text { sion Business Organ } \\
\text { Management Notice }\end{array}$ & $\begin{array}{l}\text { 广电总局关于进 } \\
\text { 一步加强广播电 } \\
\text { 视节目制作经营 } \\
\text { 机构管理的通知 }\end{array}$ & 2005 & SARFT & \\
\hline
\end{tabular}




\begin{tabular}{|c|c|c|c|c|}
\hline $\begin{array}{l}\text { Some Opinions Concerning } \\
\text { Attracting Foreign Capital in } \\
\text { the Cultural Area }\end{array}$ & $\begin{array}{l}2005 \text { Foreign Capital } \\
\text { Opinions }\end{array}$ & $\begin{array}{l}\text { 文化部、国家广 } \\
\text { 播电影电视总局 } \\
\text { 、新闻出版署、 } \\
\text { 国家发展和改革 } \\
\text { 委员会、商务部 } \\
\text { 关于文化领域引 } \\
\text { 进外资的若干意 } \\
\text { 见 }\end{array}$ & 2005 & $\begin{array}{l}\text { MoC, SARFT, GAPP, } \\
\text { NDRC, MOFCOM }\end{array}$ \\
\hline $\begin{array}{l}\text { Urgent Notice Concerning } \\
\text { Launching the Audiovisual } \\
\text { Market Administration } \\
\text { Winter Campaign to Se- } \\
\text { verely Attack DVD Con- } \\
\text { densed Discs }\end{array}$ & $\begin{array}{l}2004 \text { Winter Campaign } \\
\text { Notice }\end{array}$ & $\begin{array}{l}\text { 关于立即开展 } \\
\text { 音像市场治理 } \\
\text { 冬季行动严厉 } \\
\text { 打击DVD压缩 } \\
\text { 碟的紧急通知 }\end{array}$ & 2004 & MoC \\
\hline $\begin{array}{l}\text { Provisions on the Main Du- } \\
\text { ties, Internal Organization } \\
\text { and Personnel Allotment of } \\
\text { the Jinan Municipal Radio, } \\
\text { Film and Television Bureau }\end{array}$ & $\begin{array}{l}2004 \text { Jinan Radio, Film } \\
\text { and Television Struc- } \\
\text { ture }\end{array}$ & $\begin{array}{l}\text { 济南市广播电视 } \\
\text { 局主要职责、内 } \\
\text { 设机构和人员编 } \\
\text { 制规定 }\end{array}$ & 2004 & $\begin{array}{l}\text { Jinan People's } \\
\text { Government }\end{array}$ \\
\hline $\begin{array}{l}\text { Rules on Sino-Foreign Co- } \\
\text { operative Audiovisual Pro- } \\
\text { duct Sub-Distribution En- } \\
\text { terprise Management }\end{array}$ & $\begin{array}{l}2004 \text { Audiovisual Sub- } \\
\text { Distribution Rule }\end{array}$ & $\begin{array}{l}\text { 中外合作音像制 } \\
\text { 品分销企业管理 } \\
\text { 办法( }\end{array}$ & 2004 & MoC \\
\hline $\begin{array}{l}\text { Television Drama Examin- } \\
\text { ation Management Regula- } \\
\text { tions }\end{array}$ & $\begin{array}{l}2004 \text { Television Drama } \\
\text { Examination Regula- } \\
\text { tions }\end{array}$ & $\begin{array}{l}\text { 电视剧审查管理 } \\
\text { 规定 }\end{array}$ & 2004 & SARFT \\
\hline $\begin{array}{l}\text { Provisional Film Enterprises } \\
\text { Business Qualification Entry } \\
\text { Regulations }\end{array}$ & $\begin{array}{l}2004 \text { Film Entry Regula- } \\
\text { tions }\end{array}$ & $\begin{array}{l}\text { 电影企业经营资 } \\
\text { 格准入暂行规定 }\end{array}$ & 2004 & $\begin{array}{l}\text { SARFT, MOF- } \\
\text { COM }\end{array}$ \\
\hline $\begin{array}{l}\text { Radio and Television Pro- } \\
\text { gramme Production Busi- } \\
\text { ness Management Regula- } \\
\text { tions }\end{array}$ & $\begin{array}{l}2004 \text { Radio and Televi- } \\
\text { sion Business Manage- } \\
\text { ment Regulations }\end{array}$ & $\begin{array}{l}\text { 广播电视节目制 } \\
\text { 作经营管理规定 }\end{array}$ & 2004 & SARFT \\
\hline $\begin{array}{l}\text { Notice Concerning En- } \\
\text { forcement of Propaganda } \\
\text { Discipline, Preventing Dis- } \\
\text { semination Activities Violat- } \\
\text { ing Regulations }\end{array}$ & $\begin{array}{l}2004 \text { Propaganda Dis- } \\
\text { cipline Enforcement } \\
\text { Notice }\end{array}$ & $\begin{array}{l}\text { 关于严肃宣传纪 } \\
\text { 律, 制止违规播 } \\
\text { 出行为的通知 }\end{array}$ & 2004 & SARFT \\
\hline $\begin{array}{l}\text { On-demand Radio and } \\
\text { Television Broadcast Man- } \\
\text { agement Rules }\end{array}$ & $\begin{array}{l}2004 \text { On-demand } \\
\text { Radio and Television } \\
\text { Rules }\end{array}$ & $\begin{array}{l}\text { 广播电视视频点 } \\
\text { 播业务管理办法 }\end{array}$ & 2004 & SARFT \\
\hline $\begin{array}{l}\text { Some Opinions Concerning } \\
\text { Strengthening Radio and } \\
\text { Television Information } \\
\text { Work }\end{array}$ & $\begin{array}{l}2004 \text { Radio and Televi- } \\
\text { sion Information Opin- } \\
\text { ions }\end{array}$ & $\begin{array}{l}\text { 国家广电总局办 } \\
\text { 公厅关于加强广 } \\
\text { 播影视信息工作 } \\
\text { 的若干意见 }\end{array}$ & 2004 & SARFT \\
\hline $\begin{array}{l}\text { Interpretation by the Sup- } \\
\text { reme People's Court and } \\
\text { the Supreme People's Pro- } \\
\text { curatorate on Several Issues } \\
\text { of Concrete Application of } \\
\text { Laws in Handling Criminal } \\
\text { Cases of Infringing Intellec- } \\
\text { tual Property }\end{array}$ & $\begin{array}{l}2004 \text { Judicial Interpre- } \\
\text { tation on Criminal IPR } \\
\text { Infringement }\end{array}$ & $\begin{array}{l}\text { 最高人民法院、 } \\
\text { 最高人民检察院 } \\
\text { 关于办理侵犯知 } \\
\text { 识产权刑事案件 } \\
\text { 具体应用法律若 } \\
\text { 干问题的解释 }\end{array}$ & 2004 & SPC, SPP \\
\hline $\begin{array}{l}\text { Internet and Other Informa- } \\
\text { tion Networks Dissemina- } \\
\text { tion of Audiovisual Products } \\
\text { Management Rules }\end{array}$ & $\begin{array}{l}2004 \text { Internet Audio- } \\
\text { visual Dissemination } \\
\text { Management Rules }\end{array}$ & $\begin{array}{l}\text { 互联网等信息网 } \\
\text { 络传播视听节目 } \\
\text { 管理办法 }\end{array}$ & 2004 & SARFT \\
\hline
\end{tabular}




\begin{tabular}{|c|c|c|c|c|}
\hline $\begin{array}{l}\text { Internet and Other Informa- } \\
\text { tion Networks Audiovisual } \\
\text { Programme Dissemination } \\
\text { Management Rules }\end{array}$ & $\begin{array}{l}2004 \text { Internet Audio- } \\
\text { visual Dissemination } \\
\text { Rules }\end{array}$ & $\begin{array}{l}\text { 互联网等信息网 } \\
\text { 络传播视听节目 } \\
\text { 管理办法 }\end{array}$ & 2004 & SARFT \\
\hline $\begin{array}{l}\text { Provisional Sino-foreign } \\
\text { Joint Venture and Coopera- } \\
\text { tive Radio and Television } \\
\text { Programme Production } \\
\text { Business Enterprise Man- } \\
\text { agement Regulations }\end{array}$ & $\begin{array}{l}2004 \text { Joint Venture } \\
\text { Radio and Television } \\
\text { Production Regulations }\end{array}$ & $\begin{array}{l}\text { 中外合资、合作 } \\
\text { 广播电视节目制 } \\
\text { 作经营企业管理 } \\
\text { 暂行规定 }\end{array}$ & 2004 & $\begin{array}{l}\text { SARFT, MOF- } \\
\text { COM }\end{array}$ \\
\hline $\begin{array}{l}\text { Opinions Concerning } \\
\text { Stimulating Radio and Tele- } \\
\text { vision Industry Develop- } \\
\text { ment }\end{array}$ & $\begin{array}{l}2004 \text { Radio and Televi- } \\
\text { sion Development } \\
\text { Opinions }\end{array}$ & $\begin{array}{l}\text { 国家广播电影电 } \\
\text { 视总局关于促进 } \\
\text { 广播影视产业发 } \\
\text { 展的意见 }\end{array}$ & 2004 & SARFT \\
\hline $\begin{array}{l}\text { Interpretation Concerning } \\
\text { Some Issues Concerning } \\
\text { Applicable Law in Cases } \\
\text { Involving Computer Net- } \\
\text { work Copyright Disputes }\end{array}$ & $\begin{array}{l}2003 \text { Internet Copy- } \\
\text { right Interpretation }\end{array}$ & $\begin{array}{l}\text { 关于审理涉及计 } \\
\text { 算机网络著作权 } \\
\text { 纠纷案件适用法 } \\
\text { 律若干问题的解 } \\
\text { 释 }\end{array}$ & 2003 & SPC \\
\hline $\begin{array}{l}\text { Foreign Satellite Television } \\
\text { Channel Landing Manage- } \\
\text { ment Rules }\end{array}$ & $\begin{array}{l}2003 \text { Foreign Satellite } \\
\text { TV Rules }\end{array}$ & $\begin{array}{l}\text { 境外卫星电视频 } \\
\text { 道落地管理办法 }\end{array}$ & 2003 & SARFT \\
\hline $\begin{array}{l}\text { Internet and Other Informa- } \\
\text { tion Networks Dissemina- } \\
\text { tion of Audiovisual Products } \\
\text { Management Rules }\end{array}$ & $\begin{array}{l}2003 \text { Internet Audio- } \\
\text { visual Dissemination } \\
\text { Management Rules }\end{array}$ & $\begin{array}{l}\text { 互联网等信息网 } \\
\text { 络传播视听节目 } \\
\text { 管理办法 }\end{array}$ & 2003 & SARFT \\
\hline $\begin{array}{l}\text { Copyright Administrative } \\
\text { Punishment Implementation } \\
\text { Rules }\end{array}$ & $\begin{array}{l}2003 \text { Administrative } \\
\text { Punishment Rules }\end{array}$ & $\begin{array}{l}\text { 著作权行政处罚 } \\
\text { 实施办法 }\end{array}$ & 2003 & $\mathrm{NCA}$ \\
\hline $\begin{array}{l}\text { Provisional Foreign Busines- } \\
\text { ses Investing in Cinema } \\
\text { Regulations }\end{array}$ & $\begin{array}{l}2003 \text { Foreign Cinema } \\
\text { Investment Regulations }\end{array}$ & $\begin{array}{l}\text { 外商投资电影院 } \\
\text { 暂行规定 }\end{array}$ & 2003 & $\begin{array}{l}\text { SARFT, MOF- } \\
\text { COM, MoC }\end{array}$ \\
\hline $\begin{array}{l}\text { Provisional Regulations } \\
\text { Concerning Measures for } \\
\text { Radio and Television Broad- } \\
\text { casting Organ Personnel } \\
\text { Breaking Propaganda Disci- } \\
\text { pline }\end{array}$ & $\begin{array}{l}2002 \text { Provisional Per- } \\
\text { sonnel Breaking Disci- } \\
\text { pline Regulations }\end{array}$ & $\begin{array}{l}\text { 广播电视播出机 } \\
\text { 构工作人员违反 } \\
\text { 宣传纪律处分处 } \\
\text { 理暂行规定 }\end{array}$ & 2002 & SARFT \\
\hline $\begin{array}{l}\text { Interpretation Concerning } \\
\text { Several Issues on Applica- } \\
\text { tion of Law in Correctly } \\
\text { Hearing Civil Copyright } \\
\text { Cases }\end{array}$ & $\begin{array}{l}2002 \text { Civil Copyright } \\
\text { Interpretation }\end{array}$ & $\begin{array}{l}\text { 关于审理著作权 } \\
\text { 民事纠纷案件适 } \\
\text { 用法律若干问题 } \\
\text { 的解释 }\end{array}$ & 2002 & SPC \\
\hline $\begin{array}{l}\text { Notice on Preventing and } \\
\text { Attacking Unlawful Audio- } \\
\text { visual Products Pirating } \\
\text { "Hero", Etc. }\end{array}$ & 2002 Hero Notice & $\begin{array}{l}\text { 预防和打击盗版 } \\
\text { 电影《英雄》等 } \\
\text { 违法音像制品的 } \\
\text { 通知 }\end{array}$ & 2002 & MoC \\
\hline $\begin{array}{l}\text { Notice Concerning Cleaning } \\
\text { Up and Reorganizing the } \\
\text { Publications Market Order } \\
\text { Activities, Investigating } \\
\text { Handed Over American } \\
\text { Film DVD's }\end{array}$ & $\begin{array}{l}\text { 200I American Film } \\
\text { Notice }\end{array}$ & $\begin{array}{l}\text { 关于配合清理整 } \\
\text { 顿出版物市场秩 } \\
\text { 序活动, 查缴盗 } \\
\text { 版美国电影DVD } \\
\text { 的通知 }\end{array}$ & 2001 & $\mathrm{NCA}$ \\
\hline $\begin{array}{l}\text { Provisional Cable Television } \\
\text { On-demand Video Broad- } \\
\text { cast Management Rules }\end{array}$ & $\begin{array}{l}\text { 200I On-demand } \\
\text { Broadcasting Rules }\end{array}$ & $\begin{array}{l}\text { 有线电视视频点 } \\
\text { 播管理暂行办法 }\end{array}$ & 2001 & SARFT \\
\hline $\begin{array}{l}\text { Implementation Regulations } \\
\text { Concerning Implementing a }\end{array}$ & $\begin{array}{l}\text { 200I Radio and Televi- } \\
\text { sion Access Regulations }\end{array}$ & 关于实行广播电 & 2001 & SARFT \\
\hline
\end{tabular}




\begin{tabular}{|c|c|c|c|c|}
\hline $\begin{array}{l}\text { Radio and Television Pro- } \\
\text { gramme Production and } \\
\text { Distribution Sector Access } \\
\text { System (Trial) }\end{array}$ & & $\begin{array}{l}\text { 视节目制作、发 } \\
\text { 行行业准入制度 } \\
\text { 的实施细则(试行) }\end{array}$ & & \\
\hline $\begin{array}{l}\text { Copyright Law of the Peo- } \\
\text { ple's Republic of China }\end{array}$ & 200I Copyright Law & $\begin{array}{l}\text { 中华人民共和国 } \\
\text { 著作权法 }\end{array}$ & 2001 & NPC \\
\hline $\begin{array}{l}\text { Film Management Regula- } \\
\text { tions }\end{array}$ & $\begin{array}{l}\text { 200I Film Management } \\
\text { Regulations }\end{array}$ & 电影管理规定 & 2001 & State Council \\
\hline $\begin{array}{l}\text { Notice Concerning Further } \\
\text { Rectification and Standardiz- } \\
\text { ing of the Culture Market } \\
\text { Order }\end{array}$ & $\begin{array}{l}2001 \text { Cultural Market } \\
\text { Rectification Notice }\end{array}$ & $\begin{array}{l}\text { 国务院办公厅关 } \\
\text { 于进一步整顿和 } \\
\text { 规范文化市场秩 } \\
\text { 序的通知 }\end{array}$ & 2001 & State Council \\
\hline $\begin{array}{l}\text { Implementation Rules Con- } \\
\text { cerning Strengthening the } \\
\text { Construction of a Legal } \\
\text { System for Radio, Film and } \\
\text { Television (Trial) }\end{array}$ & $\begin{array}{l}\text { 200I Radio, Film and } \\
\text { Television Legal System } \\
\text { Rules. }\end{array}$ & $\begin{array}{l}\text { 国家广播电影电 } \\
\text { 视总局关于加强 } \\
\text { 广播影视法制建 } \\
\text { 设的实施细则(试 } \\
\text { 行) }\end{array}$ & 2001 & $\begin{array}{l}\text { SARFT, MOF- } \\
\text { COM }\end{array}$ \\
\hline $\begin{array}{l}\text { Provisional Hotels and Res- } \\
\text { taurants On-demand Video } \\
\text { Management Rules }\end{array}$ & $\begin{array}{l}\text { 200I Hotel On- } \\
\text { demand Broadcasting } \\
\text { Rules }\end{array}$ & $\begin{array}{l}\text { 宾馆饭店视频点 } \\
\text { 播管理暂行办法 }\end{array}$ & 2001 & SARFT \\
\hline $\begin{array}{l}\text { Notice Concerning Con- } \\
\text { tinuing to Launch Activities } \\
\text { Attacking Smuggled and } \\
\text { Pirated Films }\end{array}$ & 200I Smuggling Notice & $\begin{array}{l}\text { 文化部、国家广 } \\
\text { 播电影电视总局 } \\
\text { 关于继续开展打 } \\
\text { 击走私和盗版影 } \\
\text { 片活动的通知 }\end{array}$ & 2001 & MoC, SARFT \\
\hline $\begin{array}{l}\text { Audiovisual Products Man- } \\
\text { agement Regulations }\end{array}$ & $\begin{array}{l}\text { 200I Audiovisual Pro- } \\
\text { duct Regulations }\end{array}$ & $\begin{array}{l}\text { 音像制品管理条 } \\
\text { 例 }\end{array}$ & 2001 & State Council \\
\hline $\begin{array}{l}\text { Film Management Regula- } \\
\text { tions }\end{array}$ & $\begin{array}{l}\text { 200I Film Management } \\
\text { Regulations }\end{array}$ & 电影管理条例 & 2001 & State Council \\
\hline $\begin{array}{l}\text { Implementation Rules Con- } \\
\text { cerning the Radio, Film and } \\
\text { Television "Matching Out } \\
\text { Project" (Trial) }\end{array}$ & $\begin{array}{l}2001 \text { Marching Out } \\
\text { Rules }\end{array}$ & $\begin{array}{l}\text { 国家广播电影电 } \\
\text { 视总局关于广播 } \\
\text { 影视“走出去工程” } \\
\text { 的实施细则（试 } \\
\text { 行） }\end{array}$ & 2001 & SARFT \\
\hline $\begin{array}{l}\text { Some Opinions Concerning } \\
\text { Further Deepening Film } \\
\text { Sector Reform }\end{array}$ & $\begin{array}{l}2000 \text { Film Reform } \\
\text { Opinions }\end{array}$ & $\begin{array}{l}\text { 关于进一步深化 } \\
\text { 电影业改革的若 } \\
\text { 干意见 }\end{array}$ & 2000 & SARFT, MoC \\
\hline $\begin{array}{l}\text { Notice Concerning Further } \\
\text { Strengthening Television } \\
\text { Drama Import, Co- } \\
\text { Production and Broadcast } \\
\text { Management }\end{array}$ & $\begin{array}{l}2000 \text { Television Drama } \\
\text { Notice }\end{array}$ & $\begin{array}{l}\text { 关于进一步加强 } \\
\text { 电视剧引进、合 } \\
\text { 拍和播放管理的 } \\
\text { 通知 }\end{array}$ & 2000 & SARFT \\
\hline $\begin{array}{l}\text { Provisional Foreign Busines- } \\
\text { ses Investing in Cinema } \\
\text { Regulations }\end{array}$ & $\begin{array}{l}2000 \text { Foreign Cinema } \\
\text { Investment Regulations }\end{array}$ & $\begin{array}{l}\text { 外商投资电影院 } \\
\text { 暂行规定 }\end{array}$ & 2000 & $\begin{array}{l}\text { SARFT, MOF- } \\
\text { COM, MoC }\end{array}$ \\
\hline $\begin{array}{l}\text { Television Drama Manage- } \\
\text { ment Regulations }\end{array}$ & $\begin{array}{l}2000 \text { Television Drama } \\
\text { Regulations }\end{array}$ & 电视剧管理规定 & 2000 & SARFT \\
\hline $\begin{array}{l}\text { Interpretation Concerning } \\
\text { Some Issues Concerning } \\
\text { Applicable Law in Cases } \\
\text { Involving Computer Net- } \\
\text { work Copyright Disputes }\end{array}$ & $\begin{array}{l}2000 \text { Internet Copy- } \\
\text { right Interpretation }\end{array}$ & $\begin{array}{l}\text { 关于审理涉及计 } \\
\text { 算机网络著作权 } \\
\text { 纠纷案件适用法 } \\
\text { 律若干问题的解 } \\
\text { 释 }\end{array}$ & 2000 & SPC \\
\hline $\begin{array}{l}\text { Decision Concerning Safe- } \\
\text { guarding Internet Safety }\end{array}$ & $\begin{array}{l}2000 \text { Internet Safety } \\
\text { Decision }\end{array}$ & $\begin{array}{l}\text { 关于维护互联网 } \\
\text { 安全的决定 }\end{array}$ & 2000 & NPC \\
\hline Provisional Television & 1999 Television Drama & 电视剧审查暂行 & 1999 & SARFT \\
\hline
\end{tabular}




\begin{tabular}{|c|c|c|c|c|}
\hline $\begin{array}{l}\text { Drama Examination Regula- } \\
\text { tions }\end{array}$ & $\begin{array}{l}\text { Examination Regula- } \\
\text { tions }\end{array}$ & 规定 & & \\
\hline $\begin{array}{l}\text { Notice Concerning Audio- } \\
\text { visual Product Import Work } \\
\text { Unit Qualification Accredi- } \\
\text { tation }\end{array}$ & $\begin{array}{l}1999 \text { Import Qualifica- } \\
\text { tion Notice }\end{array}$ & $\begin{array}{l}\text { 文化部关于音像 } \\
\text { 制品进口单位资 } \\
\text { 格认定的通告 ( } \\
\text { 一) }\end{array}$ & 1999 & MoC \\
\hline $\begin{array}{l}\text { Notice Concerning Launch- } \\
\text { ing Activities Attacking Film } \\
\text { Smuggling }\end{array}$ & 1999 Smuggling Notice & $\begin{array}{l}\text { 文化部、广播电 } \\
\text { 影电视总局关于 } \\
\text { 开展打击走私影 } \\
\text { 片活动的通知 }\end{array}$ & 1999 & MoC, SARFT \\
\hline $\begin{array}{l}\text { Notice Concerning Approv- } \\
\text { ing and Issuing the "Radio } \\
\text { and Television Programme } \\
\text { Production Permit" and the } \\
\text { "Television Drama Produc- } \\
\text { tion Permit" }\end{array}$ & $\begin{array}{l}1998 \text { Radio and Televi- } \\
\text { sion Permit Notice }\end{array}$ & $\begin{array}{l}\text { 关于核发《广播 } \\
\text { 电视节目制作经 } \\
\text { 营许可证》和《 } \\
\text { 电视剧制作许可 } \\
\text { 证》的通知 }\end{array}$ & 1998 & SARFT \\
\hline $\begin{array}{l}\text { Notice Concerning Imple- } \\
\text { menting of a Domestic } \\
\text { Television Drama Distribu- } \\
\text { tion Permit System }\end{array}$ & $\begin{array}{l}1998 \text { Television Drama } \\
\text { Distribution Permit } \\
\text { Notice }\end{array}$ & $\begin{array}{l}\text { 关于实行国产电 } \\
\text { 视剧发行许可证 } \\
\text { 制度的通知 }\end{array}$ & 1998 & SARFT \\
\hline $\begin{array}{l}\text { Supreme People's Court } \\
\text { Interpretation of Some } \\
\text { Questions Concerning the } \\
\text { Concretely Applicable Law } \\
\text { in Hearing Criminal Cases } \\
\text { Involving Illegal Publications }\end{array}$ & $\begin{array}{l}1998 \text { Illegal Publications } \\
\text { Interpretation }\end{array}$ & $\begin{array}{l}\text { 最高人民法院关 } \\
\text { 于审理非法出版 } \\
\text { 物刑事案件具体 } \\
\text { 应用法律若干问 } \\
\text { 题的解释 }\end{array}$ & 1998 & SPC, SPP \\
\hline $\begin{array}{l}\text { Criminal Law of the Peo- } \\
\text { ple's Republic of China }\end{array}$ & 1997 Criminal Law & $\begin{array}{l}\text { 中华人民共和国 } \\
\text { 刑法 }\end{array}$ & 1997 & NPC \\
\hline $\begin{array}{l}\text { Film Examination Regula- } \\
\text { tions }\end{array}$ & $\begin{array}{l}\text { I } 997 \text { Film Examination } \\
\text { Regulations }\end{array}$ & 电影审查规定 & 1997 & MRFT \\
\hline $\begin{array}{l}\text { Notice Concerning Radio } \\
\text { and Television Programme } \\
\text { Production Business Work } \\
\text { Unit Re-examination and } \\
\text { Registration }\end{array}$ & $\begin{array}{l}1997 \text { Radio and Televi- } \\
\text { sion Re-registration } \\
\text { Notice }\end{array}$ & $\begin{array}{l}\text { 关于对广播电视 } \\
\text { 节目制作经营单 } \\
\text { 位重新审核登记 } \\
\text { 的通知 }\end{array}$ & 1997 & MRFT \\
\hline $\begin{array}{l}\text { Radio and Television Man- } \\
\text { agement Regulations }\end{array}$ & $\begin{array}{l}1997 \text { Radio and Televi- } \\
\text { sion Regulations }\end{array}$ & $\begin{array}{l}\text { 广播电视管理条 } \\
\text { 例 }\end{array}$ & 1997 & State Council \\
\hline $\begin{array}{l}\text { Notice Concerning Relevant } \\
\text { Regulations for Establishing } \\
\text { a Special Fund Supporting } \\
\text { the "9550" Excellent Film } \\
\text { Product Project. }\end{array}$ & $\begin{array}{l}\text { 1996 Film Production } \\
\text { Fund Notice }\end{array}$ & $\begin{array}{l}\text { 关于设立支持电 } \\
\text { 影精品“九五五 } 0 ” \\
\text { 工程专项资金有 } \\
\text { 关规定的通知 }\end{array}$ & 1996 & $\begin{array}{l}\text { MRFT, Ministry } \\
\text { of Finance }\end{array}$ \\
\hline $\begin{array}{l}\text { Notice Concerning } \\
\text { Strengthening Press and } \\
\text { Publications, and Radio and } \\
\text { Television Sector Manage- } \\
\text { ment }\end{array}$ & $\begin{array}{l}\text { 1996 Strengthening } \\
\text { Press and Publications } \\
\text { Management Notice }\end{array}$ & $\begin{array}{l}\text { 关于加强新闻出 } \\
\text { 版广播电视业管 } \\
\text { 理的通知 }\end{array}$ & 1996 & $\begin{array}{l}\text { Central Committee, } \\
\text { State Council }\end{array}$ \\
\hline $\begin{array}{l}\text { Film Management Regula- } \\
\text { tions }\end{array}$ & $\begin{array}{l}\text { 1996 Film Management } \\
\text { Regulations }\end{array}$ & 电影管理条例 & 1996 & State Council \\
\hline $\begin{array}{l}\text { Notice Concerning Sticking } \\
\text { a Uniform Anti-Counterfeit } \\
\text { Symbol on Audiovisual Pro- } \\
\text { ducts }\end{array}$ & $\begin{array}{l}1996 \text { Anti-Counterfeit } \\
\text { Symbol Notice }\end{array}$ & $\begin{array}{l}\text { 关于音像制品加 } \\
\text { 贴统一防伪标识 } \\
\text { 的通知 }\end{array}$ & 1996 & MoC \\
\hline $\begin{array}{l}\text { Regulations Concerning } \\
\text { Reforming Feature Film } \\
\text { Shooting Management } \\
\text { Work }\end{array}$ & $\begin{array}{l}1995 \text { Film Shooting } \\
\text { Regulations }\end{array}$ & $\begin{array}{l}\text { 关于改革故事影 } \\
\text { 片摄制管理工作 } \\
\text { 的规定 }\end{array}$ & 1995 & MRFT \\
\hline
\end{tabular}




\begin{tabular}{|c|c|c|c|c|c|}
\hline $\begin{array}{l}\text { Regulations Concerning } \\
\text { Implementing Film Distribu- } \\
\text { tion and Screening Permits } \\
\text { and Annual Examination } \\
\text { Systems }\end{array}$ & $\begin{array}{l}1995 \text { Film Distribution } \\
\text { and Screening Regula- } \\
\text { tions }\end{array}$ & $\begin{array}{l}\text { 关于实行电影发 } \\
\text { 行放映许可证及 } \\
\text { 年检制度的规定 }\end{array}$ & 1995 & MRFT & \\
\hline $\begin{array}{l}\text { Sino-foreign Television } \\
\text { Drama (Video) Co- } \\
\text { Production Management } \\
\text { Regulations }\end{array}$ & $\begin{array}{l}1995 \text { Television Drama } \\
\text { Co-Production Rules }\end{array}$ & $\begin{array}{l}\text { 中外合作制作电 } \\
\text { 视剧（录像片） } \\
\text { 管理规定 }\end{array}$ & 1995 & MRFT & \\
\hline $\begin{array}{l}\text { Audiovisual Products Man- } \\
\text { agement Regulations }\end{array}$ & $\begin{array}{l}\text { I994 Audiovisual Pro- } \\
\text { duct Regulations }\end{array}$ & $\begin{array}{l}\text { 音像制品管理条 } \\
\text { 例 }\end{array}$ & 1994 & State Council & \\
\hline $\begin{array}{l}\text { Notice Concerning } \\
\text { Strengthening and Improv- } \\
\text { ing the Newspaper and Pe- } \\
\text { riodicals, Film and Televi- } \\
\text { sion and Audiovisual Market }\end{array}$ & $\begin{array}{l}1994 \text { Market Improve- } \\
\text { ment Notice }\end{array}$ & $\begin{array}{l}\text { 关于加强和改进 } \\
\text { 书报刊影视音像 } \\
\text { 市场管理的通知 }\end{array}$ & 1994 & $\begin{array}{l}\text { Central Committee } \\
\text { State Council }\end{array}$ & \\
\hline $\begin{array}{l}\text { Provisional Rules on } \\
\text { Strengthening Television } \\
\text { Drama Theme Planning } \\
\text { Management } \\
\end{array}$ & $\begin{array}{l}\text { I994 Provisional Tele- } \\
\text { vision Drama Theme } \\
\text { Rules }\end{array}$ & $\begin{array}{l}\text { 加强电视剧题材 } \\
\text { 规划管理的暂行 } \\
\text { 办法 }\end{array}$ & 1994 & MRFT & \\
\hline $\begin{array}{l}\text { Decision on the Punishment } \\
\text { of the Crime of Copyright } \\
\text { Infringement }\end{array}$ & $\begin{array}{l}1994 \text { Copyright Crimi- } \\
\text { nal Punishment Deci- } \\
\text { sion }\end{array}$ & $\begin{array}{l}\text { 全国人民代表大 } \\
\text { 会常务委员会关 } \\
\text { 于惩治侵犯著作 } \\
\text { 权的犯罪的决定 }\end{array}$ & 1994 & NPC & \\
\hline $\begin{array}{l}\text { Management Regulations for } \\
\text { Import and Broadcast of } \\
\text { Foreign Television Pro- } \\
\text { grammes }\end{array}$ & $\begin{array}{l}\text { 1994 Foreign Television } \\
\text { Programme Regulations }\end{array}$ & $\begin{array}{l}\text { 引进、播出境外 } \\
\text { 电视节目的管理 } \\
\text { 规定 }\end{array}$ & 1994 & MRFT & \\
\hline $\begin{array}{l}\text { Management Regulations for } \\
\text { Import and Broadcast of } \\
\text { Foreign Television Pro- } \\
\text { grammes }\end{array}$ & $\begin{array}{l}\text { 1994 Television Drama } \\
\text { Import and Broadcast } \\
\text { Regulations, }\end{array}$ & $\begin{array}{l}\text { 引进、播出境外 } \\
\text { 电视节目的管理 } \\
\text { 规定 }\end{array}$ & 1994 & MRFT & \\
\hline $\begin{array}{l}\text { Provisional Film Examin- } \\
\text { ation Regulations }\end{array}$ & $\begin{array}{l}\text { I993 Film Examination } \\
\text { Regulations }\end{array}$ & $\begin{array}{l}\text { 电影审查暂行规 } \\
\text { 定 }\end{array}$ & 1993 & MRFT & \\
\hline $\begin{array}{l}\text { Regulations Implementing } \\
\text { the International Copyright } \\
\text { Treaties }\end{array}$ & $\begin{array}{l}1992 \text { Copyright Treaty } \\
\text { Implementation Regula- } \\
\text { tions }\end{array}$ & $\begin{array}{l}\text { 实施国际著作权 } \\
\text { 条约的规定 }\end{array}$ & 1992 & State Council & \\
\hline $\begin{array}{l}\text { Notice Concerning Com- } \\
\text { pression and Rectification of } \\
\text { Audiovisual Work Units }\end{array}$ & $\begin{array}{l}1992 \text { Audiovisual } \\
\text { Compression and Rec- } \\
\text { tification Notice }\end{array}$ & $\begin{array}{l}\text { 关于压缩整顿音 } \\
\text { 像单位的通知 }\end{array}$ & 1992 & $\begin{array}{l}\text { Central Committee } \\
\text { State Councill }\end{array}$ & \\
\hline $\begin{array}{l}\text { Civil Procedure Law of the } \\
\text { People's Republic of China }\end{array}$ & $\begin{array}{l}\text { 199I Civil Procedure } \\
\text { Law }\end{array}$ & $\begin{array}{l}\text { 中华人民共和国 } \\
\text { 民事诉讼法 }\end{array}$ & I99I & NPC & $*$ \\
\hline $\begin{array}{l}\text { Regulations for the Imple- } \\
\text { mentation of the Copyright } \\
\text { Law of the People's Repub- } \\
\text { lic of China }\end{array}$ & $\begin{array}{l}\text { 1991 Copyright Law } \\
\text { Implementation Regula- } \\
\text { tions }\end{array}$ & $\begin{array}{l}\text { 中华人民共和国 } \\
\text { 著作权法实施条 } \\
\text { 例 }\end{array}$ & I991 & State Council & \\
\hline $\begin{array}{l}\text { Notice Concerning Prob- } \\
\text { lems with Production Per- } \\
\text { mit Application for Shooting } \\
\text { Major Revolutionary and } \\
\text { History-Themed Television } \\
\text { Dramas }\end{array}$ & $\begin{array}{l}1990 \text { Revolution and } \\
\text { History-Themed Tele- } \\
\text { vision Drama Notice }\end{array}$ & $\begin{array}{l}\text { 广播电影电视部 } \\
\text { 关于拍摄重大革 } \\
\text { 命历史题材电视 } \\
\text { 剧申领制作许可 } \\
\text { 证问题的通知 }\end{array}$ & 1990 & MRFT & \\
\hline $\begin{array}{l}\text { Supplementary Regulations } \\
\text { Concerning the Implemen- } \\
\text { tation of a Television Drama } \\
\text { Production Permit System }\end{array}$ & $\begin{array}{l}1990 \text { Television Drama } \\
\text { Production Permit } \\
\text { Supplementary Regula- } \\
\text { tions }\end{array}$ & $\begin{array}{l}\text { 关于实行电视剧 } \\
\text { 制作许可证制度 } \\
\text { 的规定的补充规 } \\
\text { 定 }\end{array}$ & 1990 & MRFT & \\
\hline Provisional Regulations & 1990 Provisional Manu- & 书籍稿酬暂行规 & 1990 & NCA & \\
\hline
\end{tabular}




\begin{tabular}{|c|c|c|c|c|}
\hline $\begin{array}{l}\text { Governing Remuneration } \\
\text { for Book Manuscripts }\end{array}$ & $\begin{array}{l}\text { script Remuneration } \\
\text { Regulations }\end{array}$ & 定 & & \\
\hline $\begin{array}{l}\text { Provisional Regulations } \\
\text { Concerning Import of For- } \\
\text { eign Television Programme } \\
\text { Management }\end{array}$ & $\begin{array}{l}1990 \text { Foreign Television } \\
\text { Drama Import Regula- } \\
\text { tions }\end{array}$ & $\begin{array}{l}\text { 广播电影电视部 } \\
\text { 关于引进海外电 } \\
\text { 视节目管理的暂 } \\
\text { 行规定 }\end{array}$ & 1990 & MRFT \\
\hline $\begin{array}{l}\text { Decision on the Punishment } \\
\text { of Criminal Smuggling, Pro- } \\
\text { duction, Sale or Dissemina- } \\
\text { tion of Obscene Goods }\end{array}$ & $\begin{array}{l}1990 \text { Obscene Goods } \\
\text { Punishing Decision }\end{array}$ & $\begin{array}{l}\text { 全国人民代表大 } \\
\text { 会常务委员会关 } \\
\text { 于惩治走私、制 } \\
\text { 作、贩卖、传播 } \\
\text { 淫秽物品的犯罪 } \\
\text { 分子的决定 }\end{array}$ & 1990 & NPC \\
\hline $\begin{array}{l}\text { Notice Concerning Prob- } \\
\text { lems with Production Per- } \\
\text { mit Application for Shooting } \\
\text { Major Revolutionary and } \\
\text { History-Themed Television } \\
\text { Dramas }\end{array}$ & $\begin{array}{l}1990 \text { Revolutionary and } \\
\text { History Drama Notice }\end{array}$ & $\begin{array}{l}\text { 广播电影电视部 } \\
\text { 关于拍摄重大革 } \\
\text { 命历史题材电视 } \\
\text { 剧申领制作许可 } \\
\text { 证问题的通知 }\end{array}$ & 1990 & MRFT \\
\hline $\begin{array}{l}\text { Examination Standards } \\
\text { Concerning Imported For- } \\
\text { eign Television Dramas }\end{array}$ & $\begin{array}{l}1990 \text { Foreign Television } \\
\text { Drama Import Stand- } \\
\text { ards }\end{array}$ & $\begin{array}{l}\text { 广播电影电视部 } \\
\text { 关于引进海外电 } \\
\text { 视剧的审查标准 }\end{array}$ & 1990 & MRFT \\
\hline $\begin{array}{l}\text { Copyright Law of the Peo- } \\
\text { ple's Republic of China }\end{array}$ & 1990 Copyright Law & $\begin{array}{l}\text { 中华人民共和国 } \\
\text { 著作权法 }\end{array}$ & 1990 & NPC \\
\hline $\begin{array}{l}\text { Notice Concerning Estab- } \\
\text { lishment of an Examination } \\
\text { and Projection Classification } \\
\text { System for a Number of } \\
\text { Films }\end{array}$ & $\begin{array}{l}1989 \text { Film Classification } \\
\text { Notice }\end{array}$ & $\begin{array}{l}\text { 广播电影电视部 } \\
\text { 关于对部分影片 } \\
\text { 实行审查、放映 } \\
\text { 分级制度的通知 }\end{array}$ & 1989 & MRFT \\
\hline $\begin{array}{l}\text { China Film Distribution and } \\
\text { Projection Company Man- } \\
\text { agement Rules Concerning } \\
\text { Projecting Films "Not Suit- } \\
\text { able for Children" }\end{array}$ & $\begin{array}{l}\text { I } 989 \text { Unsuitable for } \\
\text { Children Rules }\end{array}$ & $\begin{array}{l}\text { 中国电影发行放 } \\
\text { 映公司关于放映“ } \\
\text { 少儿不宜”影片的 } \\
\text { 管理办法 }\end{array}$ & 1989 & $\begin{array}{l}\text { China Film Com- } \\
\text { pany }\end{array}$ \\
\hline $\begin{array}{l}\text { Notice Concerning that the } \\
\text { "Trial Regulations on Books } \\
\text { and Periodicals Copyright } \\
\text { Protection" May Not Be } \\
\text { Openly Published }\end{array}$ & $\begin{array}{l}1987 \text { Notice Concern- } \\
\text { ing Copyright Regula- } \\
\text { tions }\end{array}$ & $\begin{array}{l}\text { 关于不得公开发 } \\
\text { 表《图书期刊版 } \\
\text { 权保护试行条例 } \\
》\end{array}$ & 1987 & $\mathrm{NCA}$ \\
\hline $\begin{array}{l}\text { Notice Concerning Severely } \\
\text { Attacking Illegal Publication } \\
\text { Activities }\end{array}$ & $\begin{array}{l}\text { I987 Illegal Publications } \\
\text { Notice }\end{array}$ & $\begin{array}{l}\text { 国务院关于严厉 } \\
\text { 打击非法出版活 } \\
\text { 动的通知 }\end{array}$ & 1987 & State Council \\
\hline $\begin{array}{l}\text { Provisional Management } \\
\text { Rules for Distribution of } \\
\text { Film Videotapes Published } \\
\text { by the China Distribution } \\
\text { and Screening Company }\end{array}$ & $\begin{array}{l}1986 \text { Provisional Film } \\
\text { Videotapes Distribution } \\
\text { Management Rules }\end{array}$ & $\begin{array}{l}\text { 中国电影发行放 } \\
\text { 映公司出版的电 } \\
\text { 影录像带发行管 } \\
\text { 理暂行办法 }\end{array}$ & 1986 & MRFT \\
\hline $\begin{array}{l}\text { General Principles of the } \\
\text { Civil Law of the People's } \\
\text { Republic of China }\end{array}$ & $\begin{array}{l}1986 \text { General Principles } \\
\text { of the Civil Law }\end{array}$ & $\begin{array}{l}\text { 中华人民共和国 } \\
\text { 民法通则 }\end{array}$ & 1986 & NPC \\
\hline $\begin{array}{l}\text { Provisional Audio and Video } \\
\text { Publishing Work Regula- } \\
\text { tions }\end{array}$ & $\begin{array}{l}\text { 1986 Provisional Audio } \\
\text { and Video Publishing } \\
\text { Work Regulations }\end{array}$ & $\begin{array}{l}\text { 录音录像出版工 } \\
\text { 作暂行条例 }\end{array}$ & 1986 & MRFT \\
\hline $\begin{array}{l}\text { Notice Concerning Improv- } \\
\text { ing Culture and Art Pro- } \\
\text { gramme Video Tape Supply } \\
\text { and Strengthening Video } \\
\text { Screening Management }\end{array}$ & $\begin{array}{l}\text { I986 Video Tape Sup- } \\
\text { ply Notice }\end{array}$ & $\begin{array}{l}\text { 关于改进文艺节 } \\
\text { 目录像带供应并 } \\
\text { 加强录像放映管 } \\
\text { 理的通知 }\end{array}$ & 1986 & MRFT \\
\hline
\end{tabular}




\begin{tabular}{|c|c|c|c|c|c|}
\hline $\begin{array}{l}\text { Temporary Regulations on } \\
\text { Copyright Protection of } \\
\text { Audio and Video Publica- } \\
\text { tions }\end{array}$ & $\begin{array}{l}\text { 1986 Temporary } \\
\text { Audiovisual Copyright } \\
\text { Regulations }\end{array}$ & $\begin{array}{l}\text { 录音录像出版物 } \\
\text { 版权保护暂行条 } \\
\text { 例 }\end{array}$ & 1986 & $\begin{array}{l}\text { MRFT, MOF- } \\
\text { COM, SAIC }\end{array}$ & \\
\hline $\begin{array}{l}\text { Notice Concerning Ques- } \\
\text { tions regarding Shooting } \\
\text { Films or Television Dramas } \\
\text { with Public Security Themes }\end{array}$ & $\begin{array}{l}\text { I } 986 \text { Public Security } \\
\text { Film Questions }\end{array}$ & $\begin{array}{l}\text { 公安部关于拍摄 } \\
\text { 公安题材的电影 } \\
\text { 、电视剧问题的 } \\
\text { 通知 }\end{array}$ & 1986 & PSB & \\
\hline $\begin{array}{l}\text { Ministry of Radio, Film and } \\
\text { Television, Ministry of } \\
\text { Commerce, State Adminis- } \\
\text { tration for Industry and } \\
\text { Commerce Notice Con- } \\
\text { cerning Rectification of the } \\
\text { Audio and Video Products } \\
\text { Market and Stopping Pirate } \\
\text { Recording Activities }\end{array}$ & $\begin{array}{l}1986 \text { Audiovisual Recti- } \\
\text { fication Notice }\end{array}$ & $\begin{array}{l}\text { 广播电影电视部 } \\
\text { 、商业部、国家 } \\
\text { 工商行政管理局 } \\
\text { 关于整顿录音录 } \\
\text { 像制品的市场制 } \\
\text { 止违章翻录销售 } \\
\text { 活动的通知 }\end{array}$ & 1986 & $\begin{array}{l}\text { MRFT, MOF- } \\
\text { COM, SAIC }\end{array}$ & \\
\hline $\begin{array}{l}\text { Notice Concerning Prohibi- } \\
\text { tion of Commercial Video } \\
\text { Screening and Strengthening } \\
\text { Video Management }\end{array}$ & $\begin{array}{l}1985 \text { Commercial } \\
\text { Video Notice }\end{array}$ & $\begin{array}{l}\text { 关于禁止营业性 } \\
\text { 录像放映和加强 } \\
\text { 录像管理的通知 }\end{array}$ & 1985 & $\begin{array}{l}\text { Central Committee } \\
\text { State Council }\end{array}$ & \\
\hline $\begin{array}{l}\text { Regulations Concerning } \\
\text { Prohibiting Obscene Goods }\end{array}$ & $\begin{array}{l}\text { 1985 Obscene Goods } \\
\text { Prohibition Regulations }\end{array}$ & $\begin{array}{l}\text { 国务院关于严禁 } \\
\text { 淫秽物品的规定 }\end{array}$ & 1985 & State Council & \\
\hline $\begin{array}{l}\text { Implementing Rules of the } \\
\text { Trial Regulations on Copy- } \\
\text { right Protection of Books } \\
\text { and Periodicals] }\end{array}$ & $\begin{array}{l}\text { 1984 Copyright Regula- } \\
\text { tion Implementation } \\
\text { Rules }\end{array}$ & $\begin{array}{l}\text { 图书、期刊版权 } \\
\text { 保护试行条件实 } \\
\text { 施细则 }\end{array}$ & 1985 & MOC & \\
\hline $\begin{array}{l}\text { Provisional Film Videotape } \\
\text { Distribution Management } \\
\text { Rules }\end{array}$ & $\begin{array}{l}\text { I } 985 \text { Film Videotape } \\
\text { Distribution Rules }\end{array}$ & $\begin{array}{l}\text { 影片录像带发行 } \\
\text { 管理暂行办法 }\end{array}$ & 1985 & MoC & \\
\hline $\begin{array}{l}\text { Report Concerning Issues } \\
\text { on Foreign and Hong Kong } \\
\text { and Taiwan Music Audio } \\
\text { Products Import and Publi- } \\
\text { cation }\end{array}$ & $\begin{array}{l}1984 \text { Hong Kong and } \\
\text { Taiwan Import Report }\end{array}$ & $\begin{array}{l}\text { 关于外国及港台 } \\
\text { 音乐录音制品进 } \\
\text { 口和出版问题的 } \\
\text { 报告 }\end{array}$ & 1984 & MRT & \\
\hline $\begin{array}{l}\text { Trial Regulations on Copy- } \\
\text { right Protection of Books } \\
\text { and Periodicals }\end{array}$ & $\begin{array}{l}\text { I } 984 \text { Trial Copyright } \\
\text { Regulations }\end{array}$ & $\begin{array}{l}\text { 图书、期刊版权 } \\
\text { 保护实行条例 }\end{array}$ & 1984 & MOC & \\
\hline $\begin{array}{l}\text { Regulations on Strict Prohi- } \\
\text { bition of Import, Duplica- } \\
\text { tion, Sale and Broadcast of } \\
\text { Reactionary, Pornographic } \\
\text { and Obscene Audio and } \\
\text { Video Products }\end{array}$ & $\begin{array}{l}\text { I982 Audiovisual Pro- } \\
\text { duct Regulations }\end{array}$ & $\begin{array}{l}\text { 关于严禁进口、 } \\
\text { 复制、销售、播 } \\
\text { 放反动黄色下流 } \\
\text { 录音录像制品的 } \\
\text { 规定 }\end{array}$ & 1982 & $\begin{array}{l}\text { Central Committee } \\
\text { State Councill }\end{array}$ & \\
\hline $\begin{array}{l}\text { Report of the Third Plenum } \\
\text { of the II th Party Congress } \\
\text { of the CCP }\end{array}$ & $\begin{array}{l}\text { I } 978 \text { Party Congress } \\
\text { Report }\end{array}$ & $\begin{array}{l}\text { 中国共产党第十 } \\
\text { 一届中央委员会 } \\
\text { 第三次全体会议 } \\
\text { 公报 }\end{array}$ & 1978 & $\mathrm{CCP}$ & $*$ \\
\hline $\begin{array}{l}\text { Decision Concerning Deal- } \\
\text { ing with Illegal Books and } \\
\text { Magazines }\end{array}$ & $\begin{array}{l}\text { I955 Illegal Books and } \\
\text { Magazines Decision }\end{array}$ & $\begin{array}{l}\text { 关于处理违法的 } \\
\text { 图书杂志的决定 }\end{array}$ & 1955 & NPC & \\
\hline $\begin{array}{l}\text { Common Programme of the } \\
\text { Chinese People's Political } \\
\text { Consultative Conference }\end{array}$ & $\begin{array}{l}1949 \text { CPPCC Common } \\
\text { Programme }\end{array}$ & $\begin{array}{l}\text { 中国人民政治协 } \\
\text { 商会议共同纲领 }\end{array}$ & 1949 & CPPCC & \\
\hline $\begin{array}{l}\text { Film Examination Law of the } \\
\text { Republic of China }\end{array}$ & $\begin{array}{l}\text { I930 Film Examination } \\
\text { Law }\end{array}$ & $\begin{array}{l}\text { 中华民国电影审 } \\
\text { 查法 }\end{array}$ & 1930 & $\begin{array}{l}\text { Republican Gov- } \\
\text { ernment }\end{array}$ & \\
\hline $\begin{array}{l}\text { Copyright Law of the Re- } \\
\text { public of China }\end{array}$ & $\begin{array}{l}1928 \text { Republican Copy- } \\
\text { right Law }\end{array}$ & 中华民国著作权 & 1928 & $\begin{array}{l}\text { Republican Gov- } \\
\text { ernment }\end{array}$ & * \\
\hline
\end{tabular}




\begin{tabular}{|l|l|l|l|l|l|}
\hline & & 法 & & & \\
\hline $\begin{array}{l}\text { Beiyang Government Copy- } \\
\text { right Law }\end{array}$ & $\begin{array}{l}\text { I915 Beiyang Copyright } \\
\text { Law }\end{array}$ & $\begin{array}{l}\text { 北洋政府著作权 } \\
\text { 法 }\end{array}$ & 1915 & $\begin{array}{l}\text { Beiyang Gov- } \\
\text { ernment }\end{array}$ & $*$ \\
\hline Great Qing Copyright Code & $\begin{array}{l}\text { 1910 Qing Copyright } \\
\text { Code }\end{array}$ & 大清著作权律 & 1910 & $\begin{array}{l}\text { Qing Gov- } \\
\text { ernment }\end{array}$ & $*$ \\
\hline
\end{tabular}




\section{Nederlandstalige samenvatting: Een verklaring voor audiovisuele mediapiraterij in China: mediacontrole, afdwinging en globalisering}

\section{Inleiding}

Audiovisuele mediapiraterij in China is reeds lange tijd een doorn in het oog van buitenlandse mediabedrijven, die zichzelf geconfronteerd zien met grote verliezen in de potentieel lucratieve Chinese markt. Ook Chinese mediabedrijven lijden erg onder piraterij, en slagen er vaak niet in winstgevend en succesvol te worden. Vanaf het midden van de jaren ' 80 , werd de bescherming van auteursrechten een hoge prioriteit, en - onder andere door druk van de Verenigde Staten, creëerde China stapsgewijs een structuur met wetgeving, administratieve, criminele en civiele afdwingingsorganen, met als doel de bescherming van auteursrechten en het stimuleren van de binnenlandse creatieve industrie.

We moeten echter vaststellen dat mediapiraterij tot op dit moment een grote impact blijft hebben op de audiovisuele mediamarkt, en dat China er niet in is geslaagd het terug te dringen tot beheersbare proporties, ofschoon de vele acties die de voorbije decennia zijn ondernomen. Dit proefschrift probeert te begrijpen waarom dit het geval is, en wat de invloed is van het WTO-lidmaatschap, dat China in 200 I verwierf. In het bijzonder wil dit proefschrift zich richten op de rol van de staat in het veroorzaken en in stand houden van piraterij in China. Het auteursrecht is immers een zeer contextafhankelijk juridisch fenomeen. In zijn huidige internationale vorm, veronderstelt het een vrije markt die in principe gebaseerd is op private actoren, waarin de staat een scheidsrechterlijke rol speelt, en in principe toegang tot die markt vrij is. In China zijn deze omstandigheden echter anders. De Partijstaat heeft een zeer groot belang bij het beheersen van het publieke discours. Het valt te verwachten dat dit dus een impact zal hebben op de mediamarkt, en de manier waarop het economische mechanisme vervat in auteursrecht, zal werken.

Dit proefschrift baseert de diagnose van piraterij op een functionele verklaring, waarbij wordt aangenomen dat piraterij gebeurt wanneer consumenten en producenten menen dat dit in hun belang is. Deze belangen kunnen verschillende vormen hebben. Voor consumenten gaat het vooral over toegang tot werken, alsook prijs, kwaliteit en keuzegrootte. Voor commerciële piraten gaat het vooral over het verwerven van inkomen en het ongestraft verder kunnen werken, terwijl voor internetpiraterij, het aanbieden van werken vaak een voorwaarde is voor het mogen downloaden van andere werken. Natuurlijk wordt dit sterk beïnvloed door de omgeving. Als legale producten duur of slecht van kwaliteit zijn, zal er meer ruimte ontstaan voor piraterij. Hetzelfde geldt voor een kleiner productgamma. Deze omstandigheden worden beïnvloed door twee andere partijen: rechthebbenden en de staat. Commerciële rechthebbenden willen in principe inkomen verwerven, terwijl de staat politieke belangen heeft: het beheersen van het publieke discours, omwille van morele redenen, maar vaak ook om het beperken van kritiek en oppositie. Dit proefschrift zal dus proberen te achterhalen welk belang de Chinese Partijstaat heeft bij het controleren van media, hoe dat gebeurt en wat de gevolgen hiervan zijn op het legitime media-aanbod. Daarnaast is de staat in principe ook verantwoordelijk van 
het afdwingen van recht. Gezien het auteursrecht in China zeer duidelijk is ten aanzien van commerciële piraterij, moet de vraag worden gesteld waarom dit recht ogenschijnlijk niet wordt toegepast of afgedwongen. Immers, een lage pakkans beïnvloedt de belangen van potentiële piraten.

Daarnaast stelt dit proefschrift de vraag hoe WTO-lidmaatschap piraterij in China heeft beïnvloed. WTO-discipline richt zich in principe op staten, en het is dus mogelijk om af te vragen hoe eventuele staatsgebonden oorzaken van piraterij zich verhouden tot WTO-verplichtingen. Daarnaast is de WTO het voornaamste kanaal dat de Verenigde Staten tot nog toe gebruikt hebben om piraterij in China te bestrijden.

\section{De ontwikkeling van het auteursrecht en de markt voor mediaproducten}

De uitvinding van de boekdrukkunst in de $15^{\mathrm{e}}$ eeuw leidde tot de mogelijkheid om snel grote aantallen boeken en andere geschriften te kopiëren en verspreiden. Dit leidde bij de toenmalige regimes, zowel religieus als wereldlijk, tot de angst dat dit zou leiden tot rebellie en onrust. Er werden dus systemen ingevoerd om de pers te controleren, die vaak gebaseerd waren op licenties en privileges: koninklijke toestemming was nodig vooraleer een boek mocht worden gedrukt. De Kerk stelde catalogi samen met verboden boeken. Echter, mettertijd groeide de roep om vrijheid van meningsuiting. Dit leidde tot een stelselmatige afschaffing van de licentiesystemen in Europa. Tegelijkertijd werden vroege vormen van auteursrechten ingesteld, en verschoof de aandacht dus meer van perscontrole naar de creatie van mechanismen ter beloning van creativiteit. Toen film, en later televisie, hun intrede maakten, kwamen opnieuw de zorgen over mogelijke morele impact van deze technologie, maar met name na de Tweede Wereldoorlog werd ook deze sector meer en meer geliberaliseerd, al blijven er overal systemen aanwezig die films classificeren op basis van hun geschiktheid voor bepaalde segmenten van het publiek, en regels over wat kan worden uitgezonden en wanneer. Ook economisch werd de mediasector geliberaliseerd. Hierbij diende het auteursrecht als een economisch mechanisme om op een kunstmatige wijze schaarste te creëren, en het dus mogelijk te maken om rechten te verhandelen. Ook kwam er vanaf het einde van de $19^{\mathrm{e}}$ eeuw, met de Berner Conventie, een beweging van internationalisering op gang, die het mogelijk maakte werken te verhandelen op internationale schaal. Het belang van deze conventie blijft erg groot, onder andere gezien een deel hiervan overgenomen is in TRIPS, het WTOverdrag over intellectuele eigendom.

In China kende het auteursrecht een andere ontstaansgeschiedenis. Hoewel er op verschillende punten in de geschiedenis indicaties zijn dat sommige uitgevers bezorgd waren over kopie van hun werken, is er in China geen commerciële boekenmarkt tot stand gekomen zoals dat in Europa het geval was. Er was wel sterke controle over de publicatie van werken die mogelijk tegen het keizerlijke gezag indruisten. De eerste echte auteursrechtenwet werd ingevoerd tijdens de nadagen van de Qingdynastie, aan het einde van de $19^{e}$ eeuw, onder invloed van buitenlandse druk. Echter, de politieke verdeling en chaos die daarna plaatsvond, zorgde ervoor dat op een enkel moment een stabiele economie, laat staan een markt voor mediaproducten tot stand kwam. Toen de Guomindang China verenigde, publiceerden ook zij een auteursrechtenwet, maar deze diende vooral het doel van perscontrole. Het communistische regime controleerde media op een andere manier, door administratieve kanalen. Films werden geproduceerd door staatsbedrijven om ideologische redenen, en werden verplicht getoond aan het publiek als propaganda. In 1978 ging het roer 
opnieuw om. De markthervormingen van Deng Xiaoping zorgden ervoor dat intellectueel eigendom een belangrijkere rol kreeg toegespeeld. Het auteursrecht bleef hierin echter een moeilijke zaak, omwille van het feit dat de Partij nog steeds de pers wenste te controleren. Tegelijkertijd ontstond het fenomeen piraterij, dat met name in de jaren ' 90 een twistappel was in de betrekkingen tussen China en de Verenigde Staten. Vanaf dat punt werd het auteursrecht in China vooral beïnvloed door de politieke nood om te conformeren met internationale standaarden. Toetreding tot de WTO versterkte deze dynamiek. China is op dit ogenblik aan zijn derde auteursrechtenwet toe, en deze is nu conform met de vereisten van de WTO. Piraterij blijft echter op grote schaal bestaan. Het is daarom nuttig te kijken naar de onderliggende regulering van de markt voor mediaproducten.

\section{Mediacontrole: methodes en redenen}

De Chinese regering heeft een uitgebreid apparaat ter controle voor de media. Dit omvat onder andere het Centraal Propagandadepartement, de Staatsadministratie van Radio, Film en Televisie, het Ministerie van Cultuur en de Algemene Administratie voor Pers en Publicaties. Deze beheren nagenoeg de volledige mediamarkt, door middel van administratieve regelgeving. Met uitzondering van auteursrechten en reclame, is er geen centrale wetgeving voor media. Deze regelgeving controleert de media op verschillende punten. Vooreerst zijn er de licentieprocedures: licenties zijn vereist om als bedrijf in media actief te mogen zijn, en zijn vaak ook per product vereist. Deze laatste hangen ook samen met inhoud: elk werk moet door een censuurprocedure vooraleer te mogen worden verspreid. Daarnaast zijn er beperkingen op investeringen en eigendom: private actoren mogen slechts investeren in een klein gedeelte van de mediacyclus. Er worden ook actieve maatregelen genomen: de Partijstaat investeert op verschillende manieren in werken en projecten die haar doel dienen, zoals het maken van politiek correcte films, en het verbeteren van infrastructuur, zodat de boodschap beter bij het publiek terecht kan komen. In de internationale dimensie is de Partijstaat zeer wantrouwig ten aanzien van vermeende buitenlandse pogingen om China te destabiliseren. Ondermeer hierom zijn er strenge beperkingen op het aantal buitenlandse producten dat in China op de markt komt, de manier waarop dat gebeurt, en wie dat mag. Al deze maatregelen samen resulteren in het feit dat het aanbod van legale mediaproducten in China erg klein is, waardoor vraag ontstaat naar een breder aanbod, en dus piraterij in de hand werkt.

De reden waarom deze maatregelen worden toegepast, zijn vrij duidelijk: de Chinese Communistische Partij acht controle over de media noodzakelijk voor de instandhouding van het Chinese politieke status quo. De beheersing van het nationale discours is in dit opzicht een voorwaarde om de legitimiteit van de Partij te behouden. Dit gebeurt onder andere door het voeren van een nationalistisch discours, waarbij de Partij zichzelf in het voetlicht zet als de enige macht die van China een modern, welvarend en sterk land kan maken. Echter, er zijn steeds meer aanwijzingen dat het Chinese publiek meer verlangt ter ontspanning dan deze boodschap. Dit zorgt voor spanningen, waarbij succesvolle Chinese media vaak het voorwerp worden van ingrepen door de Staat.

\section{Afdwinging}

De vraag naar piraterij die wordt veroorzaakt door het kleine legitieme aanbod wordt in de hand gewerkt door het gebrek aan sterke afdwinging. In tegenstelling tot Westerse landen, waar auteursrecht een privaat recht is, is antipiraterij in China 
vooral een zaak van dezelfde administratieve lichamen waarvan hoger sprake. Deze lijden echter aan een aantal structurele problemen, waardoor consistente en kwalitatieve afdwinging niet mogelijk is. Vooreerst is de Chinese politieke cultuur gefragmenteerd. Er zijn horizontale splitsingen tussen verschillende beheersniveaus en verticale splitsingen tussen verschillende diensten. Deze werken lokaal en administratief protectionisme in de hand, waardoor het moeilijk is om coherent tegengewicht te bieden aan piraterij. Dit leidt ook tot corruptie, waarbij het voorkomt dat piraten door lokale ambtenaren de hand boven het hoofd wordt gehouden, gezien zij bijdragen aan de lokale economie. Van tijd tot tijd worden er grootschalige campagnes gehouden, om door deze verlammende versnippering heen te dringen, maar deze zijn vaak van tijdelijke aard, worden niet altijd kwalitatief uitgevoerd, en vallen vaak ten prooi aan dezelfde problemen. Ook ligt er een probleem bij het doel van afdwinging: dit is vaak niet het beschermen van individuele rechthebbenden, vooral niet als deze buitenlands zijn, maar in het controleren van de pers.

De laatste jaren is er meer aandacht gekomen voor civiele afdwinging van auteursrechten. China heeft gespecialiseerde intellectuele eigendomsrechtbanken opgericht, en deze beslissen hoe langer hoe meer zaken. Deze hebben ook hun structurele problemen: vonnissen zijn moeilijk af te dwingen, rechtbanken zijn - buiten de grote steden - ook vaak onderhevig aan lokaal protectionisme, schadevergoedingen zijn klein, en het is voor buitenlandse rechthebbenden vaak minder interessant hun rechten te beschermen voor een Chinese rechtbank, als niet altijd duidelijk is of hun werken überhaupt wel legaal op de Chinese markt zouden kunnen worden gebracht.

\section{De WTO}

Deze studie concludeert dat er twee belangrijke staatsgebonden factoren zijn die mediapiraterij in de hand werken: de strenge mediacontrole die het legale aanbod verkleint, en de structurele moeilijkheden met afdwinging. De vraag is nu in welke mate de WTO hier invloed op kan hebben, en op welke manier dit tot nog toe is gebeurd.

China is onderhevig aan twee belangrijke regelsystemen in de WTO: het WTOacquis zelf, alsook de extra voorwaarden die vastgelegd zijn in China's toetredingsprotocol. In het veld van media, betekent dit dat China valt onder de intellectuele eigendomspoot van de WTO, TRIPS; dat China in principe het recht tot handel moet toelaten aan alle buitenlandse bedrijven; dat China verplicht is de principes van nationale behandeling en meest bevoorrechte natie toe te passen; en dat China verplicht is haar dienstensector open te stellen op basis van de voorwaarden die door onderhandeling zijn vastgelegd. De vraag of dit wel degelijk het geval was is voorwerp geweest van twee zaken, DS362 en DS363, die door de Verenigde Staten werden aangespannen. In de eerste zaak kwam de Chinese auteursrechtenwet ter sprake. Deze verleende namelijk geen bescherming aan werken die niet waren toegelaten op de Chinese markt. De Berner Conventie (en dus TRIPS) vereist echter dat bescherming automatisch wordt verleend. Daarnaast stelden de Verenigde Staten dat kwantitatieve minimumdrempels voor strafrechtelijke vervolging niet voldeden aan de eis voor strafrechtelijke vervolging voor alle piraterij op commerciële schaal. Hier kregen zij echter nul op het rekest, gezien gesteld werd dat dit misschien wel zo was, maar dat de Verenigde Staten niet konden aantonen wat "commerciële schaal" betekende in deze context. De tweede zaak behandelde een grote reeks barrières tegen buitenlandse producten en bedrijven. Hier wonnen de Verenigde Staten over vrijwel 
de hele lijn. De WTO bevestigde hier dat een aantal van deze Chinese maatregelen in strijd zijn met de Chinese toezeggingen en verplichtingen. In principe zouden deze beperkingen dus moeten worden aangepast.

In de realiteit merken we echter dat de invloed van deze twee zaken vooralsnog beperkt blijft. In het geval van de bepalingen over auteursrecht, valt dit te verklaren door het feit dat de aanpassing aan de auteursrechtenwet weinig bijdraagt aan het stimuleren van - met name buitenlandse - rechthebbenden om hun rechten voor Chinese rechtbanken te verdedigen. Immers, als deze werken verboden zijn op de Chinese markt is het voor de rechthebbende weinig interessant om hier tijd en middelen aan te besteden. Wat betreft de bepalingen ten aanzien van buitenlandse media, spelen een aantal factoren. Vooreerst blijft de juridische impact van de zaak beperkt. De Chinese toezeggingen waren namelijk beperkt wat de mediamarkt betreft. Daarnaast is het zo dat deze zaak betekent dat buitenlandse bedrijven zelf media zouden moeten kunnen importeren in China, maar distributie blijft een staatszaak. Ten laatste is het zo dat China treuzelt met de implementatie van de bevindingen in deze zaak. In dit geval hebben de Verenigde Staten de mogelijkheid om strafmaatregelen aan te vragen bij de WTO, maar dit is vooralsnog niet gebeurd. Men kan zich de vraag stellen of dat in het huidige economische en politieke klimaat een goed idee is.

\section{Conclusie}

Deze studie geeft aan dat mediapiraterij in China in de hand wordt gewerkt door twee belangrijke factoren: mediacontrole en het gebrek aan afdwinging. Beide zijn op hun eigen manier verbonden aan de Chinese politieke structuur. Het lijkt niet zo te zijn dat de Chinese mediasector snel vrijer zal worden, en ook politieke hervormingen die nodig zijn om de Chinese administratie effectiever te doen werken lijken niet op komst. De impact van de WTO hierop is beperkt, gezien deze factoren slechts ten dele onderhevig zijn aan WTO-recht, en gezien de implementering van WTOverplichtingen sterk beïnvloed worden door binnenlandse en internationale politieke beslommeringen.

Deze studie beweert niet dat dit de enige causale factoren voor piraterij zijn. Piraterij komt ook in het Westen voor, waar het voor een deel een gevolg van marktfalen is. Wel is het zo dat de beperkingen ten aanzien van de mediamarkt logisch voorafgaan aan marktfalen. Deze studie doet ook geen ethische uitspraak over piraterij in China. Immers, piraterij is de enige manier waarop de individuele Chinese burger toegang heeft tot een grote hoeveelheid informatie, die anders niet beschikbaar zou zijn. Ook is er het risico dat pleiten voor sterkere afdwinging mensenrechtenschendingen in de hand zou werken. 


\section{Curriculum vitae}

Rogier Creemers (1982) has obtained degrees in Sinology (2004) and International Relations (2006) at the University of Leuven. He also holds a Chinese language certificate from Peking University. He joined Maastricht University in 2008, where he was responsible for a number of China-related projects. He also taught Chinese language and intellectual property law courses there; and was the coordinator for a course on law and society. He spent an academic year in China with a grant from the China-EU School of Law. He is also a fellow of the Institute for Globalization and International Regulation. In 20II, Rogier joined the Programme for Comparative Media Law and Policy at the University of Oxford, where he contributes to an EUfunded project aimed to broaden the scope of protection for freedom of expression in China. 